Aus der Abteilung Gastroenteropathologie

(Komm. Direktor Prof. Dr. med. J. Rüschoff) im Zentrum Pathologie

der Medizinischen Fakultät der Universität Göttingen

\title{
Chromosomale Veränderungen in Hirnmetastasen vom Lungenkrebs
}

\author{
INAUGURAL-DISSERTATION \\ zur Erlangung des Doktorgrades \\ der Medizinischen Fakultät \\ der Georg-August-Universität zu Göttingen
}

vorgelegt von

Gerrit Christopher Klipp

aus

Eschwege

Göttingen 2011 
Dekan: Prof. Dr. med. C. Frömmel

I. Berichterstatter: Prof. Dr. med. L. Füzesi

II. Berichterstatterin: Prof. Dr. rer. nat. Bartels

III. Berichterstatterin: Prof. Dr. rer. nat. Virsik-Köpp

Tag der mündlichen Prüfung: 26.11.2012 


\section{Inhaltsverzeichnis}

1 Einleitung 1

1.1 Hirnmetastasen und Lungenkrebs . . . . . . . . . . . . . . . . . . . 1

1.1.1 Hirnmetastasen als Sonderfall . . . . . . . . . . . . . . . . 2

1.1.2 Die Situation beim Lungenkrebs . . . . . . . . . . . . . . . 3

1.2 Genotyp und Phänotyp . . . . . . . . . . . . . . . . 5

1.2.1 Eigenschaften der Krebszelle - Hallmarks of Cancer . . . . . . . 5

1.2.2 Krebs als molekulargenetische Erkrankung . . . . . . . . . . . 6

1.3 Veränderungen der Chromosomen . . . . . . . . . . . . . . . . 7

1.3.1 Strukturelle Chromosomenaberrationen . . . . . . . . . . 8

1.3.2 Numerische Chromosomenaberrationen und Aneuploidie . . . . . . 8

1.3.3 Amplifikationen . . . . . . . . . . . . . . . . 8

1.4 CGH: Eine Screeningmethode für chromosomale Veränderungen . . . . . . 11

1.4.1 Die Methode der komparativen genomischen Hybridisierung . . . . 11

1.4 .2 Vorteile und Nachteile . . . . . . . . . . . . . . . . . . 12

1.5 Stand der molekularzytogenetischen Forschung . . . . . . . . . . . . . . 14

1.5.1 CGH und Metastasierung . . . . . . . . . . . . . . . 14

1.5.2 CGH und Hirnmetastasen . . . . . . . . . . . . . . . . 16

1.6 Erkenntnisinteresse . . . . . . . . . . . . . . . . . 16

2 Patienten, Material und Methoden 18

2.1 Patienten . . . . . . . . . . . . . . . . . . . . . . . . . 18

2.2 Material . . . . . . . . . . . . . . . . . . . . . 18

2.3 Allgemeine pathologische und biochemische Methoden . . . . . . . . . . 21

2.3.1 Histopathologie und Immunhistochemie . . . . . . . . . . . . . 21

2.3.2 Agarose-Gelelektrophorese von DNA . . . . . . . . . . . . . 22

2.3.3 Fotometrische DNA-Konzentrationsbestimmung . . . . . . . . . . . 23

2.3.4 Gewinnung genomischer DNA aus Paraffinblöcken . . . . . . . . . 24

2.3.5 Gewinnung genomischer DNA aus tiefgefrorenem Gewebe . . . . . 26

2.4 Arbeitsschritte der CGH . . . . . . . . . . . . . . . . . . . . 27

2.4 .1 Markierung . . . . . . . . . . . . . . . . . . . 27

2.4.2 Hybridisierung . . . . . . . . . . . . . . . . . . . . 28

2.4 .3 Detektion . . . . . . . . . . . . . . . . . . 31

2.4.4 Bilderfassung und quantitative Auswertung . . . . . . . . . . . . . 34

2.4.5 Berichtigung der Ergebnisse . . . . . . . . . . . . . . 36 
2.4.6 Codierung der Ergebnisse . . . . . . . . . . . . . . . . . . 36

2.4.7 Darstellung der Ergebnisse _. . . . . . . . . . . . . . . 37

2.5 Metaanalyse . . . . . . . . . . . . . . . . . . . . . 38

2.5.1 Literaturrecherche . . . . . . . . . . . . . . . . . . 38

2.5.2 Extraktion der Daten . . . . . . . . . . . . . . . . 40

2.5.3 Darstellung der Ergebnisse . . . . . . . . . . . . . . . . . . . 41

2.6 Vergleich von Primärtumoren und Hirnmetastasen . . . . . . . . . . . . . 41

2.6.1 Qualitativer Vergleich . . . . . . . . . . . . . . . . . 41

2.6.2 Quantitativ-statistischer Vergleich . . . . . . . . . . . . . 41

2.6.3 Automatische Klassifikation . . . . . . . . . . . . . . . . . . 42

2.7 Qualitätssicherung: Negativkontrolle und Standardreferenzintervalle . . . 42

3 Ergebnisse 43

3.1 Untersuchte Hirnmetastasen . . . . . . . . . . . . . . . . . . . . . 43

3.1.1 Ausschluss ungeeigneter Gewebeproben . . . . . . . . . . . . 43

3.1.2 Histopathologische Klassifikation . . . . . . . . . . . . . . . 43

3.2 Pathologische, allgemeine und klinische Daten . . . . . . . . . . . . . . 43

3.2.1 Allgemeine Angaben zu den Patienten . . . . . . . . . . . . . . . 44

3.2.2 Klinische Parameter . . . . . . . . . . . . . . . . . . . . . 44

3.3 CGH-Befunde der Hirnmetastasen . . . . . . . . . . . . . . . . . . 46

3.3.1 Hirnmetastasen vom kleinzelligen Karzinom . . . . . . . . . . . . . 46

3.3.2 Hirnmetastasen vom Plattenepithelkarzinom . . . . . . . . . . . . 48

3.3.3 Hirnmetastasen vom Adenokarzinom . . . . . . . . . . . . . . . 50

3.3.4 Hirnmetastasen vom adenosquamösen Karzinom . . . . . . . . . . 52

3.3.5 Hirnmetastasen vom großzelligen Karzinom . . . . . . . . . . . . . 54

3.4 Ergebnisse der Metaanalyse: CGH-Befunde der Primärtumoren . . . . . . 56

3.4.1 Ergebnisse der Literaturrecherche . . . . . . . . . . . . . 56

3.4.2 Primärtumoren des kleinzelligen Karzinoms . . . . . . . . . . . . 57

3.4.3 Primärtumoren des Plattenepithelkarzinoms . . . . . . . . . . . . . 60

3.4.4 Primärtumoren des Adenokarzinoms . . . . . . . . . . . . . 63

3.5 Vergleich von Primärtumoren und Hirnmetastasen . . . . . . . . . . . . 66

3.5.1 Primärtumoren und Hirnmetastasen des kleinzelligen Karzinoms 66

3.5.2 Primärtumoren und Hirnmetastasen des Plattenepithelkarzinoms . 69

3.5.3 Primärtumoren und Hirnmetastasen des Adenokarzinoms . . . . . 72

3.6 Automatische Klassifizierung von Primärtumoren und Hirnmetastasen . . 75

3.7 Negativkontrollen und Standardreferenzintervalle . . . . . . . . . . . . 76

4 Diskussion $\quad 77$

4.1 Vorbemerkungen . . . . . . . . . . . . . . . . . . . . . . . 77

4.1 .1 Banden oder Arme? . . . . . . . . . . . . . . . . . 77

4.1.2 Auflösung, Präzision und Richtigkeit . . . . . . . . . . . . . . . 79

4.1 .3 Messabweichungen . . . . . . . . . . . . . . . . 81 
4.1.4 Die Berichtigung systematischer Messabweichung bei der CGH . . 84

4.2 Kritische Beurteilung der Ergebnisse . . . . . . . . . . . . . . . . . 88

4.2.1 Primärtumoren und Hirnmetastasen des kleinzelligen Karzinoms . 88

4.2.2 Primärtumoren und Hirnmetastasen des Plattenepithelkarzinoms . 91

4.2.3 Primärtumoren und Hirnmetastasen des Adenokarzinoms . . . . . 98

4.2.4 Adenosquamöse und großzellige Hirnmetastasen . . . . . . . . . . . 101

4.3 Interpretation der Ergebnisse . . . . . . . . . . . . . . . . . . . . . . . . 102

4.3.1 Verdächtige Genorte und Kandidatengene . . . . . . . . . . . . . . 102

4.3.2 Molekularzytogenetische Muster und Klassifikation . . . . . . . . . 104

4.4 Schlussbetrachtung . . . . . . . . . . . . . . . . . 105

4.4.1 Antworten auf die gestellten Fragen . . . . . . . . . . . . . . 105

4.4 .2 Zur Methode ................. 106

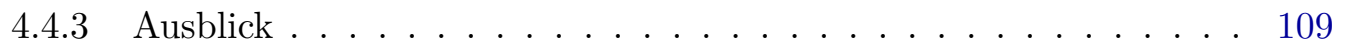

5 Zusammenfassung $\quad 110$

6 Literaturverzeichnis 112

7 Abbildungsverzeichnis 129

8 Tabellenverzeichnis $r$

9 Abkürzungsverzeichnis 132

$\begin{array}{lr}\text { A Anhang } & 134\end{array}$

A.1 Pathologische, allgemeine und klinische Daten . . . . . . . . . . . . . . 134

A.2 CGH-Befunde . . . . . . . . . . . . . . . . . . . . 138

A.2.1 Befunde der Hirnmetastasen . . . . . . . . . . . . . . . 138

A.2.2 Befunde der Primärtumoren . . . . . . . . . . . . . . . . . . . . 141

A.3 Statistische Auswertung . . . . . . . . . . . . . . . . . . . 156 


\section{Einleitung}

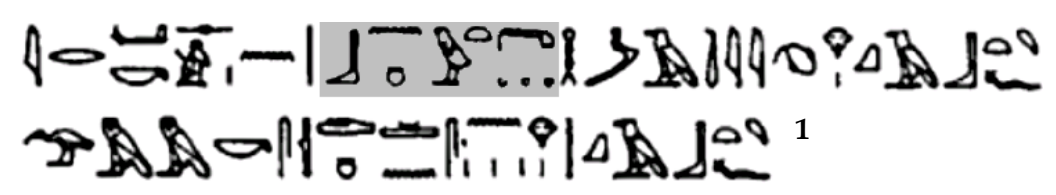

Eine hervortretende Geschwulst, die sich hart und kühl anfühle, so lautet die allererste Definition des Krebsleidens und weiter heißt es: Es gäbe keine Heilung. Diese Beschreibung findet sich im 45. Fallbeispiel des Papyrus Edwin Smith, einer altägyptischen medizinischen Schrift aus dem 16. vorchristlichen Jahrhundert, die eine Abschrift einer noch tausend Jahre älteren Quelle darstellt (Breasted 1930).

Die Abgrenzung der Krebserkrankung von anderen, gutartigen Geschwülsten nahmen die Ägypter schon vorweg, indem sie sagten, dass es keine Heilung gäbe. Krebs ist definitionsgemäß eine bösartige Neubildung des Gewebes, eine maligne Neoplasie. Kriterien für die Malignität sind ein ungehemmtes lokales Fortschreiten des Gewebewachstums mit Einbruch in benachbarte Strukturen - Invasion, von Rudolf Virchow „Fressen“ genannt und die Bildung von Herden in entfernten Regionen des Körpers, die Metastasierung (vgl. Virchow 1863, S. 57).

In der vorliegenden Studie wird versucht, für die Fähigkeit des Lungenkrebses zur Metastasierung eine Entsprechung im Erbgut der Tumorzellen zu finden. Dazu wird in Hirnmetastasen vom Lungenkrebs nach Veränderungen der Chromosomen gesucht, die für diese Metastasen charakteristisch sind.

\subsection{Hirnmetastasen und Lungenkrebs}

Die Metastasierung, also das Absiedeln eines Tumors in andere Regionen des Körpers, ist ein Kriterium für die Malignität des Krebses und zumeist ein gewichtiges Ereignis im Verlauf der Erkrankung. Oftmals sind die Metastasen für das Überleben des Patienten bedeutsamer als der Ursprungstumor (Minn und Massagué 2008, S. 117), was insbesondere

1 Auszug aus Fall 45 des Papyrus Edwin Smith, der die früheste Beschreibung eines Krebsleidens enthält. Die Hieroglyphen für "Tumor" sind hervorgehoben (Kopie der originalen Hieroglyphen, zitiert nach Dawson 1998, S. 230). 
für Hirnmetastasen gilt. Im Folgenden wird die Metastasierung ins Gehirn sowie deren Zusammenhang mit der Krebserkrankung der Lunge vorgestellt.

\subsubsection{Hirnmetastasen als Sonderfall}

Betrachtet man eine Krebserkrankung in ihrem anatomisch-funktionellen Umfeld, so besteht ein gewaltiger Unterschied darin, ob eine fünf Zentimeter durchmessende Metastase in einer weniger bedeutenden Körperregion oder im Gehirn gewachsen ist. Mit dem Auftreten einer Hirnmetastase wird eine unmittelbar lebensbedrohende Stufe der Krebserkrankung erreicht.

\section{Häufigkeit}

Genaue Zahlen zur Inzidenz von Hirnmetastasen gibt es nicht. Die Angaben für die jährliche Inzidenzrate pro 100.000 Einwohner reichen von 2,8 bei Guð̊mundsson (1970) bis hin zu 11,1 bei Percy et al. (1972). Die größte Studie mit über 17.000 eingeschlossenen Hirnmetastasen stammt von Walker et al. (1985) und geht von 8,3 Hirnmetastasen pro 100.000 Einwohner und Jahr aus. Für all diese Studien gilt, dass aufgrund der verwendeten Methoden Hirnmetastasen nur unvollständig erfasst werden konnten. Es ist daher von einer deutlichen Unterschätzung der wahren Inzidenz auszugehen (Gavrilovic und Posner 2005).

Für den klinischen Alltag scheint die Bedeutung der Hirnmetastasierung zuzunehmen, die Inzidenz scheint zu steigen (Gavrilovic und Posner 2005). Ursache sind sensitivere diagnostische Möglichkeiten durch bildgebende Verfahren wie die Computer- und vor allem die Magnetresonanztomografie, so dass immer kleinere Hirnmetastasen aufgespürt werden können (Hochstenbag et al. 2000; Seute et al. 2008).

Weiterhin werden durch eine immer besser werdende Behandlung der zugrunde liegenden Krebserkrankungen längere Überlebenszeiten erzielt - Zeit, in der die Hirnmetastasen wachsen können. Dazu kommt die Besonderheit, dass das Gehirn hinter der Blut-HirnSchranke eingewanderten Tumorzellen wahrscheinlich ein Refugium zu bieten vermag, in dem sie der Behandlung mit Chemotherapie entgehen können. Während im übrigen Körper die Krebszellen vernichtet werden können, verwandelt sich das Gehirn zum Hauptschauplatz (Bendell et al. 2003; Chen et al. 2007; Paterson et al. 1982).

\section{Zugrundeliegende Krebserkrankungen}

Die zugrundeliegenden Krebserkrankungen ermittelten Nussbaum et al. (1996) bei 729 Patienten mit Hirnmetastasen: Lungenkrebs steht mit einem Anteilswert von zusammengenommen $39 \%$ an erster Stelle, wobei $24 \%$ auf das nicht-kleinzellige Karzinom entfallen und $15 \%$ auf das kleinzellige. Es folgen der Brustkrebs mit 17\%, das Melanom mit $11 \%$, das Nierenzellkarzinom und der Krebs des Magen-Darm-Traktes mit jeweils $6 \%$.

Für diese fünf Krebserkrankungen, die für etwa vier Fünftel aller Hirnmetastasen verantwortlich sind, liegen genauere Daten aus großen Inzidenzstudien vor: Das Risiko, im 
Verlauf einer dieser fünf Krebserkrankungen eine Hirnmetastase zu entwickeln, liegt bei 8,5-9,6\% (Barnholtz-Sloan et al. 2004; Schouten et al. 2002).

\section{Therapeutische Möglichkeiten und Prognose}

Als therapeutische Maßnahmen stehen die operative Entfernung der Hirnmetastase und die Strahlentherapie in Form der Ganzhirnbestrahlung im Vordergrund. Die Radiochirurgie kann eine Alternative zur Operation darstellen. Die Chemotherapie spielt nur eine untergeordnete Rolle (Weller und Schackert 2008).

Ohne Therapie beträgt das mediane Überleben nur einen Monat. Durch Strahlentherapie, zumeist Ganzhirnbestrahlung, kommt es zu einer Verlängerung auf 3-6 Monate. Handelt es sich um eine einzelne operable Metastase, so sind durch deren Entfernung in Kombination mit einer anschließenden Strahlentherapie weitere 6-9 Monate medianer Überlebenszeit erzielbar (Weller und Schackert 2008). Die Prognose ist insgesamt sehr schlecht.

\subsubsection{Die Situation beim Lungenkrebs}

Lungenkrebs ist in Deutschland die dritthäufigste Krebserkrankung der Männer wie auch der Frauen. Er macht damit 14,3\% aller Krebsneuerkrankungen bei den Männern aus, bei den Frauen sind es 6,4\%. Rund 46.200 Neuerkrankungen in Deutschland entsprechen einer geschätzten jährlichen Inzidenzrate von 81,4 pro 100.000 Einwohner bei den Männern und von 30,6 bei den Frauen (Batzler et al. 2008, S. 46, 49).

Die relativen 5-Jahres-Überlebensraten betragen etwa $15 \%$ bei den Männern und $18 \%$ bei den Frauen. Allerdings gibt es große Unterschiede in Abhängigkeit vom Stadium der Erkrankung. Ist der Tumor noch auf das Organ begrenzt, so beträgt die 5-JahresÜberlebensrate mehr als $50 \%$, liegt jedoch eine Fernmetastase vor, dann sinkt sie auf $5 \%$ (Batzler et al. 2008, S. 46).

$\mathrm{Zu}$ dieser schlechten Prognose trägt auch die ausgeprägte Fähigkeit zur Metastasierung ins Hirn bei. Das Risiko, im Verlauf einer Lungenkrebserkrankung eine Hirnmetastase zu entwickeln, beträgt 16,3-19,9\%. Lungenkrebs steht damit an erster Stelle, Platz zwei und drei belegen das Nierenzellkarzinom mit 6,5-9,8\% und das Melanom mit 6,9-7,4\% (Barnholtz-Sloan et al. 2004; Schouten et al. 2002).

Der Lungenkrebs stellt keine einheitliche Gruppe dar. Er wird in verschiedene histologische Typen eingeteilt, welche nun vorgestellt werden.

\section{Einteilung des Lungenkrebses}

Die Einteilung des Lungenkrebses folgt einer von der Weltgesundheitsorganisation (WHO) vorgeschlagenen Klassifikation zur histologischen Einordnung (Travis et al. 2004, S. 10). Die Tumoren sind fast ausschließlich epithelialer Herkunft, andere histologische Typen machen weniger als $1 \%$ aus (Parkin et al. 2004, S. 12). Tabelle 1.1 zeigt die Einteilung der Tumoren der Lunge. 
Häufige histologische Typen sind das kleinzellige Karzinom mit einem Anteil von $20 \%$ und das großzellige mit $9 \%$. Das Adenokarzinom und das Plattenepithelkarzinom variieren in ihren Anteilswerten je nach Geschlecht: Plattenepithelkarzinome machen $44 \%$ bei den Männern und $25 \%$ bei den Frauen aus, Adenokarzinome finden sich in $28 \%$ der Fälle bei den Männern und $42 \%$ bei den Frauen (Parkin et al. 2004, S. 12).

Tabelle 1.1: WHO-Klassifikation nach Travis et al. (2004, S. 10). Nur die Einteilung der malignen epithelialen Tumoren ist detaillierter aufgeführt, deren weitere Unterklassifikation ist ebenfalls nicht dargestellt.

Histologische Klassifikation der Lungentumoren nach WHO

Maligne epitheliale Tumoren

Plattenepithelkarzinom

Kleinzelliges Karzinom

Adenokarzinom

Großzelliges Karzinom

Adenosquamöses Karzinom

Sarkomatoides Karzinom

Karzinoidtumor

Karzinome der Bronchialwanddrüsen

Sonstige

Benigne epitheliale Tumoren

Lymphoproliferative Tumoren

Sonstige Tumoren

Metastasen

Aus klinischen Gesichtspunkten lässt sich der kleinzellige Lungenkrebs (Small Cell Lung Cancer, SCLC) von den übrigen histologischen Typen unterscheiden, die daher zusammenfassend als nicht-kleinzellige (Non-Small Cell Lung Cancer, NSCLC) bezeichnet werden. Nicht-kleinzellig heißen dabei alle Karzinome, die weder kleinzellige Anteile enthalten, noch zu den typischen Karzinoidtumoren gezählt werden können (Drings 2008).

\section{Kleinzelliger Lungenkrebs}

Das kleinzellige Lungenkarzinom ist ein äußerst aggressiver Tumor mit einer sehr ungünstigen Prognose, welche durch eine frühzeitige Ausbreitung mitbedingt ist (Jackman und Johnson 2005). Die Metastasierung ins Gehirn stellt eine häufige Komplikation dieser Erkrankung dar (van Oosterhout et al. 1996). Die kumulative Inzidenz für eine Hirnmetastase nach 5 Jahren beträgt 29,7\% (Schouten et al. 2002). Da die Hirnmetastasierung 
beim kleinzelligen Lungenkrebs eine so häufige und schwerwiegende Komplikation ist, wird eine prophylaktische Bestrahlung des gesamten Gehirns empfohlen, also wenn noch gar keine Hirnmetastase nachgewiesen werden konnte (Arriagada et al. 1995; van de Pol et al. 1997). Unter der Nachweisgrenze liegende Metastasen sollen dadurch zerstört und diese bedrohliche Komplikation verhindert werden.

\section{Nicht-kleinzelliger Lungenkrebs}

Nicht-kleinzelliger Lungenkrebs metastasiert nicht so häufig ins Hirn wie der kleinzellige. Dennoch ist die kumulative Inzidenz nach 5 Jahren mit 12,6\% sehr hoch (Schouten et al. 2002). Eine engmaschige Überwachung des Gehirns mit bildgebenden Verfahren sollte durchgeführt werden, insbesondere bei fortgeschrittenen Stadien (Carolan et al. 2005).

\subsection{Genotyp und Phänotyp}

Der Genotyp eines Organismus entspricht der Gesamtheit aller Gene, die dieser Organismus besitzt. Beim Menschen muss man genauer über Gen-Paare sprechen, weil von jeder Art zwei Ausgaben (Allele) existieren. Der Phänotyp hingegen ist die Gesamtheit aller Eigenschaften, die diesen Organismus kennzeichnen (Mahner und Kary 1997). Beide Begriffe stellen abstrahierende Beschreibungen der physisch zugrundeliegenden Welt dar. Vergliche man dies mit einer Autofabrik, so hätten wir einerseits die Gesamtheit aller Konstruktionspläne, andererseits die Eigenschaften eines Fahrzeugs.

Das Interesse des Wissenschaftlers besteht darin, den Zusammenhang zwischen Genotyp und Phänotyp zu ergründen. Im Falle dieser Studie hieße das, den Zusammenhang zwischen genetischen Veränderungen und der Krebserkrankung aufzudecken. Nun ist unter den krankheitsspezifischen Eigenschaften eine für den an Krebs leidenden Menschen existenziell: Die Frage nach der Lebenszeit.

Einen Genotyp-Phänotyp-Brückenschlag von den genetischen Veränderungen zur Überlebenszeit zu unternehmen, wäre sehr weit gefasst. Hier einen direkten Zusammenhang zu suchen, ist problematisch, wie auch das Beispiel der Autofabrik zeigt: Zwischen Konstruktionsplan und Höchstgeschwindigkeit liegen Rohstoffe, Maschinen, Arbeiter, Fahrgeschick usw. Es ist daher sinnvoll, den Blick auf ausgewählte Eigenschaften zu begrenzen, die jeweils einen kleinen, dafür aber überschaubaren Teil des Krankheitsgeschehens abbilden. Man spricht dabei von Partialphänotypen.

\subsubsection{Eigenschaften der Krebszelle - Hallmarks of Cancer}

Douglas Hanahan und Robert Weinberg warfen in ihrem Review „Hallmarks of Cancer" im Jahr 2000 einen Blick auf den damaligen Stand der Krebsforschung: Bei aller Vielfalt der Eigenschaften, die Krebszellen in ihrem Verhalten von normalen Zellen unterscheiden, erkannten sie sechs essentielle, die sie Hallmarks of Cancer nannten. Diese Eigenschaften bewirken in ihrem Zusammenspiel, dass bösartiges Wachstum überhaupt möglich wird. Es 
sind diese sechs besonderen Eigenschaften, diese sechs zellulären Partialphänotypen, die den Krebs zum Krebs machen.

Zu den hallmarks of cancer zählen: (i) Die Selbstversorgung mit Wachstumssignalen, (ii) eine Unempfindlichkeit gegenüber wachstumshemmenden Signalen, (iii) die Vermeidung zellulären Selbstmords, der Apoptose, (iv) ein unbegrenztes Zellteilungspotential, (v) die Anregung der Gefäßneubildung (Angiogenese) und schließlich (vi) die Fähigkeit zu Invasion und Metastasierung.

Die Ausbreitung des Krebses in andere Regionen des Körpers ist ein außerordentlich komplexer Vorgang. Zunächst sind dazu sämtliche der Fähigkeiten (i) bis (v) vonnöten. Wenn diese um die Fähigkeit zur Invasion und Metastasierung (vi) ergänzt werden, sind alle drei Kriterien der Malignität erfüllt und es kommt zum Vollbild der Krebserkrankung.

Die vorliegende Studie befasst sich mit dieser letzten und sehr bedeutenden Eigenschaft der Krebserkrankung: dem Partialphänotyp der Metastasierungsfähigkeit. Doch nachdem damit der zu untersuchende Phänotyp spezifiziert wurde, muss auch ein Blick auf die andere Seite, die der Gene, geworfen werden.

\subsubsection{Krebs als molekulargenetische Erkrankung}

Durch immer genauere mikroskopische Untersuchungen waren in Krebszellen sichtbare Veränderungen der Chromosomen aufgefallen. David Hansemann und später Theodor Boveri sahen in diesen Veränderungen den Mechanismus für die Transformation einer gesunden Zelle zur Krebszelle (Boveri 1914; Hansemann 1890). Da diese Veränderungen (lat. Mutationen) der Chromosomen und damit des Erbgutes in normalen Körperzellen auftreten und nicht in Keimzellen, bei denen es im Rahmen der Fortpflanzung ein natürlicher Prozess ist, spricht man von somatischen Mutationen (Tyzzer 1916).

„Molecular Structure of Nucleic Acids. A Structure for Deoxyribose Nucleic Acid“: In diesem berühmten Artikel aus dem Jahr 1953 beschrieben James Watson und Francis Crick die Struktur der Desoxyribonukleinsäure (DNA), des Trägers der Erbinformation. Damit war eine Zeitenwende in der Krebsforschung gekommen. Nun konnten die Veränderungen auf molekularer Ebene erforscht werden (Watson und Crick 1953).

1976 konnten Harold Varmus und Michael Bishop einen Zusammenhang zwischen einer Genaktivierung und einer Krebserkrankung nachweisen (Stehelin et al. 1976). In jeder Zelle existieren demnach Gene, sogenannte Proto-Onkogene, welche durch Mutationen aktiviert werden können. Das dadurch aus dem Proto-Onkogen entstehende Onkogen fördert die Krebsentstehung.

Weiterhin legten Überlegungen von Alfred Knudson und anderen nahe, dass es auch Gene geben müsse, deren Ausfall die Krebsentstehung fördert (Harris et al. 1969; Knudson 1971). Stephen Friend isolierte dann 1986 das erste dieser Tumorsuppressor genannten Gene (Friend et al. 1986).

Die Erkenntnis, dass zumeist nicht eine Veränderung allein für die Entstehung einer Krebserkrankung ausreichend ist, führte dann zu dem heute aktuellen molekularbiologischen Konzept: Die Krebserkrankung ist ein fortschreitender Prozess, getrieben durch 
somatische Mutationen und klonale Selektion. Somatische Mutationen entstehen fortwährend im Laufe des Tumorwachstums durch Fehler bei der Teilung der Tumorzellen. Die vorteilhaften unter diesen Mutationen setzen sich durch und werden an die Folgegenerationen weitergegeben. Es ist letztlich eine sequentielle Aktivierung von Onkogenen und Inaktivierung von Tumorsuppressorgenen. Durch das Ansammeln dieser Veränderungen kommt es zum Fortschreiten der Erkrankung, von anfangs noch ungefährlichen Vorstufen bis hin zum Vollbild eines zur Invasion und Metastasierung fähigen und damit tödlichen Krebses (Fearon und Vogelstein 1990).

\section{Genotyp und Phänotyp}

Es zeigt sich eine deutliche Parallele: Bei den krebsspezifischen Eigenschaften, den Hallmarks of Cancer, wie auch bei den somatischen Mutationen ist es die Ansammlung mehrerer Faktoren, die die voll ausgeprägte Krebserkrankung möglich macht. Es liegt die Vermutung nahe, dass die Aktivierung bestimmter Onkogene und der Ausfall bestimmter Tumorsuppressorgene die Ursache dieser Eigenschaften sein könnten. Eine fortschreitende Ansammlung von Mutationen würde somit Hand in Hand mit dem Erwerb spezifischer Eigenschaften gehen, die letztlich die Malignität des Krebses begründen. In der vorliegenden Studie soll daher eine Genotyp-Phänotyp-Korrelation unternommen werden, um genetische Veränderungen zu finden, die mit der Eigenschaft der Metastasierung verknüpft sind.

Aktivierte Onkogene und ausgefallene Tumorsuppressorgene sind nicht direkt zugänglich. In Kapitel 1.3 wird auf die mit der verwendeten Methode erfassbaren Veränderungen des Erbgutes eingegangen, die Veränderungen der Chromosomen.

\subsection{Veränderungen der Chromosomen}

Wie zuvor bereits erwähnt, hielten David Hansemann und Theodor Boveri chromosomale Veränderungen für die Grundlage der Krebsentstehung (Boveri 1914; Hansemann 1890). Dass dieses Konzept berechtigt ist, zeigte sich spätestens durch die Entdeckung des sogenannten Philadelphia-Chromosoms, einer wichtigen chromosomalen Veränderung bei Leukämien (Nowell 1962), die bis zum beteiligten Gen hinab erforscht werden konnte (Groffen et al. 1984; Heisterkamp et al. 1983).

David Hansemann und Theodor Boveri stand nur das Mikroskop zur Verfügung. Derart umfangreiche Veränderungen von Chromosomen, die selbst im Mikroskop sichtbar sein können, werden chromosomale Aberrationen oder Chromosomenmutationen genannt. Man unterscheidet zwei Formen chromosomaler Aberrationen: Änderungen innerhalb der Struktur der Chromosomen und Abweichungen von der normalen Anzahl. Zunächst soll auf die strukturellen Veränderungen eingegangen werden; die numerischen werden im darauf folgenden Abschnitt zusammen mit der Aneuploidie besprochen. Als besondere Veränderung wird zusätzlich die Amplifikation vorgestellt. 


\subsubsection{Strukturelle Chromosomenaberrationen}

Bei strukturellen Veränderungen muss zwischen primären und sekundären chromosomalen Aberrationen unterschieden werden. Primäre Veränderungen liegen direkt nach Schädigung der Chromosomen vor. Rein mechanisch betrachtet beruht dies immer auf einem Bruch im Chromosom, mit oder ohne Wiedervereinigung der Bruchstellen. Die meisten der primären Aberrationen sind mit einer Teilung und dem weiteren Überleben der Zelle nicht vereinbar und führen zum Untergang einer oder beider Tochterzellen. Die wenigen Aberrationen, die an folgende Generationen weitergegeben werden können, heißen sekundäre oder abgeleitete Veränderungen (Savage 1976).

In Abbildung 1.1 (S.9) sind die wichtigsten der sekundären Veränderungen dargestellt.

\subsubsection{Numerische Chromosomenaberrationen und Aneuploidie}

Eine somatische menschliche Zelle enthält einen diploiden Chromosomensatz, d.h. jedes der 23 Chromosomen ist doppelt (2n) vorhanden. Die Geschlechtschromosomen bilden eine Ausnahme, die männliche Kombination besteht aus jeweils einem X- und einem YChromosom. Weichen die in einer Zelle vorhandenen Chromosomen von dieser Verteilung ab, ist z.B. ein Chromosom nur einfach (1n, Monosomie) oder gleich dreifach (3n, Trisomie) vorhanden, so spricht man von einer numerischen Chromosomenaberration (Ferguson-Smith 2002; Pearson 2002). Das Vorliegen einer solchen numerischen Abweichung bezeichnet man als Aneuploidie.

Aneuploidie ist ein außerordentlich weit verbreitetes Phänomen in soliden Tumoren. Eine Zusammenfassung zytogenetischer Daten von 2780 soliden Tumoren in der Mitelman Datenbank ergab, dass Aneuploidie bei über $90 \%$ zu finden ist (Mitelman et al. 2009; Weaver und Cleveland 2006).

Im Zuge zytogenetischer Untersuchungen wurde dieser Begriff erweitert: Von Aneuploidie spricht man auch dann, wenn nur ein Segment eines Chromosoms in einer anderen als diploiden Ausführung vorliegt. Wie die zuvor beschriebenen strukturellen Aberrationen zeigen, kann dies auch bei einer korrekten Gesamtzahl von 46 Chromosomen der Fall sein, z.B. bei Deletionen und Duplikationen (Pathak und Multani 2006). Abbildung 1.2 zeigt ein Beispiel eines normalen und eines aneuploiden Chromosomensatzes.

\subsubsection{Amplifikationen}

Von Amplifikationen spricht man, wenn ein Abschnitt der Basensequenz des Genoms in weit mehr als der üblichen Kopienzahl vorliegt. Die Amplifikation geht über eine Verdoppelung hinaus, wodurch sie von der Duplikation zu unterscheiden ist. Für gewöhnlich liegen mehr als fünf Kopien vor, aber auch Amplifikationen von 500 Kopien sind möglich. Dabei betreffen die amplifizierten Sequenzen Abschnitte von einigen Kilobasenpaaren bis hin zu etlichen Megabasenpaaren Länge (Savelyeva und Schwab 2001).

Es gibt mehrere Möglichkeiten, wie Amplifikationen in der chromosomalen Struktur organisiert sein können: Zum einen kommen die zusätzlichen Kopien in extrachromosomalen 


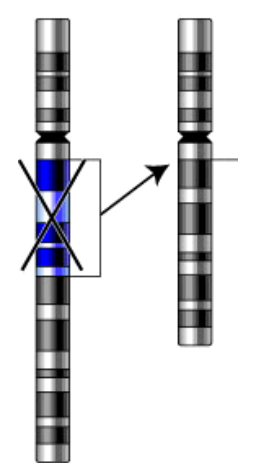

interstitielle Deletion
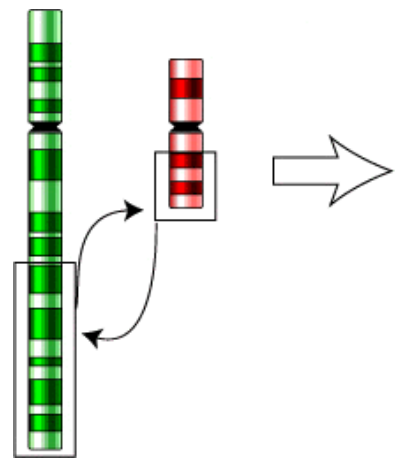

balancierte Translokation
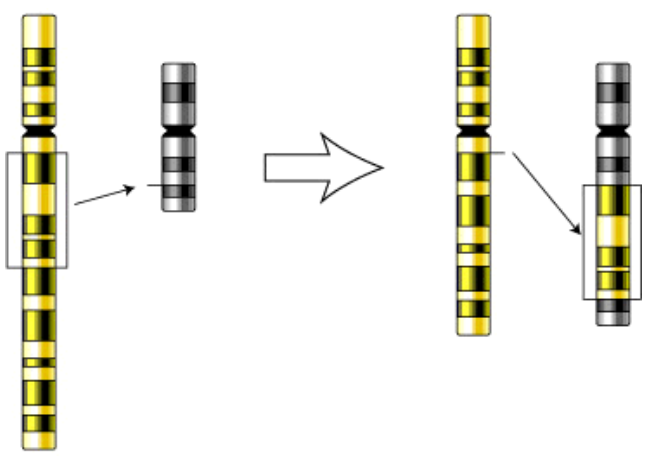

Insertion

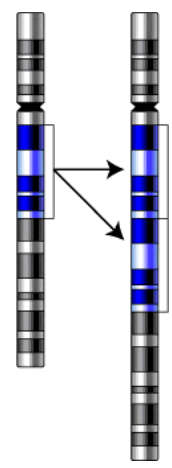

interstitielle Duplikation

Abbildung 1.1: Die wichtigsten strukturellen Chromosomenaberrationen. Bei der Duplikation kommt ein Chromosomenabschnitt hinzu, bei der Deletion fällt einer weg. Insertion und Translokation sind balanciert, d.h. der DNA-Gehalt ändert sich nicht. (Abbildung nach Mutation 2009).

DNA-Strukturen vor, den sogenannten double minutes. Die Extrakopien können auch in einer Tandemanordnung innerhalb eines Chromosoms gelegen sein; diese fallen dann als zytologisch sichtbare Regionen auf, die homogeneously staining regions (HSR). Auch eine Verteilung von Insertionen über zahlreiche Orte im gesamten Genom ist möglich (Albertson 2006). Abbildung 1.3 zeigt dies schematisch. 


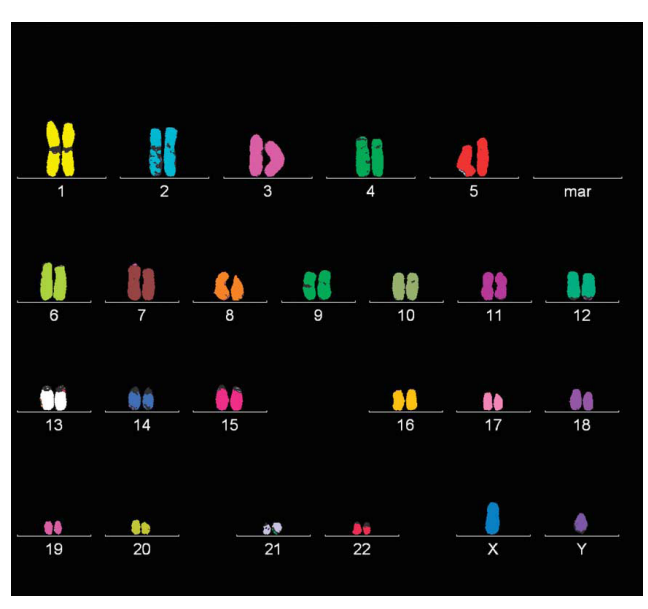

Karyotyp einer normalen (diploiden) männlichen Zelle

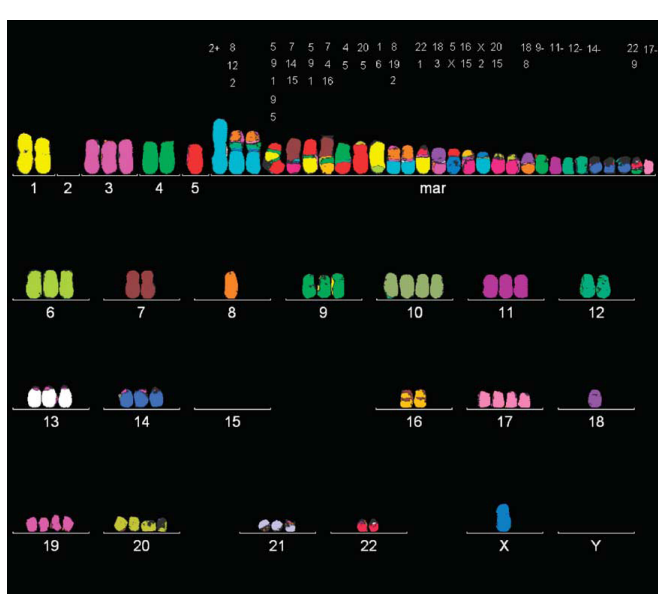

Karyotyp einer aneuploiden Tumorzelle

Abbildung 1.2: Karyotyp einer normalen diploiden Zelle und einer Tumorzelle. Die Tumorzelle stammt aus der Brustkrebszelllinie MDA 231, die Darstellung erfolgte durch multicolor-FISH (Fluorescence in situ Hybridization)-Technik (Abbildung nach Duesberg et al. 2005, S. 297, 298).

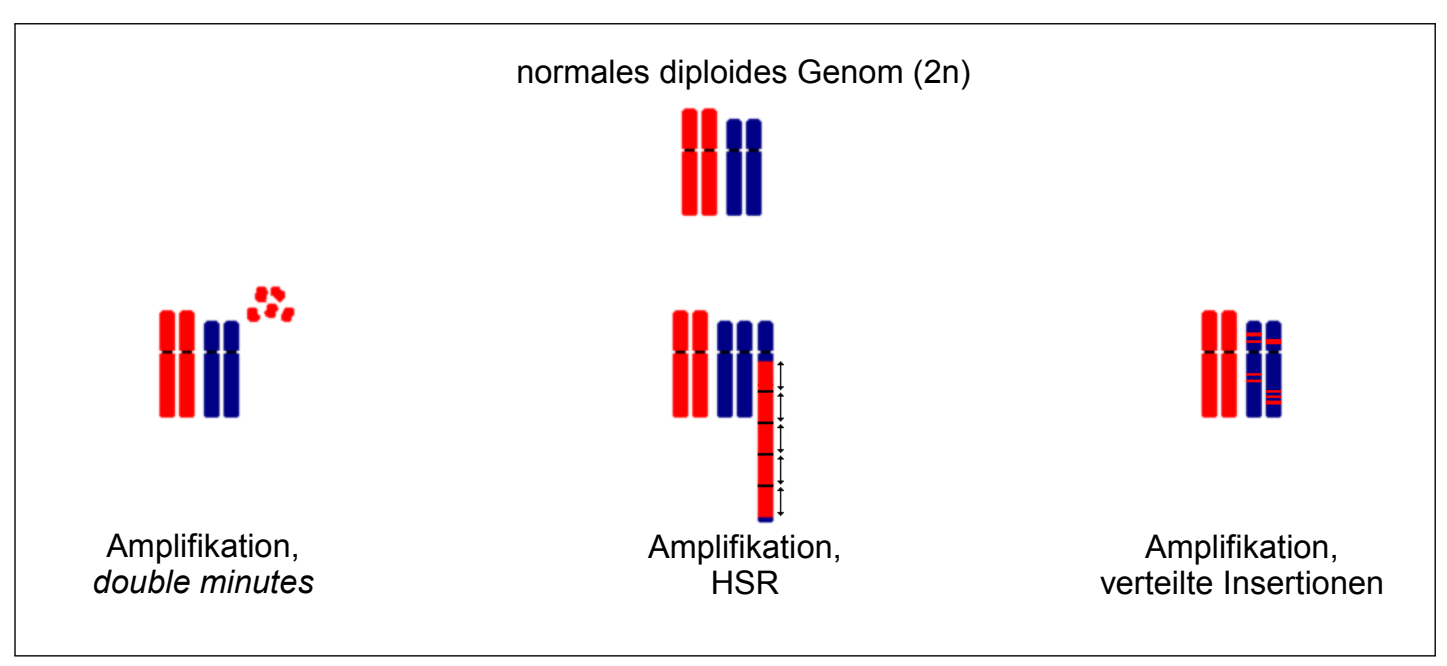

Abbildung 1.3: Strukturelle Grundlage der Amplifikation. Es kann entweder extrachromosomale DNA vorliegen (double minutes), eine Tandemanordnung von Extrakopien (homogeneously staining regions, HSR) oder zahlreiche über das Genom verteilte Insertionen (Abbildung neu gezeichnet nach Albertson 2006, S. 450). 


\subsection{CGH: Eine Screeningmethode für chromosomale Veränderungen}

Die vergleichende genomische Hybridisierung, im Englischen Comparative Genomic Hybridization $(\mathrm{CGH})$ genannt, ist eine molekularzytogenetische Methode, die einen Überblick über die Chromosomenveränderungen in Tumorgewebe erlaubt. Im Jahre 1992 war diese Methode von Anne und Olli Kallioniemi aus der Arbeitsgruppe von Dan Pinkel an der University of California vorgestellt worden (Kallioniemi A et al. 1992). Die Arbeitsgruppen von Thomas Cremer und Peter Lichter in Heidelberg konnten die Methode unabhängig davon präsentieren (du Manoir et al. 1993).

\subsubsection{Die Methode der komparativen genomischen Hybridisierung}

CGH beruht auf einem Vergleich von DNA, die aus Tumorgewebe isoliert wurde, mit einer Referenz-DNA aus gesundem Gewebe. Zunächst werden gleich große Mengen von Tumor- und Referenz-DNA markiert, indem sie mit einem Fluoreszenzfarbstoff versehen werden. Tumor-DNA wird grün markiert, Referenz-DNA rot. Beide DNAs liegen in Form kleiner Bruchstücke vor, die als Sonden im anschließenden Hybridisierungsschritt dienen. Bei der Hybridisierung lagern sich die Sonden ihrem Ziel an, einer Präparation normaler Metaphasechromosomen. Dies geschieht ortspezifisch, d.h. die Sonden lagern sich genau den Chromosomenregionen an, denen sie entstammen. Da nun zwei verschiedene Sondengemische - je eines aus Tumor- und Referenz-DNA - vorliegen, kommt es zu einem Konkurrieren um die Bindungsstellen. Liegen in beiden Proben die gleichen DNAMischungsverhältnisse vor, so sollten sich je zur Hälfte rote und zur Hälfte grüne Sonden anlagern, schließlich werden gleich große Mengen DNA eingesetzt. Das Mischungsverhältnis innerhalb der Proben weicht aber ab, sobald durch eine der beschriebenen Aberrationen eine Chromosomenregion in der Tumor-DNA in einer anderen als der normalen diploiden (2n) Ausführung vorliegt. Solche Abweichungen spiegeln sich im Verhältnis der angelagerten roten und grünen Sonden wider. Fehlt im Tumorgenom ein Chromosom, d.h. für dieses liegt Monosomie (1n) vor, so stehen einem Teil grüner Tumor-DNA-Sonden zwei Teile roter Referenz-DNA-Sonden gegenüber. Das Chromosom nimmt daher eine überwiegend rote Färbung an, man spricht dann von einem Verlust. Besitzt dagegen das Tumorgenom ein zusätzliches Chromosom, d.h. es liegt für dieses Trisomie (3n) vor, so stehen drei Teilen grüner Tumor-DNA-Sonden nur zwei Teile roter Referenz-DNA-Sonden gegenüber. Das Chromosom färbt sich überwiegend grün an, man spricht von einem Zugewinn. Besonders intensive Grünfärbung, die auf eine höhere Kopienzahl als 3n schließen lässt, bezeichnet man als Amplifikation. Dies gilt nicht nur für ganze Chromosomen, sondern auch für einzelne Regionen. Abbildung 1.4 und 1.5 veranschaulichen das Beschriebene. Zusammenfassend kann man also sagen: CGH detektiert die Aneuploidie, zu der es in der Folge chromosomaler Veränderungen kommt. Man spricht daher auch vom „copy number karyotype“(Kallioniemi OP et al. 1994, S. 232).

Wie Abbildung 1.4 zeigt, sind die aneuploiden Regionen an ihrer roten und grünen Färbung beim Blick durch das Fluoreszenzmikroskop bereits mit dem Auge zu erkennen. 


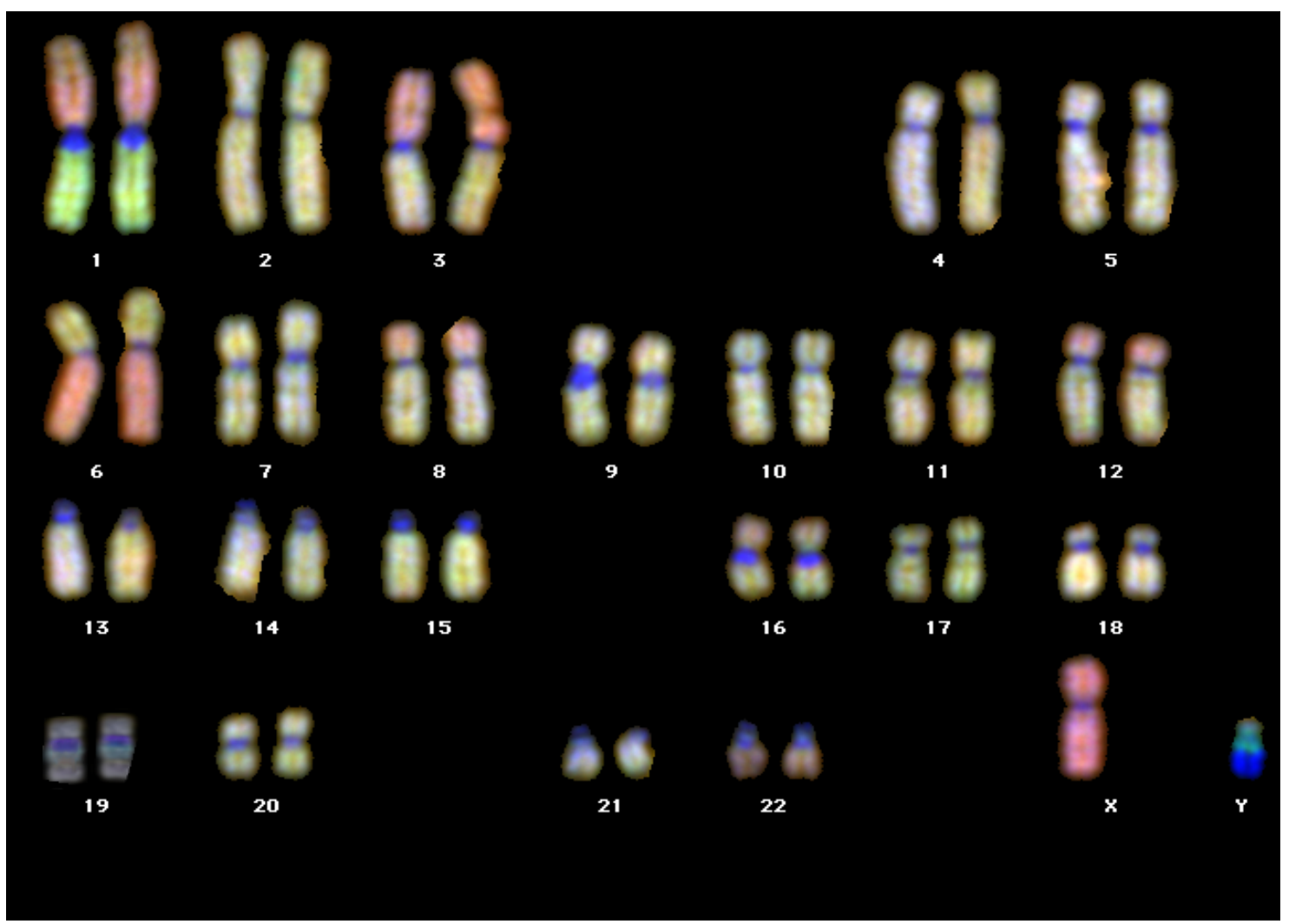

Abbildung 1.4: Karyotyp eines Metaphasenpräparats nach CGH. Es handelt sich um ein Mischbild, das eine Überlagerung von drei Farbkanälen zeigt: Grün entspricht dabei der Tumor-DNA, rot der Referenz-DNA, eine zusätzliche blaue Färbung hilft, die Chromosomen $\mathrm{zu}$ identifizieren.

Es handelt sich um ein CGH-Metaphasenpräparat aus dem in der vorliegenden Studie untersuchten Fall ADC-08. Deutlich sichtbar sind z.B. der Zugewinn auf Chromosomenarm 1q (vermehrte Grünfärbung) und der Verlust auf 1p (vermehrte Rotfärbung).

Um eine hohe Genauigkeit der Methode zu erreichen, schließt sich eine quantitative Auswertung an: Die Metaphasen werden im Fluoreszenzmikroskop mit digitaler Fotografie erfasst und durch ein spezielles Bildanalyseprogramm ausgewertet.

\subsubsection{Vorteile und Nachteile}

Vorteile

Die klassische Zytogenetik ist bei soliden Tumoren mit einigen Schwierigkeiten behaftet: Die Tumorzellen wachsen nur schlecht in einer Zellkultur, die Qualität der Chromosomen 
Referenz-DNA aus gesundem Gewebe wird rot markiert.

Hybridisierung der unterschiedlich markierten DNA auf normale Metaphasechromosomen. Grün und rot markierte DNA-Sonden konkurrieren dabei um Bindungsstellen.

Ist die Tumor-DNA im Verhältnis überrepräsentiert, färbt sich die zugehörige Region grün. Es liegt ein Zugewinn vor.
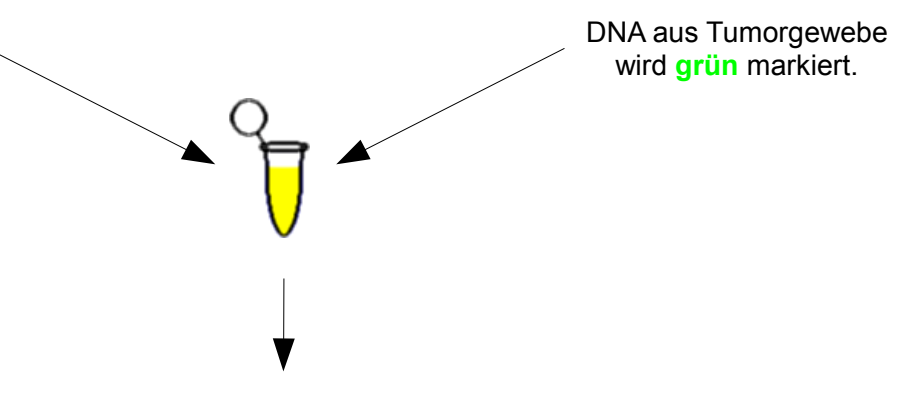

Ist die Tumor-DNA vermindert, so dass die Referenz-DNA überwiegt, färbt sich die Region rot. Es liegt ein Verlust vor.

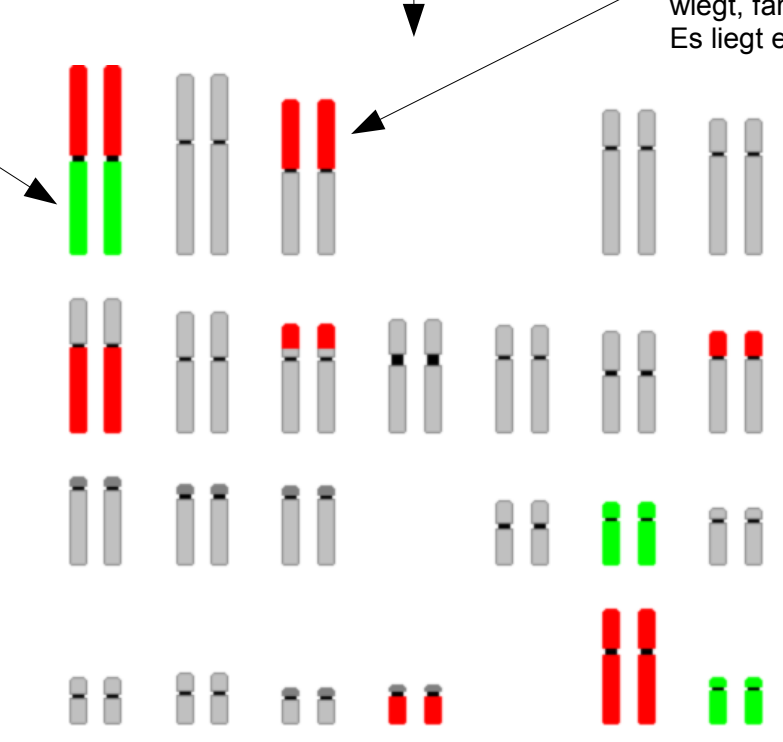

Abbildung 1.5: Die Abbildung stellt das Prinzip der vergleichenden genomischen Hybridisierung (CGH) dar, eine genaue Erläuterung erfolgt im Text (Abbildung neu gezeichnet nach McNeil und Ried 2000, S. 7). 
ist oft unzureichend und aufgrund der hohen Komplexität der Veränderungen sind diese schwierig zu identifizieren (Houldsworth und Chaganti 1994; Mitelman et al. 1997). Mit der CGH können diese Probleme umgangen werden: Eine Zellkultur ist nicht notwendig, als Untersuchungsmaterial kann frisches oder eingefrorenes Gewebe ebenso dienen wie formalinfixiertes und in Paraffin eingebettetes Archivmaterial (Isola et al. 1994; Speicher et al. 1993). Des Weiteren ist das gesamte Genom in einem einzigen Experiment erfassbar (Tönnies et al. 2001).

\section{Nachteile}

Ein großer Nachteil der CGH ist, dass nur die Aneuploidie erfasst wird, die als Folge der chromosomalen Veränderungen auftritt. CGH liefert keine Information über die strukturelle Natur der zugrunde liegenden Veränderungen (du Manoir et al. 1993). Da nur die resultierende Aneuploidie erfasst wird, bleiben auch sämtliche balancierten Veränderungen wie z.B. Translokationen unentdeckt (Kallioniemi OP et al. 1994). Aber auch bei der Aneuploidie gibt es eine Ausnahme: CGH erfasst nicht, wenn sämtliche Chromosomen vermehrt oder vermindert sind (Kallioniemi OP et al. 1994); Polyploidie z.B., ein vollständig verdoppelter Chromosomensatz (4n), fiele nicht auf.

Weiterhin stellt die Verunreinigung des Tumorgewebes mit gesunden Zellen ein Problem dar (Weiss et al. 1999). Gelegentlich wird als ein Nachteil auch die geringe Auflösung der Methode genannt. Bei der Frage nach der Auflösung oder treffender nach der Genauigkeit der Methode wird oft die grundlegende Publikation der Kallioniemis aus dem Jahr 1992 zitiert. Dort ist beschrieben, dass ein chromosomaler Verlust mit einer Länge von 10-20 Megabasenpaaren (Mbp) detektiert werden konnte, ebenso eine Amplifikationen von 300 Kilobasenpaaren (kbp) Länge. (Kallioniemi A et al. 1992). Da die Frage nach der Auflösung von großer Wichtigkeit für die Interpretation der Ergebnisse der vorliegenden Studie ist, sei an dieser Stelle auf den Diskussionsteil (Kapitel 4.1.2, S. 79) verwiesen.

\subsection{Stand der molekularzytogenetischen Forschung}

Im Folgenden wird kurz auf den aktuellen Stand der molekularzytogenetischen Forschung zum Thema Metastasierung und Hirnmetastasen beim Lungenkrebs eingegangen. Die Molekularzytogenetik der Primärtumoren wird nicht weiter vorgestellt, weil es Gegenstand der in der vorliegenden Studie durchgeführten Metaanalyse ist, ein möglichst umfassendes Bild davon zu gewinnen.

\subsubsection{CGH und Metastasierung}

Die verfügbare Literatur zum Thema CGH beim metastasierenden Lungenkrebs wird getrennt nach den kleinzelligen und nicht-kleinzelligen Karzinomen vorgestellt. 


\section{Nicht-kleinzelliger Lungenkrebs}

Es gibt mehrere CGH-Studien, die sich mit der Metastasierung beim nicht-kleinzelligen Lungenkrebs beschäftigt haben. Petersen S et al. (2000) konnten in einem Kollektiv von 64 metastasierten und nicht metastasierten Plattenepithelkarzinomen zeigen, dass Zugewinne auf den Chromosomenarmen 1q und 8q sowie Verluste auf 3p, 4p, 8p und 10q mit dem metastatischen Phänotyp verbunden sind. Yan et al. (2005a) hatten ebenfalls Plattenepithelkarzinome untersucht, 18 metastasierte und 21 nicht metastasierte. Dabei waren Zugewinne auf Chromosom 7 und den Armen 2p und 20p sowie Verluste auf 2q, 4q, 6p, Chromosom 16, 18q, 20q und 21q häufiger bei den metastasierenden Tumoren aufgefallen; auch war die Anzahl der Veränderungen je Fall in der metastasierenden Gruppe höher. Chujo et al. (2002) konnten nachweisen, dass die Anzahl der Veränderungen je Fall auch in lymphogen metastasierenden Tumoren signifikant höher ist, und zwar bei 41 Plattenepithelkarzinomen. Ebenfalls lymphogene Metastasierung betrachteten Ma et al. (2006) bei 23 und Rydzanicz et al. (2008) bei 42 Plattenepithelkarzinomen: Erstere konnten Zugewinne auf den Chromosomenarmen 1q, 12q und 17q als metastasenspezifisch nachweisen, letztere konnten dies für einen Zugewinn auf Chromosomenarm 7q zeigen.

Die Studie von Boelens et al. (2009) weicht von diesen Befunden ab: Es waren ebenfalls Plattenepithelkarzinome untersucht worden, allerdings mit der genaueren Methode der Array-CGH. Dabei waren in einem Kollektiv von 34 Tumoren Zugewinne auf Chromosomenarm 8q und Verluste auf 8p und 13q mit fernmetastasierenden Tumoren assoziiert. Dazu kommen ungewöhnliche Ergebnisse: Das Fehlen eines Zugewinnes auf $2 p$ und eines Verlustes auf 11q war ebenfalls mit der Fernmetastasierung verbunden.

Bei den Adenokarzinomen konnte ebenfalls ein metastatischer Genotyp gefunden werden: Goeze et al. (2002) untersuchten 80 metastasierende und nicht metastasierende Tumoren und fanden in der metastasierenden Gruppe häufigere Zugewinne auf 1q, 7q, 9q, 11q, 14q und 17q sowie Verluste auf 3p, Chromosom 4, 6q, 8p, 10q, 14q, 17p, 20p und 21q. Hayashi et al. (2005) untersuchten 42 Adenokarzinome und beschrieben Zugewinne auf Chromosomenarm 9q, 10q und Verluste auf 15q als signifikant mit lymphogener Metastasierung assoziiert.

Ohne genaue Trennung nach histologischen Subtypen hatten Pei et al. (2001) 67 Adenound Plattenepithelkarzinome untersucht. Zugewinne auf Chromosomenarm 5q und 7q waren mit lymphogener Metastasierung assoziiert.

\section{Kleinzelliger Lungenkrebs}

Für den kleinzelligen Lungenkrebs fand sich nur eine vergleichbare Publikation: Schwendel et al. (1997) untersuchten 10 kleinzellige Primärtumoren und 16 korrespondierende Metastasen mit CGH. In diesem Kollektiv konnten keine für die Metastasen spezifischen Veränderungen gefunden werden. 


\subsection{2 $\mathrm{CGH}$ und Hirnmetastasen}

Zum Thema Hirnmetastasen existieren nur wenige molekularzytogenetische Untersuchungen. Petersen I et al. (2000) untersuchten 14 Hirnmetastasen vom Lungenkrebs mit CGH, allerdings nicht nach histologischen Subtypen getrennt. Es fand sich ein sehr komplexes Spektrum von Veränderungen. Insbesondere Zugewinne auf den Chromosomenarmen 1q, 3p, 5p, 7p, 8q und 17q schienen beteiligt zu sein, zudem Verluste auf 4q und 5q.

Darüber hinaus sind Hirnmetastasen mit anderen Methoden untersucht worden. Shiseki et al. $(1994,1996)$ hatten 22 Hirnmetastasen vom nicht-kleinzelligen Lungenkrebs auf Allelverlust untersucht und diese mit Primärtumoren verglichen. Verluste auf den Chromosomenarmen 2q, 3p, 9p, 17p, 18q und 22q hatten sich signifikant häufiger bei den Hirnmetastasen gefunden.

\subsection{Erkenntnisinteresse}

In der vorliegenden Studie werden vier Fragen gestellt. Die ersten beiden beinhalten die im Rahmen der verwendeten Methode fassbaren chromosomalen Veränderungen. Frage drei und vier gehen über dieses rein molekularzytogenetische Erkenntnisinteresse hinaus, denn durch sie könnten langfristig klinisch relevante Anwendungen ableitbar sein.

\section{Frage 1: Gibt es einen metastatischen Genotyp?}

Wie bereits ausgeführt, geht es um die Frage, ob auf Seiten des Genoms Mutationen zu finden sind, die der phänotypischen Eigenschaft der Metastasierung zugeordnet werden können. Im Rahmen der Methode beschränkt sich die Suche dabei auf chromosomale Mutationen und weiter auf die durch diese verursachte Aneuploidie.

Die Forschungsergebnisse der letzten Jahre zeigen, dass beim nicht-kleinzelligen Lungenkrebs ein metastatischer Genotyp zu existieren scheint. Diese Ergebnisse könnten mit der vorliegenden Studie bestätigt werden. Für den kleinzelligen Lungenkrebs war die Frage mit den bisher durchgeführten Untersuchungen nicht zu beantworten, was daher im Folgenden versucht werden wird.

\section{Frage 2: Welche sind die metastasenspezifischen Veränderungen?}

Findet sich ein metastatischer Genotyp, so sind die daran beteiligten Chromosomenregionen und die Art der Veränderungen zu benennen. Eine genaue Eingrenzung der metastasenspezifischen Veränderungen leitet dann unmittelbar zur dritten Frage über.

\section{Frage 3: Lassen sich Kandidatengene ausmachen?}

Fiele unter den metastasenspezifischen Veränderungen eine chromosomale Region besonders ins Auge, etwa eine für ein Tumorsuppressor- oder Onkogen bekannte Region, so könnte man über ein dort gelegenes Kandidatengen zumindest spekulieren. In jedem Falle aber 
wäre der Befund ein Wegweiser, um in diesen Regionen mit speziellen Methoden weiter nach den verantwortlichen Genen zu fahnden.

\section{Frage 4: Ist eine molekularzytogenetische Klassifikation möglich?}

Fände sich ein metastatischer Genotyp, so wäre es denkbar, dass dieser bereits im Primärtumor angelegt sein könnte. Dies eröffnete die Möglichkeit, bereits in einer Gewebeprobe des Primärtumors dessen Metastasierungsverhalten erkennen zu können, noch bevor die erste Metastase diagnostiziert worden ist. Ziel wäre also, einen klinischen und prognostischen Marker zu finden.

Um sich dieser Frage zu nähern, wird versucht, Hirnmetastasen und Primärtumoren allein anhand ihrer genetischen Veränderungen in die Metastasen- und Primärtumorgruppe aufzutrennen. 


\section{Patienten, Material und Methoden}

\subsection{Patienten}

Der Einschluss der Patienten in die Studie geschah durch Aufsuchen der Operationspräparate von Hirnmetastasen, die in der Abteilung für Neuropathologie der Universitätsmedizin Göttingen untersucht und mit der Primärtumorlokalisation "Lunge“ versehen worden waren. Es wurden Fälle aus dem Jahrzehnt von 1995 bis 2004 eingeschlossen. Insgesamt handelte es sich um 126 formalinfixierte und in Paraffin eingebettete Operationspräparate.

Alle Fälle waren mit einer Codenummer versehen, durch die im Rahmen der pathologischen Befundung die Stammdaten der Patienten codiert werden. Die Patienten selbst waren im Labor nicht bekannt und konnten dort nicht nachträglich identifiziert werden. Die somit pseudonymisiert vorliegenden Fälle wurden für diese Studie mit einer neuen Codierung versehen. Der Zuordnungsschlüssel wurde anschließend verworfen, die Ergebnisse wurden anonymisiert ausgewertet.

\subsection{Material}

\section{Chemikalien und Biochemikalien}

6x Loading Dye Solution

10x Reaction Buffer

Actinomycin-D-Mannitol

Agarose-LE

Albumin Fraktion V

Aqua ad iniectabilia

Aqua bidest.

Borsäure

Dextransulfat

EDTA

Ethanol $100 \%$

Ethanol $85 \%$

Ethanol $70 \%$

Ethidiumbromid

Formamid

$\mathrm{Na}_{2} \mathrm{HPO}_{4}$
Fermentas

Fermentas

Sigma-Aldrich

Biozym

Merck

Fresenius Kabi

UMG

Merck

Merck

Serva Electrophoresis

Sigma-Aldrich

Sigma-Aldrich

Sigma-Aldrich

Sigma-Aldrich

Sigma-Aldrich

Merck
St. Leon-Rot

St. Leon-Rot

Hamburg

Hessisch Oldendorf

Darmstadt

Bad Homburg

Göttingen

Darmstadt

Darmstadt

Heidelberg

Hamburg

Hamburg

Hamburg

Steinheim

Hamburg

Darmstadt 


\author{
$\mathrm{NaH}_{2} \mathrm{PO}_{4}$ \\ Natriumacetat \\ Natriumchlorid \\ Polysorbat 20 \\ Resin \\ Salzsäure $1 \mathrm{~mol} / \mathrm{L}$ \\ Salzsäure $37 \%$ \\ Salzsäure $5 \mathrm{~mol} / \mathrm{L}$ \\ tri-Natriumcitrat-Dihydrat \\ Tris \\ Tris-HCl \\ Vectashield Mounting Medium \\ Xylol
}

Merck

Merck

Merck

Sigma-Aldrich

Bio-Rad

Merck

Merck

Merck

Merck

Merck

Merck

Vector Laboratories

Carl Roth
Darmstadt

Darmstadt

Darmstadt

Hamburg

München

Darmstadt

Darmstadt

Darmstadt

Darmstadt

Darmstadt

Darmstadt

Burlingame, USA

Darmstadt

\section{Geräte}

Anregungsfilter DAPI

Anregungsfilter FITC

Anregungsfilter TRITC/TxRed

Brutschrank

Digitalkamera SenSys

Elektrophoresekammer

BlueMarine 100

Feinwaage BL 1500S

Fotometer BioPhotometer

Hybridisierungskammer HYBrite

Magnetrührer MR 3001

Mikroskop Axioskop 40 FL

Mikrotom HM 400

Objektiv Plan-Neofluar 10x/0,30

Objektiv Plan-Neofluar

$63 \mathrm{x} / 1,25$ Oil

pH-Meter CG820

Pipetten

Polaroid-Kamera MP4+ ICS

Power Mac G3

Power Mac G5

Quecksilberdampflampe

HBO 103W/2

Thermomixer comfort
Genetix

Genetix

Genetix

Memmert

Photometrics

Serva Electrophoresis

Sartorius

Eppendorf

Vysis

Heidolph Instruments

Carl Zeiss

Microm

Carl Zeiss

Carl Zeiss

Schott Geräte

Eppendorf

Polaroid

Apple

Apple

Carl Zeiss

Eppendorf
New Milton, UK

New Milton, UK

New Milton, UK

Schwabach

München

Heidelberg

Göttingen

Hamburg

Downers Grove, USA

Schwabach

Jena

Volketswil, Schweiz

Jena

Jena

Mainz

Hamburg

Dreieich-Sprendlingen

Cupertino, USA

Cupertino, USA

Göttingen

Hamburg 
UV-Transilluminator FLX-20.M Vortex-Genie 2

Zentrifuge Centrifuge 5417R

Zentrifuge Concentrator 5301

Verbrauchsmaterialien

Deckgläser

Fixogum

Küvetten

Objektträger

Pipettenspitzen

Reagiergefäße $1,5 \mathrm{~mL}$

Isolierungssysteme

QIAamp DNA Mini Kit

Molekulare Standards

Lambda-DNA/EcoRI Marker pUC19 DNA/MspI (HpaII) Marker

Fermentas

Fermentas
Eberhardzell

Bohemia, USA

Hamburg

Hamburg
Menzel-Gläser

Marabu

Eppendorf

Menzel-Gläser

Sarstedt

Sarstedt

Qiagen

Hilden
Braunschweig

Tamm

Hamburg

Braunschweig

Nümbrecht

Nümbrecht

Nukleotide und DNA-Präparate

Biotin-16-dUTP

COT Human DNA

Dioxigenin-11-dUTP

Sequencing Grade dNTP Set
Roche

Roche

Roche

Amersham Biosciences
St. Leon-Rot

St. Leon-Rot
Penzberg

Penzberg

Penzberg

Piscataway, USA 
Fluoreszenzfarbstoffe und -konjugate

$\begin{array}{lll}\text { Anti-Digoxigenin-Rhodamin } & \text { Roche } & \text { Penzberg } \\ \text { DAPI } & \text { Sigma-Aldrich } & \text { Hamburg } \\ \text { Fluorescein Avidin DCS } & \text { Vector Laboratories } & \text { Burlingame, USA }\end{array}$

\section{Enzyme}

DNA-Polymerase I, E.coli

Fermentas

Roche

Sigma-Aldrich

Roche

Proteinkinase K

Metaphasenpräparate

CGH Metaphase Target Slides
Abott Molecular

Wiesbaden

\section{Auswertungssoftware}

QUIPS Karyotyping/CGH-Software SmartCapture-

Bilderfassungssoftware
Visys

Digital Scientific
St. Leon-Rot

Mannheim

Hamburg

Mannheim

\subsection{Allgemeine pathologische und biochemische Methoden}

Alle Puffer und Lösungen wurden, soweit nicht anders angegeben, mit Aqua bidest. angesetzt.

\subsubsection{Histopathologie und Immunhistochemie}

Um die Patienten den pathologischen Gruppen des kleinzelligen oder nicht-kleinzelligen Lungenkrebses zuordnen zu können sowie die nicht-kleinzelligen deren histologischen Untergruppen, wurde auf die vorliegenden histologischen Präparate der Hirnmetastasen zurückgegriffen. Alle Präparate wurden von einem erfahrenen Pathologen durchgesehen. War 
die Diagnose in den histologischen Standardfärbungen eindeutig, wurde die Hirnmetastase in die entsprechende Gruppe aufgenommen.

Weckte das histologische Bild der Hirnmetastase Zweifel, so wurden spezielle immunhistochemische Färbungen hinzugezogen, um die Diagnose zu sichern. Dabei wurden je nach Fall und Fragestellung Färbungen gegen Zytokeratin 5/6, CD56, S100, TTF-1, Vimentin und andere betrachtet.

\subsubsection{Agarose-Gelelektrophorese von DNA}

DNA-Fragmente lassen sich in Agarosegelen elektrophoretisch trennen. Dabei ist die Wanderungsgeschwindigkeit dieser Fragmente umgekehrt proportional zum Logarithmus ihres Molekulargewichts. Durch den Vergleich mit einem Längenstandard kann so die Fragmentlänge ermittelt werden (Sambrook und Russell 2001).

Puffer und Lösungen

\begin{tabular}{llr} 
TBE-Puffer & & $1000 \mathrm{~mL}$ \\
\hline Tris & $89 \mathrm{mmol} / \mathrm{L}$ & $10,78 \mathrm{~g}$ \\
Borsäure & $89 \mathrm{mmol} / \mathrm{L}$ & $5,5 \mathrm{~g}$ \\
EDTA & $2 \mathrm{mmol} / \mathrm{L}$ & $0,58 \mathrm{~g}$ \\
\hline
\end{tabular}

Probenpuffer: 6x Loading Dye Solution

\begin{tabular}{ll}
\hline Tris-HCl & $10 \mathrm{mmol} / \mathrm{L}$ \\
Bromphenolblau & $0,03 \%$ \\
Xylencyanol FF & $0,03 \%$ \\
Glycerol & $60 \%$ \\
EDTA & $60 \mathrm{mmol} / \mathrm{L}$ \\
\hline
\end{tabular}

Es handelt sich um ein Fertigreagenz, der Hersteller macht keine genaueren Angaben. 


\begin{tabular}{lrr} 
Gelansatz & $100 \mathrm{~mL}$ \\
\hline Agarose LE & $1,5 \%(\mathrm{~m} / \mathrm{v})$ & $1,5 \mathrm{~g}$ \\
& ad $100 \mathrm{~mL}$ TBE-Puffer \\
\hline
\end{tabular}

Die Lösung wurde zusätzlich mit $15 \mu \mathrm{L}$ Ethidiumbromidlösung $[1 \mathrm{~g} / \mathrm{L}]$ versetzt.

Laufpuffer

\begin{tabular}{lr}
\hline TBE-Puffer & $100 \mathrm{~mL}$ \\
Ethidiumbromidlösung $[1 \mathrm{~g} / \mathrm{L}]$ & $15 \mu \mathrm{L}$ \\
\hline
\end{tabular}

\section{Durchführung}

$5 \mu \mathrm{L}$ der zu analysierenden DNA wurden zusammen mit $3 \mu \mathrm{L}$ Probenpuffer in die Taschen des Agarosegels pipettiert. In einer Spur wurden 1,5 $\mu \mathrm{L}$ des Längenstandards zusammen mit $3 \mu \mathrm{L}$ Probenpuffer und $5 \mu \mathrm{L}$ sterilem Wasser aufgetragen. Zur Fragmentlängenbestimmung nach DNA-Isolierung diente der Lambda-DNA/EcoRI Marker, dessen DNA-Fragmente Größen von 21226, 7421, 5804, 5643, 4878 und 3530 Basenpaaren besitzen. Zur Kontrolle nach Nicktranslation kam der pUC19 DNA/MspI (HpaII) Marker zum Einsatz. Dieser enthält DNA-Fragmente der Größen 501, 489, 404, 331, 242, 190, 147, 111, 110, 67, 34, 34 und 26 Basenpaare. In einer mit Laufpuffer gefüllten Elektrophoresekammer wurde bei $80 \mathrm{~V}$ für 45 min aufgetrennt. Sowohl das Agarosegel als auch der Laufpuffer enthielten zum Sichtbarmachen der DNA den interkalierenden Fluoreszenzfarbstoff Ethidiumbromid. Das Gel wurde anschließend auf einem UV-Leuchtkasten fotografiert.

\subsubsection{Fotometrische DNA-Konzentrationsbestimmung}

Spektralfotometrisch ist es möglich, die Konzentration einer DNA-Lösung durch deren Extinktion bei $260 \mathrm{~nm}$ Wellenlänge zu ermitteln. Bei einem neutralen oder leicht basischen $\mathrm{pH}$ gemessen, entspricht ein Extinktionskoeffizient von 1,0 einer Konzentration doppelsträngiger DNA von $50 \mathrm{\mu g} / \mathrm{mL}$ (Surzycki 2003).

Weiterhin ist es möglich, die Reinheit der DNA durch den Quotienten der Extinktionen bei $260 \mathrm{~nm}$ und $280 \mathrm{~nm}$ abzuschätzen (Glasel 1995; Wilfinger et al. 1997). 


\section{Durchführung}

Um die DNA-Konzentration zu bestimmen, wurden zunächst $5 \mu \mathrm{L}$ DNA-Lösung mit $95 \mu \mathrm{L}$ Aqua bidest. verdünnt. Die Extinktion dieses Gemisches wurde bei $260 \mathrm{~nm}$ gegen Aqua bidest. als Leerwert gemessen. Die Konzentration ist dann am Gerät direkt ablesbar.

Der Quotient der Extinktionen bei $260 \mathrm{~nm}$ und $280 \mathrm{~nm}$ ist ebenfalls direkt ablesbar. Werte zwischen 1,8 und 1,9 wurden als optimal angesehen.

\subsubsection{Gewinnung genomischer DNA aus Paraffinblöcken}

DNA, die aus formalinfixiertem paraffineingebettetem Archivmaterial stammt, ist meist nicht intakt, sondern mehr oder weniger stark fragmentiert (Goelz et al. 1985). Dennoch kann die CGH recht gut mit derart gewonnener DNA durchgeführt werden (Isola et al. 1994; Speicher et al. 1993). Dazu wird zunächst geeignetes Gewebe aus dem Paraffinblock entnommen und entparaffiniert. Danach wird die DNA aus dem Gewebe freigesetzt und mit einem speziellen Isolierungssystem aufgereinigt.

\section{Puffer und Lösungen}

DNA-Isolierungspuffer

\begin{tabular}{llc} 
Tris- $\mathrm{HCl}$ & $50 \mathrm{mmol} / \mathrm{L}$ & $7,88 \mathrm{~g}$ \\
EDTA & $1 \mathrm{mmol} / \mathrm{L}$ & $0,29 \mathrm{~g}$ \\
Polysorbat 20 & $0,5 \%(\mathrm{~V} / \mathrm{v})$ & $5 \mathrm{~mL}$ \\
\hline
\end{tabular}

Die Lösung wurde auf $\mathrm{pH}=8,5$ eingestellt.

Buffer AL

\begin{tabular}{lc}
\hline Guanidiniumchlorid & $25-50 \%$ \\
\hline $\begin{array}{l}\text { Der Puffer lag dem QIAamp DNA Mini-Kit bei, der Hersteller macht keine } \\
\text { genaueren Angaben. }\end{array}$
\end{tabular}


Buffer AW1

\begin{tabular}{l}
\hline Guanidiniumchlorid $50-100 \%$ \\
\hline Der Puffer lag dem QIAamp DNA Mini-Kit bei, der Hersteller macht keine \\
genaueren Angaben. Es soll sich um eine Ethanol-basierte Waschlösung \\
handeln, die einen geringen Anteil Guanidiniumchlorid enthält (Ban 2003).
\end{tabular}

Buffer AW2

Der Puffer lag dem QIAamp DNA Mini-Kit bei, der Hersteller macht keine Angaben. Es soll sich um eine Tris-basierte Lösung handeln, die einen geringen Anteil Guanidiniumchlorid enthält (Ban 2003).

Buffer AE

Der Puffer lag dem QIAamp DNA Mini-Kit bei, der Hersteller macht keine Angaben. Es soll sich um eine Tris-EDTA Lösung handeln (Ban 2003).

\section{Durchführung}

Die Gewinnung genomischer DNA umfasst mehrere getrennte Schritte, die in den folgenden Abschnitten detailliert beschrieben sind.

\section{Auswahl des Gewebes}

In Gewebeproben von Tumoren findet sich meist ein gewisser Anteil normaler Zellen. Für ein gutes Resultat der CGH ist es aber notwendig, dass die zu untersuchende Tumor-DNA nicht allzu stark durch normale DNA kontaminiert ist (Weiss et al. 1999). Daher muss sichergestellt werden, dass das Gewebe, aus dem die Test-DNA gewonnen wird, einen möglichst hohen Anteil an Tumorzellen enthält.

Zunächst wurden die mit den Blöcken korrespondierenden histologischen Schnitte von einem Pathologen gesichtet und die tumorhaltigen Areale markiert. Anschließend wurden vom Block 10-20 Schnitte von je $10 \mu \mathrm{m}$ Dicke mit einem Mikrotom angefertigt. War ausschließlich Tumorgewebe vorhanden, wurden dieses direkt in ein Reagiergefäß überführt. 
Stammte nur ein Teil des Gewebes vom Tumor, so wurden die Schnitte auf Objektträger gezogen und mikrodisseziert.

\section{Entparaffinieren}

Zum Entparaffinieren wurde das zuvor gewonnene fixierte Tumorgewebe mit $1 \mathrm{~mL}$ Xylol versetzt und geschüttelt. Nach einer 10-minütigen Einwirkzeit wurde zentrifugiert und der Überstand verworfen. Dieser Arbeitsschritt wurde einmal mit Xylol wiederholt und zweimal mit Ethanol $100 \%$. Danach wurde das Gewebe getrocknet.

\section{Freisetzen der DNA durch Lyse und enzymatischen Verdau}

Das Freisetzen der DNA aus dem Gewebe geschah durch Lyse der Zellen und enzymatischen Verdau der zellulären Proteine. Zur Lyse wurden $200 \mu \mathrm{L}$ DNA-Isolierungspuffer und zum Verdau $40 \mu \mathrm{L}$ einer Proteinkinase-K-Lösung dem Gewebe hinzugegeben. Über Nacht wurde bei $55^{\circ} \mathrm{C}$ im Thermomixer inkubiert. Danach wurde die Proteinkinase K durch Erhitzen auf $95^{\circ} \mathrm{C}$ inaktiviert, zentrifugiert und der DNA-haltige Überstand entnommen.

\section{Isolieren und Aufreinigen}

Zum Isolieren und Aufreinigen der DNA wurde ein spezielles DNA-Isolierungssystem verwendet, das QIAamp DNA Mini Kit. Das Prinzip dieses Systems besteht darin, dass die zu isolierende DNA im ersten Schritt an eine Siliciumdioxidmembran adsorbiert wird. Danach folgen zum Aufreinigen zwei Waschschritte. Im letzten Schritt wird die so isolierte und gereinigte DNA mit einem speziellen Puffer von der Membran wieder abgelöst. Für Details sei auf die Dokumentation des Herstellers verwiesen (QIAamp 2007).

Zunächst wurden dem DNA-haltigen Ansatz $200 \mu \mathrm{L}$ Buffer AL hinzugegeben und für $10 \mathrm{~min}$ bei $70^{\circ} \mathrm{C} \mathrm{im}$ Thermomixer inkubiert. Danach wurden $100 \mu \mathrm{L}$ Ethanol $100 \%$ hinzugefügt. Dieses Gemisch wurde nun im ersten Schritt durch eine Filtersäule zentrifugiert, die die Siliciumdioxidmembran enthielt, damit die DNA adsorbiert werden konnte. Zwei Waschschritte folgten, einmal mit $500 \mu \mathrm{L}$ Buffer AW1, einmal mit Buffer AW2. Im letzten Schritt wurde die DNA von der Membran abgelöst, dazu wurden zweimal je $50 \mu \mathrm{L}$ Buffer AE durch die Säule zentrifugiert und aufgefangen. Es verblieben $100 \mu \mathrm{L}$ gereinigter DNA-Lösung.

\subsubsection{Gewinnung genomischer DNA aus tiefgefrorenem Gewebe}

Referenz-DNA wurde aus normalen Lebergewebe gewonnen, das bei $-80^{\circ} \mathrm{C}$ gelagert worden war. 
Puffer und Lösungen

Buffer ATL

\begin{tabular}{lc}
\hline Edetinsäure & $2,5-10 \%$ \\
Natriumlaurylsulfat & $2,5-10 \%$ \\
\hline $\begin{array}{l}\text { Der Puffer lag dem QIAamp DNA Mini-Kit bei, der Hersteller macht keine } \\
\text { genaueren Angaben. }\end{array}$
\end{tabular}
genaueren Angaben.

\section{Durchführung}

Das gefrorene Lebergewebe wurde aufgetaut, mit $360 \mu \mathrm{L}$ Buffer ATL und $40 \mu \mathrm{L}$ ProteinkinaseK-Lösung versetzt und über Nacht bei $55^{\circ} \mathrm{C}$ im Thermomixer inkubiert. Alle weiteren Schritte entsprechen den zuvor für paraffineingebettetes Gewebe beschriebenen.

\subsection{Arbeitsschritte der $\mathrm{CGH}$}

\subsubsection{Markierung}

Um DNA-Sonden für Hybridisierungsexperimente zu markieren, stehen direkte und indirekte Methoden zur Verfügung. Bei der direkten Markierung ist das nachweisbare Molekül, z.B. ein Fluoreszenzfarbstoff, unmittelbar an die Sonde gebunden. Beim indirekten Verfahren wird die Sonde zunächst mit einem Markermolekül versehen, das nach der Hybridisierung durch einen geeigneten Antikörper-konjugierten Farbstoff detektiert werden kann. In der vorliegenden Studie wurde ein indirektes Verfahren angewendet.

Puffer und Lösungen

10x Reaction Buffer

\begin{tabular}{ll}
\hline Tris-HCl & $0,5 \mathrm{~mol} / \mathrm{L}$ \\
Magnesiumchlorid & $0,1 \mathrm{~mol} / \mathrm{L}$ \\
Dithiothreitol & $10 \mathrm{mmol} / \mathrm{L}$ \\
\hline
\end{tabular}

Der Puffer war der DNA-Polymerase I beigefügt. 


\section{Nicktranslation}

Die Nicktranslation ist eine Markierungstechnik, bei der unmarkierte DNA durch neu synthetisierte markierte DNA ersetzt wird (Rigby et al. 1977). Zunächst erzeugt DNAse im DNA-Substrat Einzelstrangbrüche, sogenannte nicks (engl. Kerben). Von diesen nicks ausgehend baut die $5^{\prime} \rightarrow 3^{\prime}$-Exonukleaseaktivität der DNA-Polymerase I Nukleotide ab, wobei gleichzeitig durch die $5^{\prime} \rightarrow 3^{\prime}$-Polymeraseaktivität komplementäre DNA neu synthetisiert wird. Bei der Neusynthese werden dann markierte Nukleotide eingebaut (Nick 1999).

Da ein indirektes Verfahren genutzt werden sollte, kamen Hapten-gekoppelte Nukleotide zum Einsatz: Biotin-16-dUTP bei der Tumor-DNA und Digoxigenin-11-dUTP bei der Referenz-DNA. Durch die Wirkung der DNAse wird die Substrat-DNA während der Nicktranslation fragmentiert. Da die Fragmentlänge von Bedeutung für die Qualität der Hybridisierung ist (Kallioniemi OP et al. 1994), wurde diese nach jeder Reaktion durch Agarose-Gelelektrophorese kontrolliert.

\section{Durchführung}

Zu $3 \mu \mathrm{g}$ Tumor-DNA oder Referenz-DNA - das entsprechende Volumen wurde mit Hilfe der zuvor gemessenen Konzentration berechnet - wurden auf Eis pipettiert: $10 \mu \mathrm{L} 10 \mathrm{x}$ Reaction Buffer, je $2 \mu \mathrm{L}$ dATP, dGTP, dCTP $[100 \mathrm{mmol} / \mathrm{L}], 1 \mu \mathrm{L}$ dTTP $[100 \mathrm{mmol} / \mathrm{L}], 1 \mu \mathrm{L}$ DNAse und

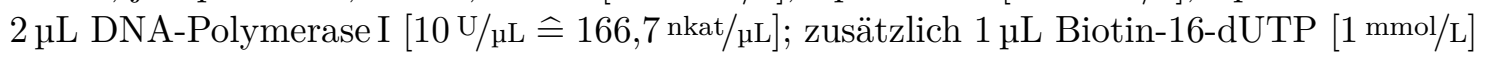
bei der Tumor-DNA oder $1 \mu \mathrm{L}$ Digoxigenin-11-dUTP [1 mmol/L] bei der Referenz-DNA. Mit sterilem Wasser wurde auf $100 \mathrm{\mu L}$ aufgefüllt, kurz gemischt und zentrifugiert. Der Ansatz mit Referenz-DNA wurde anschließend für 60 min bei $15^{\circ} \mathrm{C}$ inkubiert. Der Ansatz mit Tumor-DNA hingegen wurde nur 50 min inkubiert, weil aus Paraffin isolierte DNA bereits teilweise fragmentiert ist. Anschließend wurde die Reaktion durch Abkühlen auf $-20^{\circ} \mathrm{C}$ vorläufig gestoppt und eine Fragmentlängenbestimmung mit Agarose-Gelelektrophorese durchgeführt. Lagen die Fragmentlängen im gewünschten Bereich von 150-750 bp, so wurde die Reaktion durch Zugabe von $5 \mu \mathrm{L}$ EDTA-Lösung [0,5 mol/L] und kurze Inkubation abgestoppt. Waren die Fragmente noch zu groß, so wurde für $5-10$ min bei $15^{\circ} \mathrm{C}$ nachinkubiert und erneut die Fragmentlänge bestimmt.

\subsubsection{Hybridisierung}

Erhitzt man DNA, so trennen sich die DNA-Doppelstränge in Einzelstränge auf (Meselson und Stahl 1958), man spricht vom Denaturieren oder Schmelzen der DNA. Beim Abkühlen kehrt sich dieser Prozess um und die zusammengehörigen komplementären DNA-Einzelstränge finden wieder zu Doppelsträngen zusammen. Doch nicht nur vollständig komplementäre DNA-Sequenzen finden zusammen, dies ist auch bei kleineren Abweichungen von der Sequenz möglich: Mehr oder weniger komplementäre Einzelstränge von Nukleinsäuren können sich zu sogenannten Hybriden zusammenlagern (Doty et al. 1960; Marmur und Lane 1960). Dieser Prozess wird daher Hybridisierung genannt. Bei der CGH 
werden solche Hybride zwischen den markierten DNA-Sonden und den entsprechenden Abschnitten auf den Metaphasechromosomen ausgebildet. Da die Hybridisierung in der Struktur der Chromosomen stattfindet, spricht man von In-situ-Hybridisierung (Pardue und Gall 1969).

Die Stabilität der Hybride ist hauptsächlich vom Ausmaß ihrer Sequenzabweichung abhängig. Es gibt aber äußere Faktoren, die generell die Stabilität doppelsträngiger DNA beeinflussen. Indem man diese Faktoren in einer Hybridisierungsmixtur verändert, kann das Hybridisierungsexperiment gesteuert werden - insbesondere der Anteil schlechter Paarungen. Zu diesen Faktoren gehören: der Gehalt an Salzen (Schildkraut 1965) und der pH-Wert der Mixtur (Wetmur und Davidson 1968) sowie der Anteil von Formamid (Bonner et al. 1967; McConaughy et al. 1969) und Dextransulfat (Wetmur 1975).

Menschliches Genom enthält etliche Regionen mit repetitiven Sequenzen, die einander sehr ähnlich sind (Schmid und Jelinek 1982; Singer 1982). Sonden aus genomischer DNA würden wahllos an diese repetitiven Sequenzen binden, die Fluoreszenz der spezifischen Hybride überstrahlen und damit die Qualität des gesamten CGH-Experiments herabsetzen. Um dies zu umgehen, wird ein Überschuss an humaner Cot-1-DNA hinzugegeben, die viele repetitive Sequenzen enthält. In einem Vorhybridisierung (preannealing) genannten Schritt sättigt die Cot-1-DNA die repetitiven Sequenzen in den Tumor- und Referenz-DNA-Sonden ab, so dass diese nicht mehr am eigentlichen Hybridisierungsschritt teilhaben (Landegent et al. 1987; Lichter et al. 1988; Pinkel et al. 1988).

\section{Puffer und Lösungen}

\begin{tabular}{lr} 
Pepsinlösung & $100 \mathrm{~mL}$ \\
\hline Pepsinstammlösung & $20 \mu \mathrm{LL}$ \\
{$[0,1 \mathrm{~g} / \mathrm{mL}]$} & \\
Salzsäure $[1 \mathrm{~mol} / \mathrm{L}]$ & $1 \mathrm{~mL}$ \\
\hline
\end{tabular}

\begin{tabular}{lcc} 
20x SSC (Saline Sodium Citrate)-Puffer & $1000 \mathrm{~mL}$ \\
\hline tri-Natriumcitrat- & $0,3 \mathrm{~mol} / \mathrm{L}$ & $88,23 \mathrm{~g}$ \\
$\begin{array}{l}\text { Dihydrat } \\
\text { Natriumchlorid }\end{array}$ & $3 \mathrm{~mol} / \mathrm{L}$ & $175,5 \mathrm{~g}$ \\
\hline
\end{tabular}

Die Lösung wurde mit Salzsäure auf $\mathrm{pH}=7,0$ eingestellt. Für geringer konzentrierte SSC-Lösungen wurde mit Aqua bidest. entsprechend verdünnt. 


\begin{tabular}{llr} 
Phosphatpuffer [0,5 mol/L] & $1000 \mathrm{~mL}$ \\
\hline $\mathrm{Na}_{2} \mathrm{HPO}_{4}$ & $305 \mathrm{mmol} / \mathrm{L}$ & $42,09 \mathrm{~g}$ \\
$\mathrm{NaH}_{2} \mathrm{PO}_{4}$ & $195 \mathrm{mmol} / \mathrm{L}$ & $26,91 \mathrm{~g}$ \\
\hline
\end{tabular}

Durch Zugabe von $\mathrm{Na}_{2} \mathrm{HPO}_{4}$-Lösung wurde auf $\mathrm{pH}=7,0$ eingestellt.

\begin{tabular}{llr} 
Denaturierungslösung & & $100 \mathrm{~mL}$ \\
\hline Formamid & $70 \%(\mathrm{~V} / \mathrm{v})$ & $70 \mathrm{~mL}$ \\
20x SSC & $10 \%(\mathrm{~V} / \mathrm{v}) \hat{=} 2 \mathrm{xSSC}$ & $10 \mathrm{~mL}$ \\
Phosphatpuffer [0,5 mol/L] & $50 \mathrm{mmol} / \mathrm{L}$ & $10 \mathrm{~mL}$ \\
\hline
\end{tabular}

Der pH-Wert wurde auf 7,0 eingestellt.

\begin{tabular}{llr} 
Hybridisierungspuffer & & $10 \mathrm{~mL}$ \\
\hline Dextransulfat & $30 \%(\mathrm{~m} / \mathrm{v})$ & $3 \mathrm{~g}$ \\
20x SSC & $20 \%(\mathrm{~V} / \mathrm{v}) \widehat{=} 4 \mathrm{xSC}$ & $2 \mathrm{~mL}$ \\
\hline
\end{tabular}

\section{Durchführung}

Die Hybridisierung umfasst mehrere getrennte Arbeitsschritte, die in den folgenden Abschnitten detailliert beschrieben sind.

\section{Vorbereitung der Sonden}

In diesem Schritt werden alle Komponenten, die an der Hybridisierung teilhaben, zusammengeführt: Tumor-DNA, Referenz-DNA sowie Cot-1-DNA. Dazu wurden jeweils $67 \mu \mathrm{L}$ Tumor- und Referenz-DNA-Lösung zusammengegeben, hinzu kamen $80 \mu \mathrm{L}$ humane Cot-1-DNA-Lösung [1 mg/mL], $12 \mu \mathrm{L}$ Natriumacetatlösung [3 mol/L] und $580 \mu \mathrm{L}$ Ethanol $100 \%$. Nach dem Mischen wurde die DNA bei $-80^{\circ} \mathrm{C}$ gefällt, dann zentrifugiert und der Überstand verworfen.

Anschließend wurde die im Reagiergefäß zurückgebliebene DNA nochmals gereinigt: Es wurden $800 \mu \mathrm{L}$ Ethanol $70 \%$ hinzugegeben, die im Thermomixer für 45 min bei $45^{\circ} \mathrm{C}$ einwirkten. Danach wurde erneut zentrifugiert und der Überstand verworfen. Das zurückbleibende DNA-Pellet wurde getrocknet. 


\section{Vorbereitung der Metaphasenpräparate}

Um die Hybridisierung störende Proteinrückstände zu entfernen, wurden die Metaphasenpräparate zunächst für $5 \mathrm{~min}$ in die bei $37^{\circ} \mathrm{C}$ temperierte Pepsinlösung getaucht. Abstoppen und Dehydrieren schloss sich dem an, jeweils durch Eintauchen für 5 min in 2x SSC-Lösung und eine aufsteigende Alkoholreihe mit $70 \%$-, $85 \%$ - und $100 \%$-Ethanol bei $-20{ }^{\circ} \mathrm{C}$. Danach wurden die Präparate getrocknet.

Durch 2-minütige Behandlung in der auf $69^{\circ} \mathrm{C}$ erwärmten Denaturierungslösung wurde die doppelsträngige DNA in den Metaphasenpräparaten aufgetrennt. Es schloss sich eine erneute Dehydrierung durch die aufsteigende Alkoholreihe und eine Trocknung an.

\section{Denaturierung und Vorhybridisierung der Sonden}

Zunächst wurde das gereinigte DNA-Pellet, das bereits alle Komponenten für die Hybridisierung enthielt, resuspendiert. Dies geschah in $6 \mu \mathrm{L}$ deionisiertem Formamid, das bei $37^{\circ} \mathrm{C}$ eine Stunde im Thermomixer wirken konnte. Danach wurden $7 \mu \mathrm{L}$ des Hybridisierungspuffers hinzugefügt, die die Hybridisierungsmixtur vervollständigten.

Durch Erhitzen auf $78^{\circ} \mathrm{C}$ wurde die DNA denaturiert, die Doppelstränge wurden aufgetrennt. Es schloss sich die Vorhybridisierung für $30 \mathrm{~min}$ bei $37^{\circ} \mathrm{C}$ an.

\section{Hybridisierung}

Zur eigentlichen Hybridisierung wurden $13 \mu \mathrm{L}$ der denaturierten und vorhybridisierten Sondenlösung auf das vorbereitete Metaphasenpräparat gegeben. Das Hybridisierungsfeld des Objektträgers wurde mit einem Deckglas und Fixogum verschlossen, in einer feuchten Kammer wurde für 3 Tage bei $37^{\circ} \mathrm{C}$ inkubiert.

\subsubsection{Detektion}

Bei der indirekten Markierungstechnik werden die DNA-Sonden mit speziellen Markermolekülen versehen (siehe Kapitel 2.4.1, S. 27), die anschließend detektiert werden müssen. Dazu werden Proteine verwendet, die spezifische Bindungen mit den Markermolekülen eingehen und ihrerseits mit einem Fluoreszenzfarbstoff gekoppelt sind: Avidin, welches mit dem grün fluoreszierenden Farbstoff Fluorescein gekoppelt ist, bindet an das Markermolekül Biotin, mit dem die Tumor-DNA versehen worden war. Ein Antikörper gegen Digoxigenin, welcher mit dem rot fluoreszierenden Farbstoff Rhodamin gekoppelt ist, bindet an das Digoxigenin, mit dem die Referenz-DNA markiert worden war.

Da auch die zur Detektion eingesetzten Proteine unspezifische Bindungen eingehen können, wird zuvor Rinderserumalbumin auf die Metaphasenpräparate gegeben, welches die dort gelegenen unspezifischen Bindungsstellen blockiert. 
Puffer und Lösungen

Waschlösung A

$1000 \mathrm{~mL}$

\begin{tabular}{lll}
\hline Formamid & $50 \%(\mathrm{~V} / \mathrm{v})$ & $500 \mathrm{~mL}$ \\
$20 \mathrm{xSC}$ & $10 \%(\mathrm{~V} / \mathrm{v}) \hat{=} 2 \mathrm{xSSC}$ & $100 \mathrm{~mL}$ \\
\hline
\end{tabular}

Die Lösung wurde mit Salzsäure auf $\mathrm{pH}=7,0$ eingestellt.

Waschlösung B

Es handelt sich um eine 2x SSC-Lösung.

Die Lösung wurde mit Salzsäure auf $\mathrm{pH}=7,0$ eingestellt.

\begin{tabular}{llr} 
Waschlösung C & $1000 \mathrm{~mL}$ \\
\hline Polysorbat 20 & $0,1 \%(\mathrm{~V} / \mathrm{v})$ & $1 \mathrm{~mL}$ \\
$20 \mathrm{x}$ SSC & $20 \%(\mathrm{~V} / \mathrm{v}) \widehat{=} 4 \mathrm{xSSC}$ & $200 \mathrm{~mL}$ \\
\hline
\end{tabular}

Die Lösung wurde mit Salzsäure auf $\mathrm{pH}=7,0$ eingestellt.

Blockierungslösung $100 \mathrm{~mL}$

\begin{tabular}{llr}
\hline Polysorbat 20 & $0,1 \% \mathrm{~V} / \mathrm{V}$ & $0,1 \mathrm{~mL}$ \\
20x SSC & $20 \%(\mathrm{~V} / \mathrm{v}) \widehat{=} 4 \mathrm{xSSC}$ & $20 \mathrm{~mL}$ \\
Albumin Fraktion V & $3 \%(\mathrm{~m} / \mathrm{v})$ & $3 \mathrm{~g}$ \\
\hline
\end{tabular}




\begin{tabular}{llr} 
Detektionslösung & & $10 \mathrm{~mL}$ \\
\hline Polysorbat 20 & $0,1 \% \mathrm{v} / \mathrm{v}$ & $10 \mu \mathrm{L}$ \\
20x SSC & $20 \% \mathrm{~V} / \mathrm{v}=4 \mathrm{x} \mathrm{SSC}$ & $2 \mathrm{~mL}$ \\
Albumin Fraktion V & $1 \% \mathrm{~m} / \mathrm{v}$ & $0,1 \mathrm{~g}$ \\
Anti-Digoxigenin- & & $150 \mu \mathrm{L}$ \\
Rhodamin $[200 \mu \mathrm{m} / \mathrm{mL}]$ & & \\
Fluorescein Avidin $[5 \mathrm{\mu g} / \mathrm{mL}]$ & $50 \mu \mathrm{L}$ \\
\hline
\end{tabular}

Die Lösung wurde lichtgeschützt hergestellt und der pH-Wert mit Salzsäure auf 7,0 eingestellt.

\begin{tabular}{lc} 
DAPI-Lösung & $1 \mathrm{~mL}$ \\
\hline Actinomycin-Lösung & $50 \mu \mathrm{L}$ \\
DAPI-Stammlösung & $1 \mu \mathrm{L}$
\end{tabular}
$[0,2 \mathrm{~g} / \mathrm{L}]$

ad $1 \mathrm{~mL}$ Vectashield Mounting Medium

Bei dem Vectashield Mounting Medium handelt es sich um eine Glycerollösung $(99,2 \%(\mathrm{~m} / \mathrm{v}))$.

\section{Waschen}

Zunächst wurden Rückstände der Hybridisierungsmixtur und unspezifisch gebundene Sonden vom Metaphasenpräparat gewaschen. Dies geschah durch jeweils 3 Waschschritte in Waschlösung A und danach in Waschlösung B für 5 min bei $42{ }^{\circ} \mathrm{C}$.

\section{Blockieren}

Die Metaphasenpräparate wurden zum Blockieren mit $300 \mu \mathrm{L}$ der Blockierungslösung versehen und für $30 \mathrm{~min}$ bei $37^{\circ} \mathrm{C}$ inkubiert. Die Blockierungslösung wurde danach mit Waschlösung C entfernt.

\section{Detektieren}

Zum Detektieren wurden $300 \mu \mathrm{L}$ der Detektionslösung auf die Metaphasenpräparate gegeben, eine Inkubation für $60 \mathrm{~min}$ bei $37^{\circ} \mathrm{C}$ folgte. Die Detektionslösung wurde danach in drei 5-minütigen Waschschritten bei $42^{\circ} \mathrm{C}$ mit Waschlösung $\mathrm{C}$ entfernt. 


\section{Gegenfärbung}

Die Gegenfärbung erfolgte mit $25 \mu \mathrm{L}$ der DAPI-Lösung. Die Objektträger mit den fertigen CGH-Präparaten wurden bei $4{ }^{\circ} \mathrm{C}$ lichtgeschützt gelagert.

\subsubsection{Bilderfassung und quantitative Auswertung}

Im Fluoreszenzmikroskop sind Verschiebungen des Verhältnisses von grün erscheinender Tumor-DNA zu rot erscheinender Referenz-DNA oftmals schon mit bloßem Auge sichtbar. Um eine hohe Genauigkeit zu erreichen, sind Techniken entwickelt worden, die eine digitale Bilderfassung mit einer rechnergestützten Auswertung der Bilder kombinieren (du Manoir et al. 1995b; Lundsteen et al. 1995; Piper et al. 1995). Zunächst müssen per Fluoreszenzmikroskopie und digitaler Fotografie drei hochauflösende Bilder gewonnen werden: Ein Gegenfärbungsbild, das die Banden sichtbar macht und die Identifikation der Chromosomen ermöglicht, ein Referenzbild, das die Fluoreszenzintensität der ReferenzDNA erfasst, und ein Testbild, das die Fluoreszenzintensität der zu untersuchenden DNA wiedergibt. Dies geschieht getrennt für die drei Spektralbereiche der verwendeten Fluoreszenzfarbstoffe.

Die Helligkeitswerte der Pixel enthalten dann die Information über die jeweiligen Fluoreszenzintensitäten, jedoch ist deren Variabilität hoch. Es schließen sich daher zwei Mittelwertbildungen an: Die Chromosomen werden als eindimensionale Objekte betrachtet und der erste Mittelwert wird über die Breite des Chromosoms berechnet; es entsteht ein Profil der Fluoreszenzintensität in der Chromosomenlängsachse. Danach wird das Verhältnis der Fluoreszenzintensitätsprofile von Test-DNA zu Referenz-DNA berechnet und ein Profil des Fluoreszenzintensitätsverhältnisses erzeugt. Die zweite Mittelwertbildung geschieht zum Unterdrücken des Rauschens, indem Profile der Fluoreszenzintensitätsverhältnisse mehrerer homologer Chromosomen eines Falles zusammengefasst werden (Piper et al. 1995).

Überschreitet das Fluoreszenzintensitätsverhältnis von Test-DNA zu Referenz-DNA einen oberen Schwellenwert, z.B. den von 1,2, so geht man von einem chromosomalen Zugewinn aus. Unterschreitet das Verhältnis einen unteren Schwellenwert, z.B. den von 0,8, nimmt man einen chromosomalen Verlust an. Um als Amplifikation zu gelten, muss ein Zugewinn einen Verhältniswert von mehr als 1,5 aufweisen. Abbildung 2.1 stellt den Ablauf der Auswertung schematisch dar.

\section{Durchführung}

Zunächst wurden geeignete Metaphasen ausgewählt. Alle Chromosomen sollten eine kräftige und gleichmäßige Anfärbung besitzen und möglichst vollständig und ohne Überlagerungen vorliegen. Zudem sollte die Hintergrundfluoreszenz niedrig sein, Metaphasen mit hellen Artefakten oder Kernen wurden gemieden. Anschließend erfolgte die Darstellung im Fluoreszenzmikroskop, dabei kam ein 63 -fach vergrößerndes Ölimmersionsobjektiv zum Einsatz. Die Anregung erfolgte mit einer Quecksilberdampflampe, durch Wechsel 


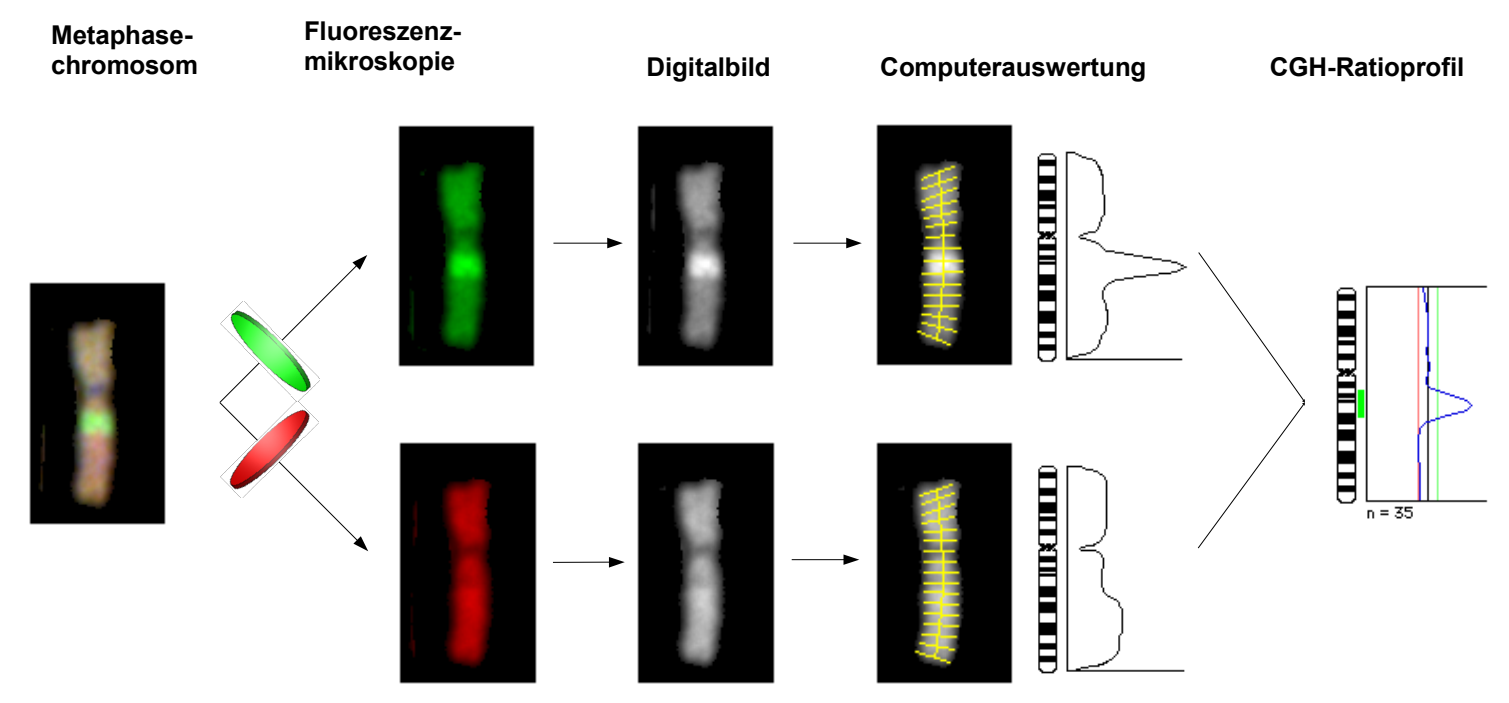

Abbildung 2.1: Schema der quantitativen CGH-Auswertung vom Metaphasechromosom bis zum Ratioprofil.

der Anregungsfilter geschah dies getrennt für die drei verwendeten Fluoreszenzfarbstoffe: Für die durch Fluorescein Avidin detektierte Tumor-DNA ergab sich das Testbild in grüner Farbe (FITC-Filter), für die durch Anti-Digoxigenin-Rhodamin detektierte Referenz-DNA ergab sich das Referenzbild in roter Farbe (TRITC/TxRed-Filter); das DAPI-Gegenfärbungsbild erschien blau (DAPI-Filter). Jede dieser drei Fluoreszenzdarstellungen wurde mit einer monochromen Digitalkamera aufgenommen, diese wurde von der SmartCapture-Bilderfassungssoftware gesteuert. Die Fluoreszenzintensitäten sind in den Grauwerten kodiert. Auf diese Art und Weise wurden pro Fall 20 Metaphasen erfasst.

Die Auswertung der Bilder erfolgte mit der QUIPS Karyotyping/CGH-Software. Die Karyotypisierung anhand des DAPI-Gegenfärbungsbildes geschieht durch diese Software prinzipiell automatisch, allerdings mit hoher Fehlerquote, so dass manuell umfassend korrigiert werden musste. Verunreinigte, abgeknickte oder übereinanderliegende Chromosomen wurden ausgeschlossen. Die Fluoreszenzintensität wurde von der Software bestimmt, ebenso erfolgte die Mittelwertbildung über alle erfassten Metaphasen eines Falles. Man erhielt letztendlich ein Ratioprofil der Fluoreszenzintensitätsverhältnisse, das zusammen mit einem schematisierten Chromosom dargestellt wird. Die Schwellen wurden individuell für jeden Einzelfall auf Werte von 1,15-1,2 für Zugewinne und 0,8-0,85 für Verluste eingestellt. Für Amplifikationen lag die Schwelle generell bei 1,5. Zugewinne wurden von der Software in Form eines grünen Balkens dargestellt, Verluste in Form eines roten Balkens. 


\subsubsection{Berichtigung der Ergebnisse}

Durch die zuvor beschriebene Auswertung erhält man ein unberichtigtes Ergebnis. Nicht alle der Schwellenwertüberschreitungen dürfen als Zugewinn oder Verlust gewertet werden, denn es kann zu falsch positiven Befunden kommen. Es ist bekannt, dass bestimmte chromosomale Regionen hierfür anfällig sind: Zentromere und Telomere, die p-Arme akrozentrischer Chromosomen, gewisse heterochromatinreiche Regionen sowie die Chromosomenabschnitte 1p32pter, 16p, 19 und 22; solch problematische Regionen sind mit Vorsicht zu interpretieren oder aus der Bewertung auszuschließen (Kallioniemi OP et al. 1994). Durch diese kritische Bewertung der Ergebnisse entsteht aus dem unberichtigten Ergebnis das endgültige berichtigte Ergebnis.

\section{Durchführung}

Sämtliche Ratioprofile wurden von einer Gruppe erfahrener Spezialisten für CGH bewertet und berichtigt. In Zweifelsfällen wurden die fotografischen Aufnahmen der Metaphasen eines Falles zur Entscheidungsfindung hinzugenommen.

Da dieser manuell ausgeführte qualitative Auswertungsschritt sich als sehr bedeutsam für die Ergebnisse der vorliegenden Studie erwiesen hat, ist ihm Kapitel 4.1 des Diskussionsteils (S. 77) gewidmet.

\subsubsection{Codierung der Ergebnisse}

\section{Nomenklatur}

CGH-Ergebnisse werden für gewöhnlich mit einer standardisierten Nomenklatur codiert. Als Grundlage dient das International System for Human Cytogenetic Nomenclature (ISCN), eine Nomenklatur zur Beschreibung zytogenetischer und molekularzytogenetischer Befunde (Shaffer et al. 2009).

Die mit CGH detektierten Veränderungen von Chromosomen werden in der speziellen reverse-in-situ-hybridization-Schreibweise notiert, abgekürzt als rev ish. Dabei steht der Terminus rev ish am Anfang der Formel, gefolgt von dim (diminished) für Verluste, enh (enhanced) für Zugewinne und amp (amplified) für Amplifikationen. Diesen Bezeichnern folgt die Angabe der jeweils betroffenen Chromosomenregion. Der Buchstabe p (für französisch petit) steht dabei für den kürzeren, im Karyogramm immer oben gelegenen Chromosomenarm, der Buchstabe q steht für den längeren Chromosomenarm, der im Karyogramm immer unten gelegen ist.

Die Angabe rev ish dim 3 stünde für einen Verlust des Chromosoms 3, rev ish enh $3 q$ stünde für den Zugewinn des q-Armes von Chromosom 3 und rev ish amp 3q24q26 stünde für eine Amplifikation des Chromosomenabschnitts, der von der Bande q24 bis hin zur Bande q26 auf Chromosom 3 reichte. Ginge die Veränderung bis zum Telomer, könnte statt der letzten Bande je nach Arm auch - qter oder -pter notiert werden. In Abbildung 2.2 ist die ISCN-Nomenklatur an einem Beispiel dargestellt. 

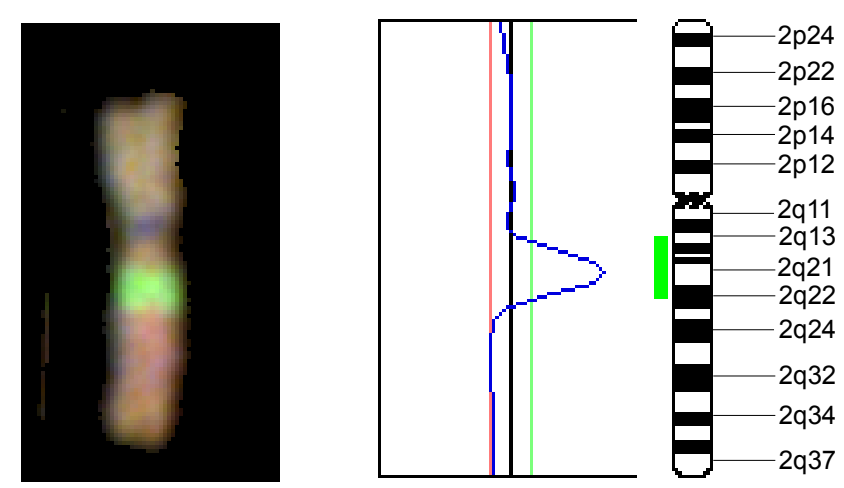

Abbildung 2.2: Metaphasechromosom und Ratioprofil mit deutlich sichtbarem Zugewinn. Entsprechend der ISCN-Nomenklatur ist dieser Zugewinn als rev ish enh 2q13q22 zu notieren.

\section{Durchführung}

Die endgültigen CGH-Ergebnisse wurden direkt aus den Ratioprofilen abgelesen, dabei wurden die vom Auswerteprogramm vorgeschlagenen Markierungen für Zugewinne und Verluste als Orientierung genutzt. Dies geschah im Rahmen des zuvor beschriebenen Berichtigungsschrittes, so dass die endgültigen berichtigten Ergebnisse notiert wurden. Für die Codierung der Ergebnisse kam die rev-ish-Schreibweise zum Einsatz.

\subsubsection{Darstellung der Ergebnisse}

Die folgenden Angaben zur Darstellung der Ergebnisse gelten sowohl für die CGH-Befunde der Hirnmetastasen als auch für die im Rahmen der Metaanalyse extrahierten CGHBefunde in rev-ish-Schreibweise (siehe Kapitel 2.5.2, S. 40).

\section{Erzeugung von Summenidiogrammen}

CGH-Ergebnisse mehrerer Untersuchungen können in Form von Histogrammen zusammengefasst werden, welche die relativen Häufigkeitsverteilungen von Zugewinnen und Verlusten abbilden (Petersen I et al. 1997a). Dies geschieht mit Bezug auf die schematisierte bandengenaue Darstellung der einzelnen Chromosomen innerhalb eines sogenannten Idiogrammes. Die Kombination aus Histogramm und Idiogramm wird als Summenidiogramm bezeichnet.

Zur Erzeugung der Summenidiogramme wurde die Analysefunktion auf der Website der molekularzytogenetischen Datenbank Progenetix verwendet (Baudis 2000; Baudis und Cleary 2001). Dort ist ein Parser verfügbar, der einen Datensatz in rev-ish-Schreibweise in eine Datenmatrix überführt, die weiter ausgewertet werden kann. Unter anderem ist 
die grafische Darstellung als Summenidiogramm möglich. Für Informationen zum Zugang siehe Baudis (2009a) sowie zur Dokumentation Baudis (2006, 2009b).

\section{Qualitative Beschreibung: „Häufige“ Veränderungen}

Die statistische Verteilung der chromosomalen Veränderungen ist nicht bekannt und so ist eine rationale Festlegung eines Schwellenwertes, ab dem eine Veränderung als bedeutsam einzuschätzen wäre, nicht möglich. In der vorliegenden Studie wird daher eine willkürliche Schwelle definiert: Zugewinne und Verluste heißen „häufig“, wenn ihr Anteilswert, d.h. die relative Häufigkeit im Histogramm, bei mindestens $20 \%$ liegt. Bei „häufigen“ Amplifikationen sind mindestens $10 \%$ erforderlich.

\section{Anzahl der Veränderungen pro Fall}

Das Auszählen der Veränderungen pro Fall ist nicht standardisiert. Es existieren mehrere unterschiedliche Ansätze, die auch die Gefahr in sich bergen, weit auseinanderliegende Werte zu erbringen. Damit eine Vergleichbarkeit gegeben ist, folgt diese Studie dem Vorschlag von Hummel et al. (2006a,b):

Zusammenhängende Zugewinne, Verluste und Amplifikationen zählen jeweils als Einzelveränderung. Veränderungen, die einen gesamten Chromosomenarm betreffen, zählen ebenfalls als Einzelveränderung und werden hinzuaddiert. Alle Einzelveränderungen werden schließlich aufsummiert. Somit ergäbe sich für einen Fall mit einem Verlust von 9p (eine Veränderung), einem Verlust von Chromosom 18 (zwei Veränderungen) und einem Zugewinn von 1q12q21 (eine Veränderung) ein Wert von 4.

\subsection{Metaanalyse}

\subsubsection{Literaturrecherche}

Für die Literaturrecherche wurde ein systematischer Ansatz gewählt, um einerseits eine möglichst vollständige Übersicht über den Forschungsstand der CGH-Untersuchung beim Lungenkrebs sowie dessen Hirnmetastasen zu gewinnen. Andererseits wird so eine Verzerrung durch die unterbewusste Bevorzugung einer Arbeitsgruppe umgangen.

Es wurde eine Online-Recherche in MEDLINE, Progenetix, der Mitelman-Datenbank und der SKY/M-FISH \& CGH-Datenbank durchgeführt. In den molekularzytogenetischen Datenbanken (Progenetix, Mitelman und SKY/M-FISH \& CGH) sind CGH-Daten mit Bezug auf die entsprechenden Publikationen direkt erhältlich. Die durch MEDLINE gefundenen Literaturangaben wurden überprüft, die dem Thema entsprechenden Publikationen durchgesehen und brauchbare CGH-Ergebnisse manuell extrahiert. Zusätzlich wurde bei jeder Publikation das Literaturverzeichnis überprüft, um bei der Suche möglicherweise entgangene Publikationen zu entdecken. 


\section{Medline}

MEDLINE (Medical Literature Analysis and Retrieval System Online) ist eine bibliografische Datenbank der United States National Library of Medicine (NLM). Eine Besonderheit sind die Medical Subject Headings (MeSH), die einen Thesaurus darstellen, mit dessen Hilfe alle Artikel indiziert sind. Eine Suche in der Datenbank ist über das Internet-Portal PubMed möglich (MEDLINE 2009).

\section{Progenetix}

Progenetix ist eine molekularzytogenetische Online-Datenbank für Krebserkrankungen (Progenetix - Genomic copy number abnormalities in cancer), die auf CGH-Daten spezialisiert ist (Baudis 2000; Baudis und Cleary 2001).

\section{Mitelman-Datenbank}

Die Mitelman-Datenbank für chromosomale Aberrationen bei Krebserkrankungen ist ebenfalls eine zytogenetische Datenbank (Mitelman et al. 2009). Allerdings sind dort mehr klassische zytogenetische Befunde und weniger molekularzytogenetische zu finden.

\section{SKY/M-FISH \& CGH-Datenbank}

Die SKY/M-FISH \& CGH-Datenbank ist ebenfalls eine molekularzytogenetische Datenbank (SKY/M-FISH \& CGH 2001). Sie ist ein gemeinsames Projekt des National Center for Biotechnology Information (NCBI), das zur United States National Library of Medicine (NLM) gehört, und dem National Cancer Institute (NCI), welches dem Gesundheitsministerium der Vereinigten Staaten (United States Department of Health and Human Services) untersteht.

\section{Durchführung}

Zur Suche in PubMed wurde das Medical Subject Heading (MeSH) "Lung Neoplasms“ mit den Suchbegriffen „cgh", „comparative genomic hybridization" und „comparative genomic hybridisation" kombiniert. Die Publikationssuche in Progenetix wurde mit den Suchbegriffen „lung“, „small cell" und „large cell" in der technischen Kategorie „CGH (chromosomal)" durchgeführt. In der Mitelman-Datenbank wurde in der topografischen Kategorie "Lung" gesucht. Die SKY/M-FISH \& CGH-Datenbank wurde in der Kategorie "CGH" mit den Begriffen "lung", „small cell" und "large cell" durchsucht.

\section{Einschlusskriterien}

Alle durch die Suche aufgefundenen Publikationen wurden nach inhaltlichen und methodischen Kriterien überprüft: Die Studien sollten Lungenkrebs zum Gegenstand haben und 
CGH-Untersuchungen von Operations- oder Autopsiepräparaten beinhalten, keine Untersuchungen von Zelllinien. Die Histologie der Lungentumoren sollte gesichert sein und den Kategorien „kleinzellig“, „Plattenepithelkarzinom“, „Adenokarzinom“, „adenosquamös“ oder „großzellig“ zuzuordnen sein. Sonderformen wurden nicht erfasst. Als Methode sollte die klassische CGH an Metaphasechromosomen verwendet worden sein.

\subsubsection{Extraktion der Daten}

Die Publikationen enthielten die Ergebnisse der durchgeführten CGH-Studien in zwei verschiedenen Formen: Einerseits präsentierten die Autoren die Ergebnisse als qualitative Angabe, und zwar in Form einer Experteneinschätzung. Andererseits lagen auch detaillierte Befunde in Form der auf den Einzelfall bezogenen CGH-Ergebnisse in rev-ish-Schreibweise vor.

Da der übliche Ansatz der Metaanalyse mit Erfassung von Effektstärken hier nicht anwendbar war, wurde ein zweigeteilter gewählt: Sowohl die Expertenmeinung in Form qualitativer Angaben wurde extrahiert als auch die verfügbaren CGH-Befunde in rev-ishSchreibweise.

\section{Qualitative Angaben}

In sehr vielen CGH-Publikationen werden die Ergebnisse in der qualitativen Form einer Experteneinschätzung vorgestellt. Zugewinne und Verluste werden präsentiert als „most common changes" (Björkqvist et al. 1998a, S. 79), „regions frequently affected“ (Petersen I et al. 1997a, S. 2333) oder es ist von den „häufigsten Defekten“ die Rede (Johnen et al. 2003, S. 306). Allen Publikationen gemein ist die Einschätzung nach Häufigkeiten, exakte Kriterien existieren zumeist nicht. Diese qualitative Größe soll daher rekursiv definiert erwähnenswerte Veränderungen genannt werden.

Im Sinne eines vote-counting wurden die erwähnenswerten Veränderungen aus den Publikationen zusammengetragen. Nur solche Zugewinne und Verluste, die in mindestens einem Drittel der Publikationen als erwähnenswert beschrieben worden waren, wurden in die weitere Auswertung übernommen. Amplifikationen wurden aufgenommen, wenn in mehr als einer Studie die Veränderung mehr als nur ein einziges Mal aufgefallen war.

\section{Exakte Befunde in rev-ish-Schreibweise}

Exakte Befunde in rev-ish-Schreibweise wurden soweit möglich direkt aus den Datenbanken entnommen. Ansonsten wurde auf die Publikationen zurückgegriffen und die Befunde wurden manuell übertragen. In jedem Fall schloss sich eine grobe Überprüfung auf Fehler an - offensichtliche Schreibfehler und Zahlendreher wurden korrigiert. In einem Fall (Petersen I et al. 1997b) war es nötig, die bandengenauen Befunde aus einer grafischen Darstellung zu entnehmen und manuell in rev-ish-Schreibweise zu übertragen. 


\subsubsection{Darstellung der Ergebnisse}

Die Darstellung der Ergebnisse, die sich bei der Auswertung der exakten CGH-Befunde in rev-ish-Schreibweise ergeben hatten, geschah analog der Auswertung der HirnmetastasenCGHs. Es sei daher auf Kapitel 2.4.7 (S. 37) verwiesen.

\subsection{Vergleich von Primärtumoren und Hirnmetastasen}

\subsubsection{Qualitativer Vergleich}

Da in der Metaanalyse zwei verschiedene Wege der Datenextraktion verfolgt worden waren, gab es für die Primärtumoren zwei unterschiedliche Quellen qualitativer Beschreibungen: einerseits die „erwähnenswerten“ Veränderungen der Experten, andererseits die definitionsgemäß „häufigen“ (d.h. über $20 \%$ Anteilswert liegenden) Veränderungen, die bei der Auswertung der extrahierten CGH-Befunde in rev-ish-Schreibweise aufgefallen waren. Da es sich um inhaltlich vergleichbare Größen handelt - die „häufigen“ Veränderungen stellen die „erwähnenswerten“ dieser Studie dar (vergl. Kapitel 2.5.2) -, wurden beide Gruppen zunächst gemeinsam betrachtet. Traten große Diskrepanzen auf, so wurde korrigiert. Das in den Vergleich einfließende Muster der Veränderungen ergab sich aus dieser Zusammenschau.

Der Vergleich selbst bestand dann aus einer direkten Gegenüberstellung der so gewonnenen Veränderungen aus dem Primärtumorkollektiv mit den häufigen Veränderungen aus dem Hirnmetastasenkollektiv.

\subsubsection{Quantitativ-statistischer Vergleich}

Mit quantitativ statistischen Methoden wurde drei Fragen nachgegangen: (i) Unterscheiden sich die Anteilswerte der Zugewinne und Verluste im Primärtumorkollektiv von denen im Hirnmetastasenkollektiv? (ii) Unterscheidet sich die Anzahl der Veränderungen pro Fall im Primärtumorkollektiv von der im Hirnmetastasenkollektiv? (iii) Ist eine Klassifikation der Primärtumoren und Hirnmetastasen aufgrund der gefundenen Merkmale möglich?

\section{Vergleich der Anteilswerte der chromosomalen Veränderungen}

Um zu prüfen, ob sich die Anteilswerte von Zugewinnen und Verlusten in Primärtumoren und Hirnmetastasen voneinander unterscheiden, kam der $\chi^{2}$-Unabhängigkeitstest zum Einsatz. Dieser wurde für jede einzelne Bande durchgeführt.

Da die Frage jeweils für Zugewinne, Verluste und ebenso auch für die unveränderten Banden geprüft werden musste, bestand die Gefahr einer $\alpha$-Fehler-Kumulierung durch multiples Testen in derselben Grundgesamtheit. Um dieser entgegenzuwirken, wurden die p-Werte bezüglich der false discovery rate (FDR) adjustiert. Dazu kam das Verfahren von Yoav Benjamini und Yosef Hochberg zum Einsatz (Benjamini und Hochberg 1995). Als Signifikanzniveau wurde $\alpha=0,05$ gewählt. 
Die Darstellung der Ergebnisse erfolgte durch eine Überlagerung der Histogramme von Primärtumoren und Hirnmetastasen; signifikante Unterschiede wurden markiert. Zu dieser Differenzhistogramm genannten Darstellung siehe Petersen I et al. (1997a) und Bockmühl et al. (1997).

\section{Vergleich der Anzahl der Veränderungen pro Fall}

Um die Frage zu klären, ob es bei der Anzahl der Veränderungen Unterschiede gibt, wurden die Verteilungen der Werte in Primärtumor- und Hirnmetastasenkollektiv miteinander verglichen. Da bereits die Inspektion der Daten im Histogramm ergeben hatte, dass von keiner gewöhnlichen Verteilung ausgegangen werden darf, wurde ein parameterfreier Test verwendet: der Mann-Whitney-U-Test. Als Signifikanzniveau wurde $\alpha=0,05$ gewählt.

\subsubsection{Automatische Klassifikation}

Die beim Vergleich der Anteilswerte aufgefundenen Veränderungen wurden als Merkmale für eine automatische Klassifikation genutzt. Es kam dabei die auf der Website der Datenbank Progenetix angebotene Funktion zur Clusteranalyse zum Einsatz (Baudis 2000; Baudis und Cleary 2001). Für Zugang und Dokumentation siehe Baudis (2009a,b). Obwohl die verwendete Funktion nicht gut dokumentiert ist, darf dahinter wohl ein geeigneter distanzbasierter Algorithmus vermutet werden. Für Details zum Verfahren siehe Liu J et al. (2006).

\subsection{Qualitätssicherung: Negativkontrolle und Standardreferenzintervalle}

Negativkontrollen sind Experimente, in denen das zu messende Objekt durch ein neutrales ersetzt wird. Im Falle der CGH bedeutet dies, dass statt Tumor- und Referenz-DNA ein Gemisch zweier Referenz-DNAs eingesetzt wird. Dadurch sind Messabweichungen, die durch die Methode selbst und nicht durch das Messobjekt erzeugt werden, erfassbar.

\section{Durchführung}

Es waren $8 \mathrm{CGH}$-Untersuchungen durchgeführt worden, bei denen gegen Normalgewebe vergleichend hybridisiert worden war. Auf Grundlage der Daten aus diesen Hybridisierungen wurden Standardreferenzintervalle nach Kirchhoff et al. (1998) berechnet. Näheres hierzu findet sich im Kapitel 4.1.4 des Diskussionsteils (S. 84). 


\section{Ergebnisse}

\subsection{Untersuchte Hirnmetastasen}

Zunächst wurden die 126 Gewebeproben überprüft und nicht den Kriterien entsprechende ausgeschlossen. Die in der Studie verbleibenden wurden anschließend den histologischen Typen zugeordnet.

\subsubsection{Ausschluss ungeeigneter Gewebeproben}

Von den 126 aufgefundenen Operationspräparaten mussten 38 aus der Studie genommen werden: In 15 Fällen war es nicht möglich, ausreichend Tumorgewebe für die CGHUntersuchung aus dem archivierten Präparat zu gewinnen. 10 vermeintliche Lungenkrebsmetastasen hielten der eingehenden histopathologischen Überprüfung nicht stand. In 7 Fällen gelang die CGH aus technischen Gründen nicht. Bei 3 Patienten lagen doppelte Präparate vor, es wurde jeweils nur eines in der Studie belassen. In weiteren 3 Fällen handelte es sich nicht um Hirnmetastasen, die Präparate waren fehlerhaft in die Kategorie „Hirnmetastase" eingeordnet worden.

\subsubsection{Histopathologische Klassifikation}

Die 88 in der Auswertung verbliebenen Fälle konnten wie folgt eingeordnet werden: 22 Fälle von kleinzelligem und 66 Fälle von nicht-kleinzelligem Lungenkrebs. Bei den nichtkleinzelligen Fällen konnten wiederum 32 Plattenepithel- und 16 Adenokarzinome sowie 11 adenosquamöse und 7 großzellige unterschieden werden.

Alle derart eingeordneten Hirnmetastasen wurden mit einer sprechenden Bezeichnung versehen: Hirnmetastasen vom kleinzelligen Karzinom mit dem Kürzel SCLC (Small Cell Lung Cancer), vom Plattenepithelkarzinom mit SQC (Squamous Cell Carcinoma), vom Adenokarzinom mit ADC (Adenocarcinoma), vom adenosquamösen Karzinom mit ADSQ (Adenosquamous Carcinoma) und vom großzelligen Karzinom mit LCC (Large Cell Carcinoma).

\subsection{Pathologische, allgemeine und klinische Daten}

Da Kriterien, wie sie für die Erstellung einer Zufalls- oder systematischen Stichprobe erforderlich sind, beim Entwurf dieser Studie nicht zugrunde gelegt worden waren, soll ein statistisches Schätzen auf eine klinische Grundgesamtheit unterbleiben. Die im Folgenden 
präsentierten klinischen Daten dienen daher ausschließlich der Beschreibung des untersuchten Patientenkollektivs. Einzelheiten zu den dargestellten Daten können Tabelle A.1 des Anhangs entnommen werden.

\subsubsection{Allgemeine Angaben zu den Patienten}

Das Geschlechterverhältnis lag auf Seiten der Männer: 15 der 22 am kleinzelligen Lungenkrebs erkrankten Patienten waren männlich (68\%). Beim nicht-kleinzelligen Lungenkrebs war das Ungleichgewicht noch ausgeprägter: 55 der 66 Patienten waren männlich (83\%).

Das Durchschnittsalter der Patienten beim kleinzelligen Lungenkrebs betrug zum Zeitpunkt der Hirnmetastasenentfernung $58 \pm 8$ Jahre, beim nicht-kleinzelligen Lungenkrebs $60 \pm 9$ Jahre.

\subsubsection{Klinische Parameter}

Angaben zum klinischen Verlauf lagen in 16 von 22 Fällen mit kleinzelligem Lungenkrebs vor. Bei den Patienten mit nicht-kleinzelligem Lungenkrebs existierten Angaben zu 53 der 66 Fälle. Das Folgende bezieht sich auf diese Gruppen.

\section{Intervall zwischen Erstdiagnose des Tumorleidens und der Hirnmetastase}

In beiden Patientenkollektiven gab es einen hohen Anteil synchroner Hirnmetastasen, also solcher Hirnmetastasen, deren Entdeckung mit der Erstdiagnose des Tumorleidens zusammenfiel oder in den drei Folgemonaten gemacht wurde. Im Kollektiv des kleinzelligen Lungenkrebses waren 12 der 16 Hirnmetastasen synchron aufgetreten, im Kollektiv des nicht-kleinzelligen Lungenkrebses gab es unter 53 Metastasen 34 synchrone. Der Median in beiden Gruppen lag dementsprechend bei 0 Monaten.

Bei den metachronen, d.h. verzögert aufgetretenen, Hirnmetastasen betrug das längste Intervall in der Gruppe der kleinzelligen 16 Monate und in der Gruppe der nicht-kleinzelligen 23 Monate.

\section{Klinisches Stadium}

Da diese Studie den ins Hirn metastasierten Lungenkrebs zum Gegenstand hat, befanden sich sämtliche Patienten definitionsgemäß im fortgeschrittensten Stadium der Erkrankung, Stadium IV gemäß der UICC-Stadiengruppierung (Wittekind et al. 2005). Für die Kategorien Tumor $(\mathrm{T})$ und Lymphknotenstatus $(\mathrm{N})$ entsprechend der TNM-Klassifikation lagen keine ausreichenden Daten vor, weil nur wenige der Patienten eine operative Therapie des Primärtumors erhalten hatten (s.u.).

\section{Therapie vor Auftreten der Hirnmetastase}

Da die meisten Hirnmetastasen synchron aufgetreten waren und deren operative Entfernung den Beginn der therapeutischen Maßnahmen darstellte, gab es zumeist keine 
vorangegangene Therapie: 10 der 16 Patienten mit kleinzelligen Tumoren waren zum Zeitpunkt der Hirnmetastasenentfernung nicht vorbehandelt, 30 der 53 Patienten mit nicht-kleinzelligen Tumoren.

Unter den Patienten mit kleinzelligem Lungenkrebs hatten die vorbehandelten 6 eine Chemo- und/oder Strahlentherapie erhalten. Bei einem dieser Patienten war zusätzlich der Primärtumor operativ entfernt worden. Ein anderer dieser Patienten hatte eine vorbeugende Bestrahlung des Schädels erhalten. Bei den 23 vorbehandelten Patienten mit nicht-kleinzelligem Lungenkrebs war in 12 Fällen der Primärtumor operativ entfernt worden, die übrigen 11 hatten eine Chemo- und/oder Strahlentherapie erhalten. 


\subsection{CGH-Befunde der Hirnmetastasen}

Vom nicht-kleinzelligen Lungenkrebs ist seit langem bekannt, dass sich die histologischen Typen auch molekularzytogenetisch unterscheiden. Insbesondere für die beiden großen Gruppen des Plattenepithel- und des Adenokarzinoms ist dies intensiv beforscht worden (Björkqvist et al. 1998a; Petersen I et al. 1997a; Sy et al. 2004). Aus diesem Grunde erfolgt die Darstellung der gewonnen CGH-Ergebnisse für die nicht-kleinzelligen Hirnmetastasen von Beginn an nach den histologischen Typen getrennt.

\subsubsection{Hirnmetastasen vom kleinzelligen Karzinom}

Abbildung 3.1 zeigt im Summenidiogramm Verluste, Zugewinne und Amplifikationen der 22 untersuchten kleinzelligen Hirnmetastasen. Detaillierte Beschreibungen der einzelnen Fälle in rev-ish-Schreibweise sind in Tabelle A.2 des Anhangs zu finden.
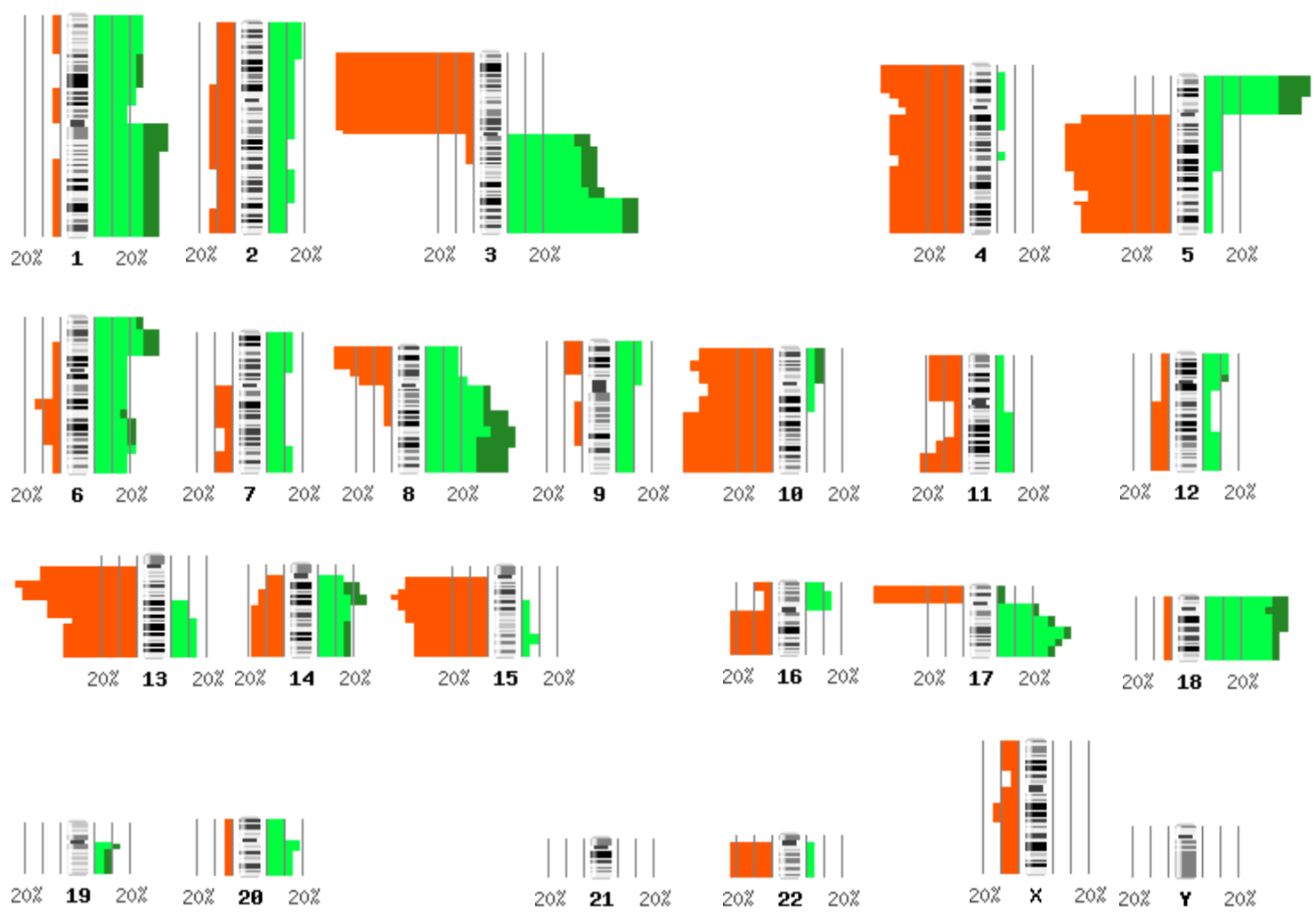

Abbildung 3.1: CGH-Summenidiogramm der 22 Hirnmetastasen vom kleinzelligen Karzinom. Verluste erscheinen rot, Zugewinne grün und Amplifikationen dunkelgrün. 
Häufige Veränderungen und Anzahl der Veränderungen pro Fall

Ganze Chromosomen, Chromosomenarme oder -abschnitte, auf denen in wenigstens $20 \%$ der Fälle ein Verlust oder ein Zugewinn gefunden wurde, sind in Tabelle 3.1 als häufige Veränderungen aufgeführt. Zeichnete sich im Summenidiogramm ein Bereich maximaler Häufigkeit ab, so ist dieser bandengenau angegeben. Amplifikationen wurden erfasst, wenn der entsprechende Chromosomenabschnitt in mindestens $10 \%$ der untersuchten Fälle als amplifiziert zu bewerten war.

Der Median der Anzahl chromosomaler Veränderungen pro Fall beträgt 13,5 ( $\mathrm{min}=$ $4, \max =26)$.

Tabelle 3.1: Häufige chromosomale Veränderungen der 22 Hirnmetastasen vom kleinzelligen Karzinom

\begin{tabular}{|c|c|c|c|}
\hline Veränderung & Lokalisation & Häufungsbereich & maximaler Anteilswert [\%] \\
\hline \multirow{10}{*}{ Zugewinne } & $3 q$ & \multirow[t]{5}{*}{$3 q 26 q t e r$} & 73 \\
\hline & $5 \mathrm{p}$ & & 59 \\
\hline & $8 q$ & & 50 \\
\hline & 18 & & 46 \\
\hline & $1 q$ & & 41 \\
\hline & $17 q$ & \multirow[t]{5}{*}{$17 \mathrm{q} 22 \mathrm{q} 23$} & 41 \\
\hline & 6p21pter & & 36 \\
\hline & $1 \mathrm{p}$ & & 27 \\
\hline & $14 q 12 q 21$ & & 27 \\
\hline & $6 q 22 q 24$ & & 23 \\
\hline \multirow{12}{*}{ Verluste } & $3 p$ & \multirow{12}{*}{$13 \mathrm{q} 13 \mathrm{q} 14$} & 77 \\
\hline & $13 \mathrm{q}$ & & 68 \\
\hline & $5 q$ & & 59 \\
\hline & $10 \mathrm{q}$ & & 50 \\
\hline & $15 \mathrm{q}$ & & 50 \\
\hline & $17 \mathrm{p}$ & & 50 \\
\hline & $10 \mathrm{p}$ & & 46 \\
\hline & 4 & & 41 \\
\hline & 8p12pter & & 32 \\
\hline & 11q22qter & & 23 \\
\hline & $16 q$ & & 23 \\
\hline & $22 q$ & & 23 \\
\hline \multirow{3}{*}{ Amplifikationen } & 8q21qter & \multirow[t]{3}{*}{$8 \mathrm{q} 23$} & 23 \\
\hline & $5 \mathrm{p}$ & & 18 \\
\hline & $1 q 11 q 23$ & & 14 \\
\hline
\end{tabular}




\subsubsection{Hirnmetastasen vom Plattenepithelkarzinom}

Abbildung 3.2 zeigt im Summenidiogramm Verluste, Zugewinne und Amplifikationen der 32 untersuchten Hirnmetastasen vom Plattenepithelkarzinom. Detaillierte Beschreibungen der einzelnen Fälle in rev-ish-Schreibweise sind in Tabelle A.2 des Anhangs zu finden.

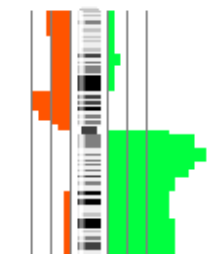

$20 \% 120 \%$
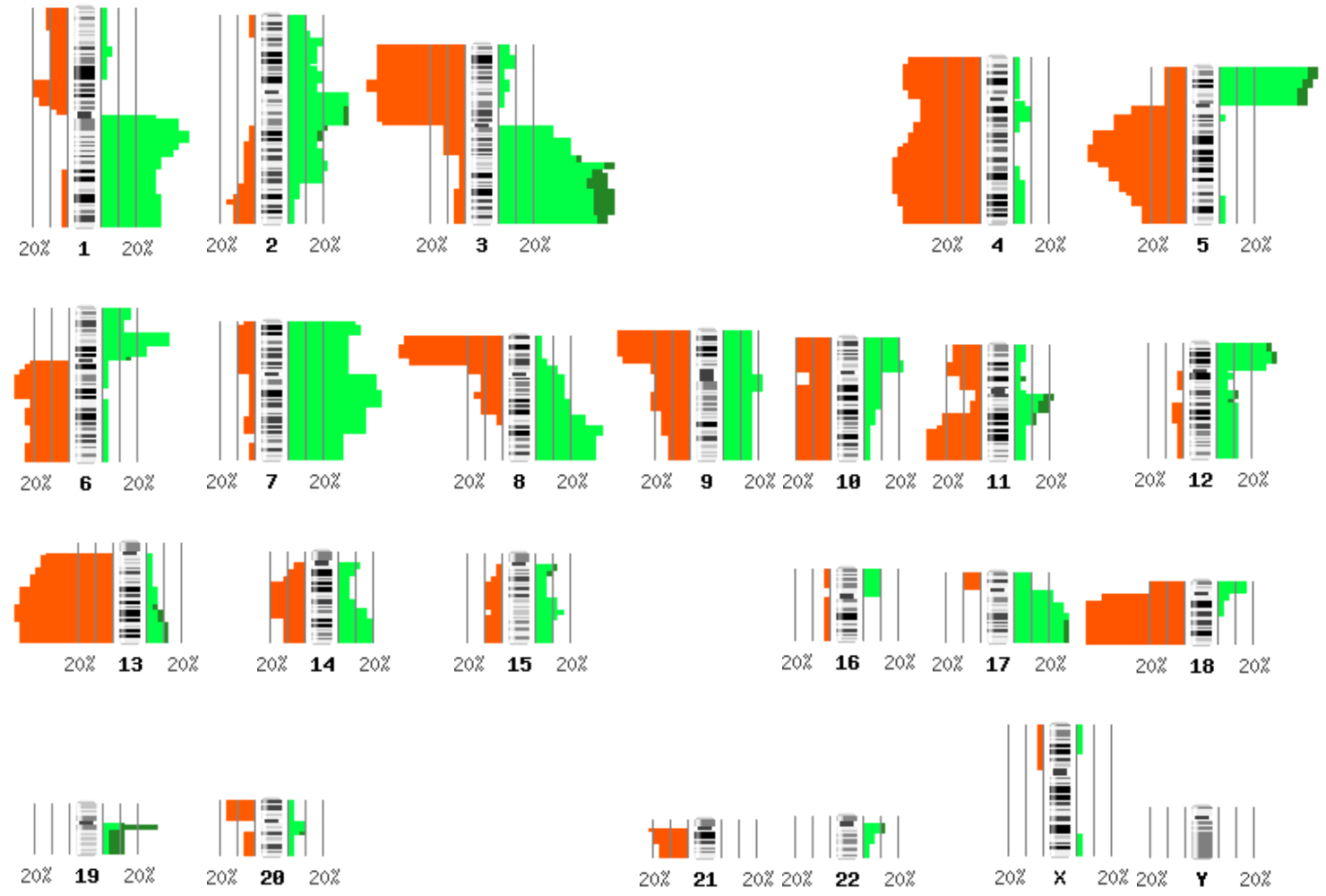

Abbildung 3.2: CGH-Summenidiogramm der 32 Hirnmetastasen vom Plattenepithelkarzinom. Verluste erscheinen rot, Zugewinne grün und Amplifikationen dunkelgrün.

\section{Häufige Veränderungen und Anzahl der Veränderungen pro Fall}

Ganze Chromosomen, Chromosomenarme oder -abschnitte, auf denen in wenigstens $20 \%$ der Fälle ein Verlust oder ein Zugewinn gefunden wurde, sind in Tabelle 3.2 als häufige Veränderungen aufgeführt. Zeichnete sich im Summenidiogramm ein Bereich maximaler Häufigkeit ab, so ist dieser bandengenau angegeben. Amplifikationen wurden erfasst, wenn der entsprechende Chromosomenabschnitt in mindestens $10 \%$ der untersuchten Fälle als amplifiziert zu bewerten war.

Der Median der Anzahl chromosomaler Veränderungen pro Fall beträgt 15,0 ( $\mathrm{min}=$ $3, \max =27)$. 
Tabelle 3.2: Häufige Veränderungen der 32 Hirnmetastasen vom Plattenepithelkarzinom

\begin{tabular}{|c|c|c|c|}
\hline Veränderung & Lokalisation & Häufungsbereich & maximaler Anteilswert [\%] \\
\hline \multirow{13}{*}{ Zugewinne } & $3 q$ & $3 q 22 q$ ter & 66 \\
\hline & $5 p$ & & 56 \\
\hline & 7 & $7 q 11 q 21$ & 53 \\
\hline & $1 q$ & $1 \mathrm{q} 12 \mathrm{q} 23$ & 50 \\
\hline & $6 \mathrm{p} 12 \mathrm{p} 21$ & $6 \mathrm{p} 21$ & 38 \\
\hline & $8 q 22$ qter & & 38 \\
\hline & $2 q 11 q 21$ & $2 q 11 q 14$ & 34 \\
\hline & $12 p$ & & 34 \\
\hline & $17 q$ & 17q22qter & 31 \\
\hline & $19 \mathrm{q} 12$ & & 31 \\
\hline & $2 q 31$ & & 22 \\
\hline & 10p11 & & 22 \\
\hline & $11 \mathrm{q} 12$ & & 22 \\
\hline \multirow{11}{*}{ Verluste } & 8p12pter & & 59 \\
\hline & $13 q$ & 13q21qter & 56 \\
\hline & $18 \mathrm{q}$ & & 56 \\
\hline & $5 q$ & $5 q 14 q 21$ & 56 \\
\hline & $3 p$ & & 56 \\
\hline & $4 q$ & $4 q 26 q 31$ & 50 \\
\hline & $4 \mathrm{p}$ & & 43 \\
\hline & $9 \mathrm{p}$ & & 41 \\
\hline & $6 q$ & & 31 \\
\hline & 11q14qter & 11q22qter & 31 \\
\hline & $9 \mathrm{q} 21$ & & 22 \\
\hline \multirow{2}{*}{ Amplifikationen } & $19 q 12$ & & 22 \\
\hline & $3 q 25 q 27$ & & 13 \\
\hline
\end{tabular}




\subsubsection{Hirnmetastasen vom Adenokarzinom}

Abbildung 3.3 zeigt im Summenidiogramm Verluste, Zugewinne und Amplifikationen der 16 untersuchten Hirnmetastasen vom Adenokarzinom. Detaillierte Beschreibungen der einzelnen Fälle in rev-ish-Schreibweise sind in Tabelle A.2 des Anhangs zu finden.
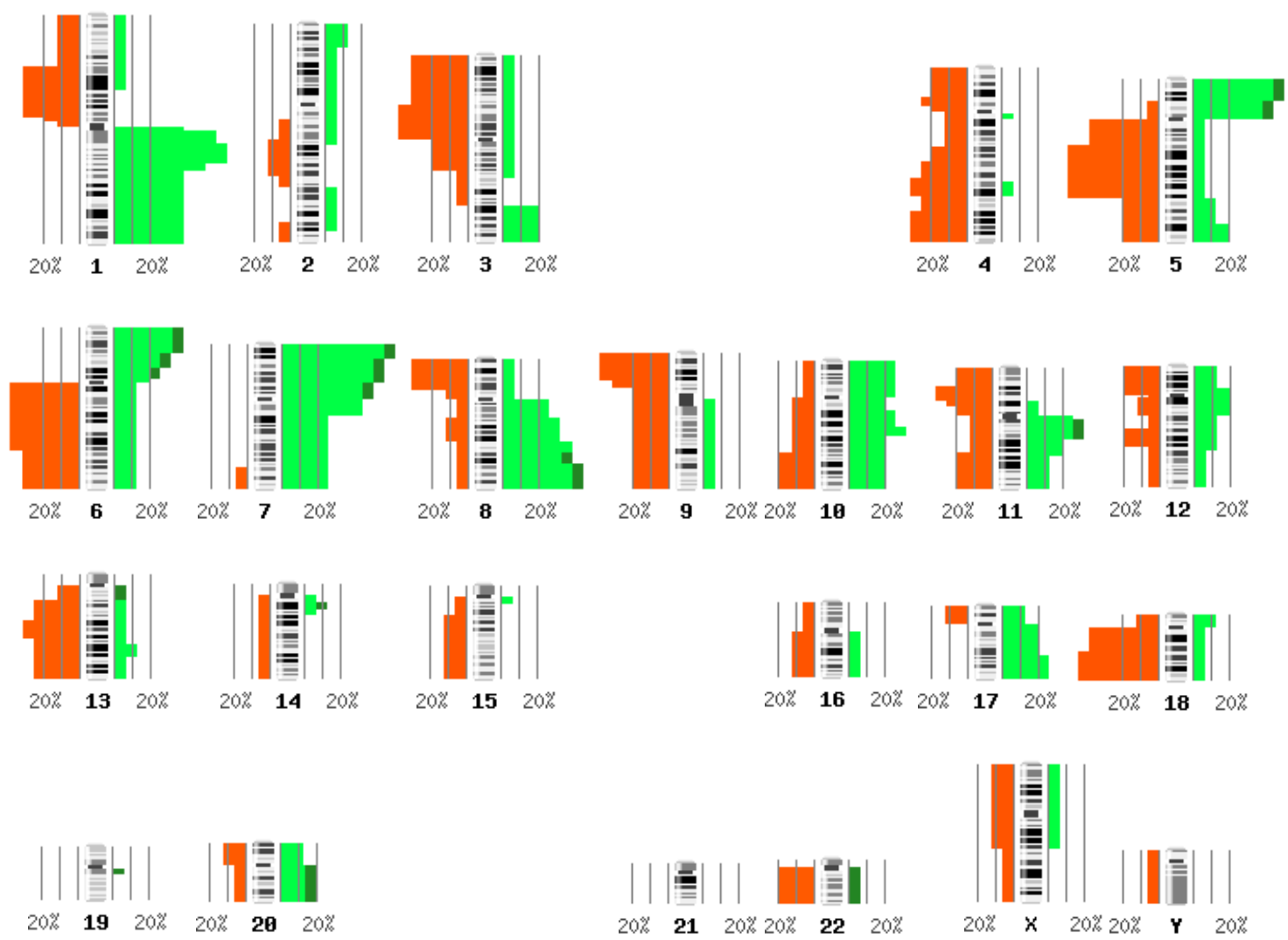

Abbildung 3.3: CGH-Summenidiogramm der 16 Hirnmetastasen vom Adenokarzinom. Verluste erscheinen rot, Zugewinne grün und Amplifikationen dunkelgrün.

\section{Häufige Veränderungen und Anzahl der Veränderungen pro Fall}

Ganze Chromosomen, Chromosomenarme oder -abschnitte, auf denen in wenigstens $20 \%$ der Fälle ein Verlust oder ein Zugewinn gefunden wurde, sind in Tabelle 3.3 als häufige Veränderungen aufgeführt. Zeichnete sich im Summenidiogramm ein Bereich maximaler Häufigkeit ab, so ist dieser bandengenau angegeben. Amplifikationen wurden erfasst, wenn der entsprechende Chromosomenabschnitt in mindestens $10 \%$ der untersuchten Fälle als amplifiziert zu bewerten war.

Der Median der Anzahl chromosomaler Veränderungen pro Fall beträgt 12,5 ( $\mathrm{min}=$ $4, \max =22$ ). 
Tabelle 3.3: Häufige Veränderungen der 16 Hirnmetastasen vom Adenokarzinom

\begin{tabular}{llcc} 
Veränderung & Lokalisation & Häufungsbereich & maximaler Anteilswert [\%] \\
& $1 \mathrm{q}$ & $1 \mathrm{q} 12 \mathrm{q} 23$ & 63 \\
$7 \mathrm{p}$ & $7 \mathrm{p} 21 \mathrm{pter}$ & 63 \\
$5 \mathrm{p}$ & & 50 \\
Zugewinne & & $4 \mathrm{p}$ & 44 \\
& $6 \mathrm{p}$ & $6 \mathrm{q} 24 \mathrm{pter}$ & 38 \\
$10 \mathrm{q} 21 \mathrm{q} 22$ & & 31 \\
$11 \mathrm{q} 11 \mathrm{q} 13$ & & 31 \\
$10 \mathrm{p}$ & & 25 \\
$17 \mathrm{q} 23 \mathrm{q}$ ter & 25 \\
\hline $5 \mathrm{q} 11 \mathrm{q} 23$ & & 50 \\
$18 \mathrm{q}$ & & 44 \\
$3 \mathrm{p}$ & 38 \\
$6 \mathrm{q}$ & 38 \\
$9 \mathrm{p}$ & & 38 \\
$1 \mathrm{p} 13 \mathrm{p} 31$ & & 31 \\
$4 \mathrm{q} 24 \mathrm{q}$ ter & & 31 \\
$8 \mathrm{p}$ & & 31 \\
Verluste & & 31 \\
$11 \mathrm{p} 12 \mathrm{p} 14$ & & 25 \\
\hline
\end{tabular}




\subsubsection{Hirnmetastasen vom adenosquamösen Karzinom}

Abbildung 3.4 zeigt im Summenidiogramm Verluste, Zugewinne und Amplifikationen der 11 untersuchten adenosquamösen Hirnmetastasen. Detaillierte Beschreibungen der einzelnen Fälle in rev-ish-Schreibweise sind in Tabelle A.2 des Anhangs zu finden.
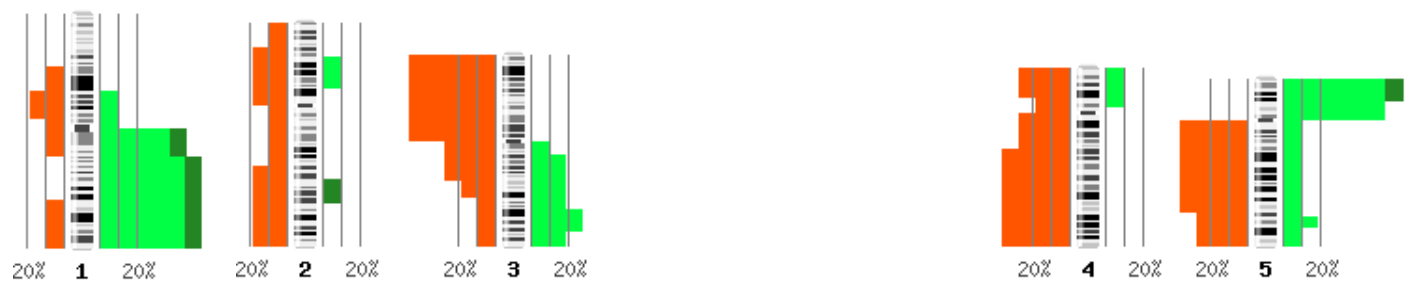

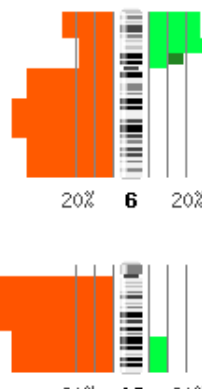

$20 \% 1320 \%$
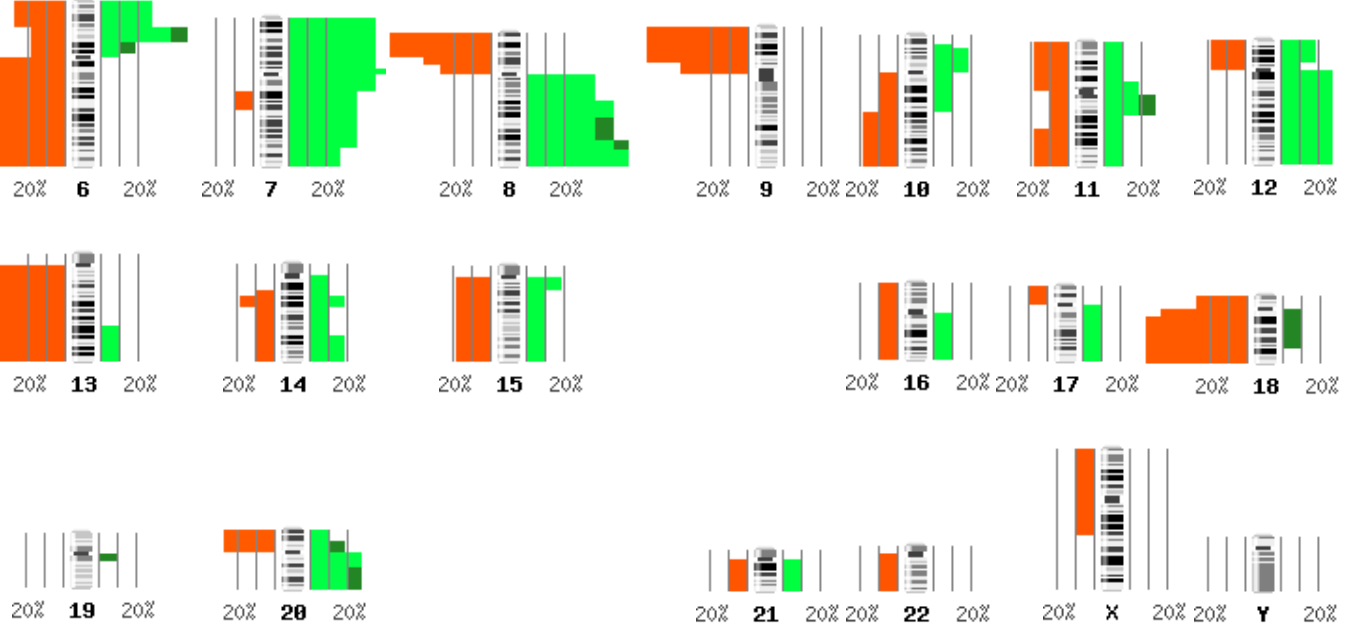

Abbildung 3.4: CGH-Summenidiogramm der 11 Hirnmetastasen vom adenosquamösen Karzinom. Verluste erscheinen rot, Zugewinne grün und Amplifikationen dunkelgrün.

\section{Häufige Veränderungen und Anzahl der Veränderungen pro Fall}

Ganze Chromosomen, Chromosomenarme oder -abschnitte, auf denen in wenigstens $20 \%$ der Fälle ein Verlust oder ein Zugewinn gefunden wurde, sind in Tabelle 3.4 als häufige Veränderungen aufgeführt. Zeichnete sich im Summenidiogramm ein Bereich maximaler Häufigkeit ab, so ist dieser bandengenau angegeben. Amplifikationen wurden erfasst, wenn der entsprechende Chromosomenabschnitt in mindestens $10 \%$ der untersuchten Fälle als amplifiziert zu bewerten war.

Der Median der Anzahl chromosomaler Veränderungen pro Fall beträgt 13,0 ( $\mathrm{min}=$ $2, \max =23)$. 
Tabelle 3.4: Häufige Veränderungen der 11 Hirnmetastasen vom adenosquamösen Karzinom

\begin{tabular}{|c|c|c|c|}
\hline Veränderung & Lokalisation & Häufungsbereich & maximaler Anteilswert [\%] \\
\hline \multirow{10}{*}{ Zugewinne } & $5 p$ & & 64 \\
\hline & $1 q$ & & 55 \\
\hline & $8 q$ & $8 q 24$ & 55 \\
\hline & $6 \mathrm{p}$ & $6 \mathrm{p} 21$ & 45 \\
\hline & $7 \mathrm{p}$ & & 45 \\
\hline & $7 q$ & & 36 \\
\hline & $3 \mathrm{q} 26$ & & 27 \\
\hline & $11 q$ & & 27 \\
\hline & $12 q$ & & 27 \\
\hline & $20 q$ & & 27 \\
\hline \multirow{13}{*}{ Verluste } & $13 q$ & & 64 \\
\hline & $6 q$ & & 55 \\
\hline & $8 \mathrm{p}$ & 8p21pter & 55 \\
\hline & $9 \mathrm{p}$ & & 55 \\
\hline & $18 \mathrm{q}$ & & 55 \\
\hline & $3 p$ & & 45 \\
\hline & $4 q$ & & 36 \\
\hline & $5 \mathrm{p}$ & & 36 \\
\hline & $3 q 11 q 21$ & & 27 \\
\hline & 4p15pter & & 27 \\
\hline & $6 \mathrm{p} 22$ pter & & 27 \\
\hline & $18 \mathrm{p}$ & & 27 \\
\hline & $20 \mathrm{p}$ & & 27 \\
\hline
\end{tabular}




\subsubsection{Hirnmetastasen vom großzelligen Karzinom}

Abbildung 3.5 zeigt im Summenidiogramm Verluste, Zugewinne und Amplifikationen der 7 untersuchten großzelligen Hirnmetastasen. Detaillierte Beschreibungen der einzelnen Fälle in rev-ish-Schreibweise sind in Tabelle A.2 des Anhangs zu finden.
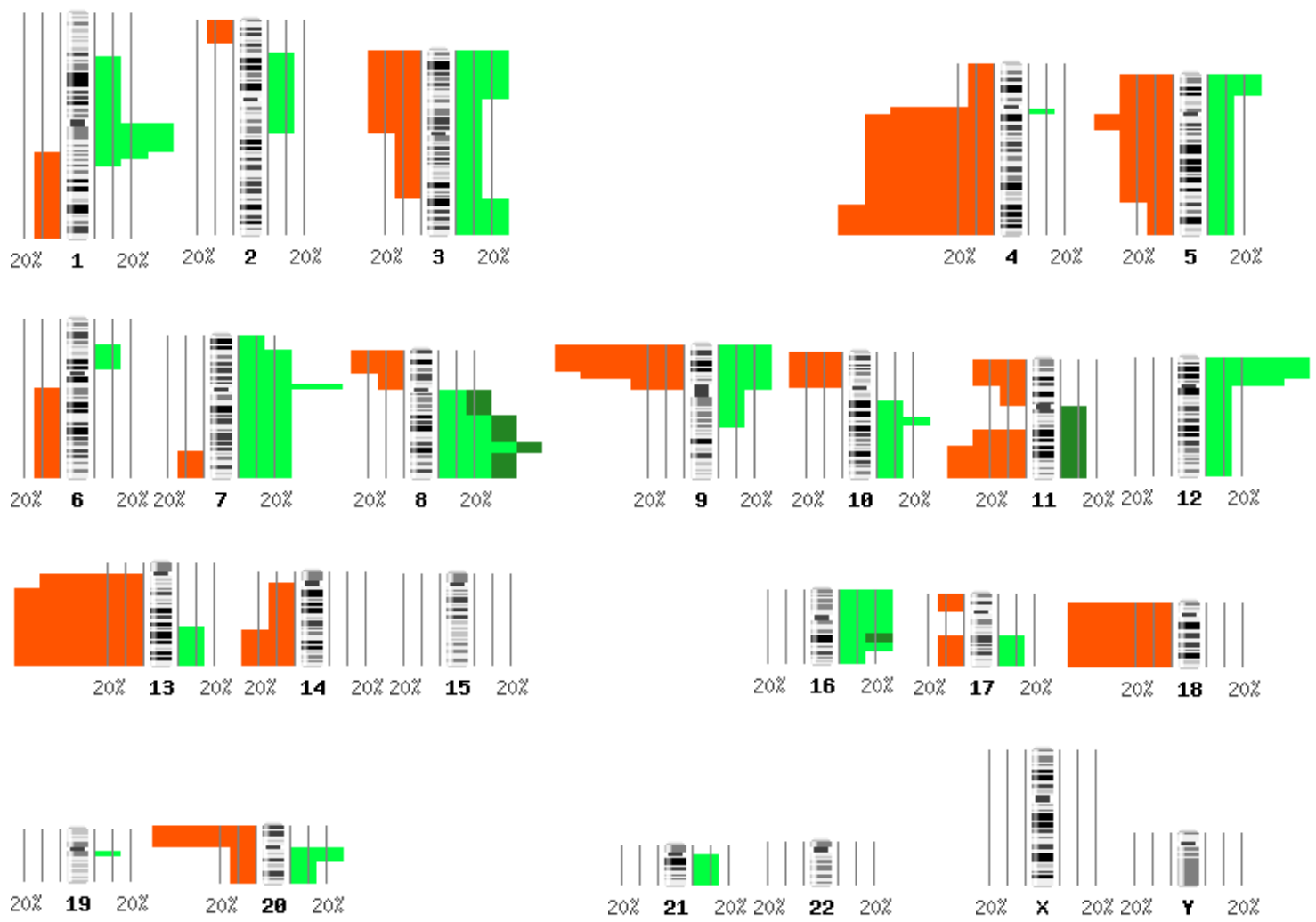

Abbildung 3.5: CGH-Summenidiogramm der 7 Hirnmetastasen vom großzelligen Karzinom. Verluste erscheinen rot, Zugewinne grün und Amplifikationen dunkelgrün.

\section{Häufige Veränderungen und Anzahl der Veränderungen pro Fall}

Ganze Chromosomen, Chromosomenarme oder -abschnitte, auf denen in wenigstens $20 \%$ der Fälle ein Verlust oder ein Zugewinn gefunden wurde, sind in Tabelle 3.5 als häufige Veränderungen aufgeführt. Zeichnete sich im Summenidiogramm ein Bereich maximaler Häufigkeit ab, so ist dieser bandengenau angegeben. Amplifikationen wurden erfasst, wenn der entsprechende Chromosomenabschnitt in mindestens $10 \%$ der untersuchten Fälle als amplifiziert zu bewerten war.

Der Median der Anzahl chromosomaler Veränderungen pro Fall beträgt 12,0 ( $\mathrm{min}=$ $7, \max =19)$. 
Tabelle 3.5: Häufige Veränderungen der 7 Hirnmetastasen vom großzelligen Karzinom

\begin{tabular}{|c|c|c|c|}
\hline Veränderung & Lokalisation & Häufungsbereich & maximaler Anteilswert [\%] \\
\hline \multirow{13}{*}{ Zugewinne } & $12 p$ & \multirow{13}{*}{$8 q 23$} & 57 \\
\hline & $8 q$ & & 57 \\
\hline & $1 q 12 q 23$ & & 43 \\
\hline & 3p21pter & & 29 \\
\hline & $3 q 26$ qter & & 29 \\
\hline & 5 p14pter & & 29 \\
\hline & $7 \mathrm{p} 11 \mathrm{p} 15$ & & 29 \\
\hline & $7 q$ & & 29 \\
\hline & $9 \mathrm{p}$ & & 29 \\
\hline & $10 \mathrm{q} 22$ & & 29 \\
\hline & $16 \mathrm{p}$ & & 29 \\
\hline & $16 q 11 q 22$ & & 29 \\
\hline & $20 q 11 q 12$ & & 29 \\
\hline \multirow{13}{*}{ Verluste } & $4 q$ & \multirow{13}{*}{ 9p21pter } & 86 \\
\hline & $9 p$ & & 71 \\
\hline & $13 \mathrm{q}$ & & 71 \\
\hline & 18 & & 57 \\
\hline & $20 \mathrm{p}$ & & 57 \\
\hline & 11q14qter & & 43 \\
\hline & $3 p$ & & 29 \\
\hline & $5 p$ & & 29 \\
\hline & $5 q 11 q 31$ & & 29 \\
\hline & 8p21pter & & 29 \\
\hline & $10 \mathrm{p}$ & & 29 \\
\hline & 11p14pter & & 29 \\
\hline & 14q24qter & & 29 \\
\hline
\end{tabular}




\subsection{Ergebnisse der Metaanalyse: CGH-Befunde der Primärtumoren}

\subsubsection{Ergebnisse der Literaturrecherche}

Die Literaturrecherche wurde am 16. Juli 2008 durchgeführt. Die Suche in MEDLINE erbrachte 170 Publikationen. Die Suchen in Progenetix, der Mitelman-Datenbank und der SKY/M-FISH \& CGH-Datenbank erbrachten keine zusätzlichen Ergebnisse.

Eine Überprüfung gemäß der in Kapitel 2.5.1 (S. 38) formulierten Kriterien schloss sich dem an: 91 Publikationen mussten aus inhaltlichen Gründen ausgeschlossen werden, 42 aus methodischen. Weitere sechs Publikationen entsprachen den Anforderungen, konnten aber aus formalen Gründen nicht verwendet werden: Eine histologische Zuordnung war zwar erfolgt, doch war diese nicht bei der Ergebnisdarstellung berücksichtigt worden. Sechs weitere Publikationen waren nicht erhältlich. Es verblieben 25 Publikationen, denen die Experteneinschätzung, CGH-Befunde in rev-ish-Schreibweise oder beides entnommen werden konnte; Tabelle 3.6 gibt eine Übersicht.

Kollektive mit zufriedenstellender Fallzahl ergaben sich nur für die kleinzelligen, die Plattenepithel- und die Adenokarzinome. Angaben über großzellige Karzinome fanden sich nur für insgesamt 19 untersuchte Fälle (Björkqvist et al. 1998b; Yakut et al. 2006), über adenosquamöse nur für zwei Fälle (Yakut et al. 2006). Für diese beiden histologischen Typen wurden daher keine Vergleiche unternommen.

Tabelle 3.6: In die Metaanalyse eingeschlossene Publikationen

\begin{tabular}{|c|c|c|c|c|c|}
\hline \multirow[t]{2}{*}{ Publikation } & \multirow[t]{2}{*}{ Experteneinschätzung } & \multirow[t]{2}{*}{ rev-ish-Befunde } & \multicolumn{3}{|c|}{ Fallzahlen } \\
\hline & & & SCLC & SQC & ADC \\
\hline Björkqvist et al. (1998a) & $\checkmark$ & $\checkmark$ & & 16 & 17 \\
\hline Björkqvist et al. (1998b) & & $\checkmark$ & & & 10 \\
\hline Chujo et al. (2002) & $\checkmark$ & $\checkmark$ & & 41 & \\
\hline Goeze et al. (2002) & $\checkmark$ & & & & $83^{a}$ \\
\hline Johnen et al. (2003) & $\checkmark$ & & 10 & & \\
\hline Levin et al. (1995) & $\checkmark$ & & $10^{b}$ & & \\
\hline Lindström et al. (2002) & $\checkmark$ & $\checkmark$ & & & 25 \\
\hline Lui et al. (2001) & $\checkmark$ & $\checkmark$ & 23 & & \\
\hline Luk et al. (2001) & & $\checkmark$ & & 4 & 4 \\
\hline Ma et al. (2006) & $\checkmark$ & & & 23 & \\
\hline O-charoenrat et al. $(2004)^{c}$ & $\checkmark$ & & & 17 & 4 \\
\hline Park et al. (2004) & $\checkmark$ & & & 27 & 16 \\
\hline Pei et al. (2001) & $\checkmark$ & & & 32 & 35 \\
\hline Petersen I et al. (1997a) & $\checkmark$ & & & 25 & 25 \\
\hline Petersen I et al. (1997b) & $\checkmark$ & $\checkmark$ & 22 & & \\
\hline Petersen S et al. (2000) & $\checkmark$ & & & $64^{d}$ & \\
\hline
\end{tabular}

Fortsetzung... 
...Fortsetzung

\begin{tabular}{|c|c|c|c|c|c|}
\hline \multirow[t]{2}{*}{ Publikation } & \multirow[t]{2}{*}{ Experteneinschätzung } & \multirow[t]{2}{*}{ rev-ish-Befunde } & \multicolumn{3}{|c|}{ Fallzahlen } \\
\hline & & & SCLC & SQC & ADC \\
\hline Ried et al. (1994) & $\checkmark$ & $\checkmark$ & 13 & & \\
\hline Schwendel et al. (1997) & $\checkmark$ & $\checkmark$ & 10 & & \\
\hline Shen et al. (2008) & $\checkmark$ & & & & 50 \\
\hline Sy et al. (2004) & $\checkmark$ & & & 35 & 34 \\
\hline Tai et al. (2004) & $\checkmark$ & $\checkmark$ & & 39 & 30 \\
\hline Walch et al. (1998) & & $\checkmark$ & 3 & & \\
\hline Wong et al. (2003) & $\checkmark$ & & & & 32 \\
\hline Yakut et al. (2006) & & $\checkmark$ & & 21 & 9 \\
\hline Yan et al. (2005a) & $\checkmark$ & & & 39 & \\
\hline
\end{tabular}

${ }^{a} 60$ Primärtumoren und 23 korrespondierende Metastasen.

b 7 Primärtumoren und 3 Metastasen.

${ }^{c}$ Experteneinschätzung wurde nur bei den Plattenepithelkarzinomen erfasst.

${ }^{d} 44$ Primärtumoren und 20 Metastasen.

\subsubsection{Primärtumoren des kleinzelligen Karzinoms}

Sieben Publikationen mit insgesamt 91 untersuchten Fällen wurden in die Auswertung eingeschlossen. Aus 6 dieser Publikationen, die zusammen 88 Fälle enthielten, konnte die Experteneinschätzung in Form der „erwähnenswerten Veränderungen“ sowie die mittlere Anzahl der Veränderungen pro Fall entnommen werden. Zusätzlich war es möglich, für 71 Fälle detaillierte CGH-Befunde in rev-ish-Schreibweise zu extrahieren.

\section{Experteneinschätzung: Erwähnenswerte Veränderungen}

Für die folgenden Chromosomen oder Chromosomenarme wurde in mindestens einem Drittel der ausgewerteten Publikationen eine „erwähnenswerte Veränderung“ beschrieben: Zugewinne auf 1, 3q, 5p, 8q, 17q, 18 und 19; Verluste auf 3p, 4, 5q, 8p, 10q, 13q, 16q und 17p. Amplifikationen, die in mindestens einem Drittel der Publikationen mehr als nur ein einziges Mal beobachtet worden waren, lagen auf den Chromosomenarmen 1p, 2p und 5p.

\section{Extrahierte rev-ish-Befunde}

Abbildung 3.6 zeigt im Summenidiogramm Verluste, Zugewinne und Amplifikationen der 71 Fälle, von denen detaillierte CGH-Befunde in rev-ish-Schreibweise erhältlich waren. 
Genaue Angaben zu den eingeschlossenen Fällen sind in Tabelle A.3 des Anhangs zu finden.
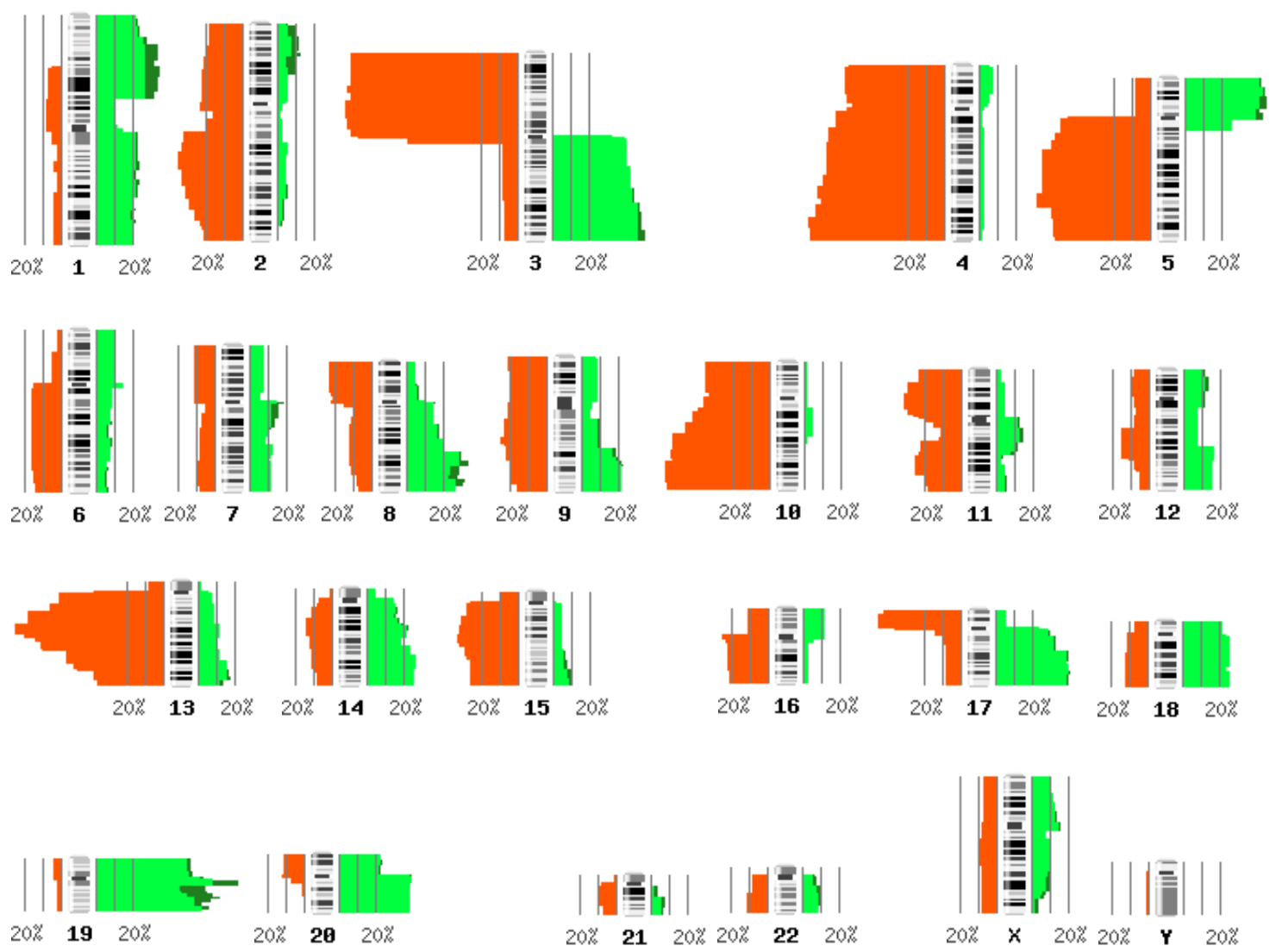

Abbildung 3.6: CGH-Summenidiogramm von 71 Primärtumoren des kleinzelligen Karzinoms. Verluste erscheinen rot, Zugewinne grün und Amplifikationen dunkelgrün.

Ganze Chromosomen, Chromosomenarme oder -abschnitte, auf denen in wenigstens $20 \%$ der Fälle ein Verlust oder ein Zugewinn gefunden wurde, sind in Tabelle 3.7 als häufige Veränderungen aufgeführt. Zeichnete sich im Summenidiogramm ein Bereich maximaler Häufigkeit ab, so ist dieser bandengenau angegeben. Amplifikationen wurden erfasst, wenn der entsprechende Chromosomenabschnitt in mindestens $10 \%$ der untersuchten Fälle als amplifiziert zu bewerten war.

Der Median der Anzahl chromosomaler Veränderungen pro Fall beträgt 15,0 ( $\mathrm{min}=$ $2, \max =28)$. 
Tabelle 3.7: Häufige Veränderungen von 71 Primärtumoren des kleinzelligen Karzinoms

\begin{tabular}{|c|c|c|c|}
\hline Veränderung & Lokalisation & Häufungsbereich & maximaler Anteilswert [\%] \\
\hline \multirow{13}{*}{ Zugewinne } & 19 & $19 q 12$ & 78 \\
\hline & $3 q$ & & 51 \\
\hline & 5 pterq12 & & 45 \\
\hline & $17 q$ & & 39 \\
\hline & $20 q$ & & 38 \\
\hline & $1 \mathrm{p} 22.2 \mathrm{pter}$ & $1 \mathrm{p} 22.2 \mathrm{p} 35.1$ & 35 \\
\hline & $8 \mathrm{q} 21.3 \mathrm{qter}$ & $8 \mathrm{q} 22.3 \mathrm{qter}$ & 34 \\
\hline & 14q23.3qter & & 27 \\
\hline & 18 & & 25 \\
\hline & 1q12qter & & 24 \\
\hline & $20 p$ & & 24 \\
\hline & $9 \mathrm{q} 31.2 \mathrm{qter}$ & & 23 \\
\hline & $14 \mathrm{q} 21.3 \mathrm{q} 22$ & & 23 \\
\hline \multirow{17}{*}{ Verluste } & $3 \mathrm{p}$ & & 94 \\
\hline & $13 q$ & $13 q 13.3 q 21.31$ & 82 \\
\hline & $4 q$ & & 75 \\
\hline & $5 \mathrm{q}$ & & 62 \\
\hline & $10 \mathrm{q}$ & 10q22.3qter & 58 \\
\hline & $4 \mathrm{p}$ & & 55 \\
\hline & $17 \mathrm{p}$ & & 45 \\
\hline & 2q14.3qter & & 35 \\
\hline & $10 \mathrm{p}$ & & 35 \\
\hline & $15 \mathrm{q}$ & & 34 \\
\hline & $11 \mathrm{p}$ & & 31 \\
\hline & $9 \mathrm{q} 11 \mathrm{q} 31.2$ & & 25 \\
\hline & $11 \mathrm{q} 13.5 \mathrm{q} 23.2$ & & 25 \\
\hline & $8 \mathrm{p}$ & & 24 \\
\hline & $2 \mathrm{p} 11 \mathrm{p} 21$ & & 23 \\
\hline & $16 q$ & & 23 \\
\hline & $9 \mathrm{p} 22.2 \mathrm{pter}$ & & 21 \\
\hline Amplifikationen & $19 \mathrm{q} 12 \mathrm{q} 13.31$ & & 14 \\
\hline
\end{tabular}

\section{Zusammenschau}

Sowohl bei den Zugewinnen als auch bei den Verlusten konnten die „erwähnenswerten Veränderungen" der Experten durch die Auswertung der extrahierten rev-ish-Befunde 
bestätigt werden. Darüber hinaus erbrachte die Auswertung der CGH-Daten noch weitere als häufig einzustufende Veränderungen. Dass es sich dabei um keinen Schwelleneffekt aufgrund der mit $20 \%$ möglicherweise niedriger gewählten Schwelle handelt, zeigt sich dadurch, dass diese zusätzlichen Veränderungen zum Teil auch mit höheren Anteilswerten auftreten. Beispielhaft sind hier der Zugewinn auf 20q mit 38\% und der Verluste auf 10p mit $35 \%$ zu nennen.

Die in den Publikationen genannten Amplifikationen weisen keine Übereinstimmung mit denen auf, die in der Auswertung der extrahierten rev-ish-Befunde aufgefallen waren. Allerdings sind alle drei der in den Publikationen beschriebenen Amplifikationen mit unterschwelligen Anteilswerten nachvollziehbar: 1p mit 8,5\%, 2p mit 5,6\% und 5p mit $4,2 \%$.

Das Bild der Veränderungen, das sich aus den zusammengetragenen Experteneinschätzungen ergeben hat, scheint gut, aber unvollständig zu sein. Daher sollen im Folgenden die häufigen Zugewinne und Verluste, die die Auswertung der extrahierten CGH-Daten erbracht hat, als Grundlage für die Beurteilung des Veränderungsmusters dienen. Amplifikationen sollen nicht bewertet werden. Das zu verwendende Muster der Veränderungen beim kleinzelligen Lungenkrebs lautet bei armgenauer Auflösung somit: Zugewinne von 1, $3 \mathrm{q}, 5 \mathrm{p}, 8 \mathrm{q}, 9 \mathrm{q}, 14,17 \mathrm{q}, 18,19$ und 20; Verluste von 2, 3p, 4, 5q, 8p, 9, 10, 11, 13q, 15q, $16 \mathrm{q}$ und $17 \mathrm{p}$.

\subsubsection{Primärtumoren des Plattenepithelkarzinoms}

13 Publikationen mit insgesamt 383 untersuchten Fällen wurden in die Auswertung eingeschlossen. Aus elf dieser Publikationen, die zusammen 358 Fälle enthielten, konnte eine Experteneinschätzung in Form der „erwähnenswerten Veränderungen“ sowie die mittlere Anzahl der Veränderungen pro Fall entnommen werden. Zusätzlich war es möglich, für 121 Fälle detaillierte CGH-Befunde in rev-ish-Schreibweise zu extrahieren.

\section{Experteneinschätzung: Erwähnenswerte Veränderungen}

Für die folgenden Chromosomen oder Chromosomenarme wurde in mindestens einem Drittel der ausgewerteten Publikationen eine „erwähnenswerte Veränderung“ beschrieben. Zugewinne auf 1q, 3q, 5p, 8q, 12p, 17q und 19q; Verluste auf 1p, 3p, 4, 5q, 8p, 13q und 17p. Amplifikationen, die in mindestens einem Drittel der Publikationen mehr als nur ein einziges Mal beobachtet worden waren, lagen auf den Chromosomenarmen 1q, 3q, 5p, 8q und $12 \mathrm{p}$.

\section{Extrahierte rev-ish-Befunde}

Abbildung 3.7 zeigt im Summenidiogramm Verluste, Zugewinne und Amplifikationen der 121 Fälle, von denen detaillierte CGH-Befunde in rev-ish-Schreibweise erhältlich waren. Genaue Angaben zu den eingeschlossenen Fällen sind in Tabelle A.4 des Anhangs zu finden. 

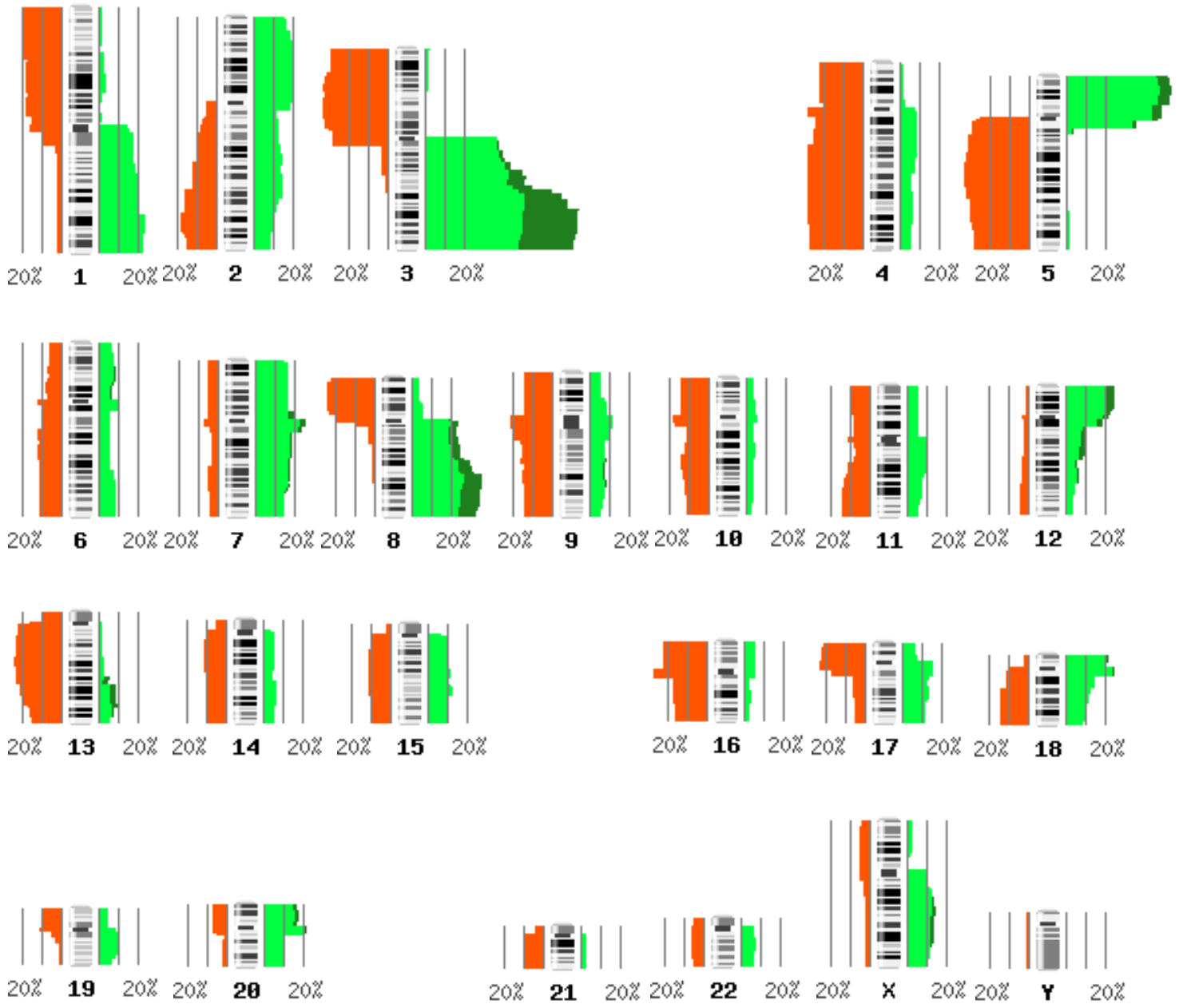

Abbildung 3.7: CGH-Summenidiogramm von 121 Primärtumoren des Plattenepithelkarzinoms. Verluste erscheinen rot, Zugewinne grün und Amplifikationen dunkelgrün.

Ganze Chromosomen, Chromosomenarme oder -abschnitte, auf denen in wenigstens $20 \%$ der Fälle ein Verlust oder ein Zugewinn gefunden wurde, sind in Tabelle 3.8 als häufige Veränderungen aufgeführt. Zeichnete sich im Summenidiogramm ein Bereich maximaler Häufigkeit ab, so ist dieser bandengenau angegeben. Amplifikationen wurden erfasst, wenn der entsprechende Chromosomenabschnitt in mindestens $10 \%$ der untersuchten Fälle als amplifiziert zu bewerten war.

Der Median der Anzahl chromosomaler Veränderungen pro Fall beträgt 8,0 ( $\min =$ $8, \max =36)$. 
Tabelle 3.8: Häufige Veränderungen von 121 Primärtumoren des Plattenepithelkarzinoms

\begin{tabular}{|c|c|c|c|}
\hline Veränderung & Lokalisation & Häufungsbereich & maximaler Anteilswert [\%] \\
\hline \multirow{6}{*}{ Zugewinne $^{a}$} & $3 q$ & 3q23qter & 79 \\
\hline & $5 \mathrm{p}$ & & 54 \\
\hline & $8 q$ & 8q22.3qter & 36 \\
\hline & $12 p$ & & 25 \\
\hline & $1 \mathrm{q} 25.3 \mathrm{qter}$ & & 24 \\
\hline & $18 \mathrm{p}$ & & 22 \\
\hline \multirow{8}{*}{ Verluste $^{a}$} & $3 p$ & & 33 \\
\hline & $5 q$ & & 33 \\
\hline & $4 q$ & & 29 \\
\hline & $8 \mathrm{p}$ & & 24 \\
\hline & $13 \mathrm{q} 11 \mathrm{q} 31.2$ & & 24 \\
\hline & $4 \mathrm{p}$ & & 22 \\
\hline & $16 \mathrm{p}$ & & 22 \\
\hline & $17 \mathrm{p}$ & & 22 \\
\hline \multirow{2}{*}{ Amplifikationen } & $3 \mathrm{q} 22.3 \mathrm{qter}$ & & 28 \\
\hline & $8 \mathrm{q} 23.3 \mathrm{q} 24.2$ & & 11 \\
\hline
\end{tabular}

${ }^{a}$ Die Zentromerbereiche von Chromosom 7, 16, 18 und 20 wurden nicht bewertet.

\section{Zusammenschau}

Bei den Zugewinnen und Verlusten konnten die „erwähnenswerten Veränderungen“ der Experten weitgehend durch die Auswertung der rev-ish-Befunde bestätigt werden. Dennoch gab es einige Unterschiede.

Zusätzliche Veränderungen in der Auswertung der rev-ish-Daten: Bei dem Zugewinn auf 18p und dem Verlust auf 16p handelt es sich um Veränderungen mit Anteilswerten, die sehr nah an der festgesetzten Schwelle liegen (beide $22 \%$ ). Da auch von den Experten als erwähnenswert eingestufte Veränderungen wie der Verlust an $4 \mathrm{p}$ und $17 \mathrm{p}$ ebenfalls Anteilswerte von $22 \%$ besitzen, werden die beiden als zusätzliche Veränderungen in die weitere Auswertung aufgenommen.

Zusätzliche Veränderungen in der Auswertung der Experteneinschätzung: Die beiden zusätzlich beschriebenen Zugewinne an 17q und 19q können anhand der extrahierten rev-ishDaten nicht nachvollzogen werden: 17q erreicht nur in einem kleinen Bereich 15,7\% und 19q zeigt einen Zugewinn von durchgängig unter $10 \%$. Die beiden Veränderungen werden nicht in die weitere Auswertung übernommen. Der zusätzlich an 1p beschriebene Verlust erreicht in größeren Bereichen Anteilswerte von 19,8\% und dies in einem Chromosomenbereich, der 
bei Berücksichtigung der Standardreferenzintervalle eher unterschätzt wird (siehe Kapitel 4.1.4 des Diskussionsteils, S. 84, und vergl. Kapitel 4.2.2, S. 91). Der Verlust an 1p wird daher als zusätzliche Veränderung aufgenommen.

Fünf Amplifikationen fanden sich in den Publikationen, von denen zwei durch die extrahierten rev-ish-Daten bestätigt werden konnten. Es handelt sich um die auf Chromosomenarm 3q und 8q lokalisierten Amplifikationen. Von den drei übrigen Amplifikationen waren die auf $5 \mathrm{p}$ und $12 \mathrm{p}$ gelegenen in der Auswertung sichtbar, allerdings mit unterschwelligen Anteilswerten von 6,6 und 5\%. Die für 1q beschriebene Amplifikation konnte mit den vorliegenden Daten nicht nachvollzogen werden.

Im Weiteren soll als Grundlage für die Beurteilung des Veränderungsmusters das durch die Auswertung der extrahierten CGH-Daten gewonnene dienen, und zwar für Zugewinne, Verluste und Amplifikationen. Darüber hinaus wird der Verlust auf $1 \mathrm{p}$ als zusätzliche bedeutsame Veränderung angesehen. Das Muster der Veränderungen beim Plattenepithelkarzinom lautet bei armgenauer Auflösung somit: Zugewinne auf 1q, 3q, 5p, 8q, 12p und 18p; Verluste auf 1p, 3p, 4, 5q, 8p, 13q, 16p und 17p sowie Amplifikationen auf 3q und $8 \mathrm{p}$.

\subsubsection{Primärtumoren des Adenokarzinoms}

13 Publikationen mit insgesamt 364 untersuchten Fällen wurden in die Auswertung eingeschlossen. Aus zehn dieser Publikationen, die zusammen 347 Fälle enthielten, konnte eine Experteneinschätzung in Form der „erwähnenswerten Veränderungen“ sowie die mittlere Anzahl der Veränderungen pro Fall entnommen werden. Zusätzlich war es möglich, für 95 Fälle detaillierte CGH-Befunde in rev-ish-Schreibweise zu extrahieren.

\section{Experteneinschätzung: Erwähnenswerte Veränderungen}

Für die folgenden Chromosomen oder Chromosomenarme wurde in mindestens einem Drittel der ausgewerteten Publikationen eine „erwähnenswerte Veränderung“ beschrieben: Zugewinne auf 1q, 5p, 7p, 8q, 16p, 17q, 19q und 20q; Verluste auf 3p, 4q, 5q, 8p, 9p und 13q. Amplifikationen, die in mindestens einem Drittel der Publikationen in mehr als nur einem Fall beobachtet worden waren, lagen auf den Chromosomenarmen 3q, 5p, 8q, 12q und 20q.

\section{Extrahierte rev-ish-Befunde}

Abbildung 3.8 zeigt im Summenidiogramm Verluste, Zugewinne und Amplifikationen der 95 Fälle, von denen detaillierte CGH-Befunde in rev-ish-Schreibweise erhältlich waren. Genaue Angaben zu den eingeschlossenen Fällen sind in Tabelle A.5 des Anhangs zu finden. 

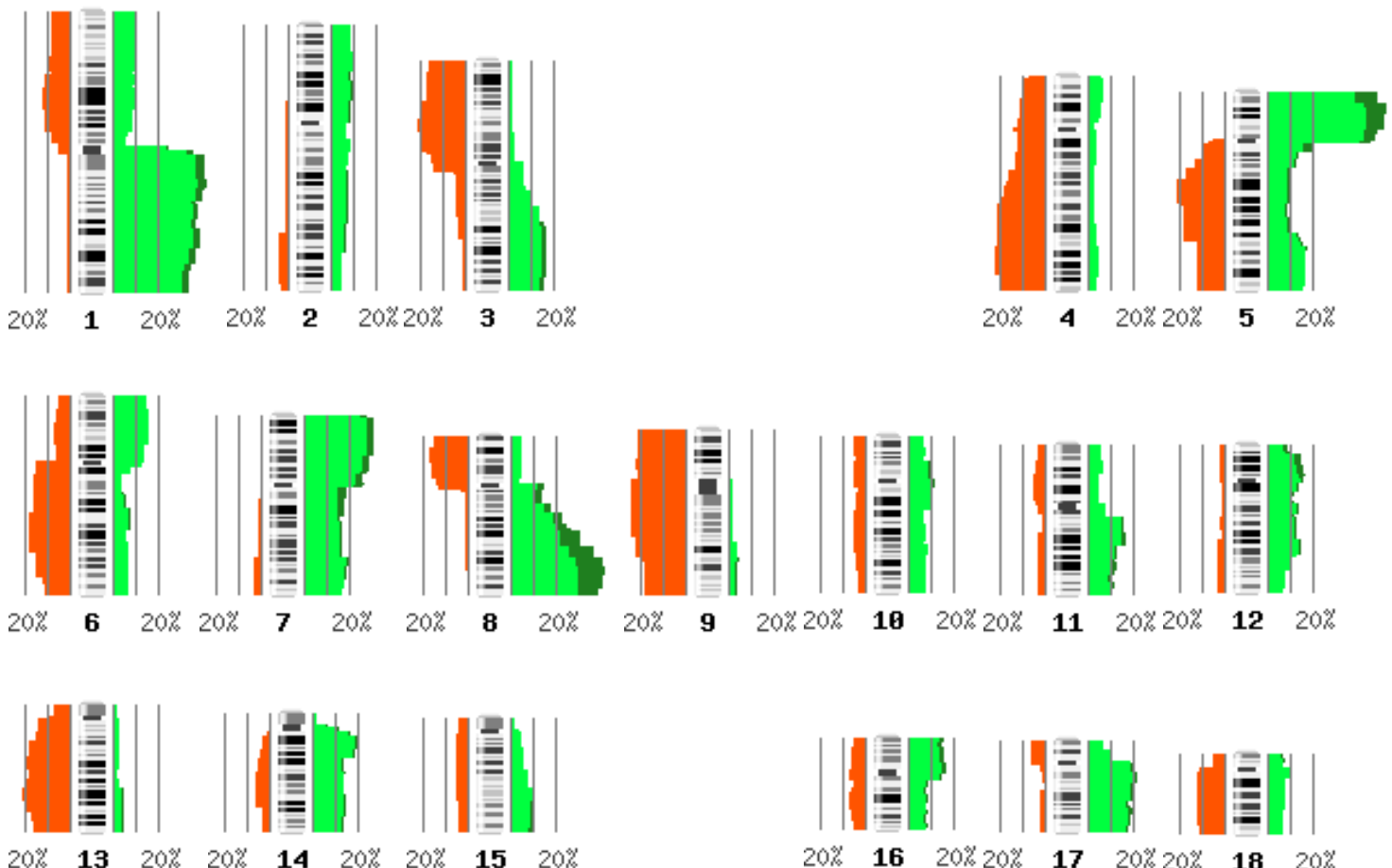

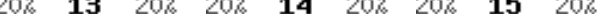
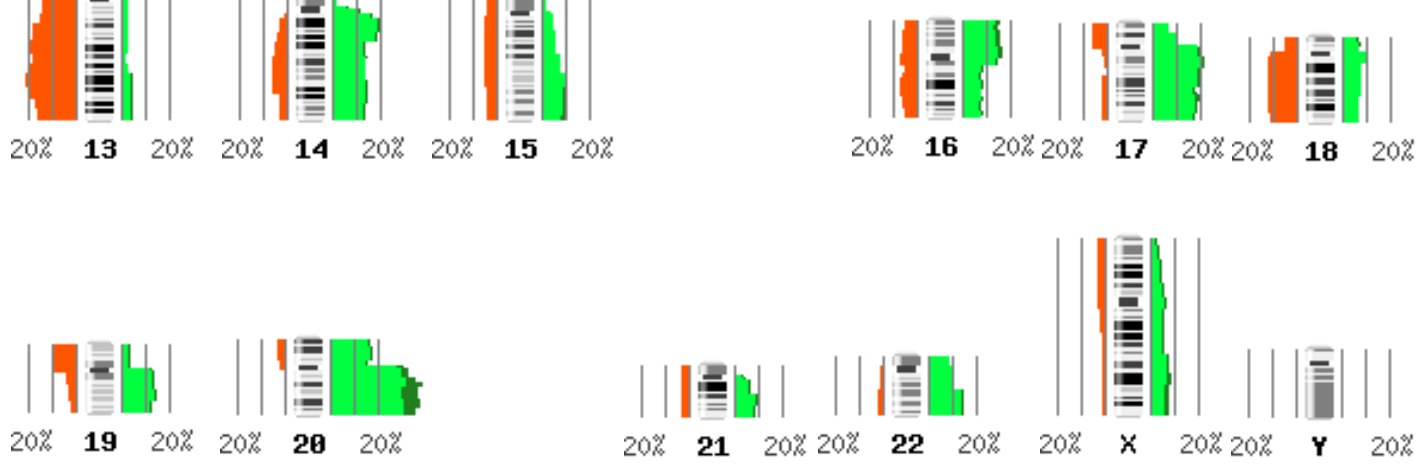

Abbildung 3.8: CGH-Summenidiogramm von 95 Primärtumoren des Adenokarzinoms. Verluste erscheinen rot, Zugewinne grün und Amplifikationen dunkelgrün.

Ganze Chromosomen, Chromosomenarme oder -abschnitte, bei denen in wenigstens $20 \%$ der Fälle ein Verlust oder ein Zugewinn gefunden wurde, sind in Tabelle 3.9 als häufige Veränderungen aufgeführt. Zeichnete sich im Summenidiogramm ein Bereich maximaler Häufigkeit ab, so ist dieser bandengenau angegeben.

Amplifikationen wurden erfasst, wenn der entsprechende Chromosomenabschnitt in mindestens $10 \%$ der untersuchten Fälle als amplifiziert zu bewerten war. Der Median der Anzahl chromosomaler Veränderungen pro Fall beträgt 6,0 $(\min =0, \max =28)$.

\section{Zusammenschau}

Bei den Zugewinnen und Verlusten wurden die „erwähnenswerten Veränderungen“ der Experten weitgehend durch die rev-ish-Befunde bestätigt. Dennoch gab es Unterschiede. 
Tabelle 3.9: Häufige Veränderungen von 95 Primärtumoren des Adenokarzinoms.

\begin{tabular}{llcc} 
Veränderung & Lokalisation & Häufungsbereich & maximaler Anteilswert [\%] \\
& $5 \mathrm{p}$ & 53 \\
& $1 \mathrm{q}$ & 42 \\
Zugewinne & $8 \mathrm{q} 21 \mathrm{q}$ ter & 8q22.3qter & 42 \\
& $20 \mathrm{q}$ & 39 \\
& $7 \mathrm{p}$ & 31 \\
& $17 \mathrm{q} 11 \mathrm{q} 22$ & 21 \\
& $14 \mathrm{q} 12 \mathrm{q} 13$ & 20 \\
\hline \multirow{4}{*}{ Verluste } & $9 \mathrm{q} 11 \mathrm{q} 31$ & 24 \\
& $4 \mathrm{q} 25 \mathrm{q} t e r$ & 22 \\
& $9 \mathrm{p}$ & 22 \\
& $3 \mathrm{p} 12.3 \mathrm{p} 22.1$ & 21 \\
& $5 \mathrm{q} 14.3 \mathrm{q} 21.2$ & 21 \\
Amplifikationen & $13 \mathrm{q} 14.3 \mathrm{q} 32.2$ & 21 \\
\hline & $5 \mathrm{q} 22.3 \mathrm{q} 24.2$ & 13 \\
& $5 \mathrm{p} 15$ & 11 \\
\hline
\end{tabular}

Zusätzliche Veränderungen in der Auswertung der rev-ish-Daten: Ein Verlust auf Chromosomenarm 9p zeigte sich mit einem Anteilswert von $24 \%$ und wird als zusätzliche Veränderung eingestuft. Im schmalen Bereich der Banden 14q12q13 trat ein grenzwertiger Zugewinn von 20,0\% Anteilswert auf. Aufgrund der im Diskussionsteil angestellten Überlegungen zur Beurteilung von CGH-Daten mit Hilfe von Standardreferenzintervallen, wird diese Veränderung in die weitere Auswertung aufgenommen.

Zusätzliche Veränderungen in der Auswertung der Experteneinschätzungen: Die beiden zusätzlich beschriebenen Zugewinne auf 16p und 19q sowie der Verlust auf $8 p$ werden durch die extrahierten rev-ish-Daten nicht bestätigt: 16p zeigt einen Zugewinn von 16,8\%, 19q erreicht 14,8\%. Die Veränderungen werden nicht in die weitere Auswertung übernommen. 8p zeigt einen Verlust von 17,9\% und wird unter Berücksichtigung des Standardreferenzintervalls in die Auswertung aufgenommen.

Fünf Amplifikationen fanden sich in den Publikationen, die auf Chromosomenarm 5p und 8q gelegenen konnten durch die rev-ish-Daten bestätigt werden. Die übrigen drei Amplifikationen waren sichtbar, allerdings mit unterschwelligen Anteilswerten: $3 \mathrm{q}$ mit $2,1 \%, 12 \mathrm{q}$ mit $1,1 \%$ und $20 \mathrm{q}$ mit $7,4 \%$.

Als Grundlage für die weitere Beurteilung des Veränderungsmusters soll das durch die Auswertung der extrahierten rev-ish-Daten gewonnene dienen, und zwar für Zugewinne, Verluste und Amplifikationen. Zusätzlich wird der Verlust auf Chromosomenarm 8p in die 
weitere Auswertung aufgenommen. Das Muster der Veränderungen beim Adenokarzinom lautet bei armgenauer Auflösung somit: Zugewinne auf 1q, 5p, 7p, 8q, 14q, 17q und 20q; Verluste auf 3p, 4q, 5q, 8p, 9 und 13q sowie Amplifikationen auf 5p und 8q.

\subsection{Vergleich von Primärtumoren und Hirnmetastasen}

Nun werden Gemeinsamkeiten und Unterschiede zwischen Hirnmetastasen und Primärtumoren beurteilt. Zuerst geschieht dies qualitativ anhand der häufigen Veränderungen. Damit wird der Frage nachgegangen, ob ein Experte das Muster des Primärtumors auch in der Hirnmetastase erkennen könnte und welche Unterschiede er sähe. Dem schließt sich eine quantitative statistische Auswertung an, die auf Grundlage der rev-ish-Befunde der untersuchten Hirnmetastasen und der aus den Publikationen und Datenbanken extrahierten rev-ish-Befunde der Primärtumoren durchgeführt wurde.

\subsubsection{Primärtumoren und Hirnmetastasen des kleinzelligen Karzinoms}

\section{Häufige Veränderungen}

Als Grundlage für das angenommene Muster der Primärtumoren diente die Auswertung der extrahierten rev-ish-Daten (siehe Kapitel 3.4.2, S. 57), wodurch die Anteilswerte bekannt sind. Die Veränderungen der Primärtumoren und der Hirnmetastasen werden in Tabelle 3.10 unter Angabe ihrer Anteilswerte einander in armgenauer Auflösung gegenübergestellt.

Die meisten der Zugewinne und Verluste fanden sich sowohl bei den Primärtumoren als auch bei den Hirnmetastasen. Dies gilt insbesondere für die Veränderungen mit höheren Anteilswerten. Eine Ausnahme stellt der Zugewinn auf Chromosom 19 dar: Mit einem Anteilswert von $78 \%$ ist dies der häufigste Zugewinn bei den Primärtumoren, bei den Hirnmetastasen hingegen zählt Chromosom 19 nicht zu den häufig veränderten.

Unterschiede fanden sich in der Gruppe der Hirnmetastasen mit einem zusätzlichen Zugewinn auf Chromosom 6 und dem Verlust auf Chromosomenarm 22q. Bei den Primärtumoren waren neben Chromosom 19 auch auf 9q und 20 zusätzliche Zugewinne zu erkennen. Zusätzliche Verluste fanden sich auf Chromosom 2 und 9 sowie dem Chromosomenarm $11 \mathrm{p}$.

Häufige Amplifikationen waren nicht in das Primärtumormuster aufgenommen worden und werden nicht verglichen.

\section{Statistische Auswertung}

Das Differenzhistogramm in Abbildung 3.9 zeigt eine Überlagerung des Summenidiogrammes der untersuchten 22 Hirnmetastasen mit dem der 71 extrahierten rev-ish-Befunde der Primärtumoren. Die Chromosomenabschnitte, die bei der statistischen Auswertung durch signifikante Unterschiede ihrer Häufigkeiten aufgefallenen waren, sind markiert. Dabei wurden nur Zugewinne und Verluste betrachtet, keine Amplifikationen. Detaillierte 
Tabelle 3.10: Häufige Veränderungen von Primärtumoren und Hirnmetastasen des kleinzelligen Karzinoms. Gemeinsame Veränderungen sind farbig hinterlegt.

\begin{tabular}{|c|c|c|c|c|}
\hline Veränderung & Primärtumoren & Anteilswert [\%] & Hirnmetastasen & Anteilswert [\%] \\
\hline \multirow{12}{*}{ Zugewinne } & 19 & 78 & $3 q$ & 73 \\
\hline & $3 q$ & 51 & $5 \mathrm{p}$ & 59 \\
\hline & $5 \mathrm{p}$ & 45 & $8 q$ & 50 \\
\hline & $17 q$ & 39 & 18 & 46 \\
\hline & $20 q$ & 38 & $1 q$ & 41 \\
\hline & $1 \mathrm{p}$ & 35 & $17 q$ & 41 \\
\hline & $8 q$ & 34 & $6 p$ & 36 \\
\hline & $14 \mathrm{q}$ & 27 & $1 \mathrm{p}$ & 27 \\
\hline & 18 & 25 & $14 q$ & 27 \\
\hline & $1 q$ & 24 & $6 q$ & 23 \\
\hline & $20 \mathrm{p}$ & 24 & & \\
\hline & $9 q$ & 23 & & \\
\hline \multirow{17}{*}{ Verluste } & $3 p$ & 94 & $3 p$ & 77 \\
\hline & $13 q$ & 82 & $13 q$ & 68 \\
\hline & $4 q$ & 75 & $5 q$ & 59 \\
\hline & $5 q$ & 62 & $10 \mathrm{q}$ & 50 \\
\hline & $10 \mathrm{q}$ & 58 & $15 q$ & 50 \\
\hline & $4 \mathrm{p}$ & 55 & $17 \mathrm{p}$ & 50 \\
\hline & $17 p$ & 45 & $10 \mathrm{p}$ & 46 \\
\hline & $2 q$ & 35 & 4 & 41 \\
\hline & $10 \mathrm{p}$ & 35 & $8 p$ & 32 \\
\hline & $15 q$ & 34 & $11 q$ & 23 \\
\hline & $11 p$ & 31 & $16 \mathrm{q}$ & 23 \\
\hline & $9 q$ & 25 & $22 q$ & 23 \\
\hline & $11 q$ & 25 & & \\
\hline & $8 \mathrm{p}$ & 24 & & \\
\hline & $2 \mathrm{p}$ & 23 & & \\
\hline & $16 q$ & 23 & & \\
\hline & $9 \mathrm{p}$ & 21 & & \\
\hline \multirow{3}{*}{ Amplifikationen } & & & $8 q$ & 23 \\
\hline & & & $5 \mathrm{p}$ & 18 \\
\hline & & & $1 q$ & 14 \\
\hline
\end{tabular}


Angaben zu den Ergebnissen der statistischen Testung finden sich in Tabelle 3.11 und Tabelle A.6 des Anhangs.

Der Vergleich der beiden Gruppen hinsichtlich der Anzahl an Veränderungen pro Fall ergab einen statistisch signifikanten Unterschied: Die zu erwartende Anzahl an Veränderungen pro Fall ist in der Gruppe der Hirnmetastasen geringer als in der Gruppe der Primärtumoren $(p<0,01)$.
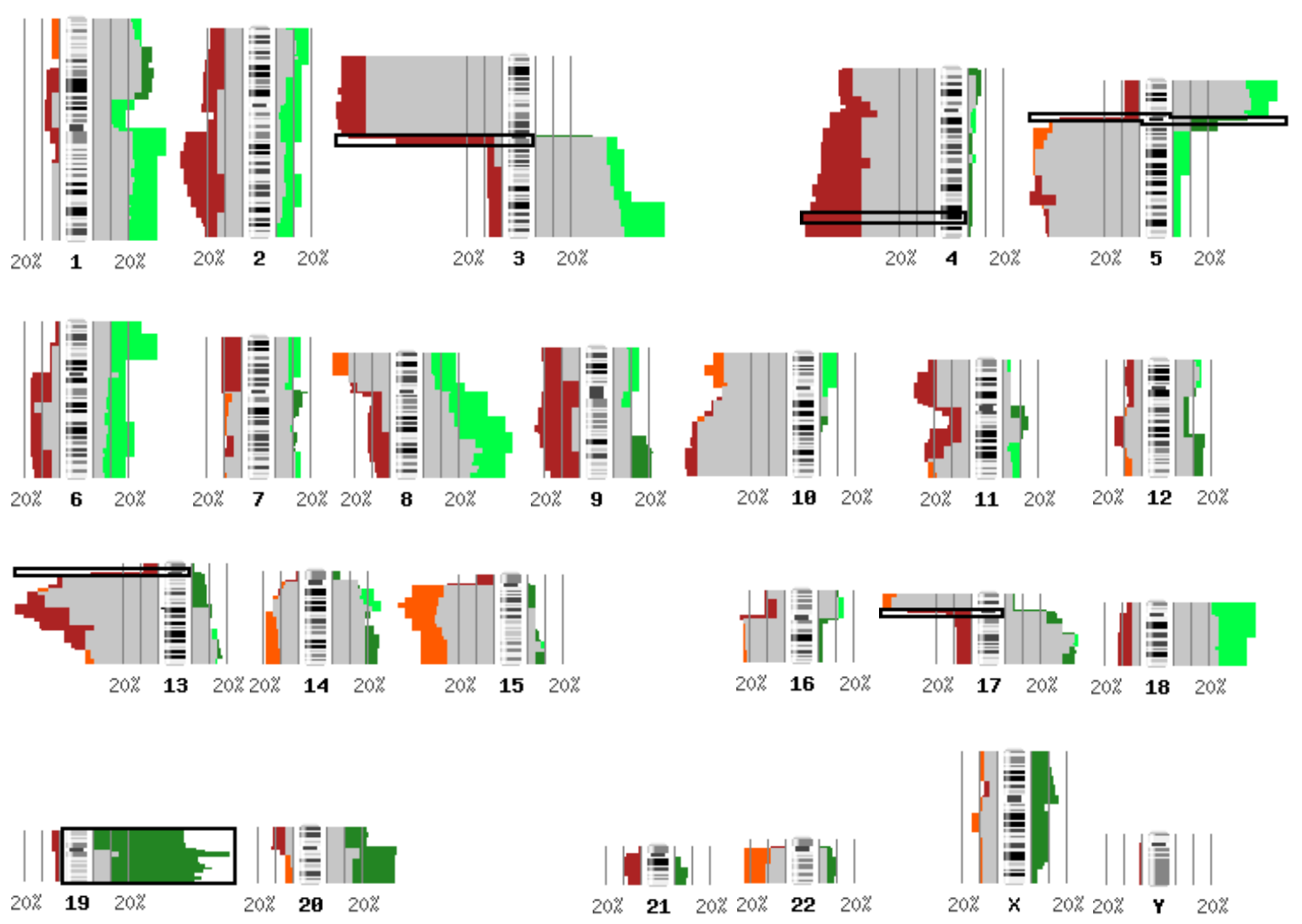

Abbildung 3.9: Differenzhistogramm von Primärtumoren und Hirnmetastasen des kleinzelligen Karzinoms. Gemeinsame Veränderungen erscheinen grau, zusätzliche Veränderungen der Hirnmetastasen erscheinen hellrot/-grün, zusätzliche Veränderungen der Primärtumoren erscheinen dunkelrot/-grün. 
Tabelle 3.11: Signifikant häufigere Veränderungen in Primärtumoren/Hirnmetastasen beim kleinzelligen Karzinom

\begin{tabular}{|c|c|c|c|c|}
\hline Veränderung & Primärtumoren & adjustierter $\mathbf{p}$-Wert & Hirnmetastasen & adjustierter $\mathbf{p}$-Wert \\
\hline \multirow{2}{*}{ Zugewinne } & $5 q 11$ & $<0,01$ & & \\
\hline & 19 & $<0,01$ & & \\
\hline \multirow{5}{*}{ Verluste } & $3 q 11$ & $<0,01$ & & \\
\hline & $4 q 32 q 33$ & 0,03 & & \\
\hline & $5 \mathrm{p} 11$ & $<0,01$ & & \\
\hline & $13 \mathrm{p} 11$ & $<0,01$ & & \\
\hline & $17 q 11$ & $<0,01$ & & \\
\hline
\end{tabular}

\subsubsection{Primärtumoren und Hirnmetastasen des Plattenepithelkarzinoms}

\section{Häufige Veränderungen}

Die Grundlage für das angenommene Muster der Primärtumoren bilden weitgehend die extrahierten rev-ish-Daten, zusätzlich wurde der Verlust auf Chromosomenarm 1p hinzugefügt (siehe Kapitel 3.4.3, S. 60). Durch die Auswertung der rev-ish-Befunde sind die Anteilswerte bekannt. Die Veränderungen der Primärtumoren und der Hirnmetastasen werden daher in Tabelle 3.12 einander unter Angabe dieser Anteilswerte in armgenauer Auflösung gegenübergestellt.

Außer einigen sehr nah an der verwendeten Schwelle liegenden Veränderungen finden sich alle häufigen Zugewinne und Verluste der Primärtumoren auch bei den Hirnmetastasen. An Unterschieden fallen etliche zusätzliche Veränderungen bei den Hirnmetastasen auf, zum Teil auch mit höheren Anteilswerten: ein zusätzlicher Zugewinn auf Chromosom 7 in $53 \%$ der Fälle, darüber hinaus die Zugewinne auf 6p, 2q, 17q, 19q, 10p, 11q; ein zusätzlicher Verlust auf 18q in $56 \%$ der Fälle sowie Verluste auf 6q, 9 und 11q. Bei den Primärtumoren finden sich ein Zugewinn auf $18 \mathrm{p}$ und Verluste auf 1p, 16p und 17p als zusätzliche, aber schwellennahe Veränderungen mit Anteilswerten von 20 und $22 \%$.

Amplifikationen fanden sich sowohl bei den Hirnmetastasen als auch bei den Primärtumoren. Die Amplifikation auf 3q lag in beiden Gruppen vor.

\section{Statistische Auswertung}

Das Differenzhistogramm in Abbildung 3.10 zeigt eine Überlagerung des Summenidiogrammes der untersuchten 32 Hirnmetastasen mit dem der 121 extrahierten rev-ish-Befunde von Primärtumoren. Die Chromosomenabschnitte, die bei der statistischen Auswertung durch signifikante Unterschiede ihrer Häufigkeiten aufgefallenen waren, sind markiert. Es wurden nur Zugewinne und Verluste betrachtet. Detaillierte Angaben zu den Ergebnissen 
Tabelle 3.12: Häufige Veränderungen von Primärtumoren und Hirnmetastasen des Plattenepithelkarzinoms. Gemeinsame Veränderungen sind farbig hinterlegt.

\begin{tabular}{|c|c|c|c|c|}
\hline Veränderung & Primärtumoren & Anteilswert [\%] & Hirnmetastasen & Anteilswert [\%] \\
\hline \multirow{12}{*}{ Zugewinne } & $3 q$ & 79 & $3 q$ & 66 \\
\hline & $5 p$ & 54 & $5 p$ & 56 \\
\hline & $8 q$ & 36 & 7 & 53 \\
\hline & $12 p$ & 25 & $1 q$ & 50 \\
\hline & $1 q$ & 24 & $6 \mathrm{p}^{2}$ & 38 \\
\hline & \multirow{7}{*}{$18 \mathrm{p}$} & \multirow[t]{7}{*}{22} & $8 \mathrm{q}$ & 38 \\
\hline & & & $2 q$ & 34 \\
\hline & & & $12 p$ & 34 \\
\hline & & & $17 q$ & 31 \\
\hline & & & $19 q$ & 31 \\
\hline & & & $10 \mathrm{p}$ & 22 \\
\hline & & & $11 q$ & 22 \\
\hline \multirow{11}{*}{ Verluste } & $3 p$ & 33 & $8 p$ & 59 \\
\hline & $5 q$ & 33 & $13 q$ & 56 \\
\hline & $4 q$ & 29 & $18 \mathrm{q}$ & 56 \\
\hline & $8 \mathrm{p}$ & 24 & $5 q$ & 56 \\
\hline & $13 q$ & 24 & $3 p$ & 56 \\
\hline & $4 p$ & 22 & $4 q$ & 50 \\
\hline & $16 \mathrm{p}$ & 22 & $4 \mathrm{p}$ & 43 \\
\hline & $17 \mathrm{p}$ & 22 & $9 \mathrm{p}$ & 41 \\
\hline & \multirow[t]{3}{*}{$1 \mathrm{p}$} & \multirow[t]{3}{*}{20} & $6 q$ & 31 \\
\hline & & & $11 q$ & 31 \\
\hline & & & $9 q$ & 22 \\
\hline \multirow{2}{*}{ Amplifikationen } & $3 q$ & \multirow{2}{*}{$\begin{array}{l}28 \\
11\end{array}$} & $19 q$ & 22 \\
\hline & $8 q$ & & $3 q$ & 13 \\
\hline
\end{tabular}


der statistischen Testung finden sich in Tabelle 3.13 und Tabelle A.7 des Anhangs. Der Vergleich der beiden Gruppen hinsichtlich der Anzahl chromosomaler Veränderungen pro Fall ergab keinen statistisch signifikanten Unterschied.
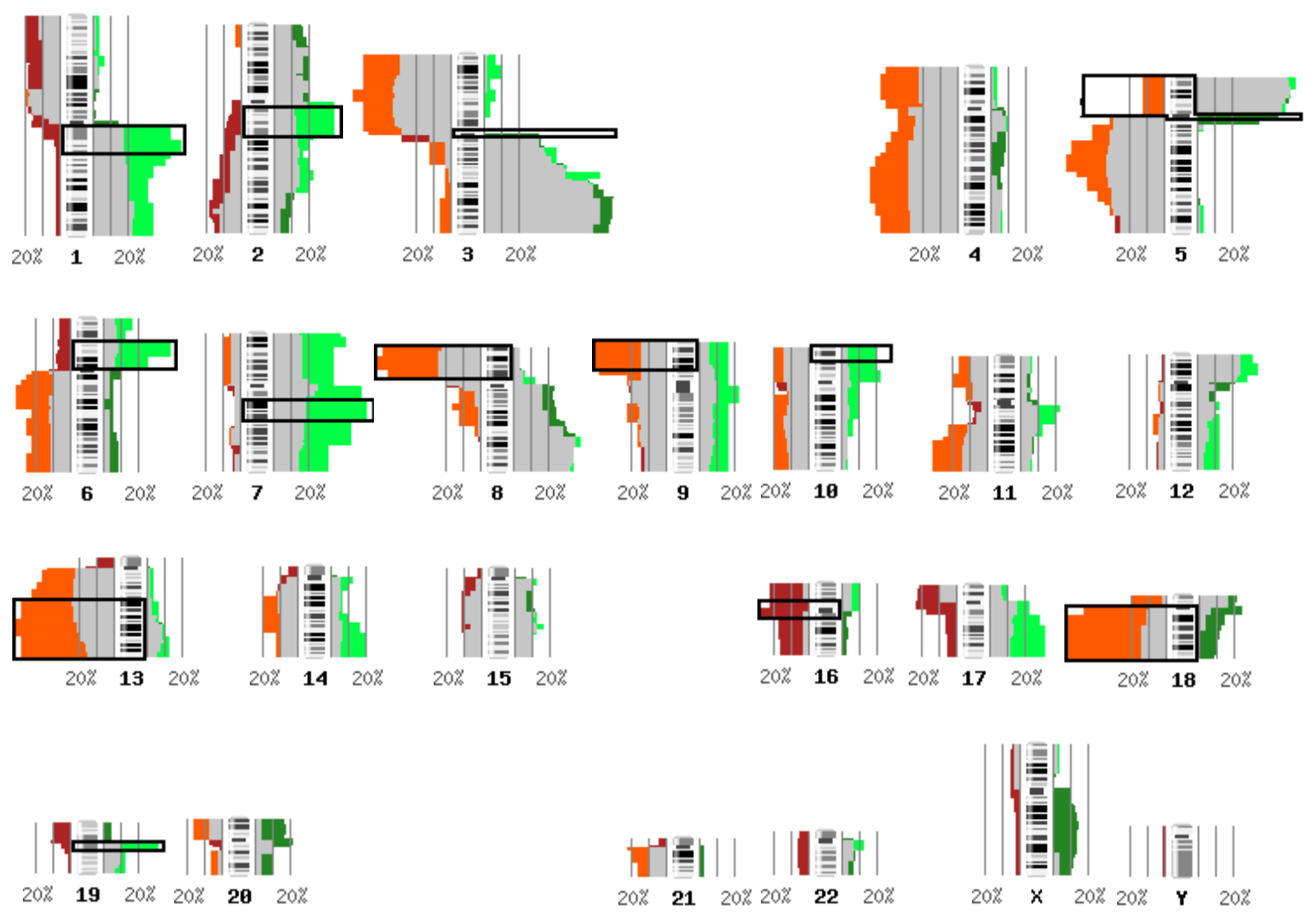

\begin{abstract}
Abbildung 3.10: Differenzhistogramm von Primärtumoren und Hirnmetastasen des Plattenepithelkarzinoms. Gemeinsame Veränderungen erscheinen grau, zusätzliche Veränderungen der Hirnmetastasen erscheinen hellrot/-grün, zusätzliche Veränderungen der Primärtumoren erscheinen dunkelrot/-grün.
\end{abstract}


Tabelle 3.13: Signifikant häufigere Veränderungen in Primärtumoren/Hirnmetastasen beim Plattenepithelkarzinom

\begin{tabular}{llclc} 
Veränderung & Primärtumoren & adjustierter $\mathbf{p}$-Wert & Hirnmetastasen & adjustierter $\mathbf{p}$-Wert \\
& $3 \mathrm{p} 11$ & $<0,01$ & $1 \mathrm{q} 12 \mathrm{q} 21$ & 0,02 \\
& $5 \mathrm{q} 11$ & $<0,01$ & $2 \mathrm{q} 12 \mathrm{q} 14$ & 0,04 \\
Zugewinne & & $6 \mathrm{p} 12 \mathrm{p} 21$ & 0,04 \\
& & $7 \mathrm{q} 21$ & $<0,01$ \\
& & $10 \mathrm{p} 13 \mathrm{pter}$ & 0,03 \\
& & $19 \mathrm{q} 12$ & 0,03 \\
\hline \multirow{2}{*}{ Verluste } & \multirow{2}{*}{0,02} & $5 \mathrm{p} 12 \mathrm{pter}$ & 0,03 \\
& & 8p12pter & 0,03 \\
& & $9 \mathrm{p} 13 \mathrm{pter}$ & 0,04 \\
& & $13 \mathrm{q} 21 \mathrm{qter}$ & 0,03 \\
& & $18 \mathrm{q}$ & $<0,01$ \\
\hline${ }^{a}$ Der maximale p-Wert der jeweiligen Region ist angegeben. \\
\hline
\end{tabular}

\subsubsection{Primärtumoren und Hirnmetastasen des Adenokarzinoms}

\section{Häufige Veränderungen}

Die Grundlage für das angenommene Muster der Primärtumoren bilden weitgehend die extrahierten rev-ish-Daten, zusätzlich wurde der Verlust auf Chromosomenarm 8p aufgenommen (siehe Kapitel 3.4.4, S. 63). Durch die Auswertung der extrahierten rev-ishBefunde sind genaue Anteilswerte bekannt. Die Veränderungen der Primärtumoren und der Hirnmetastasen werden daher in Tabelle 3.14 einander unter Angabe dieser Anteilswerte in armgenauer Aufösung gegenübergestellt.

Die meisten der Zugewinne und Verluste der Primärtumoren lassen sich auch in den Hirnmetastasen finden, doch es gibt Unterschiede. So waren die in den Primärtumoren vorkommenden Zugewinne auf 14q und 20q sowie der Verlust auf 9q in den Hirnmetastasen nicht als häufig zu bewerten. Die Hirnmetastasen wiederum zeigten einige zusätzliche Veränderungen wie Zugewinne auf 6p, 10 und 11q sowie Verluste auf 18q, 6q, 1p, 11p und $4 \mathrm{p}$.

Häufige Amplifikationen sind bei den Hirnmetastasen nicht beschrieben worden und und werden nicht verglichen.

\section{Statistische Auswertung}

Das Differenzhistogramm in Abbildung 3.11 zeigt eine Überlagerung des Summenidiogrammes der untersuchten 16 Hirnmetastasen mit dem der 95 extrahierten rev-ish-Befunde 
Tabelle 3.14: Häufige Veränderungen von Primärtumoren und Hirnmetastasen des Adenokarzinoms. Gemeinsame Veränderungen sind farbig hinterlegt.

\begin{tabular}{l|c|c|c|c} 
Veränderung & Primärtumoren & Anteilswert [\%] & Hirnmetastasen & Anteilswert [\%] \\
\hline \multirow{3}{*}{ Zugewinne } & $5 \mathrm{p}$ & 53 & $1 \mathrm{q}$ & 63 \\
& $1 \mathrm{q}$ & 42 & $7 \mathrm{p}$ & 63 \\
& $8 \mathrm{q}$ & 42 & $5 \mathrm{p}$ & 50 \\
& $20 \mathrm{q}$ & 39 & $8 \mathrm{q}$ & 44 \\
& $7 \mathrm{p}$ & 31 & $6 \mathrm{p}$ & 38 \\
& $17 \mathrm{q}$ & 21 & $10 \mathrm{q}$ & 31 \\
& $14 \mathrm{q}$ & 20 & $11 \mathrm{q}$ & 31 \\
& & & $10 \mathrm{p}$ & 25 \\
& & & $17 \mathrm{q}$ & 25 \\
\hline \multirow{3}{*}{ Verluste } & $9 \mathrm{q}$ & 24 & $5 \mathrm{q}$ & 50 \\
& $4 \mathrm{q}$ & 22 & $18 \mathrm{q}$ & 44 \\
& $9 \mathrm{p}$ & 22 & $3 \mathrm{p}$ & 38 \\
& $3 \mathrm{p}$ & 21 & $6 \mathrm{q}$ & 38 \\
& $5 \mathrm{q}$ & 21 & $9 \mathrm{p}$ & 38 \\
& $13 \mathrm{q}$ & 21 & $1 \mathrm{p}$ & 31 \\
& $8 \mathrm{p}$ & 18 & $4 \mathrm{q}$ & 31 \\
& & & $8 \mathrm{p}$ & 31 \\
\hline \multirow{2}{*}{ Amplifikationen } & & & $11 \mathrm{p}$ & 31 \\
& & & $13 \mathrm{q}$ & 31 \\
\hline & & & $4 \mathrm{p}$ & 25 \\
\hline
\end{tabular}

der Primärtumoren. Die Chromosomenabschnitte, die bei der statistischen Auswertung durch signifikante Unterschiede ihrer Häufigkeiten aufgefallenen waren, sind markiert. Es wurden nur Zugewinne und Verluste betrachtet. Detaillierte Angaben zu den Ergebnissen der statistischen Testung finden sich in Tabelle 3.15 und Tabelle A.8 des Anhangs.

Der Vergleich der beiden Gruppen hinsichtlich der Anzahl chromosomaler Veränderungen pro Fall ergab keinen statistisch signifikanten Unterschied. 

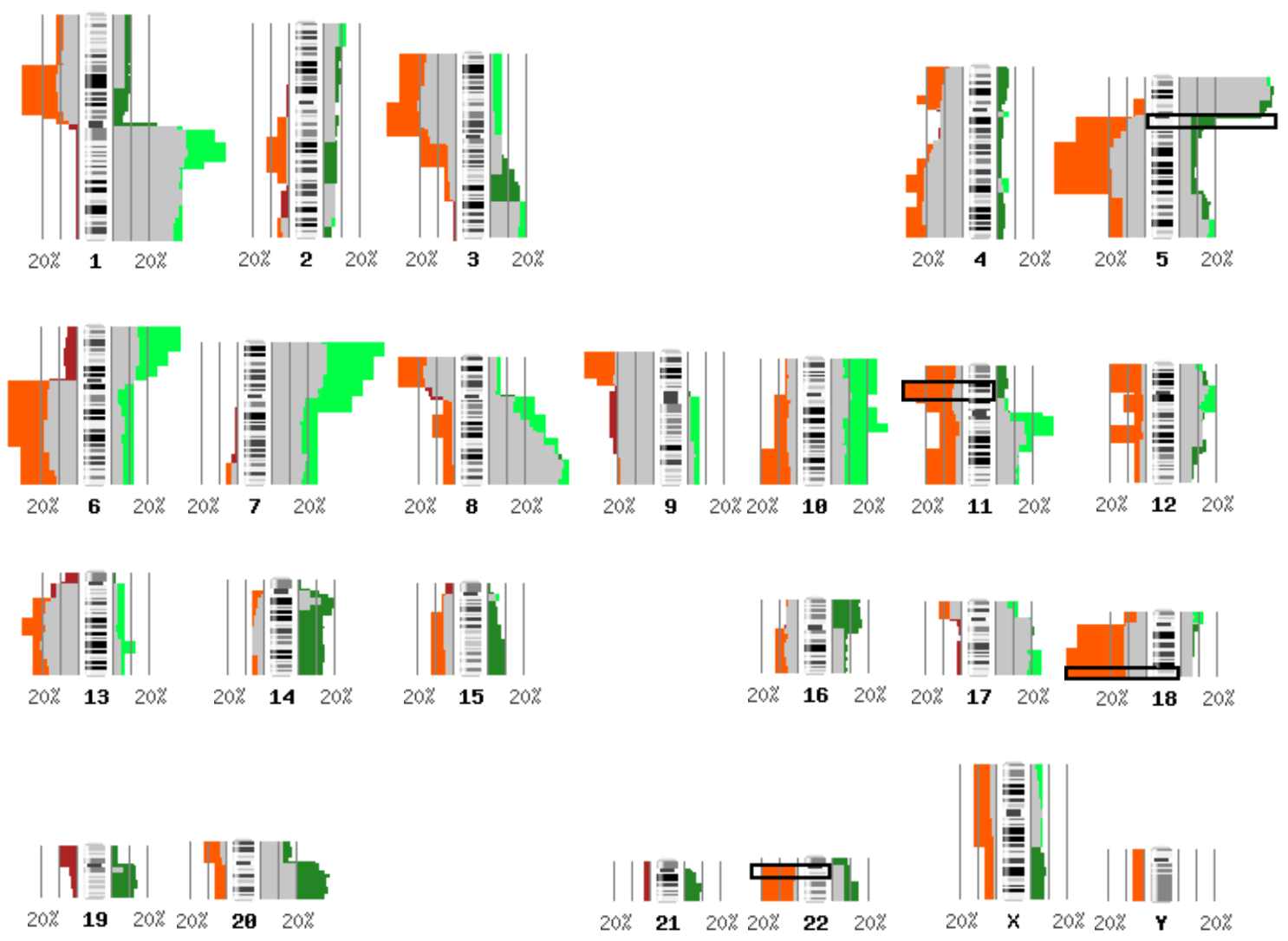

Abbildung 3.11: Differenzhistogramm von Primärtumoren und Hirnmetastasen des Adenokarzinoms. Gemeinsame Veränderungen erscheinen grau, zusätzliche Veränderungen der Hirnmetastasen erscheinen hellrot/-grün, zusätzliche Veränderungen der Primärtumoren erscheinen dunkelrot/-grün.

Tabelle 3.15: Signifikant häufigere Veränderungen in Primärtumoren/Hirnmetastasen beim Adenokarzinom

\begin{tabular}{lllll} 
Veränderung & Primärtumoren & adjustierter $\mathbf{p}$-Wert & Hirnmetastasen & adjustierter $\mathbf{p}$-Wert \\
Zugewinne & $5 \mathrm{q} 11$ & 0,01 & & \\
\hline & & $22 \mathrm{q} 11$ & 0,01 \\
Verluste & & $11 \mathrm{p} 13 \mathrm{p} 14$ & 0,02 \\
& & $18 \mathrm{q} 23$ & 0,03 \\
\hline
\end{tabular}




\subsection{Automatische Klassifizierung von Primärtumoren und Hirnmetastasen}

Nur für die Primärtumoren und Hirnmetastasen des Plattenepithelkarzinoms konnten die Ergebnisse des statistischen Vergleichs als ausreichend sicher beurteilt werden. Hierzu sei auf den Diskussionsteil verwiesen (Kapitel 4.2.2, S.91). Da die entdeckten Unterschiede allerdings die Grundlage für die automatische Klassifizierung bilden, konnte diese auch nur für jenen histologischen Typ durchgeführt werden.

Als metastasenspezifische Veränderungen wurden Zugewinne in den Bereichen 1q12q21, 2q12q14, 7q21 und 10p betrachtet, ebenso die Verluste in den Bereichen 8p, 9p, 13q21q24 und 18q. (Zur Auswahl der Veränderungen siehe Kapitel 4.2.2, S. 91). Diese 8 Merkmale flossen in die Analyse ein. Abbildung 3.12 zeigt das Ergebnis als Dendrogramm und Heat map.

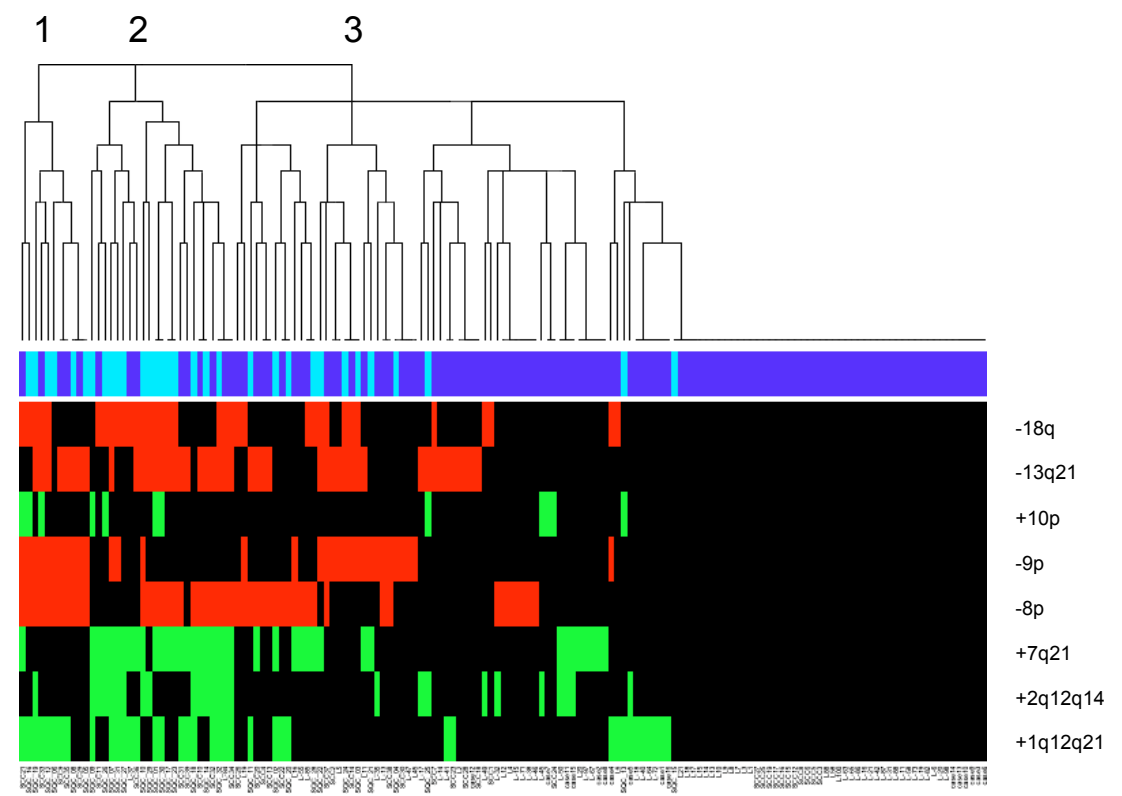

Abbildung 3.12: Clusteranalyse von Primärtumoren und Hirnmetastasen des Plattenepithelkarzinoms $(\mathrm{n}=32+121=153)$, visualisiert als Dendrogramm und Heat map. Hellblaue Spalten repräsentieren Hirnmetastasen, dunkelblaue die Primärtumoren.

Die Cluster 1 und 2, welche deutlich sichtbar etliche Hirnmetastasen beinhalten, repräsentieren 22,2\% der analysierten Fälle, beinhalten allerdings 62,5\% aller Hirnmetastasen. Cluster 3 repräsentiert 77,8\% der analysierten Fälle und beinhaltet die restlichen 37,5\% der Hirnmetastasen. Die Klassifikation konnte mit einer Sensitivität von 62,5\% und einer Spezifität von $88,4 \%$ durchgeführt werden. Der positive Vorhersagewert beträgt $58,8 \%$. 


\subsection{Negativkontrollen und Standardreferenzintervalle}

Zur Qualitätssicherung wurde auf 8 CGHs zurückgegriffen, bei denen gegen Normalgewebe vergleichend hybridisiert worden war. Mit den Ergebnissen dieser 8 Negativkontrollen wurden die Standardreferenzintervalle berechnet, die in Abbildung 3.13 dargestellt sind. Auf die Standardreferenzintervalle wird im Diskussionsteil näher eingegangen (siehe Kapitel 4.1.4, S. 84).

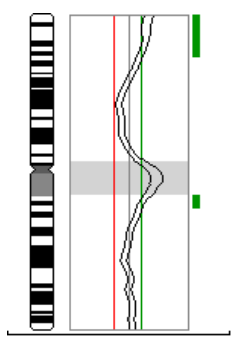

1

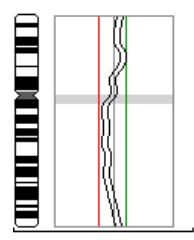

6

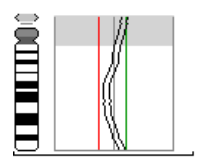

13
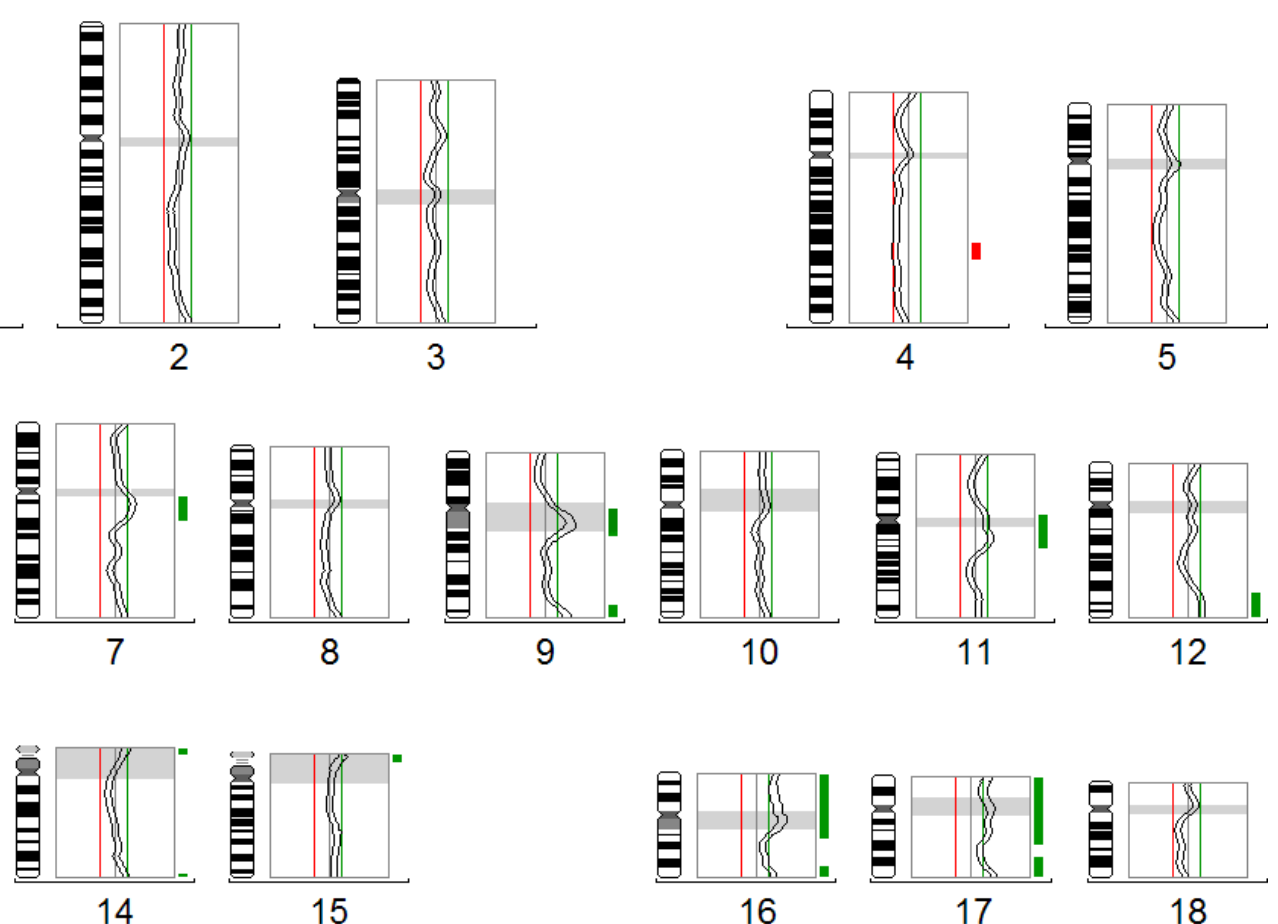

16
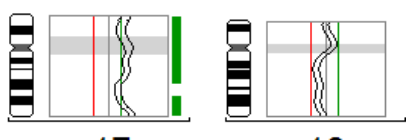

18

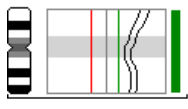

19
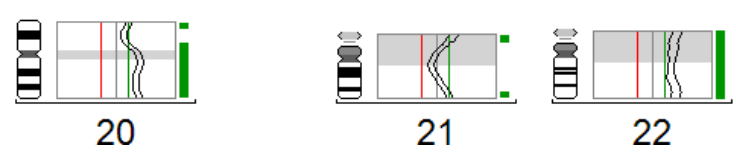

Abbildung 3.13: Standardreferenzintervalle für das in der vorliegenden Studie verwendete CGH-Protokoll. Die Schwellenwerte liegen bei $1 \pm 0,2$. 


\section{Diskussion}

\subsection{Vorbemerkungen}

\subsubsection{Banden oder Arme?}

"The most common changes were gains of DNA sequences in 3q (43\%), 1q (34\%), $8 q(32 \%), 5 p(30 \%), 7 p(25 \%)$, and 12p (25\%)."

(Björkqvist et al. 1998a, S. 79)

„The most frequently underrepresented arms were $9 q, 3 p, 8 p$, and $17 p . "$

(Pei et al. 2001, S. 282)

"The most abundant genetic changes include DNA losses of chromosome arms $3 p$, $5 q, 10 q, 13 q$, and $17 p$ and DNA gains of $3 q, 5 p, 8 q$, and $17 q . "$

(Ried et al. 1994, S. 1801)

Dies sind drei beispielhafte Zitate aus den Abstracts der in der Metaanalyse verwendeten Publikationen. Es ist deutlich zu erkennen: Die Ergebnisse werden in Form der veränderten Chromosomenarme angegeben.

\section{Eine interessante Frage}

Bei einem Blick in Publikationen aus den 90er Jahren, einer Zeit, in der die Methode der CGH noch recht jung war, finden sich auch Absätze, in denen die Methode an sich und insbesondere deren Genauigkeit diskutiert wird (Bentz et al. 1996; Joos et al. 1995; Kjellman et al. 1996; Levin et al. 1995). Bereits die grundlegende Publikation von Anne und Olli Kallioniemi aus dem Jahr 1992 macht Angaben zur Größe der aufgefundenen Veränderungen: Eine Deletion von 10-20 Mbp konnte detektiert werden, Amplifikationen waren auch bei der viel geringeren Länge von 300kbp erfassbar (Kallioniemi A et al. 1992). Allerdings ist in dieser Arbeit keineswegs von der Genauigkeit der CGH die Rede, wenn dort 10-20 Mbp erwähnt werden. Diese wurde vielmehr von den Kallioniemis bei 3-5 Mbp vermutet, bei Amplifikationen noch höher (Kallioniemi OP et al. 1994). 
Doch die eingangs zitierten Beispiele deuteten bereits an: Schaut man mit diesem Wissen in Ergebnis- und Diskussionsteile, Abstracts und Reviews, so ist sehr oft nur von kompletten Chromosomenarmen die Rede. Auch wenn es in späteren Publikationen nicht länger notwendig war, auf die Grundlagen der Methode einzugehen, so fällt dennoch ein Widerspruch auf: Die Länge einer Chromosomenbande liegt bei etwa $10 \mathrm{Mbp}$ (Lewin 2008). Warum werden mit einer Methode, deren theoretische Genauigkeit unter die Ebene der Chromosomenbanden reicht, oftmals Ergebnisse erzielt, die ganze Arme betreffen?

Drei Antworten auf diese Frage liegen nahe: (i) Die postulierte Genauigkeit der Methode ist nicht gegeben: Anne und Olli Kallioniemi lagen schlicht falsch und es liegt nicht im technisch Möglichen der CGH, bandengenau zu messen. (ii) Die Genauigkeit der Methode ist gut, doch sind immer vollständige Arme betroffen; dies müsste dann an Peter Duesbergs chromosomale Krebstheorie denken lassen (Duesberg und Rasnick 2000; Duesberg et al. 2005). (iii) Eine hohe Genauigkeit ist prinzipiell möglich, doch Messabweichungen und die daraus entstehenden Unsicherheiten verhindern eine entsprechende Auswertung, weshalb vereinfachend auf die armgenaue Auflösung reduziert werden muss.

\section{Eine interessante Antwort}

An dieser Stelle soll nun versucht werden, die oben gestellte Frage zu beantworten:

$\mathrm{Zu}$ (i): Die postulierte Genauigkeit der Methode ist nicht gegeben: falsch. Kallioniemi OP et al. (1994) hatten vermutet, dass die Genauigkeit der CGH bei 3-5 Mbp läge. Versuche zur Genauigkeit bei der Bestimmung von Verlusten hatten zunächst 10-12 Mbp als untere Grenze erbracht (Bentz et al. 1998). Verbesserungen der statistischen Auswertungsmethode hatten dann zur high-resolution-CGH geführt, mit der es möglich war, für Verluste die Grenze von $10 \mathrm{Mbp}$ zu unterschreiten, bis hinab zu $3 \mathrm{Mbp}$ (Kirchhoff et al. 1999, 2000). Weitere Versuche bestätigten die Genauigkeit der high-resolution-CGH von mindestens $6 \mathrm{Mbp}$ und zeigten, dass selbst mit konventionellen Auswertungsmethoden, d.h. mit festen Schwellenwerten, Veränderungen von 1,8 Mbp aufgespürt werden können (Schoumans et al. 2004). Man kann also zusammenfassend sagen: Die Ergebnisse einer CGH bandengenau, also mit etwa $10 \mathrm{Mbp}$ Auflösung anzugeben, ist sehr wohl gerechtfertigt.

$\mathrm{Zu}$ (ii): Es sind immer vollständige Chromosomenarme von den Veränderungen betroffen: Diese Antwort ist selbstverständlich denkbar. Auch mit einer Genauigkeit von $3 \mathrm{Mbp}$ würde man nur komplette Chromosomenarme detektieren, wenn denn immer komplette Arme verändert wären. Doch die mögliche Antwort auf (iii) sorgt dafür, dass dies erst einmal im Ungewissen bleiben muss.

$\mathrm{Zu}$ (iii): Messabweichungen und daraus entstehende Unsicherheiten zwingen zum Gebrauch einer geringeren Auflösung: Die hohe Genauigkeit der high-resolution-CGH ist nicht auf eine grundlegende Verbesserung des CGH-Protokolls zurückzuführen, sondern vielmehr darauf, dass mit quantitativ-statistischen Mitteln die zahlreichen systematischen Abweichungen, die normalerweise entstehen, berichtigt werden. Die Möglichkeit einer Korrektur systematisch auftretender Messabweichungen war mehrfach beschrieben worden (Cher et al. 1996; Kirchhoff et al. 1998; Moore et al. 1997), konnte sich jedoch nicht durch- 
setzen. Da aber das Auftreten von Abweichungen hinreichend bekannt ist (du Manoir et al. 1995b; Kallioniemi OP et al. 1994; Lundsteen et al. 1995), muss nun die folgende Frage gestellt werden: Wie wird mit systematischen Messabweichungen umgegangen, wenn keine quantitativ-statistischen Methoden zur Berichtigung eingesetzt werden? Es ist letztendlich die Frage nach der Vergleichbarkeit der CGH-Daten. Für die vorliegende Studie, die eine Metaanalyse und einen statistischen Vergleich mit Ergebnissen aus etwa 20 verschiedenen Arbeitsgruppen beinhaltet, ist dies eine zentrale Frage. Die Antwort darauf muss die Aussagekraft aller vorliegenden Ergebnisse bestimmen und gegebenenfalls limitieren.

Die nächsten Unterkapitel sind dem Nachdenken über die Genauigkeit und die Unsicherheiten der Methode CGH gewidmet sowie den Möglichkeiten, mit denen entstehende Abweichungen berichtigt werden können.

\subsubsection{Auflösung, Präzision und Richtigkeit}

Kommt die Problematik der kleinsten mit CGH noch detektierbaren Veränderung zur Sprache, so ist von „Auflösungsvermögen“ (Petersen I 1999) oder „resolution“ (Bentz et al. 1998; Kallioniemi OP et al. 1994) zu lesen. Mit dem Begriff der „Auflösung“ ist der kleinste noch mit CGH feststellbare Unterschied gemeint. Allerdings ist es ein anderer Begriff der Auflösung, als er mit der optischen Auflösung von einem Mikroskop her bekannt ist: Gemeint ist hier die Aufösung eines Messverfahrens.

Ein Beispiel soll dies erläutern: Im Ratioprofil der CGH erscheine auf dem q-Arm des Chromosoms 3 ein Ausschlag, der einen Zugewinn andeutete. Notierte man rev ish enh(3q), so läge die Auflösung des verwendeten Verfahrens bei einem Chromosomenarm. Notierte man bei genauerer Betrachtung rev ish enh(3q13.32q2\%.1), so läge die Auflösung bei einer der mehr als 850 sub-sub-Banden der ISCN-Nomenklatur. Ob das Sinn ergäbe und ob das Ergebnis mit der Wirklichkeit übereinstimmte, sei dahingestellt, denn hier liegt eine Verwechslung der Begriffe vor: Die Auflösung wird mit der Genauigkeit des Messverfahrens verwechselt.

Da die CGH als Messverfahren betrachtet werden soll, ist es notwendig, zuvor die in der Messtechnik üblichen Begriffe einzuführen. Danach werden diese Begriffe auf die CGH angewendet.

\section{Begriffsbestimmung}

„Unter Messen versteht man die Gesamtheit der Tätigkeiten zum Zweck der objektiven experimentellen Beschaffung quantitativer Angaben über bestimmte materielle Eigenschaften eines physikalisch existenten Objekts."

(Adunka 2007, Seite 1)

Das physikalisch existente Objekt besitzt für die Messgröße einen tatsächlichen Wert, den sogenannten wahren Wert. Dieser wahre Wert ist dem Objekt eigen, ganz gleich 
ob er bekannt ist oder nicht. So besitzt ein Stein einen wahren Wert für die Messgröße "Masse“, ein Stab besitzt einen wahren Wert für die Messgröße „Länge“. Das Ziel der Messung ist, dass das Messergebnis dem wahren Wert möglichst nahe kommt. Die genauen Begriffsbestimmungen hierzu sind als DIN 1319-1 (1995) normiert.

Um die Güte eines Messverfahrens zu beurteilen, also die Annäherung des Messergebnisses an den wahren Wert, betrachtet man die Genauigkeit des Verfahrens. Dabei sind zwei unterschiedliche Kriterien zu beachten, aus denen sich die Genauigkeit zusammensetzt: die Präzision und die Richtigkeit. Diese Begriffe sind als DIN ISO 5725-1 (1997) normiert. Abbildung 4.1 veranschaulicht beide Begriffe am Beispiel von Zielscheiben.

Die Präzision beschreibt die Streuung der Einzelmessungen - im Beispiel die Treffer und damit, wie dicht diese beieinanderliegen. Dies sagt allerdings nichts darüber aus, wie nahe sie dem wahren Wert - im Beispiel das Zentrum der Zielscheibe - sind. Die Richtigkeit erfasst diesen Aspekt, indem sie beschreibt, wie weit der Mittelwert der Einzelmessungen vom wahren Wert entfernt liegt. Im Beispiel entspricht eine schlechte Richtigkeit der exzentrischen Lage der Treffergruppe. Damit ist aber wiederum nichts über die Streuung der Einzelmessungen gesagt. Damit Genauigkeit erreicht werden kann, müssen sowohl Präzision als auch Richtigkeit gut sein.

Im Beispiel der Zielscheiben ist die Auflösung durch die Breite der roten und weißen Ringe, die letztlich zum Auszählen der Punkte dienen, repräsentiert (Schmidt 1997).

\section{CGH als Messverfahren}

Nun soll die vorgestellte Nomenklatur der Messtechnik auf die Methode der CGH angewendet werden. Zunächst ist die zu messende Größe zu benennen: Die Messgröße ist die Aneuploidie, die Abweichung des Tumorgenoms vom diploiden (2n) Chromosomensatz der

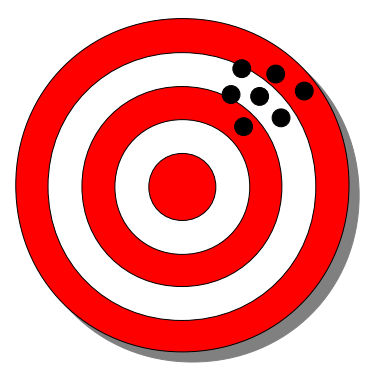

a

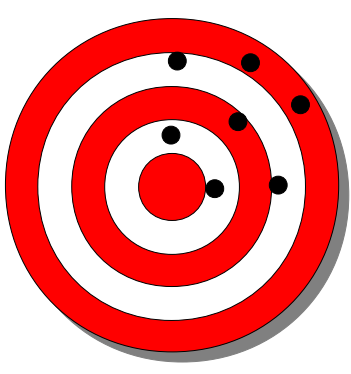

b

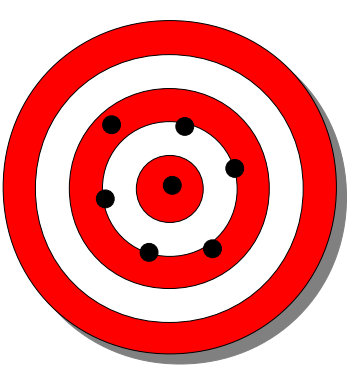

C

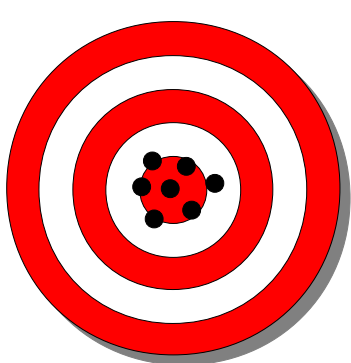

d

Abbildung 4.1: Veranschaulichung von Präzision und Richtigkeit. A: Schlechte Richtigkeit trotz hoher Präzision. B: Schlechte Richtigkeit bei niedriger Präzision. C: Gute Richtigkeit und niedrige Präzision. D: Gute Richtigkeit und hohe Präzision, daher auch hohe Genauigkeit. (Abbildung neu gezeichnet nach Accuracy 2009, Internetquelle ohne Seitenangabe) 
Referenz-DNA. Die wahren Werte, die dem zugrunde liegen, sind physikalisch existent in Form eines Fehlens oder Überzählig-Seins von Chromosomen/-abschnitten. Präzision und Richtigkeit des „Aneuploidie-Messverfahrens" CGH, und damit dessen Genauigkeit, sind eng verknüpft mit den Messabweichungen des Verfahrens. Messabweichungen bei der CGH sind Gegenstand des folgenden Kapitels.

Letztendlich beantwortet die Frage nach der Genauigkeit dann auch die Frage nach der Auflösung der CGH: Wie exakt man die Befunde ablesen darf, ob arm- oder bandengenau, muss sich an der Genauigkeit des Messverfahrens orientieren.

\subsubsection{Messabweichungen}

„Man misst eigentlich immer falsch, man muss nur wissen wieviel.“ Dave Packard ${ }^{1}$

\section{Begriffsbestimmung}

Die Messabweichung ist definiert als die Differenz aus dem wahren Wert und dem Messergebnis (Adunka 2007). Das zugehörige messtechnische Konzept ist in der DIN 1319 (1995-2005) normiert. ${ }^{2}$ Es ergibt sich ein Zusammenhang mit der Genauigkeit: Je geringer die Differenz zwischen wahrem Wert und Messergebnis, je geringer also die Messabweichung ist, desto höher wird auch die Genauigkeit. Allerdings sind bei der Messabweichung zwei unterschiedliche Arten zu beachten: die systematische und die zufällige Messabweichung.

Im vorherigen Kapitel war die Längenmessung eines Stabes als Beispiel genannt worden. Diese Messung sei sowohl mit einem normaltemperierten als auch mit einem auf $100^{\circ} \mathrm{C}$ erhitzten metallischen Längenmaß durchgeführt worden. Aufgrund der temperaturabhängigen Längenausdehnung des Messwerkzeugs ergeben sich zwei unterschiedliche Messergebnisse - bei dem erwärmten liegt eine Messabweichung vor. Diese ist aber nicht weiter problematisch: Die temperaturabhängige Längenausdehnung ist sehr wohl bekannt, sie tritt immer in der gleichen Weise auf und ist berechenbar. Das Messergebnis kann rechnerisch berichtigt werden. Aus einem unberichtigten Messergebnis wird durch diese Berichtigung ein berichtigtes Messergebnis. Eine solche immer gleichförmig auftretende und damit korrigierbare Messabweichung wird systematische Messabweichung genannt. Abbildung 4.2 verdeutlicht dies noch einmal am Beispiel der Zielscheibe.

Neben den systematischen gibt es noch die zufälligen Messabweichungen. Diese sind nicht vorhersehbar und damit nicht durch eine Berichtigung beherrschbar. Zufällige Messabweichungen machen die Messergebnisse unsicher, was mit dem Begriff der Messunsicherheit $\mathrm{zu}$ fassen ist.

1 Zitiert nach Adunka (2007, S. 39).

2 Alle der hier vorgestellten Konzepte und Begriffe sind auch international gebräuchlich, siehe hierzu ISO/IEC Guide 98-3:2008 (2008) und ISO/IEC Guide 99:2007 (2007). 


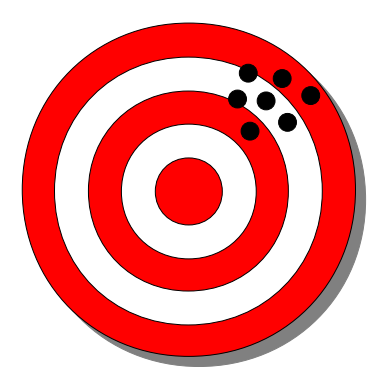

a

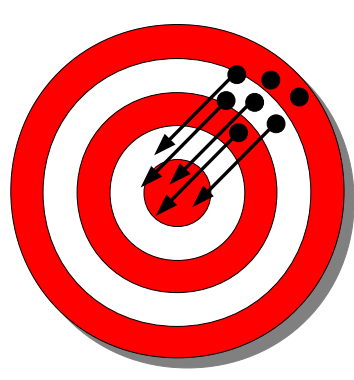

b

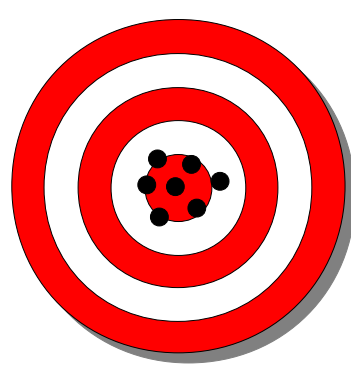

C

Abbildung 4.2: Unrichtiges Ergebnis durch systematische Messabweichung (a), deren Korrektur (b) und das berichtigte Ergebnis (c).

\section{Quellen für Messabweichung bei der CGH}

Unter dem Aspekt der Optimierung und Qualitätssicherung sind viele Schritte der CGH betrachtet worden: die DNA-Isolierung aus Paraffin (Isola et al. 1994; Speicher et al. 1993), Markierung und Hybridisierung (Kallioniemi OP et al. 1994), der Einfluss der Metaphasenpräparate (Karhu et al. 1997), die Bildgewinnung, deren quantitative Auswertung und die Interpretation der Daten (du Manoir et al. 1995a; Lundsteen et al. 1995; Piper et al. 1995). All diese Schritte bergen Quellen für zufällige und systematische Messabweichungen in sich.

Noch einmal soll die Längenmessung als Beispiel betrachtet werden: Wollte man von zwei Stäben ermitteln, welcher der längere und welcher der kürzere ist, so spielte es keine Rolle, ob man mit einem normaltemperierten oder mit einem erhitzten Messwerkzeug mäße. Einzig bedeutsam für den Vergleich wäre, dass man beide Messungen mit demselben Messwerkzeug durchführte. Auch die vorliegende Studie beruht auf einem Vergleich. Folglich muss speziell nach solchen Messabweichungen gefahndet werden, bei denen man zweierlei Maß anlegen könnte.

Insbesondere der Weg vom Ratioprofil zum abschließenden CGH-Befund in rev-ishSchreibweise scheint für derlei anfällig zu sein. Es muss entschieden werden, wann genau ein Ausschlag des Ratioprofils als Verlust, Zugewinn oder Amplifikation zu werten ist. Dabei unterscheidet man Verfahren mit festen Schwellenwerten (fixed treshhold procedures) von solchen, die ein statistisches Verfahren auf die Messwerte anwenden (data-driven procedures) (Barth et al. 2000). Als feste Schwellenwerte werden weit auseinanderliegende Werte von $1 \pm 0,25$ bis hin zu $1 \pm 0,1$ verwendet (Jeuken et al. 2002), so auch in der vorliegenden Studie: $1 \pm 0,25$ im Vergleichskollektiv bei Ried et al. (1994), 1 0,12 in einem eigenen Fall (SQC-26). Statistische Verfahren nutzen oft eine t-Teststatistik, um signifikante Abweichungen vom neutralen Fluoreszenzverhältnis von 1,0 zu ermitteln (Petersen S et al. 2000; Walch et al. 1998). 
Alle diese Wege, eine bedeutsame Abweichung vom neutralen Fluoreszenzverhältnis im Sinne eines Zugewinnes oder eines Verlustes zu ermitteln, bewegen sich innerhalb eines starren Paradigmas: dem vom neutralen Fluoreszenzverhältnis von 1,0. Der Neutralwert von 1,0 ist theoretisch genau dann zu erwarten, wenn die zu vergleichenden DNAs im Tumor- und Referenz-Gemisch in gleichen Anteilen vorliegen, normalerweise also bei Diploidie (2n) beider Proben.

\section{Negativkontrollen}

Hybridisiert man Referenzgewebe vergleichend mit Referenzgewebe im Sinne einer Negativkontrolle, so kommt es zu deutlichen Abweichungen vom theoretischen Neutralwert von 1,0. Dies war bereits in der Anfangszeit der CGH aufgefallen, insbesondere im Bereich der Zentromere und Telomere, in gewissen heterochromatinreichen Regionen sowie den Chromosomenabschnitten 1p32pter, 16p, 19 und 22; solch problematische Regionen seien daher mit Vorsicht zu interpretieren oder aus der Bewertung auszuschließen (Kallioniemi OP et al. 1994).

Weitergehende Untersuchungen zeigten, dass es sich um ein generelles Phänomen handelt und ein Fluoreszenzverhältnis von 1,0 in etlichen chromosomalen Regionen nicht zu finden ist (Cher et al. 1996; Lundsteen et al. 1995; Moore et al. 1997). Abbildung 4.3 zeigt die Mittellinienabweichungen des neutralen Ratioprofils am Beispiel eines unveränderten Chromosoms 1. Obwohl es sich um ein Beispiel mit recht milder Abweichung handelt, ist nicht nur mit bloßem Auge die Farbverschiebung am Metaphasechromosom deutlich zu erkennen, sondern es ergibt sich darüber hinaus bereits ein falsch-positiver Befund durch Überschreitung der Schwelle für Zugewinne.

Dass die im Beispiel abweichende Chromosomenregion am terminalen p-Arm als pro-
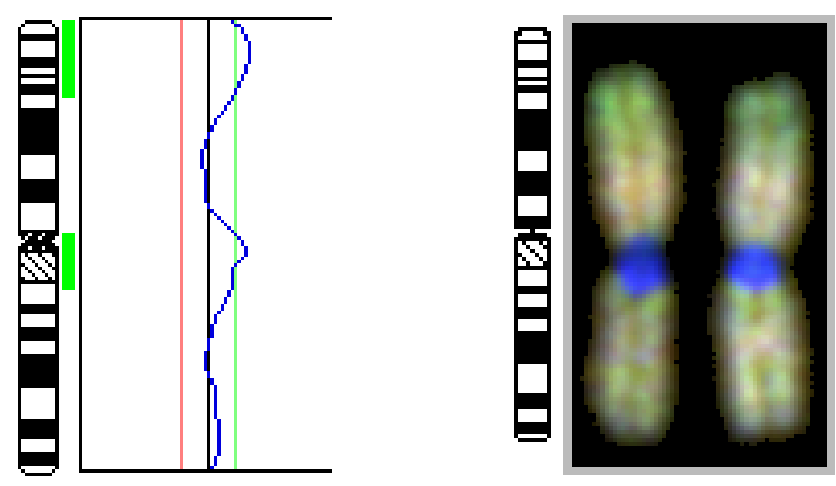

Abbildung 4.3: CGH-Beispiel eines unveränderten Chromosoms 1 aus der vorliegenden Studie: Abweichungen sind sowohl im Ratioprofil als auch in der Färbung des Metaphasechromosoms deutlich erkennbar. 
blematisch bekannt ist, war bereits erwähnt worden. Die wichtige Frage für den in der vorliegenden Studie unternommenen Vergleich ist nun, wie mit solchen problematischen Befunden in den einzelnen Arbeitsgruppen umgegangen wurde. Wie genau wurde ein vorsichtiges Interpretieren oder Ausschließen aus der Bewertung durchgeführt? Welche Kriterien wurden dabei angelegt? Insbesondere vor dem Hintergrund, dass von den verschiedenen Arbeitsgruppen auch noch verschieden hohe Schwellenwerte zugrunde gelegt worden sind (s.o.), sollte man hier äußerste Vorsicht walten lassen. Bei allzu großen Diskrepanzen sähe man sonst als Resultat womöglich mehr Unterschiede zwischen den Arbeitsgruppen als Unterschiede zwischen Primärtumoren und Metastasen.

Das folgende Unterkapitel beschäftigt sich mit der Art und Weise, mit der solchen systematischen Messabweichungen der CGH begegnet wird.

\subsubsection{Die Berichtigung systematischer Messabweichung bei der CGH}

Wie bereits erwähnt, wird im vielzitierten Review von Kallioniemi OP et al. (1994) auf die problematischen Regionen eingegangen: Zentromere und Telomere, heterochromatinreiche Regionen und die Chromosomenabschnitte 1p32pter, 16p, 19 und 22. Folgende Beispiele aus den in die Metaanalyse einbezogenen Publikationen zeigen die Art und Weise der Berichtigung, die dieser Erkenntnis folgt:

"Analysis was excluded from the following regions: centromere, acrocentric p-arms, teleomere and heterochromatic rich areas (...)."

(Luk et al. 2001, S. 88)

"Centromeric and heterochromatic regions were excluded from the analysis."

(Wong et al. 2003, S. 1265)

Oder im Falle einer Studie, die eine Negativkontrolle beinhaltete:

„Only ratio changes that exceeded the fluctuation seen in negative-control experiments were interpreted as evidence of a real gain or loss."

(Lindström et al. 2002, S. 374)

In den Publikationen, deren CGH-Befunde in der vorliegenden Studie verwendet wurden, fanden sich oft spärliche bis gar keine Angaben über den Umgang mit problematischen Regionen oder über eine Berichtigung. Es ist somit nicht leicht nachvollziehbar, auf welche Weise berichtigt wurde, und oft auch, ob dies überhaupt geschehen ist. Über die genauen Kriterien, die diesem nicht standardisierten Schritt zugrunde lagen, ist zumeist nur zu spekulieren.

Zusammengenommen handelt es sich bei den durchgeführten Berichtigungen um einen subjektiven Bewertungsschritt, der auf einer Experteneinschätzung beruht. Dies trifft 
selbst dann zu, wenn Negativkontrollen durchgeführt worden waren, die diese subjektive Beurteilung leiteten. Das prinzipiell quantitative Messverfahren CGH bekommt dadurch eine qualitative Komponente und ist somit offen für menschliche Einflüsse, die sogenannten Beobachtereinflüsse. Auch darüber hinausgehende, wie beispielsweise der Bestätigungsfehler (confirmation bias), müssen hier mitbedacht werden.

Die manuelle Berichtigung ist prinzipiell geeignet, sehr genaue Ergebnisse zu liefern. Das Problem besteht aber in der fehlenden Kalkulierbarkeit dieser Berichtigung, wenn in einer Studie Befunde aus vielen unterschiedlichen Arbeitsgruppen zusammenfließen.

\section{Standardreferenzintervalle}

Da die Neutralwerte in immer gleicher Form vom Fluoreszenzverhältnis von 1,0 abweichen, haben verschiedene Arbeitsgruppen Ansätze entwickelt, um diese systematischen Abweichungen durch Berichtigung mit quantitativ-statistischen Methoden beherrschbar zu machen. Zu nennen sind hier Cher et al. (1996) und Moore et al. (1997) sowie Kirchhoff et al. (1998). Dass diese Verfahren Vorteile gegenüber der manuellen Korrektur bieten, wird beispielhaft dadurch gezeigt, dass sie die Grundlage für die hohe Genauigkeit der eingangs beschriebenen high-resolution-CGH bilden (siehe Kapitel 4.1.1, S. 77).

Kirchhoff et al. $(1998,1999)$ verwendeten bei der high-resolution-CGH das Konzept der Standardreferenzintervalle. Dazu werden wiederholte Negativkontrollen in Form von vergleichenden Hybridisierungen normaler gegen normale DNA durchgeführt. Auf Grundlage der daraus entstehenden Daten wird ein modifiziertes 99,5\% Konfidenzintervall der neutralen Ratioprofile berechnet. Das bedeutet, dass mit einer Wahrscheinlichkeit von 99,5\% ein neutrales Ratioprofil innerhalb dieses Intervalls zu finden sein sollte. Abbildung 4.4 zeigt solche Standardreferenzintervalle.

Alle weitere Auswertung der CGH-Untersuchungen basiert dann nicht auf einem theoretischen Neutralwert von 1,0 und festen Schwellenwerten, sondern wird mit statistischen Mitteln in Bezug auf diese Referenzintervalle durchgeführt. Für Details sei auf Maria Kirchhoffs Arbeit aus dem Jahre 1998 verwiesen.

In der vorliegenden Studie wurde eine Auswertung mit festen Schwellenwerten verwendet, der sich eine manuelle Berichtigung anschloss. Damit aber die systematischen Abweichungen, die das verwendete Protokoll hervorbringt, für die Bewertung im Rahmen des Vergleichs objektiviert werden konnten, sind eigene Standardreferenzintervalle berechnet worden (siehe Kapitel 2.7, S. 42, und Kapitel 3.7, S. 76). Abbildung 4.5 zeigt die so gewonnenen Standardreferenzintervalle. 


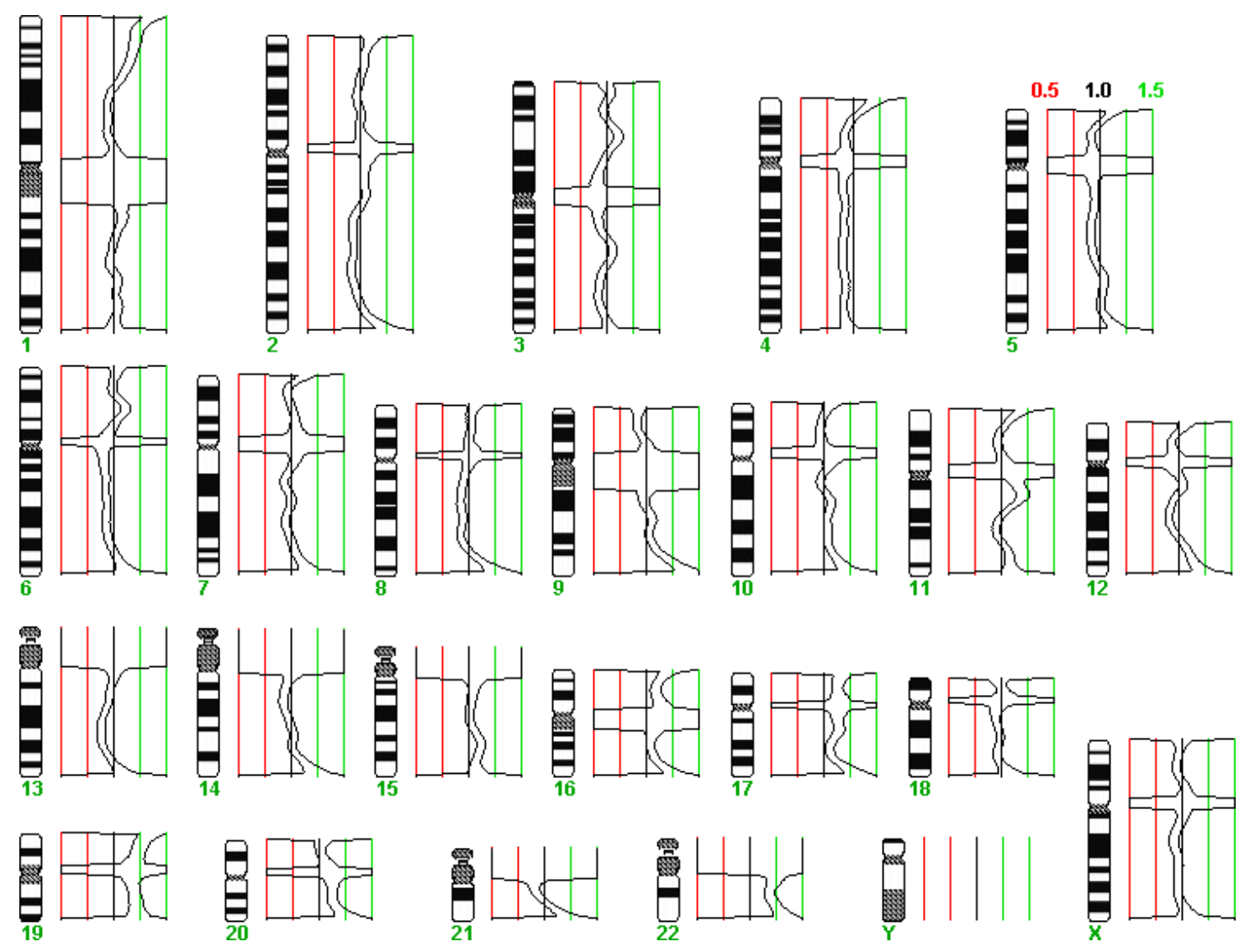

Abbildung 4.4: Standardreferenzintervalle nach Kirchhoff et al. (1998). Die Abbildung stammt von der Homepage der Arbeitsgruppe (Kirchhoff 2005). 

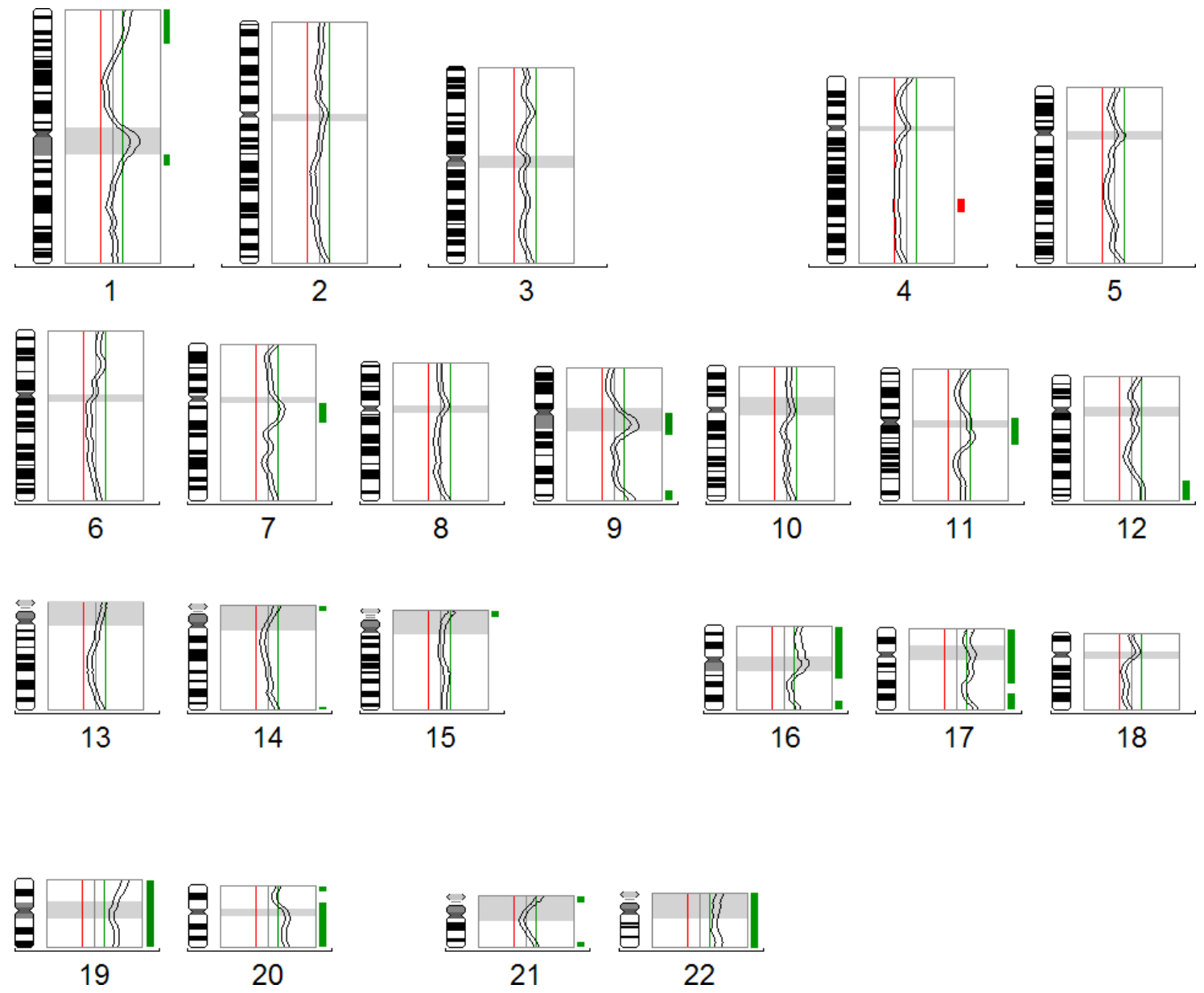

Abbildung 4.5: Standardreferenzintervalle für das in der vorliegenden Studie verwendete CGH-Protokoll. Die Schwellenwerte liegen bei $1 \pm 0,2$. 


\subsection{Kritische Beurteilung der Ergebnisse}

In diesem Kapitel werden die aufgefundenen Unterschiede zwischen Primärtumoren und Hirnmetastasen kritisch hinterfragt. Dies erfolgt sowohl für die qualitative Analyse der häufigen Veränderungen und Experteneinschätzungen als auch für den quantitativ-statistischen Vergleich mit den rev-ish-Daten aus der Metaanalyse. Dabei werden die zum Thema Messabweichung im vorangegangenen Kapitel vorgestellten Überlegungen auf die vorliegenden Ergebnisse angewendet. Zwangsläufig muss es sich um ein qualitatives Abschätzen handeln. Als Grundlage dienen die eigenen Standardreferenzintervalle, mit denen die CGH-Befunde der Hirnmetastasen beurteilt werden.

Bei der Beurteilung der CGH-Befunde aus der Metaanalyse werden zusätzlich immer auch die Standardreferenzintervalle von Kirchhoff (2005) betrachtet. Es ist nämlich vermutet worden, dass ein Teil der Abweichungen durch die Markierungstechnik begründet sein könnte (Kallioniemi OP et al. 1994). Da das eigene Protokoll die indirekte Markierungstechnik repräsentiert und das von Kirchhoff (2005) die direkte, scheint ein Einschätzen grober Fehler durch Messabweichungen in der Zusammenschau recht gut möglich.

\subsubsection{Primärtumoren und Hirnmetastasen des kleinzelligen Karzinoms}

Der Vergleich der kleinzelligen Primärtumoren und Hirnmetastasen erbrachte eine Vielzahl von Unterschieden. Dies gilt sowohl für die qualitative Prüfung der häufigen Veränderungen als auch für die quantitativ-statistische der Anteilswerte. Auch bei der mittleren Anzahl der Veränderungen fiel ein statistisch signifikanter Unterschied auf. Einer kritischen Überprüfung hält jedoch keines dieser Ergebnisse stand. In den folgenden Abschnitten werden all diese Befunde im Detail besprochen.

\section{Die Sicht der Experten: qualitative Unterschiede}

Die qualitative Auswertung, in der die häufigen und erwähnenswerten Veränderungen betrachtet wurden, ergab mehrere auffällige Chromosomen/-arme: 2, 6, 9, 11p, 19, 20p und 22q. Die meisten dieser Veränderungen besitzen Anteilswerte in der Nähe der gesetzten Schwelle von $20 \%$. Sieben der elf Veränderungen liegen bei $25 \%$ oder weniger. Es liegt nahe, dass ein Schwelleneffekt diese Veränderungen ins Blickfeld rücken ließ. Die fehlende statistische Signifikanz stützt diese Vermutung.

Eine Ausnahme stellt der Zugewinn auf Chromosom 19 dar, der nur bei den Primärtumoren zu finden war. Während dieser Zugewinn bei den Hirnmetastasen nicht als häufig eingeschätzt werden konnte, d.h. unter $20 \%$ lag, stellt er bei den Primärtumoren mit $77 \%$ die häufigste aller Veränderungen dar. Auch statistisch ist dieser Unterschied signifikant.

\section{Signifikante Unterschiede der chromosomalen Veränderungen}

Statistisch signifikant unterschiedliche Anteilswerte zeigten sich in sechs Regionen. Bei vieren handelt es sich um die zentromernahen Banden p11 oder q11. Es ist nicht möglich, 
zentromernahe Bereiche mit der CGH zu beurteilen (Kallioniemi OP et al. 1994).

Auf Chromosom 4 war ein Verlust im Bereich der Banden 4q32q33 signifikant häufiger $(p=0,03)$ bei den Primärtumoren zu finden. Dies ist ein erstaunliches Ergebnis, weshalb Chromosom 4 näher besprochen werden soll (s.u.).

Das gesamte Chromosom 19 zeigte einen statistisch signifikanten Unterschied $(p<0,01)$, der schon bei der qualitativen Auswertung herausstach: Ein Zugewinn des gesamten Chromosoms ist wesentlich häufiger bei den Primärtumoren zu finden. Ein Zugewinn oder eine Amplifikation fand sich dort in 55 von 71 Fällen (77\%), bei den Hirnmetastasen dagegen nur in 3 von 21 Fällen (14\%). Auch dies bedarf einer eingehenderen Betrachtung (s.u.).

\section{Verlust von $4 \mathrm{q} 32 \mathrm{q} 33$}

Der Verlust des Chromosomenarmes 4q ist in Zusammenhang mit Metastasierung bereits mehrfach beschrieben worden (Jiang et al. 2005; Kang et al. 2006; Liu XP et al. 2009). Untersuchungen speziell beim Lungenkrebs erhärten dies (Goeze et al. 2002; Wrage et al. 2009; Yan et al. 2005a). Allerdings ergibt sich damit ein widersprüchliches Bild: Der Verlust von 4q solle zur Metastasierung befähigen, mithin also in den Metastasen häufiger zu finden sein. Die vorliegenden Ergebnisse weisen dagegen den Verlust von 4q als statistisch signifikant häufiger bei den Primärtumoren aus. Bevor nun über die biologische Grundlage dieses überraschenden Befundes nachzudenken ist, sollen die Standardreferenzintervalle hinzugezogen werden, um eine mögliche Messabweichung beurteilen zu können.

Sowohl die für die vorliegende Studie berechneten Standardreferenzintervalle als auch die von Kirchhoff (2005) zeigen auf Chromosomenarm 4q eine durchgängige Annäherung an die Schwelle zum Verlust bis hin zu deren Überschreiten. Es ist daher mit falsch positiven Befunden zu rechnen. Ohne das Wissen um die Interpretation dieses problematischen

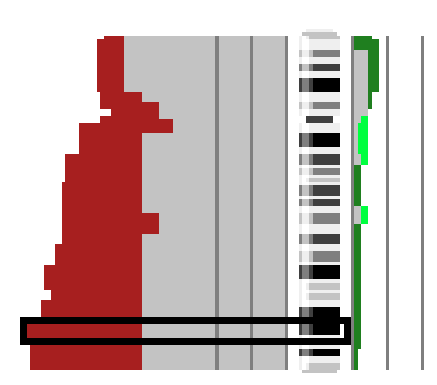

a

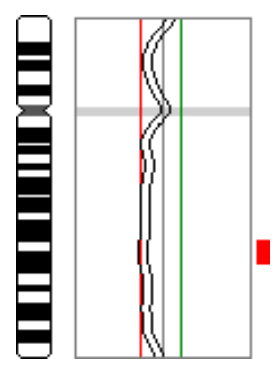

b

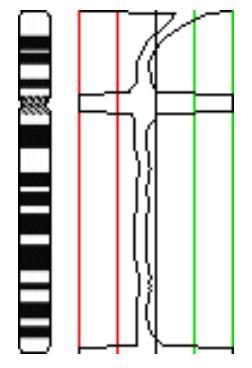

C

Abbildung 4.6: Differenzhistogramm des Chromosoms 4 aus dem kleinzelligen Kollektiv (a). Eigene Standardreferenzintervalle (b) und nach Kirchhoff et al. (1998)(c). 
Bereichs durch die Arbeitsgruppen, welche die Primärtumoren untersucht haben, ist es nicht möglich, den vorliegenden Befund zu beurteilen. Jedoch legen die reichliche Literatur zu dieser Veränderung sowie die Standardreferenzintervalle nahe, dass es sich um ein Artefakt handeln könnte.

\section{Zugewinn von Chromosom 19}

Zwar ist der Unterschied des Zugewinnes auf Chromosom 19 statistisch signifikant $(p<0,01)$, doch betrachtet man die Standardreferenzintervalle, so muss dieses Ergebnis äußerst kritisch hinterfragt werden. Sowohl die selbst berechneten Standardreferenzintervalle als auch die von Kirchhoff (2005) zeigen, dass falsch positive Befunde die Regel sind. Die von den Hirnmetastasen gewonnenen CGH-Befunde wurden unter Berücksichtigung dieses Problems berichtigt. Wäre als Maßstab für einen Zugewinn einzig die Schwellenwertüberschreitung angelegt worden, so hätten sich bei den Hirnmetastasen Anteilswerte für Zugewinne von $68 \%$ auf dem q-Arm und von $59 \%$ auf dem p-Arm ergeben. Ein signifikanter Unterschied läge bei diesen Werten fern. Da nun nicht bekannt ist, inwieweit die Arbeitsgruppen, deren Primärtumordaten in den Vergleich einflossen, diese Problematik berücksichtigt haben, kann trotz hoher statistischer Signifikanz keine Aussage über Chromosom 19 gemacht werden.

\section{Anzahl der Veränderungen pro Fall}

Der Median der chromosomalen Veränderungen pro Fall betrug bei den Primärtumoren 15 und bei den Hirnmetastasen 13,5. Eine statistische Prüfung auf Übereinstimmung der beiden zugrundeliegenden Verteilungen erbrachte einen signifikanten Unterschied $(p<0,01)$. Es wäre zu folgern, dass chromosomale Veränderungen in Hirnmetastasen seltener auftreten als in den Primärtumoren.

Bevor allerdings die biologische Bedeutsamkeit dieses Befundes diskutiert werden darf, muss dessen Plausibilität vor dem Hintergrund der oben angestellten Überlegungen zu Chromosom 19 geprüft werden: Wenn für den Zugewinn auf Chromosom 19 eine Überschätzung durch falsch positive Befunde in den Primärtumordaten angenommen werden kann,

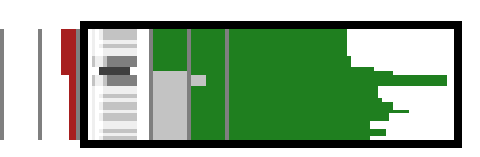

a

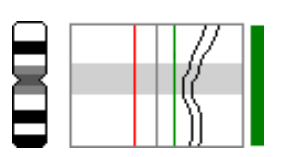

b

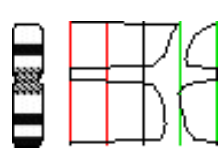

C

Abbildung 4.7: Differenzhistogramm des Chromosoms 19 aus dem kleinzelligen Kollektiv (a). Eigene Standardreferenzintervalle (b) und nach Kirchhoff et al. (1998)(c). 
ist dann ein signifikant häufigeres Auftreten von Veränderungen im Primärtumorkollektiv glaubhaft?

Ein Beispiel verdeutlicht dies: Alle Ratioprofile der Hirnmetastasen wurden erneut durchgesehen und bewertet, allerdings wurde dabei auf eine Berichtigung falsch positiver Befunde auf Chromosom 19 und dem Chromosomenarm 20q verzichtet. Es ergeben sich dadurch höhere Werte für die Anzahl der Veränderungen. Bei einer erneuten Prüfung geht dann die statistische Signifikanz für einen Unterschied zum Primärtumorkollektiv verloren $(p=0,05)$. Durch die Unsicherheiten in den vorliegenden Daten ist es somit nicht möglich, über die Anzahl der Veränderungen eine Aussage zu treffen.

\subsubsection{Primärtumoren und Hirnmetastasen des Plattenepithelkarzinoms}

Der qualitative Vergleich der Primärtumoren und Hirnmetastasen erbrachte eine Vielzahl von Unterschieden bei den häufigen Veränderungen. Davon konnten viele durch die statistische Auswertung bestätigt werden und hielten auch einer kritischen Überprüfung stand. Es handelt sich dabei um die Zugewinne von 1q12q21, 2q12q14, 7q21 und 10p13pter sowie um die Verluste von 8p12pter, 9p13pter, 13q21qter und 18q. In den folgenden Abschnitten werden all diese Befunde im Detail besprochen.

\section{Die Sicht der Experten: qualitative Unterschiede}

In der qualitativen Auswertung, in der die häufigen und erwähnenswerten Veränderungen betrachtet wurden, fanden sich etliche auffällige Chromosomen/-arme: 1p, 2q, 6, 7, 9, 10p, 11q, 16p, 17 und 18. Fast die Hälfte der so aufgefallenen Veränderungen konnte durch die statistische Auswertung bestätigt werden: Die Zugewinne auf Chromosomenarm 2q, 6p, 7q, 19q und 10p sowie die Verluste auf 9p und 18q.

Es fällt auf, dass die Anteilswerte der Veränderungen, die durch die quantitativ statistische Auswertung bestätigt werden konnten, überwiegend fern der Schwelle liegen. Dagegen sind die, die nicht durch die Statistik bestätigt werden konnten, schwellennah gelegen und könnten auf einen Schwelleneffekt zurückzuführen sein. Eine solche Verteilung war auch zu erwarten und deutet zugleich die Möglichkeiten und die Grenzen einer qualitativen Auswertung an. In der Schlussbetrachtung wird darauf weiter eingegangen (siehe Kapitel 4.4, S. 105).

\section{Statistisch signifikante Unterschiede}

Signifikante Unterschiede zeigten sich in 14 Regionen. Drei davon waren wiederum zentromernahe Banden, die nicht mit der CGH beurteilt werden können. Die verbleibenden Veränderungen waren durchgängig häufiger bei den Hirnmetastasen zu finden: Zugewinne im Bereich von 1q12q21 $(p=0,02), 2 \mathrm{q} 12 \mathrm{q} 14(p=0,04), 6 \mathrm{p} 12 \mathrm{p} 21(p=0,04), 7 \mathrm{q} 21$ $(p<0,01)$, 10p13pter $(p=0,03)$ und 19q12 $(p=0,03)$. Verluste fanden sich in den Bereichen 5p12pter $(p=0,03), 8$ p12pter $(p=0,03)$, 9p13pter $(p=0,04)$, 13q21qter 
$(p=0,03)$ und 18q $(p<0,01)$. Diese Veränderungen werden in den folgenden Abschnitten eingehend besprochen.

\section{Zugewinn von 1q12q21}

In Abbildung 4.8 ist deutlich sichtbar, dass der aufgefundene Zugewinn zum großen Teil im zentromernahen Bereich liegt, der nicht beurteilbar ist (grau hinterlegt). In dem darüber hinausreichenden Anteil sind laut Standardreferenzintervallen falsch positive Befunde zu erwarten. Diese Region ist daher mit großer Zurückhaltung zu interpretieren.

Eine erneute Durchsicht aller Ratioprofile zeigt, dass sich oftmals ein Maximum im Bereich 1q21 ergibt, welches von den Standardreferenzintervallen her nicht zu erwarten wäre. Zusätzlich übertrifft das Fluoreszenzverhältnis die Schwelle meist deutlich, wodurch ein Artefakt noch unwahrscheinlicher wird. Ein beispielhaftes Ratioprofil ist in Abbildung 4.8 dargestellt. Weiterhin handelt es sich bei diesem begrenzten Zugewinn um ein wiederkehrendes Motiv, welches auch im adenomatösen Kollektiv zu sehen ist. Auch das Histogramm der großzelligen Hirnmetastasen zeigt einen Häufungspunkt in diesem Bereich.

Selbstverständlich wäre es möglich, dass die CGH-Befunde der Primärtumoren im Wissen um falsch positive Werte im Bereich 1q12q21 allzu eifrig berichtigt wurden. Inwieweit die CGH-Befunde der Primärtumoren berichtigt wurden, ist unbekannt. Folglich ist das Ausmaß einer systematischen Messabweichung nicht kalkulierbar. Da aber die Besprechung der Kleinzeller den Gedanken nahegelegt hat, dass eher eine unzureichende denn eine übereifrige Berichtigung erwartet werden kann, soll diese Möglichkeit nicht weiter beachtet werden. Zusammenfassend lässt sich sagen: Ein Zugewinn im Bereich der Banden 1q12q21 kann als metastasenspezifische Veränderung gewertet werden.

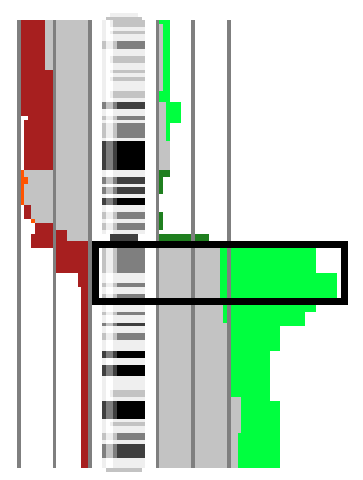

a

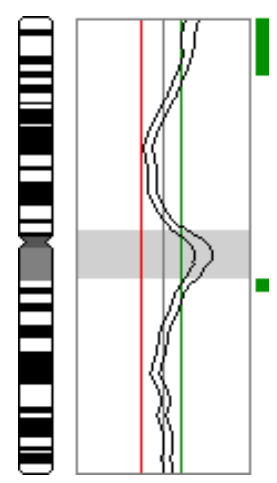

b

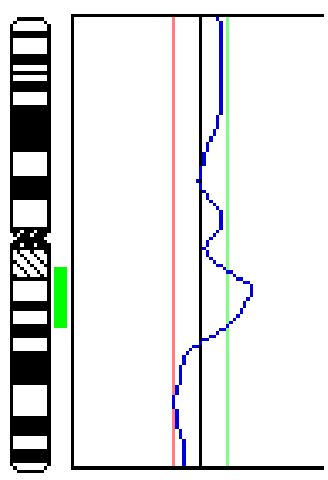

C

Abbildung 4.8: Differenzhistogramm des Chromosoms 1 aus dem Kollektiv der Plattenepithelkarzinome (a), Standardreferenzintervalle (b) und ein beispielhaftes Ratioprofil aus Fall SQC-01 (c). 


\section{Zugewinn von $2 q 12 q 14$}

Für einen Zugewinn im Bereich 2q12q14 geben die Standardreferenzintervalle keinen Anlass, falsch positive Befunde zu befürchten (siehe Abbildung 4.9). In dieser Region zeigt es eine nur geringe Abweichung vom theoretischen Neutralwert des Fluoreszenzverhältnisses von 1,0. Der Zugewinn im Bereich 2q12q14 kann als metastasenspezifische Veränderung gewertet werden.

\section{Verlust von 5p12pter}

Ein Blick auf die Rohwerte der statistischen Prüfung lässt erkennen, dass die Signifikanz in diesem Fall auf nur vier Hirnmetastasen beruht: Von 32 Hirnmetastasen zeigen 4 diesen Verlust, während er bei den Primärtumoren gar nicht auftrat. Bei den übrigen statistisch als signifikant aufgefallen Regionen flossen in die Auswertung zumeist 10 und mehr Hirnmetastasen ein. Da bereits eine einzelne Fehlbewertung hier spürbare Auswirkung haben würde, wurden die Ratioprofile noch einmal überprüft.

Die Standardreferenzintervalle zeigen im Bereich des Armes 5p eine Tendenz zur Annäherung an die Schwelle für Verluste (siehe Abbildung 4.10). Drei der vier Verluste präsentieren sich im Ratioprofil durch einen Verlauf, der die Verlustschwelle allenfalls tangiert, aber nicht überschreitet. Zudem waren in zwei Fällen die Schwellen abgesenkt worden auf ein Fluoreszenzverhältnis von 0,85 und 0,88 statt des üblichen Wertes von 0,8. Aufgrund der somit deutlich erhöhten Wahrscheinlichkeit für einen falsch positiven Befund wird der Verlust von 5p nicht weiter berücksichtigt.

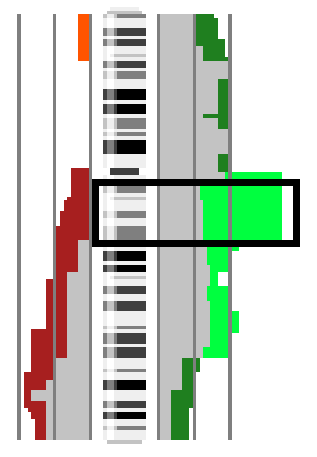

a

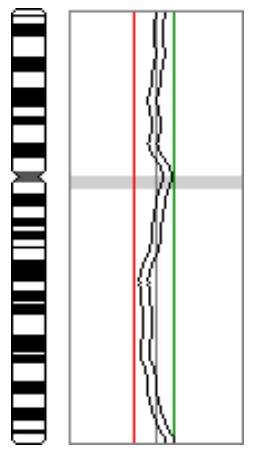

b

Abbildung 4.9: Differenzhistogramm des Chromosoms 2 aus dem Kollektiv der Plattenepithelkarzinome (a) und Standardreferenzintervalle (b). 


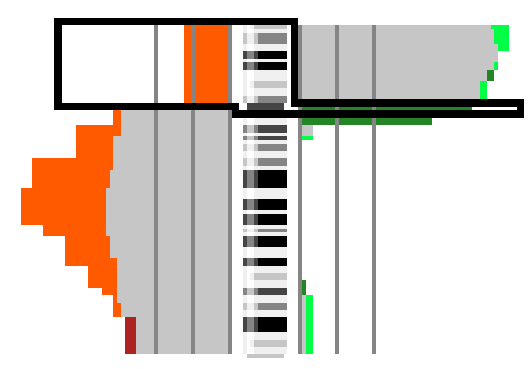

a

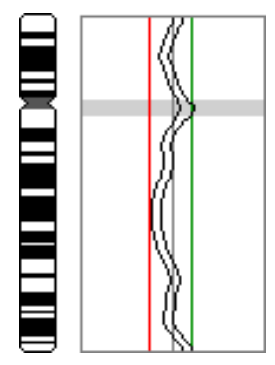

b

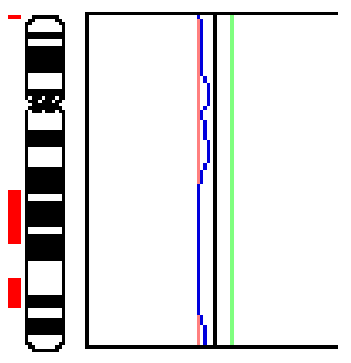

C

Abbildung 4.10: Differenzhistogramm des Chromosoms 5 aus dem Kollektiv der Plattenepithelkarzinome (a), Standardreferenzintervalle (b) und ein beispielhaftes Ratioprofil aus Fall SQC-26 (c).

\section{Zugewinn von $6 \mathrm{p} 12 \mathrm{p} 21$}

Die Standardreferenzintervalle für den p-Arm zeigen, dass sich diese der Schwelle für Zugewinne annähern, und zwar mit einem Maximum im Bereich 6p21. Das Maximum der Zugewinne im Histogramm ist genau deckungsgleich damit (siehe Abbildung 4.11). Eine erneute Durchsicht aller Ratioprofile weckt weitere Zweifel: Oftmals laufen diese Profile auf oder knapp oberhalb der Schwelle, ein deutliches Überschreiten ist selten. Ein beispielhaftes Ratioprofil ist in der Abbildung dargestellt.

Weiterhin handelt es sich bei diesem Zugewinn um ein wiederkehrendes Motiv, welches auch in der kleinzelligen Gruppe zu sehen und in der adenomatösen nicht auszuschließen ist.

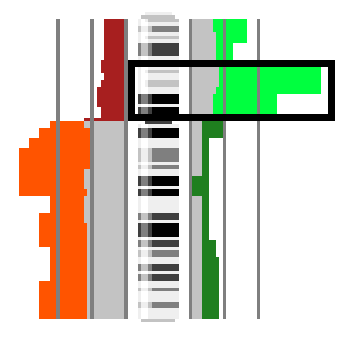

a

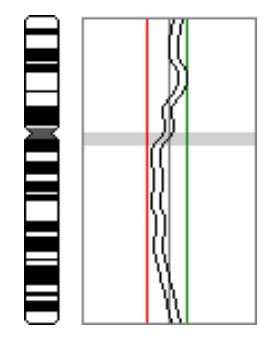

b

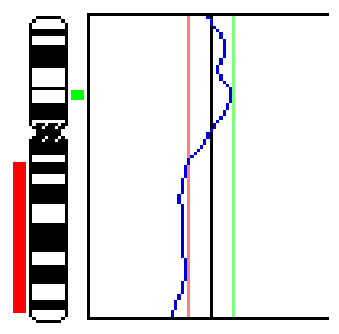

C

Abbildung 4.11: Differenzhistogramm des Chromosoms 6 aus dem Kollektiv der Plattenepithelkarzinome (a), Standardreferenzintervall (b) und ein beispielhaftes Ratioprofil aus Fall SQC-30 (c). 
Auch das Histogramm der adenosquamösen Hirnmetastasen besitzt einen Häufungspunkt in diesem Bereich. Ein derartig wiederholtes Auftreten bestärkt den Verdacht auf einen falsch positiven Befund. Es liegt in der Natur der systematischen Messabweichung, dass sie unter den gleichen Bedingungen in immer gleicher Weise auftritt, auch über histologische Gruppen hinweg. Aufgrund der vielfältigen Zweifel an diesem Befund soll der Zugewinn von $6 \mathrm{p} 21$ nicht weiter berücksichtigt werden.

\section{Zugewinn von $7 q 21$}

Die Standardreferenzintervalle zeigen, dass im Bereich der Bande 7q11 falsch positive Befunde zu erwarten sind (siehe Abbildung 4.12). Die aufgefallene Bande 7q21 liegt jedoch jenseits davon, die Standardreferenzintervalle sind dort wieder in der Nähe des theoretisch neutralen Fluoreszenzverhältnisses von 1,0 gelegen. Eine Messabweichung ist dort unwahrscheinlich, der Zugewinn der Bande 7q21 kann daher als metastasenspezifische Veränderung betrachtet werden.

\section{Verlust von 8p12pter}

Die Standardreferenzintervalle verlaufen im Bereich des p-Armes zentriert um den theoretisch neutralen Wert des Fluoreszenzverhältnisses von 1,0 (siehe Abbildung 4.13). Eine Messabweichung ist nicht zu erwarten, der Verlust von 8p muss als metastasenspezifische Veränderungen eingestuft werden.

\section{Verlust von 9p13pter}

Im Bereich des p-Armes nähern sich die Standardreferenzintervalle der Schwelle für Verluste an (siehe Abbildung 4.14). Eine genauere Durchsicht aller Ratioprofile zeigt aber, dass der Verlauf im Bereich 9p der Hirnmetastasen deutlich von dem abweicht, der von den Standardreferenzintervallen her zu erwarten wäre. Ein Beispiel ist in der Abbildung zu

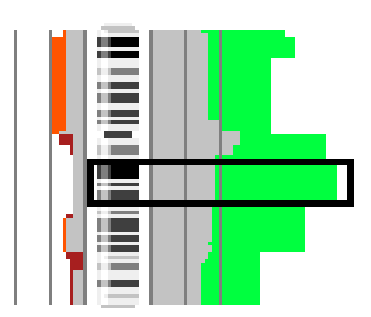

a

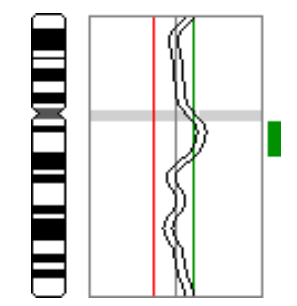

b

Abbildung 4.12: Differenzhistogramm des Chromosoms 7 aus dem Kollektiv der Plattenepithelkarzinome (a) und Standardreferenzintervalle (b). 


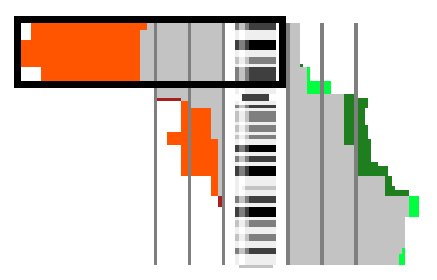

a

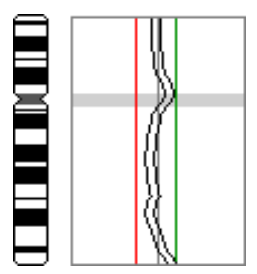

b

Abbildung 4.13: Differenzhistogramm des Chromosoms 8 aus dem Kollektiv der Plattenepithelkarzinome (a) und Standardreferenzintervalle (b).

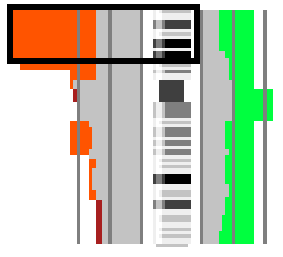

a

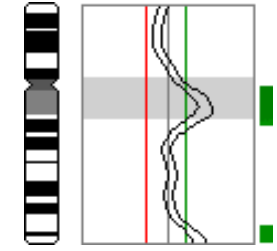

b

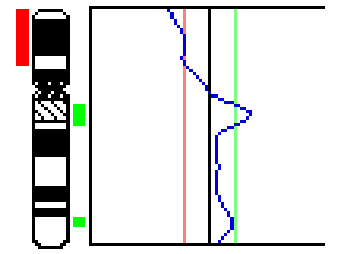

C

Abbildung 4.14: Differenzhistogramm des Chromosoms 9 aus dem Kollektiv der Plattenepithelkarzinome (a), Standardreferenzintervalle (b) und ein beispielhaftes Ratioprofil aus Fall SQC-04 (c).

sehen. Es wird daher von einer echten Veränderung ausgegangen und der Verlust von 9p13pter als metastasenspezifisch betrachtet.

\section{Zugewinn von 10p13pter}

Im Bereich des p-Armes zeigen die Standardreferenzintervalle keine größere Abweichung vom theoretisch zu erwartenden Neutralwert des Fluoreszenzverhältnisses von 1,0 (siehe Abbildung 4.15). Es ist keine systematische Messabweichung zu erwarten, der Zugewinn von Chromosomenarm 10p muss als metastasenspezifisch angesehen werden.

\section{Verlust von 13q21qter}

Die Standardreferenzintervalle nähern sich am q-Arm der Schwelle für Verluste an, und zwar im Bereich der Banden 13q21q22 (siehe Abbildung 4.16). Der als signifikanter Unterschied aufgefallene Verlust erstreckt sich aber darüber hinaus auf die Banden 13q31 bis 


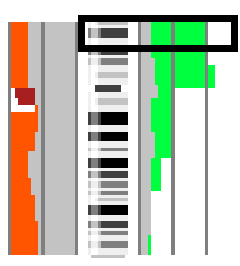

a

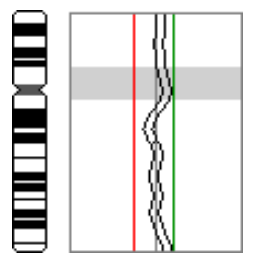

b

Abbildung 4.15: Differenzhistogramm des Chromosoms 10 aus dem Kollektiv der Plattenepithelkarzinome (a) und Standardreferenzintervalle (b).

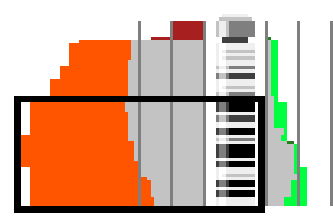

a

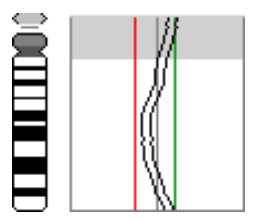

b

Abbildung 4.16: Differenzhistogramm des Chromosoms 13 aus dem Kollektiv der Plattenepithelkarzinome (a) und Standardreferenzintervalle (b).

13q33. Gerade in diesem Abschnitt laufen die Standardreferenzintervalle bereits wieder auf das neutrale Fluoreszenzverhältnis von 1,0 zu und nähern sich darüber hinaus am Chromosomenende der Schwelle für Zugewinne. Ein fehlerhaftes Ergebnis ist unwahrscheinlich. Der Verlust auf dem q-Arm des Chromosoms 13 wird daher als metastasenspezifische Veränderung aufgefasst.

\section{Verlust von $18 \mathrm{q}$}

Im Bereich des Chromosomenarms 18q zeigen die Standardreferenzintervalle eine starke Annäherung an die Schwelle für Verluste (siehe Abbildung 4.17). Unter Umständen könnten, insbesondere bei niedrig gewählter Schwelle für Verluste, falsch positive Befunde der Hirnmetastasen für die Signifikanz dieses Unterschieds verantwortlich sein. Eine Durchsicht der einzelnen Ratioprofile kann die Zweifel nicht zerstreuen, der Verlauf ist oft ähnlich dem der Standardreferenzintervalle. Normalerweise wäre der Verlust von 18q aus der weiteren Betrachtung auszuschließen.

Allerdings gibt es zweierlei zu bedenken: Ein signifikant häufigerer Allelverlust von 18q in Hirnmetastasen vom Lungenkrebs ist bereits bekannt (Shiseki et al. 1994, 1996); diese 


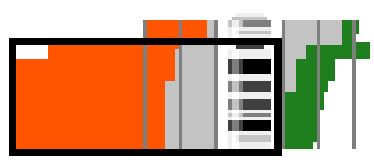

a

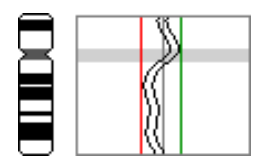

b

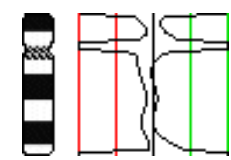

C

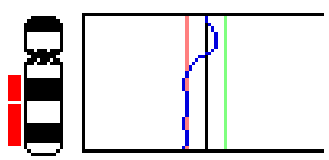

d

Abbildung 4.17: Differenzhistogramm des Chromosoms 18 aus dem Kollektiv der Plattenepithelkarzinome (a), eigene Standardreferenzintervalle (b) und nach Kirchhoff et al. (1998)(c) sowie ein beispielhaftes Ratioprofil aus Fall SQC-29 (d).

Befunde waren mit einer anderen Methode ermittelt worden. Zudem weichen die für die vorliegende Studie errechneten Standardreferenzintervalle für Chromosom 18 auffallend von denen von Kirchhoff (2005) ab. Die übrigen der selbst berechneten Standardreferenzintervalle zeigen durchweg einen Verlauf, der mit jenen vergleichbar ist. Es ist nicht auszuschließen, dass die Standardreferenzintervalle hier selbst fehlerhaft sind, was nur durch eine erneute Berechnung auf der Basis weiterer Negativkontrollen zu ermitteln wäre. Der Verlust von 18q soll unter diesem Vorbehalt in der weiteren Auswertung verbleiben.

\section{Zugewinn und Amplifikation von 19q12}

Bande 19q12 war bei den Hirnmetastasen nicht nur häufig hinzugewonnen, sondern auch oft amplifiziert. In 7 der 32 Fälle (22\%) fand sich eine Amplifikation, während bei den 121 Primärtumoren eine solche nur ein einziges Mal vorkam.

Dieses Ergebnis mag verlockend erscheinen und Anlass geben, über ein dort lokalisiertes Onkogen zu spekulieren. Amplifikationen in diesem Bereich sind beim Krebs nicht unbekannt (Leung et al. 2006). Allerdings ist die Problematik falsch positiver Befunde in dieser Region bereits bei den kleinzelligen Hirnmetastasen ausgeführt worden (siehe Kapitel 4.2.1, S. 88). Das dort Gesagte gilt für die Plattenepithelkarzinome in gleicher Weise: Solange die Art der Beurteilung durch die Arbeitsgruppen, deren Primärtumordaten in den Vergleich einflossen, im Dunkeln liegt, ist es nicht angeraten, hierzu eine Aussage zu treffen.

\subsubsection{Primärtumoren und Hirnmetastasen des Adenokarzinoms}

Der qualitative Vergleich der Primärtumoren und Hirnmetastasen hatte eine Vielzahl von Unterschieden bei den häufigen Veränderungen erbracht. Da aber aufgrund des ungünstigen Stichprobenumfangs eine statistische Auswertung nur sehr eingeschränkt möglich war, gestaltete sich ein Abgleich problematisch.

Nur zwei Unterschiede konnten mit statistischer Prüfung erkannt werden und hielten zugleich der kritischen Überprüfung stand: Der Verlust im Bereich 11p13p14 und der Verlust des Chromosomenarms 18q waren häufiger bei den Hirnmetastasen zu finden. Diese 
Veränderungen waren auch in der qualitativen Auswertung aufgefallen.

Die Zusammenschau mit der Gruppe der Plattenepithelkarzinome bestätigte in der Tendenz folgende der dort bereits beschriebenen Veränderungen: die Zugewinne im Bereich 1q12q23 sowie die Verluste von 8p und 9p. In den folgenden Abschnitten werden diese Befunde im Detail besprochen.

\section{Die Sicht der Experten: qualitative Unterschiede}

Die qualitative Auswertung, in der die häufigen und erwähnenswerten Veränderungen betrachtet wurden, ergab eine Vielzahl auffälliger Chromosomen/-arme: 1p, 4p, 6, 10, 11, 14q, 18q und 20q. Die meisten dieser Veränderungen besitzen höhere Anteilswerte von $30 \%$ und mehr, so dass nicht von einem Schwelleneffekt auszugehen ist. Die Verluste auf den Chromosomenarmen 11p und 18q konnten durch die statistische Prüfung bestätigt werden.

\section{Statistisch signifikante Unterschiede}

Aufgrund des mit 16 Hirnmetastasen ungünstigen Stichprobenumfanges war eine statistische Testung nur sehr eingeschränkt möglich. Da von einer äußerst geringen Teststärke ausgegangen werden muss, ist insbesondere ein statistischer Fehler 2. Art zu bedenken: Nur weil mit dieser kleinen Stichprobe keine signifikanten Unterschiede im Sinne eines metastatischen Genotyps zu finden waren, darf nicht davon ausgegangen werden, dass es einen solchen nicht trotzdem gäbe. Alle gewonnenen Ergebnisse müssen daher unter Vorbehalt betrachtet werden.

Signifikante Unterschiede zeigten sich in vier Regionen. Zwei davon waren wiederum zentromernahe Banden, die nicht mit der CGH beurteilt werden können. Auf Chromosom 11 war ein Verlust im Bereich der Banden 11p13p14 signifikant häufiger bei den Hirnmetastasen zu finden $(p=0,02)$. Dieser Unterschied wird im nächsten Abschnitt besprochen.

Chromosom 18 zeigte im Bereich der Bande 18q23 einen Verlust, der häufiger bei den Hirnmetastasen auftrat $(p=0,03)$. Der Verlauf des Histogramms aber zeigt, dass es sich nicht um einen Häufungspunkt handelt, sondern dass der gesamte Chromosomenarm 18q betroffen ist. Da diese Veränderung bereits in der Gruppe der Plattenepithelkarzinome aufgefallen war, sei auf die dortige Diskussion verwiesen.

\section{Verlust von $11 \mathrm{p} 13 \mathrm{p} 14$}

Um einen falsch positiven Befund ausschließen zu können, wurden die Standardreferenzintervalle betrachtet (siehe Abbildung 4.18). Diese legen im Bereich 11p13p14 keine falsch positiven Befunde nahe. Ein Verlust in diesem Bereich kommt mithin als metastasenspezifische Veränderung in Frage. 


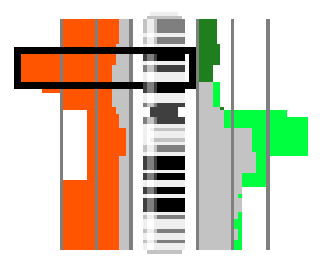

a

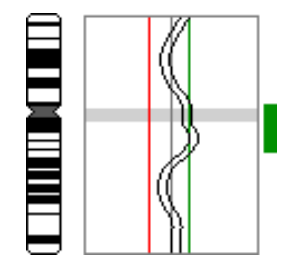

b

Abbildung 4.18: Differenzhistogramm des Chromosoms 11 aus dem Kollektiv der Adenokarzinome (a) und Standardreferenzintervalle (b).

\section{Zusammenschau mit dem Kollektiv der Plattenepithelkarzinome: 1q, 8p und 9p}

Betrachtet man das Differenzhistogramm im Wissen um die begrenzte Teststärke des vorliegenden Vergleichs, so mag man nach tendenziellen Veränderungen suchen, die den gesicherten Befunden im Kollektiv der Plattenepithelkarzinome ähneln. Wenn auch ohne statistische Signifikanz, so erkennt man in den adenomatösen Hirnmetastasen die zuvor aufgefallenen Unterschiede wieder: Verluste der Chromosomenarme $8 \mathrm{p}$ und $9 \mathrm{p}$ sind in den Hirnmetastasen häufiger zu finden, ebenso ein umschriebener Zugewinn im Bereich 1q12q23 (siehe Abbildung 4.19).

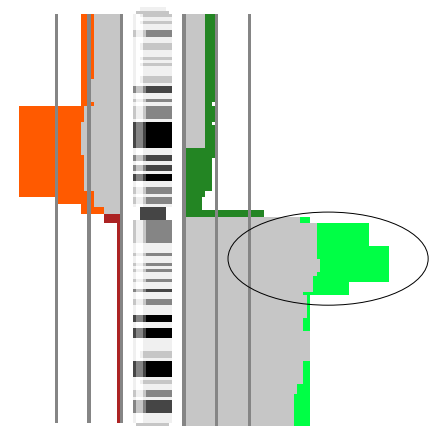

$20 \% 120 \%$

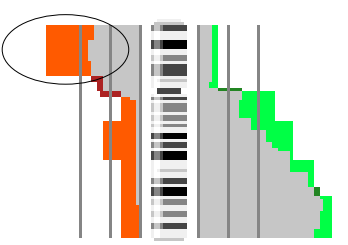

$20 \%$

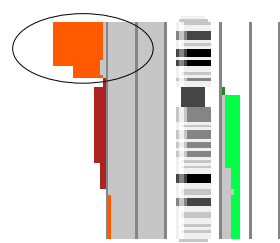

$20 \%$ g $20 \%$

Abbildung 4.19: Tendenzielle Veränderungen im Differenzhistogramm des Kollektivs der Adenokarzinome: Die Verluste der Chromosomenarme 8p und 9p sind - wenn auch nicht signifikant - häufiger bei den Hirnmetastasen. Ebenso findet sich dort ein umschriebener Zugewinn im Bereich 1q12q23. 


\subsubsection{Adenosquamöse und großzellige Hirnmetastasen}

Da für die adenosquamösen und großzelligen Tumoren weder genügend Hirnmetastasen vorlagen, noch eine ausreichende Anzahl von Primärtumoren gefunden werden konnte, musste ein Vergleich unterbleiben.

Dennoch fallen im Histogrammverlauf die auch bei den übrigen nicht-kleinzelligen Kollektiven gefundenen Regionen ins Auge: Sowohl bei den adenosquamösen als auch bei den großzelligen Hirnmetastasen sind es die Verluste der Chromosomenarme 8p, 9p und 18q. Bei den Großzellern erkennt man zusätzlich noch einen Zugewinn in der Region 1q12q23. Abbildung 4.20 stellt dies dar. Auch wenn diese Befunde keine Aussagekraft im Sinne einer quantitativ statistischen Prüfung besitzen, so ergänzen und bestärken sie dennoch das Bild der zuvor gewonnen Ergebnisse.

\section{Adenosquamöse Hirnmetastasen}

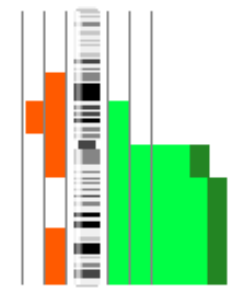

$20 \% 120 \%$

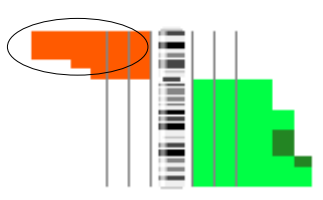

$20 \% 820 \%$

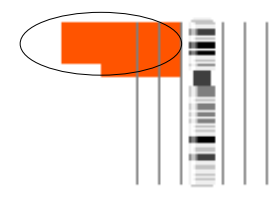

$20 \% \mathbf{9} 20 \%$

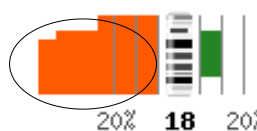

$20 \% 1820 \%$

\section{Großzellige Hirnmetastasen}
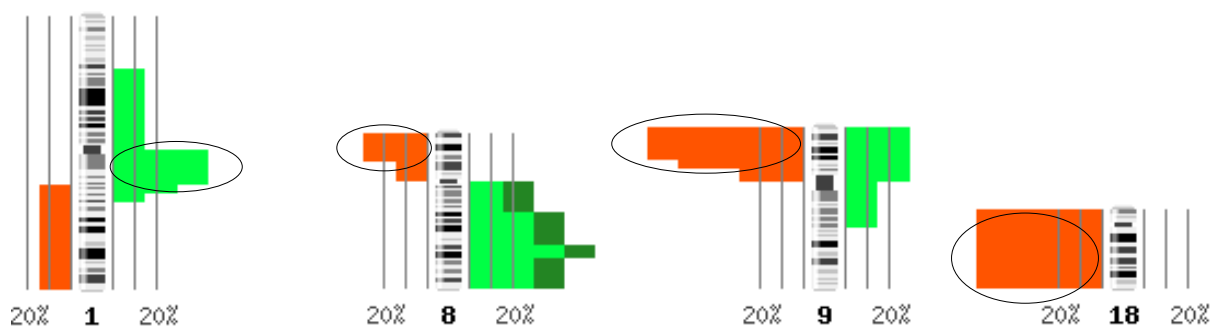

Abbildung 4.20: Histogrammverläufe der adenosquamösen und großzelligen Hirnmetastasen bestärken die zuvor gefundenen Auffälligkeiten: Verluste der Chromosomenarme 8p, 9p und 18q. Auch findet sich ein Zugewinn im Bereich 1q12q23 bei den großzelligen Metastasen. 


\subsection{Interpretation der Ergebnisse}

Da der Vergleich im kleinzelligen Kollektiv keine haltbaren Ergebnisse erbracht hatte, bezieht sich das Folgende auf die nicht-kleinzelligen Hirnmetastasen.

\subsubsection{Verdächtige Genorte und Kandidatengene}

Auch wenn die Genauigkeit der CGH ein Ablesen mit bandengenauer Auflösung zuließe, so handelt es sich dennoch nicht um die geeignete Methode, wenn man auf der Suche nach einzelnen Genen ist. Bei 21370 bisher bekannten Genen und einer Genomgröße von $3,25 \cdot 10^{9}$ bp (Ensembl 2009; Hubbard et al. 2009) müsste man im Mittel mit 65 Genen pro detektierter Bande rechnen. Die CGH ist in erster Linie ein Wegweiser für den Einsatz genauerer Methoden, wie zum Beispiel der Array-CGH.

Dennoch soll zu jeder der aufgefundenen Regionen ein Blick in die zum Thema bestehende Literatur geworfen werden. Die Frage dabei ist, ob andere Untersuchungen die vorliegenden Befunde bestärken und ob mit genaueren Methoden in diesen Regionen bereits verdächtige Gene entdeckt worden sind.

\section{Zugewinn von $1 \mathrm{q} 12 \mathrm{q} 21$}

Ein Zugewinn der Region 1q21q25 ist für einen metastatischen Phänotyp beim Adenokarzinom der Lunge beschrieben worden (Goeze et al. 2002), ebenso beim Plattenepithelkarzinom (Petersen S et al. 2000). Auf der Bande 1q21 liegt das CKS1-Gen, das beim nicht-kleinzelligen Lungenkrebs vermehrt exprimiert wird (Inui et al. 2003) und für das beim Brustkrebs ein Zusammenhang mit Lymphknotenmetastasen beschrieben wurde (Wang et al. 2009).

\section{Zugewinn von $2 \mathrm{q} 12 \mathrm{q} 14$}

Es waren keine Publikationen zu finden, die den Befund eines metastasenspezifischen Zugewinns im Bereich der Banden 2q12q14 bestärken würden.

\section{Zugewinn von $7 \mathrm{q} 21$}

In einer Studie über das Plattenepithelkarzinom der Lunge war ein Zugewinn von $7 q$ häufiger in der Gruppe der metastasierten Tumoren aufgetreten (Yan et al. 2005a). Speziell der Zugewinn der Bande 7q21 war in einer Studie über das Zungenkarzinom als metastasenspezifisch hervorgetreten (Hannen et al. 2004).

\section{Verlust von $8 p$}

In einer Array-CGH Studie über das Plattenepithelkarzinom der Lunge war ein Verlust der Bande 8p23 signifikant häufiger bei Patienten mit Fernmetastasen aufgefallen (Boelens et al. 2009). Für einen Verlust von 8p ist noch bei weiteren Krebsarten ein Zusammenhang 
mit Metastasierung bekannt, so beim kolorektalen Krebs (Macartney-Coxson et al. 2008), beim Aderhautmelanom (Onken et al. 2008) und beim hepatozellulären Karzinom (Lu und Hano 2007).

Vom Gen DLC-1 ist bekannt, dass es die Metastasierung zu unterdrücken vermag (Goodison et al. 2005). Dieses auf den Banden 8p21p22 gelegene Gen ist für seine Rolle als Tumorsuppressor beim nicht-kleinzelligen Lungenkrebs bekannt (Healy et al. 2008; Yuan et al. 2004).

\section{Verlust von $9 p$}

Dass ein Allelverlust von 9p signifikant häufiger in Hirnmetastasen vom nicht-kleinzelligen Lungenkrebs vorkommt, wurde bereits beschrieben (Shiseki et al. 1996). Beim Nasopharynxkarzinom war ein Zusammenhang zwischen einem 9p-Verlust und Metastasierung in die Lymphknoten aufgefallen (Yan et al. 2005b), beim Peniskarzinom gilt dies für einen Allelverlust von 9p21 (Poetsch et al. 2007).

Als Kandidatengen könnte CDKN2A (Synonym: p16 ${ }^{\mathrm{INK} 4}$ ) auf Bande 9p21 in Frage kommen, ein Tumorsuppressorgen, das in einer Studie über metastasierten Lungenkrebs bereits aufgefallen war (Okamoto et al. 1995). Weitere Literatur, die dies bestärken könnte, war allerdings nicht zu finden.

\section{Zugewinn von $10 p$}

Es waren keine Publikationen zu finden, die den Befund eines metastasenspezifischen Zugewinns von Chromosomenarm 10p bestärken würden.

\section{Verlust von $11 \mathrm{p} 13 \mathrm{p} 14$}

In einer Studie war ein gehäufter Allelverlust im Bereich der Banden 11p11p13 in Metastasen vom Lungenkrebs aufgefallen (Takahashi et al. 2007). In zwei Studien über Kopf-Hals-Karzinome waren Verluste der Regionen 11p13p14 und 11p14 als spezifisch für Metastasen beschrieben worden (Bockmühl et al. 1997, 2002). Das auf Bande 11p13 gelegene Gen CD44 war beim Prostatakrebs als Metastasierungssuppressor aufgefallen (Gao et al. 1997). Neuere Berichte widersprechen dem allerdings (Klingbeil et al. 2009).

\section{Verlust von $13 q 21 q t e r$}

Der Verlust der Bande 13q21 war in einer Array-CGH-Studie über das Plattenepithelkarzinom der Lunge signifikant häufiger in der Gruppe fernmetastasierter Tumoren aufgetreten (Boelens et al. 2009). Auf dieser Bande wird ein Tumorsuppressorgen des nicht-kleinzelligen Lungenkrebses vermutet, das Protocadherin PCDH20 (Imoto et al. 2006). Protocadherine werden hauptsächlich im Nervensystem exprimiert und es wird vermutet, dass sie bei der Zelladhäsion mitwirken (Morishita und Yagi 2007). 


\section{Verlust von $18 \mathrm{q}$}

Ein Allelverlust des Chromosomenarmes 18q ist bereits in zwei Studien über Hirnmetastasen vom nicht-kleinzelligen Lungenkrebs als signifikant häufiger in Metastasen aufgefallen (Shiseki et al. 1994, 1996). In Primärtumoren beim Plattenepithelkarzinom der Lunge war ein Verlust von 18q als Kennzeichen der metastasierenden Gruppe beschrieben worden (Yan et al. 2005a).

Darüber hinaus ist für diese Veränderung bei einer Vielzahl anderer Tumoren ein Zusammenhang mit Metastasierung bekannt: beim Bauchspeicheldrüsenkrebs (Lefter et al. 2003, 2004), beim kolorektalen Krebs (Sarli et al. 2004; Tanaka et al. 2008), beim squamösen Ösophaguskarzinom (Ando et al. 2007) und beim Prostatakrebs (Gagnon et al. 2006; Padalecki et al. 2003). Von dem auf Bande 18q21 gelegenen Gen SMAD4 ist bekannt, dass eine verminderte Expression beim nicht-kleinzelligen Lungenkrebs mit Lymphknotenmetastasierung assoziiert ist (Ke et al. 2008).

\subsubsection{Molekularzytogenetische Muster und Klassifikation}

Auch hier muss wieder vorangestellt werden, dass eine Aussage zu den kleinzelligen Hirnmetastasen nicht möglich ist und daher unterbleibt. Es werden nur die nicht-kleinzelligen Hirnmetastasen besprochen.

\section{Wiederkehrendes Muster in nicht-kleinzelligen Hirnmetastasen}

Zwar ergab die statistische Auswertung aufgrund der Stichprobenproblematik nur für das Kollektiv der Plattenepithelkarzinome ein zufriedenstellendes Ergebnis, aber die Zusammenschau mit den adenomatösen, adenosquamösen und großzelligen Hirnmetastasen darf trotzdem zu einigen vorsichtigen Schlüssen gereichen: Es scheint in den nicht-kleinzelligen Hirnmetastasen ein metastasenspezifisches Muster zu existieren. An diesem metastatischen Genotyp scheinen Zugewinne im Bereich von 1q12q23 und Verluste der Chromosomenarme $8 \mathrm{p}, 9 \mathrm{p}$ und 18q beteiligt zu sein.

\section{Molekularzytogenetische Klassifikation}

Ob die aufgefundenen Veränderungen ein hirnmetastasenspezifisches Muster bilden, welches letztendlich zur Klassifikation geeignet sein könnte, wurde in Kapitel 3.6 (S. 75) mittels automatischer Klassifikation geprüft. Dazu wurde im Kollektiv der Plattenepithelkarzinome eine Clusteranalyse durchgeführt. Die Merkmale, nach denen klassifiziert wurde, waren die zuvor aufgefundenen signifikant unterschiedlichen Veränderungen.

Das Ergebnis war eine Klassifizierung der Hirnmetastasen mit einem positiven Vorhersagewert von $58,8 \%$. Dieser Wert ist für einen derartigen Test nicht schlecht, was im Vergleich deutlich wird: Der positive Vorhersagewert für ein Prostatakarzinom liegt bei einem PSA-Wert von 4-10 ng bei $25 \%$ und bei einem Wert von >10 ng bei 50-60\% 
(Fornara et al. 2002). Allerdings darf dieses Ergebnis keinesfalls Anlass dazu geben, bereits über Prognosemarker nachzudenken (siehe Kapitel 4.4.1).

\subsection{Schlussbetrachtung}

\subsubsection{Antworten auf die gestellten Fragen}

Die zu Beginn der Studie gestellten Fragen werden nun kurz beantwortet.

\section{Frage 1: Gibt es einen metastatischen Genotyp?}

Die Frage ist schnell zu beantworten: Ja, beim nicht-kleinzelligen Lungenkrebs scheint ein metastatischer Genotyp in Hirnmetastasen zu existieren. Beim kleinzelligen Lungenkrebs war dies mit den vorliegenden Daten nicht zu beurteilen.

\section{Frage 2: Welche sind die metastasenspezifischen Veränderungen?}

In den Hirnmetastasen vom Plattenepithelkarzinom konnten folgende Veränderungen als metastasenspezifisch beurteilt werden: Zugewinne von 1q12q21, 2q12q14, 7q21 und 10p13pter sowie Verluste von 8p12pter, 9p13pter, 13q21qter und 18q.

In den Hirnmetastasen vom Adenokarzinom waren signifikante metastasenspezifische Veränderungen in einem Verlust der Region 11p13p14 und dem Verlust des Chromosomenarms 18q zu erkennen. Wegen der sehr geringen Teststärke dieses Vergleichs mit nur 16 adenomatösen Hirnmetastasen muss davon ausgegangen werden, dass viele Unterschiede unentdeckt geblieben sind.

Für die übrigen nicht-kleinzelligen Hirnmetastasen, die adenosquamösen und großzelligen, war wegen fehlender Vergleichsdaten und zu geringer Stichprobenumfänge keine Suche nach metastasenspezifischen Veränderungen möglich. Beim kleinzelligen Lungenkrebs ist die Existenz metastasenspezifischer Veränderungen aufgrund der unzureichenden Datenlage nicht beurteilbar.

\section{Frage 3: Lassen sich Kandidatengene ausmachen?}

Auch diese Frage ist leicht zu beantworten: Nein, wegen der beschriebenen großen Unsicherheiten und der geringen Stichprobenumfänge war es nicht möglich, einen so begrenzten chromosomalen Abschnitt - z.B. eine einzelne Bande - auszumachen, dass ein Kandidatengen ins Auge gefasst werden könnte. Auch wenn dies mit den Mitteln der CGH prinzipiell möglich erscheint, so muss doch auf deren Screeningcharakter verwiesen und ein weiteres Eingrenzen von Kandidatengenen genaueren Methoden überlassen werden. 
Frage 4: Ist eine molekularzytogenetische Klassifikation möglich?

Diese Frage kann mit den vorliegenden Daten nur für die Hirnmetastasen vom Plattenepithelkarzinom mit Ja beantwortet werden. Es gibt Hinweise, dass bei ausreichender Fallzahl dies auch für die übrigen histologischen Typen des nicht-kleinzelligen Karzinoms bestätigt werden könnte. Zu den kleinzelligen Hirnmetastasen kann wiederum keine Aussage gemacht werden.

Eine molekularzytogenetische Klassifikation der Primärtumoren und Hirnmetastasen des Plattenepithelkarzinoms anhand der chromosomalen Veränderungen ist gut möglich, und zwar mit einem positiven Vorhersagewert von 58,8\%. Allerdings muss man sich immer vor Augen halten, dass das zugrunde liegende Muster vorerst nur in den Hirnmetastasen gefunden wurde. Für den Kliniker wäre das nicht von Interesse, denn was nutzte ihm die Vorhersage der Metastasierung, wenn man sie im Nachhinein anhand einer Hirnmetastase machen wollte? Letztlich möchte man den metastatischen Genotyp bereits im Primärtumor erkennen und die Gefahr einer Metastasierung dadurch vorhersehen können. Einzig eine Folgestudie, die das spezifische Muster in metastasierenden Primärtumoren bestätigen kann, würde einer solchen Klassifikation zu prognostischer Relevanz verhelfen.

\subsubsection{Zur Methode}

\section{Von der Stichprobengröße bis zum data-mining}

Um mit der CGH ein genaues Bild chromosomaler Veränderungen zu bekommen, sind große Stichproben vonnöten. Differenzen zwischen Tumorkollektiven zu finden macht noch größere erforderlich. Dass hohe Fallzahlen sinnvoll sind, zeigt Abbildung 4.21: Im Histogramm von 647 Fällen chronisch lymphatischer Leukämie hebt sich die Bande 13q14 deutlich heraus, welche bei dieser Erkrankung als bedeutsam bekannt ist (Hanlon et al. 2009).

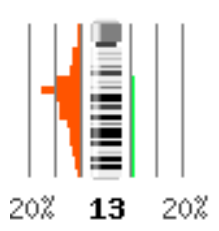

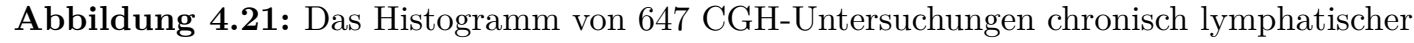
Leukämie zeigt ein deutliches Maximum der Verluste im Bereich der Bande 14q13. (Die Abbildung stammt aus der molekularzytogenetischen Datenbank Progenetix (Baudis 2000; Baudis und Cleary 2001)).
} 
Von 647 Fällen weit entfernt, lieferten die Hirnmetastasen vom Plattenepithelkarzinom mit 32 Fällen in der vorliegenden Studie dennoch brauchbare Ergebnisse. Allerdings darf ein solcher Stichprobenumfang bestenfalls als absolutes Minimum betrachtet werden. Wird diese Anzahl unterschritten, so wie bei den 16 adenomatösen Hirnmetastasen, ist eine Aussagekraft im Rahmen einer Vergleichsstudie nahezu nicht mehr gegeben.

Um mit einer statistischen Sicherheit von $95 \%$ einen Anteilswert auf $\pm 5 \%$ genau schätzen zu können, ist ein Stichprobenumfang von 385 Fällen notwendig. Strebt man einen Vergleich von Anteilswerten an, wie er in der vorliegenden Studie zum Auffinden des metastatischen Genotyps durchgeführt wurde, so lassen sich ebenfalls genaue Anforderungen formulieren: Um mit mindestens $80 \%$ iger Wahrscheinlichkeit einen Unterschied der Anteilswerte von $20 \%$ in einem Test zum Signifikanzniveau $\alpha=0,05$ aufspüren zu können, sollte ein Stichprobenumfang von jeweils 85 Fällen in beiden Gruppen gewählt werden; bei $10 \%$ Unterschied wären es bereits 155 Fälle (Casagrande et al. 1978; Haseman 1978).

Einzelstudien erreichen so gut wie nie solche Fallzahlen, möglicherweise vorhandene Muster bleiben zwangsläufig verborgen. Eine Abhilfe könnten hier molekularzytogenetische Datenbanken schaffen, in denen die Ergebnisse vieler Studien gesammelt werden. Das in Abbildung 4.21 präsentierte Bild stammt aus einer solchen molekularzytogenetischen Datenbank, Progenetix (Baudis 2000; Baudis und Cleary 2001). Durch die Ansammlung großer Datenmengen steht eine ausreichende Basis zur Verfügung, um sich auf die Suche nach verborgenen Mustern zu begeben. Rechnergestützte statistische Verfahren sind hierfür prädestiniert, man spricht dabei von data-mining oder genauer von knowledge discovery (Fayyad et al. 1996). Dies ist auch in molekularzytogenetischen Datenbanken gut möglich (Baudis 2006).

Auch wenn nicht in einem solchen Maße automatisiert, wie es beim data-mining gedacht ist, so sind in der vorliegenden Studie doch Ansätze davon verwirklicht worden: Eine mit statistischen Methoden durchgeführte Mustererkennung wurde unter Verwendung von Datenbankinhalten unternommen. Ziel war es, ein ansonsten verborgenes Muster zu finden, das des metastatischen Genotyps in Hirnmetastasen vom Lungenkrebs. Allerdings wurde dies durch unerwartete Probleme erschwert.

\section{Experteneinschätzung und der Mensch als Unsicherheitsfaktor}

Messergebnisse der CGH zu interpretieren erfordert erfahrene Spezialisten auf dem Gebiet der Molekularzytogenetik. Die Ergebnisse können dann eine sehr hohe Qualität erreichen. Die mit vote-counting zusammengetragenen Experteneinschätzungen kamen der Auswertung der rev-ish-Daten in Hinblick auf häufige Veränderungen sehr nahe. Weiterhin waren im Kollektiv der Plattenepithelkarzinome viele der später als statistisch signifikant aufgefallenen Unterschiede bereits aus der qualitativen Betrachtung der Experteneinschätzungen bekannt.

Allerdings sind zwei Einschränkungen zu machen: (i) Wann letztendlich eine Veränderung „häufig“ und damit möglicherweise auch wichtig ist, kann nirgends nachgelesen werden. Dies ist nicht verwunderlich, denn die statistische Verteilung der Veränderungen ist bisher nicht 
bekannt. Ein jeder Experte muss seinen Schwellenwert zwangsläufig willkürlich festsetzen, z.B. bei $20 \%$ wie in der vorliegenden Studie geschehen. Damit schafft man aber eine weitere Einschränkung (ii): Die meisten der in der Auswertung der Experteneinschätzung aufgefallenen Unterschiede, die dann aber statistisch nicht erhärtet werden konnten, scheinen auf Schwelleneffekte zurückführbar zu sein.

Alle Veränderungen, deren Anteilswerte sich in der Nähe der willkürlich gesetzten Schwelle befinden, sind für Fehler durch Schwelleneffekte anfällig. Die Schwelle und mit ihr die „häufigen“ Veränderungen erleichtern den Blick auf die Daten, aber dies wird durch eine Informationsreduktion erkauft. Der Unterschied zwischen $5 \%$ und $50 \%$ ist nicht länger von dem Unterschied zwischen $19 \%$ und $21 \%$ zu unterscheiden: In beiden Fällen steht eine nicht zu nennende einer „häufigen“ Veränderung gegenüber.

Möchte man derlei Fehler umgehen, so entschließt man sich für einen quantitativstatistischen Ansatz. Doch nicht nur der qualitative Ansatz der Experteneinschätzung, auch der scheinbar rein quantitative Ansatz statistischer Auswertung von Datensätzen in rev-ish-Schreibweise ist bei der CGH nicht frei von Beobachtereinflüssen. Wie sich gezeigt hat, beinhaltet das quantitative Messverfahren CGH zumeist einen subjektiven Bewertungsschritt, der bei der Übersetzung der Ratioprofile in die rev-ish-Codierung auftritt. Dieser subjektive Bewertungsschritt umfasst die manuelle Berichtigung systematischer Messabweichungen.

Ein Problem ergibt sich allein daraus, dass dieser Schritt nicht standardisiert ist und dass Daten aus unterschiedlichen Arbeitsgruppen letztendlich nicht mehr vergleichbar sind. Da eine genaue Dokumentation des Berichtigungsschrittes nicht üblich ist, können die unterschiedlichen Datensätze in einer Metaanalyse auch nicht nachträglich auf ein gemeinsames Niveau transformiert werden. Dass eine Berichtigung auch gar nicht durchgeführt worden sein kann und damit sogar Messabweichungen in den Daten vorkommen können, kommt noch hinzu. Was am Ende bleibt, sind schwierig zu kalkulierende Unsicherheiten.

\section{Lektionen für die Zukunft}

Speziell für die Suche nach dem metastatischen Genotyp sollten künftig zwei Dinge berücksichtigt werden: Einerseits sind ausreichend große Stichproben zu wählen. Andererseits sind Messabweichungen, seien sie systematischer oder zufälliger Natur, immer mitzubedenken. Für CGH-Vergleiche, wie sie in der vorliegenden Studie unternommen wurden, bedeutet dies: Die systematische Messabweichung der Methode und deren Berichtigung ist meist so unzureichend dokumentiert, dass man von der Verwendung von Befunden aus Datenbanken oder der Literatur absehen sollte. Oder anders ausgedrückt: Will man CGH-Vergleiche machen, so sollten die Befunde beider Vergleichsgruppen aus demselben Labor stammen.

Allgemein sollte das in Physik und Ingenieurswissenschaften gebräuchliche Konzept des Messens auf dafür geeignete biomedizinische Verfahren übertragen werden. Eine Leitlinie lieferte die DIN 1319, in der es zum vollständigen Messergebnis heißt: Schätzwert 
für den wahren Wert mit quantitativen Angaben zur Messgenauigkeit ${ }^{1}$. Dass eine solche Übertragung möglich ist, zeigen für die CGH die Beispiele von Kirchhoff et al. (1998) und Moore et al. (1997).

Kommen wir nun auf die eingangs gestellte Forderung nach großen Stichproben zurück und dem data-mining als einem Mittel, um in den großen Fallzahlen, die sich aus den vielen kleinen Einzelstudien ergeben, Muster erkennen zu können. Ein Schluss muss gezogen werden: Aufgrund der ausgeprägten Unsicherheiten erscheint ein solcher Ansatz nur teilweise praktikabel. Data-mining würde die groben Muster erfassen, nicht aber die feinen, die zu entdecken große Datenmengen ermöglichen sollten. Weiterhin ist bei so entdeckten Mustern nie sicher, inwieweit sie chromosomale Veränderungen widerspiegeln oder Artefakte durch systematische Fehler in den Quelldaten darstellen.

$\mathrm{Zu}$ kleine Stichproben, nicht ausreichende Standardisierung vieler Einzelstudien, Unsicherheiten über Unsicherheiten - all dies offenbart eine übergeordnete Problematik in der biomedizinischen Forschung. Im ungünstigsten Falle bliebe jede Arbeitsgruppe eine Insel, die Integration des Wissens wäre kaum möglich, der Blick aufs Ganze versperrt. Diesem „Insel"-Modell steht der Ansatz im großen Stil gegenüber, der in der Pharmaforschung üblich ist und der auch bei der Sequenzierung des menschlichen Genoms mit Erfolg gewählt wurde. Ob dieses High-throughput-Screening der Krebsforschung ebensolchen Erfolg bescheren könnte, muss die Zukunft zeigen.

\subsubsection{Ausblick}

Beim kleinzelligen Lungenkrebs muss die Suche nach einem metastatischen Genotyp mit den hier gelernten methodischen Lektionen von neuem begonnen werden. Weitergehende Aussagen sind nicht möglich.

Beim nicht-kleinzelligen Lungenkrebs ist die Situation eine bessere: Dass ein metastatischer Genotyp existiert, kann mit den vorliegenden Ergebnissen behauptet werden. Allerdings liegen aufgrund vielfältiger methodischer Unsicherheiten die Details im Dunkeln. Es wären daher drei Dinge für die Zukunft zu wünschen: (i) Die Suche nach dem metastatischen Genotyp sollte wiederholt werden, um die vorliegenden Ergebnisse zu bestätigen und um ein genaueres Bild der Veränderungen zu erhalten. Dabei sollten die methodischen Probleme durch ein entsprechendes Studiendesign umgangen werden. (ii) Die Suche nach Kandidatengenen sollte in den aufgefallenen chromosomalen Regionen mit genaueren Methoden weitergeführt werden. (iii) Eine Bestätigung des metastatischen Genotyps ist von metastasierenden Primärtumoren ausgehend zu versuchen.

Letztendlich ist dies der Anfang eines langen und steinigen Weges, an dessen Ende diagnostisch verwertbare Marker oder therapeutische Konzepte stehen könnten. Unterwegs sollte aber auch die Bedeutung eines scharfen Blickes auf die verwendeten Methoden niemals unterschätzt werden.

1 zitiert nach Geller et al. (2007) 


\section{Zusammenfassung}

Ein Merkmal der Bösartigkeit von Krebserkrankungen ist die Fähigkeit der Tumoren, in Form von Metastasen andere Regionen des Körpers zu befallen (Virchow 1863). Die Metastasierung bedroht das Leben des Patienten oft stärker als der zugrundeliegende Primärtumor (Minn und Massagué 2008). Dies gilt insbesondere für Hirnmetastasen.

Lungenkrebs trägt unter allen Krebserkrankungen den größten Anteil zur Hirnmetastasierung bei - fast $40 \%$ der diagnostizierten Hirnmetastasen stammen aus der Lunge (Nussbaum et al. 1996). Es existieren zwei histologische Gruppen, die sich auch klinisch durch ihr Verhalten unterscheiden: der seltenere kleinzellige Lungenkrebs (Small Cell Lung Cancer - SCLC) und die Gruppe des häufigeren nicht-kleinzelligen Lungenkrebses (Non Small Cell Lung Cancer - NSCLC).

Als Genotyp wird die Gesamtheit der Gene eines Organismus bezeichnet, als Phänotyp die Gesamtheit seiner Eigenschaften (Mahner und Kary 1997). In der vorliegenden Studie wurde versucht, der bösartigen Eigenschaft des Lungenkrebses, Metastasen zu bilden, eine Entsprechung auf Seiten des Genotyps gegenüberzustellen. Dazu wurden Hirnmetastasen vom Lungenkrebs auf chromosomale Veränderungen untersucht, die für diese Metastasen charakteristisch sind.

Es wurde eine molekularzytogenetische Screeningmethode eingesetzt, die vergleichende genomische Hybridisierung (Comparative Genomic Hybridization - CGH). Veränderungen der Chromosomen in Tumorgewebe können damit erfasst werden, wenn sie eine Abweichung vom normalen DNA-Gehalt verursachen. Man spricht von Zugewinnen und Verlusten (du Manoir et al. 1993; Kallioniemi A et al. 1992).

Um eine Genotyp-Phänotyp-Korrelation aufzudecken, wurden zunächst 22 kleinzellige und 66 nicht-kleinzellige (darunter 32 Plattenepithel-, 16 Adenokarzinome sowie 11 adenosquamöse und 7 großzellige) Hirnmetastasen mit CGH auf chromosomale Veränderungen untersucht. Anschließend wurden durch eine Literaturrecherche und Metaanalyse CGH-Befunde von entsprechenden Primärtumoren gewonnen. Hirnmetastasen und Primärtumoren konnten qualitativ und quantitativ-statistisch miteinander verglichen werden.

Das Erkenntnisinteresse wurde in Form von vier Fragen präzisiert, die mit den Ergebnissen der Studie beantwortet werden sollten:

\section{Frage 1: Gibt es einen metastatischen Genotyp?}

Ja, beim nicht-kleinzelligen Lungenkrebs scheint ein metastatischer Genotyp in Hirnmetastasen zu existieren. Beim kleinzelligen Lungenkrebs war dies mit den vorliegenden Daten nicht zu beurteilen. 


\section{Frage 2: Welche sind die metastasenspezifischen Veränderungen?}

Hirnmetastasen vom Plattenepithelkarzinom zeigten die folgenden metastasenspezifischen Veränderungen: Zugewinne von 1q12q21, 2q12q14, 7q21 und 10p13pter sowie Verluste von 8p12pter, 9p13pter, 13q21qter und 18q. In den Hirnmetastasen vom Adenokarzinom waren signifikante metastasenspezifische Veränderungen nur in einem Verlust der Region 11p13p14 und dem Verlust des Chromosomenarms 18q zu erkennen. Wegen der niedrigen Fallzahl adenomatöser Hirnmetastasen muss jedoch von einer Unterschätzung ausgegangen werden.

Für die übrigen nicht-kleinzelligen Hirnmetastasen, die adenosquamösen und großzelligen, war wegen fehlender Vergleichsdaten und zu geringer Stichprobenumfänge keine Suche nach metastasenspezifischen Veränderungen möglich. Beim kleinzelligen Lungenkrebs ist die Existenz metastasenspezifischer Veränderungen aufgrund der unzureichenden Datenlage nicht beurteilbar.

\section{Frage 3: Lassen sich Kandidatengene ausmachen?}

Nein. Grund dafür sind große methodische Unsicherheiten, die während der Auswertung im Studienansatz entdeckt worden waren und die auf einer unzureichend standardisierten Berichtigung systematischer Messabweichungen der CGH beruhen. Diese Schwierigkeiten und die geringen Stichprobenumfänge machen es unmöglich, einen so begrenzten chromosomalen Abschnitt - z.B. eine einzelne Bande - auszumachen, dass ein Kandidatengen ins Auge gefasst werden könnte.

\section{Frage 4: Ist eine molekularzytogenetische Klassifikation möglich?}

Diese Frage kann mit den vorliegenden Daten nur für die Hirnmetastasen vom Plattenepithelkarzinom beantwortet werden: Eine molekularzytogenetische Klassifikation von Primärtumoren und Hirnmetastasen anhand der chromosomalen Veränderungen ist gut möglich, und zwar mit einem positiven Vorhersagewert von 58,8\%. Die mögliche prognostische Relevanz dieses Befundes sollte Gegenstand weiterer Forschung sein. 


\section{Literaturverzeichnis}

Accuracy and precision (o. Verf.). Wikipedia, The Free Encyclopedia. 2009. Verfügbar unter: http://en.wikipedia.org/wiki/Accuracy_and_precision. Zugriff am 11.06.2009.

Adunka, F: Messunsicherheiten - Theorie und Praxis, 3. Auflage. Vulkan Verlag, Essen 2007.

Albertson DG (2006): Gene amplification in cancer. Trends Genet 22, 447-455

Ando T, Ishiguro H, Kimura M, Mitsui A, Mori Y, Sugito N, Tomoda K, Mori R, Harada K, Katada T (2007): Frequent loss of the long arm of chromosome 18 in esophageal squamous cell carcinoma. Oncol Rep 17, 1005-1011

Arriagada R, Le Chevalier T, Borie F, Rivière A, Chomy P, Monnet I, Tardivon A, Viader F, Tarayre M, Benhamou S (1995): Prophylactic cranial irradiation for patients with small-cell lung cancer in complete remission. J Natl Cancer Inst $\underline{87}$, 183-190

Ban JD: Fluorescent Detection PCR-Based STR DNA-Protocol: Powerplex 1.1, 2.1 and 16 Bio Systems - Forensic Biology Section Procedure Manual, Section III. Commonwealth of Virginia, Department of Criminal Justice Services, Division of Forensic Science, Richmond 2003

Barnholtz-Sloan JS, Sloan AE, Davis FG, Vigneau FD, Lai P, Sawaya RE (2004): Incidence proportions of brain metastases in patients diagnosed (1973 to 2001) in the Metropolitan Detroit Cancer Surveillance System. J Clin Oncol 22, 2865-2872

Barth TF, Benner A, Bentz M, Döhner H, Möller P, Lichter P (2000): Risk of false positive results in comparative genomic hybridization. Genes Chromosomes Cancer 2ㅛ, 353-357

Batzler WU, Giersiepen K, Hentschel S, Husmann G, Kaatsch P, Katalinic A, Kieschke J, Kraywinkel K, Meyer M: Krebs in Deutschland 2003-2004 Häufigkeiten und Trends. 8. Auflage; hrsg. Vom Robert-Koch-Institut und der Gesellschaft der epidemiologischen Krebsregister in Deutschland e.V.; Robert-Koch-Institut, Berlin 2008

Baudis M: Progenetix - cytogenetic abnormalities in human cancer. 2000. Verfügbar unter: www . progenetix.net. Zugriffe: Literaturrecherche und Datenentnahme am 16.07.2008.

Baudis M (2006): Online database and bioinformatics toolbox to support data mining in cancer cytogenetics. Biotechniques $\underline{40}, 269-70,272$ 
Baudis M: ISCN2ProgenetiXML - ISCN annotation conversion and visualization. Progenetix Website. 2009 a. Verfügbar unter: http://www.progenetix.net/cgi-bin/front_ ISCN2matrix.cgi. Zugriff am 21.06.2009.

Baudis M: (Preliminary) Guide to the Progenetix Analysis Tools. Progenetix Website. 2009 b. Verfügbar unter: http://www.progenetix.net/progenetix/presentations/ Progenetix_analysis_guide.pdf. Zugriff am 21.06.2009.

Baudis M, Cleary ML (2001): Progenetix.net: an online repository for molecular cytogenetic aberration data. Bioinformatics 17, 1228-1229

Bendell JC, Domchek SM, Burstein HJ, Harris L, Younger J, Kuter I, Bunnell C, Rue M, Gelman R, Winer E (2003): Central nervous system metastases in women who receive trastuzumab-based therapy for metastatic breast carcinoma. Cancer 97, 2972-2977

Benjamini Y, Hochberg Y (1995): Controlling the False Discovery Rate: a Practical and Powerfull Approach to Multiple Testing. J R Stat Soc Series B Stat Methodol 57, 289-300

Bentz M, Werner CA, Döhner H, Joos S, Barth TF, Siebert R, Schröder M, Stilgenbauer S, Fischer K, Möller P (1996): High incidence of chromosomal imbalances and gene amplifications in the classical follicular variant of follicle center lymphoma. Blood $\underline{88}, 1437-1444$

Bentz M, Plesch A, Stilgenbauer S, Döhner H, Lichter P (1998): Minimal sizes of deletions detected by comparative genomic hybridization. Genes Chromosomes Cancer 21, 172-175

Björkqvist AM, Husgafvel-Pursiainen K, Anttila S, Karjalainen A, Tammilehto L, Mattson K, Vainio H, Knuutila S (1998 a): DNA gains in 3q occur frequently in squamous cell carcinoma of the lung, but not in adenocarcinoma. Genes Chromosomes Cancer 22, 79-82

Björkqvist AM, Tammilehto L, Nordling S, Nurminen M, Anttila S, Mattson K, Knuutila S (1998 b): Comparison of DNA copy number changes in malignant mesothelioma, adenocarcinoma and large-cell anaplastic carcinoma of the lung. Br J Cancer $77,260-$ 269

Bockmühl U, Petersen S, Schmidt S, Wolf G, Jahnke V, Dietel M, Petersen I (1997): Patterns of chromosomal alterations in metastasizing and nonmetastasizing primary head and neck carcinomas. Cancer Res 푸, 5213-5216

Bockmühl U, Schlüns K, Schmidt S, Matthias S, Petersen I (2002): Chromosomal alterations during metastasis formation of head and neck squamous cell carcinoma. Genes Chromosomes Cancer $\underline{33}, 29-35$

Boelens MC, Kok K, van der Vlies P, van der Vries G, Sietsma H, Timens W, Postma DS, Groen HJM, van den Berg A (2009): Genomic aberrations in squamous cell lung carcinoma related to lymph node or distant metastasis. Lung Cancer, Online-Veröffentlichung vor Druck; doi: 10.1016/j.lungcan.2009.02.017 
Bonner J, Kung G, Bekhor I (1967): A method for the hybridization of nucleic acid molecules at low temperature. Biochemistry $\underline{6}, 3650-3653$

Boveri T: Zur Frage der Entwicklung maligner Tumoren. Verlag von Gustav Fischer, Jena 1914

Breasted JH: The Edwin Smith surgical papyrus, Band 1: Hieroglyphic transliteration and commentary. The University of Chicago, Oriental Institute Publications, Chicago 1930

Carolan H, Sun AY, Bezjak A, Yi QL, Payne P, Kane G, Waldron J, Leighl N, Feld R, Burkes R (2005): Does the incidence and outcome of brain metastases in locally advanced non-small cell lung cancer justify prophylactic cranial irradiation or early detection? Lung Cancer $\underline{49}$, 109-115

Casagrande JT, Pike MC, Smith PG (1978): An Improved Approximate Formula for Calculating Sample Sizes for Comparing Two Binomial Distributions. Biometrics $\underline{34}, 483-$ 486

Chen AM, Jahan TM, Jablons DM, Garcia J, Larson DA (2007): Risk of cerebral metastases and neurological death after pathological complete response to neoadjuvant therapy for locally advanced nonsmall-cell lung cancer: clinical implications for the subsequent management of the brain. Cancer 109, 1668-1675

Cher ML, Bova GS, Moore DH, Small EJ, Carroll PR, Pin SS, Epstein JI, Isaacs WB, Jensen RH (1996): Genetic alterations in untreated metastases and androgen-independent prostate cancer detected by comparative genomic hybridization and allelotyping. Cancer Res 트, 3091-3102

Chujo M, Noguchi T, Miura T, Arinaga M, Uchida Y, Tagawa Y (2002): Comparative genomic hybridization analysis detected frequent overrepresentation of chromosome $3 \mathrm{q}$ in squamous cell carcinoma of the lung. Lung Cancer $\underline{38}, 23-29$

Dawson J: A History of Cancer of the male Breast; in: Advances in Oncobiology, Band 2: Breast Cancer; hrsg. von Bittar EE, Heppner G, Peters WP, Visscher DW; Elsevier, Oxford 1998, 229-244

DIN 1319. Grundlagen der Meßtechnik, 4 Teile (o. Verf.). Norm; herausgegeben vom Deutschen Institut für Normung (DIN). Beuth Verlag, Berlin 1995-2005.

DIN 1319-1: 1995-01. Grundlagen der Meßtechnik - Teil 1: Grundbegriffe (o. Verf.). Norm; herausgegeben vom Deutschen Institut für Normung (DIN). Beuth Verlag, Berlin 1995

DIN ISO 5725-1: 1997-11. Genauigkeit (Richtigkeit und Präzision) von Meßverfahren und Meßergebnissen - Teil 1: Allgemeine Grundlagen und Begriffe. Norm; herausgegeben vom Deutschen Institut für Normung (DIN). Beuth Verlag, Berlin 1997 
Doty P, Marmur J, Eigner J, Schildkraut C (1960): Strand Separation and specific Recombination in deoxyribonucleic Acids: Physical chemical Studies. Proc Natl Acad Sci U S A $\underline{46}, 461-476$

Drings P: Nicht-kleinzelliges Lungenkarzinom; in: Kurzgefasste interdisziplinäre Leitlinien 2008 - Empfehlungen zur Diagnostik und Therapie maligner Erkrankungen; hrsg. von Garbe C, Howaldt HP, Adler G, Jakse G, Beckmann MW, Kloke M, Bootz F, Kreienberg R, Creutzig U, Schmiegel W für die Deutsche Krebsgesellschaft; W. Zuckschwerdt, München, 2008, Online-Version verfügbar unter: http://www.krebsgesellschaft. de/download/11_c_01b.pdf, Website der Deutschen Krebsgesellschaft. Zugriff am 30.06.2009.

du Manoir S, Speicher MR, Joos S, Schröck E, Popp S, Döhner H, Kovacs G, Robert-Nicoud M, Lichter P, Cremer T (1993): Detection of complete and partial chromosome gains and losses by comparative genomic in situ hybridization. Hum Genet $\underline{90}, 590-610$

du Manoir S, Kallioniemi OP, Lichter P, Piper J, Benedetti PA, Carothers AD, Fantes JA, García-Sagredo JM, Gerdes T, Giollant M (1995 a): Hardware and software requirements for quantitative analysis of comparative genomic hybridization. Cytometry $\underline{19}, 4-9$

du Manoir S, Schröck E, Bentz M, Speicher MR, Joos S, Ried T, Lichter P, Cremer T (1995 b): Quantitative analysis of comparative genomic hybridization. Cytometry $\underline{19}, 27-41$

Duesberg P, Rasnick D (2000): Aneuploidy, the somatic mutation that makes cancer a species of its own. Cell Motil Cytoskeleton 47, 81-107

Duesberg P, Li R, Fabarius A, Hehlmann R (2005): The chromosomal basis of cancer. Cell Oncol 27, 293-318

Ensembl Assembly and Genebuild Statistics (o.Verf.). Ensembl Website. 2009. Verfügbar unter: http://www.ensembl.org/Homo_sapiens/Info/StatsTable. Zugriff am 25.06.2009.

Fayyad U, Piatetsky-Shapiro G, Smyth P (1996): From Data Mining to Knowledge Discovery in Databases. AI Magazine 17, 37-54

Fearon ER, Vogelstein B (1990): A genetic model for colorectal tumorigenesis. Cell $\underline{61}$, 759767

Ferguson-Smith: Monosomy; in: Encyclopedia of Genetics, Band 3; hrsg. von Brenner S, Miller JH; Academic Press, London 2002, 1239

Fornara P, Luboldt HJ, Wolff J, Doehn C: Prostataspezifisches Antigen (PSA); in: Leitlinie PSA-Bestimmung in der Prostatakarzinomdiagnostik (Früherkennung des Prostatakarzinoms), Vollversion; hrsg. von Rübben H, Schalkhäuser 
K, Wolff J, Luboldt HJ. 2002, 27-32. Website der Deutschen Krebsgesellschaft. Verfügbar unter: http://www.krebsgesellschaft.de/download/ebm-leitlinie_ frueherkennung_des_prostatakarzinoms.pdf. Zugriff am 12.06.2009.

Friend SH, Bernards R, Rogelj S, Weinberg RA, Rapaport JM, Albert DM, Dryja TP (1986): A human DNA segment with properties of the gene that predisposes to retinoblastoma and osteosarcoma. Nature 323, 643-646

Gagnon A, Ripeau JS, Zvieriev V, Chevrette M (2006): Chromosome 18 suppresses tumorigenic properties of human prostate cancer cells. Genes Chromosomes Cancer $\underline{45}, 220-230$

Gao AC, Lou W, Dong JT, Isaacs TJ (1997): CD44 is a metastasis suppressor gene for prostatic cancer located on human chromosome 11p13. Cancer Res $\underline{57}, 846-849$

Gavrilovic IT, Posner JB (2005): Brain metastases: epidemiology and pathophysiology. J Neurooncol $\underline{75}, 5-14$

Geller R, Humpert HM, Trapp W: Grundlagen der Messtechnik; in: Glossar der Metrologie; herausgegeben von der Deutschen Akademie für Metrologie (DAM) beim Bayerischen Landesamt für Maß und Gewicht. 2007, 4-12. Website der Deutschen Akademie für Metrologie. Verfügbar unter: http://www.dam-germany.de/Fachinformation/Glossar_ 12_2007_Internet.pdf. Zugriff am 12.06.2009.

Glasel JA (1995): Validity of nucleic acid purities monitored by $260 \mathrm{~nm} / 280 \mathrm{~nm}$ absorbance ratios. Biotechniques $\underline{18}, 62-63$

Goelz SE, Hamilton SR, Vogelstein B (1985): Purification of DNA from formaldehyde fixed and paraffin embedded human tissue. Biochem Biophys Res Commun 130, 118-126

Goeze A, Schlüns K, Wolf G, Thäsler Z, Petersen S, Petersen I (2002): Chromosomal imbalances of primary and metastatic lung adenocarcinomas. J Pathol $\underline{196}$, 8-16

Goodison S, Yuan J, Sloan D, Kim R, Li C, Popescu NC, Urquidi V (2005): The RhoGAP protein DLC-1 functions as a metastasis suppressor in breast cancer cells. Cancer Res $\underline{65}, 6042-6053$

Groffen J, Stephenson JR, Heisterkamp H, de Klein A, Bartram CR, Grosveld G (1984): Philadelphia chromosomal breakpoints are clustered within a limited region, bcr, on chromosome 22. Cell $\underline{36}, 93-99$

Guðmundsson K (1970): A survey of tumors of the central nervous system in Iceland during the 10-year period 1954-1963. Acta Neurol Scand $\underline{46}, 538-552$

Hanahan D, Weinberg RA (2000): The hallmarks of cancer. Cell 100, 57-70 
Hanlon K, Ellard S, Rudin CE, Thorne S, Davies T, Harries LW (2009): Evaluation of 13q14 Status in Patients with Chronic Lymphocytic Leukemia Using Single Nucleotide Polymorphism-Based Techniques. J Mol Diagn 11, Online-Veröffentlichung vor Druck; doi: $10.2353 /$ jmoldx.2009.080167

Hannen EJM, Macville MVE, Wienk SM, Slootweg PJ, Manni JJ, Hanselaar AGJM, de Wilde PCM (2004): Different chromosomal imbalances in metastasized and nonmetastasized tongue carcinomas identified by comparative genomic hybridization. Oral Oncol $\underline{40}, 364-371$

Hansemann D (1890): Ueber assymmetrische Zellteilung in Epithelkrebsen und deren biologische Bedeutung. Virchows Arch 119, 299-326

Harris H, Miller OJ, Klein G, Worst P, Tachibana T (1969): Suppression of malignancy by cell fusion. Nature $\underline{223}, 363-368$

Haseman JK (1978): Exact Sample Sizes for Use with the Fisher-Irwin Test for 2 x 2 Tables. Biometrics $\underline{34}, 106-109$

Hayashi M, Kawauchi S, Ueda K, Kaneda Y, Oga A, Furuya T, Hamano K, Sasaki K (2005): Genomic alterations detected by comparative genomic hybridization in primary lung adenocarcinomas with special reference to the relationship with DNA ploidy. Oncol Rep 14, 1429-1435

Healy KD, Hodgson L, Kim TY, Shutes A, Maddileti S, Juliano RL, Hahn KM, Harden TK, Bang YJ, Der CJ (2008): DLC-1 suppresses non-small cell lung cancer growth and invasion by RhoGAP-dependent and independent mechanisms. Mol Carcinog 47, 326-337

Heisterkamp N, Stephenson JR, Groffen J, Hansen PF, de Klein A, Bartram CR, Grosveld G (1983): Localization of the c-ab1 oncogene adjacent to a translocation break point in chronic myelocytic leukaemia. Nature $\underline{306}, 239-242$

Hochstenbag MM, Twijnstra A, Wilmink JT, Wouters EF, ten Velde GP (2000): Asymptomatic brain metastases (BM) in small cell lung cancer (SCLC): MR-imaging is useful at initial diagnosis. J Neurooncol $\underline{48}, 243-248$

Houldsworth J, Chaganti RS (1994): Comparative genomic hybridization: an overview. Am J Pathol 145, 1253-1260

Hubbard TJP, Aken BL, Ayling S, Ballester B, Beal K, Bragin E, Brent S, Chen Y, Clapham P, Clarke L (2009): Ensembl 2009. Nucleic Acids Res 37, D690-D697

Hummel M, Bentink S, Berger H, Klapper W, Wessendorf S, Barth TFE, Bernd HW, Cogliatti SB, Dierlamm J, Feller AC (2006 a): A biologic definition of Burkitt's lymphoma from transcriptional and genomic profiling. N Engl J Med 354, 2419-2430 
Hummel M, Bentink S, Berger H, Klapper W, Wessendorf S, Barth TFE, Bernd HW, Cogliatti SB, Dierlamm J, Feller AC: A biologic definition of Burkitt's lymphoma from transcriptional and genomic profiling - Supplementary Appendix. Website des New England Journal of Medicine. 2006 b. Verfügbar unter: http: //content . nejm. org/cgi/ content/full/354/23/2419/DC1. Zugriff am 21.06.2009.

Imoto I, Izumi H, Yokoi S, Hosoda H, Shibata T, Hosoda F, Ohki M, Hirohashi S, Inazawa J (2006): Frequent silencing of the candidate tumor suppressor PCDH20 by epigenetic mechanism in non-small-cell lung cancers. Cancer Res $\underline{66}$, 4617-4626

Inui N, Kitagawa K, Miwa S, Hattori T, Chida K, Nakamura H, Kitagawa M (2003): High expression of Cks1 in human non-small cell lung carcinomas. Biochem Biophys Res Commun 303, 978-984

ISO/IEC Guide 98-3:2008. Uncertainty of measurement - Part 3: Guide to the expression of uncertainty in measurement (GUM:1995) (o. Verf.). Norm; herausgegeben von der Internationalen Organisation für Normung (ISO). o.Verl., Genf 2008

ISO/IEC Guide 99:2007. International vocabulary of metrology - Basic and general concepts and associated terms (VIM) (o. Verf.). Norm; herausgegeben von der Internationalen Organisation für Normung (ISO). o. Verl., Genf 2007.

Isola J, DeVries S, Chu L, Ghazvini S, Waldman F (1994): Analysis of changes in DNA sequence copy number by comparative genomic hybridization in archival paraffin-embedded tumor samples. Am J Pathol 145, 1301-1308

Jackman DM, Johnson BE (2005): Small-cell lung cancer. Lancet $\underline{366}$, 1385-1396

Jeuken JWM, Sprenger SHE, Wesseling P (2002): Comparative genomic hybridization: practical guidelines. Diagn Mol Pathol $\underline{11}, 193-203$

Jiang JK, Chen YJ, Lin CH, Yu IT, Lin JK (2005): Genetic changes and clonality relationship between primary colorectal cancers and their pulmonary metastases - an analysis by comparative genomic hybridization. Genes Chromosomes Cancer $\underline{43}$, 25-36

Johnen G, Krismann M, Jaworska M, Müller KM (2003): CGH-Befunde bei neuroendokrinen Tumoren der Lunge. Pathologe 24, 303-307

Joos S, Bergerheim US, Pan Y, Matsuyama H, Bentz M, du Manoir S, Lichter $\mathrm{P}$ (1995): Mapping of chromosomal gains and losses in prostate cancer by comparative genomic hybridization. Genes Chromosomes Cancer 14, 267-276

Kallioniemi A, Kallioniemi OP, Sudar D, Rutovitz D, Gray JW, Waldman F, Pinkel D (1992): Comparative genomic hybridization for molecular cytogenetic analysis of solid tumors. Science $\underline{258}, 818-821$ 
Kallioniemi OP, Kallioniemi A, Piper J, Isola J, Waldman FM, Gray JW, Pinkel D (1994): Optimizing comparative genomic hybridization for analysis of DNA sequence copy number changes in solid tumors. Genes Chromosomes Cancer 므, 231-243

Kang JU, Kang JJ, Kwon KC, Park JW, Jeong TE, Noh SM, Koo SH (2006): Genetic alterations in primary gastric carcinomas correlated with clinicopathological variables by array comparative genomic hybridization. J Korean Med Sci 21, 656-665

Karhu R, Kähkönen M, Kuukasjärvi T, Pennanen S, Tirkkonen M, Kallioniemi O (1997): Quality control of CGH: impact of metaphase chromosomes and the dynamic range of hybridization. Cytometry 28, 198-205

Ke Z, Zhang X, Ma L, Wang L (2008): Deleted in pancreatic carcinoma locus 4/Smad4 participates in the regulation of apoptosis by affecting the Bcl-2/Bax balance in non-small cell lung cancer. Hum Pathol $\underline{39}$, 1438-1445

Kirchhoff M. High Resolution CGH technical notes. Website des Chromosome Laboratory, Dept. of Clinical Genetics, Rigshospitalet, Copenhagen. 2005. Verfügbar unter: http: //www. chromosomelab.dk/cgh/cyto.htm. Zugriff am 02.05.2009.

Kirchhoff M, Gerdes T, Rose H, Maahr J, Ottesen AM, Lundsteen C (1998): Detection of chromosomal gains and losses in comparative genomic hybridization analysis based on standard reference intervals. Cytometry $\underline{31}, 163-173$

Kirchhoff M, Gerdes T, Maahr J, Rose H, Bentz M, Döhner H, Lundsteen C (1999): Deletions below 10 megabasepairs are detected in comparative genomic hybridization by standard reference intervals. Genes Chromosomes Cancer 25, 410-413

Kirchhoff M, Rose H, Maahr J, Gerdes T, Bugge M, Tommerup N, Tümer Z, Lespinasse J, Jensen PK, Wirth J (2000): High resolution comparative genomic hybridisation analysis reveals imbalances in dyschromosomal patients with normal or apparently balanced conventional karyotypes. Eur J Hum Genet $\underline{8}, 661-668$

Kjellman M, Kallioniemi OP, Karhu R, Höög A, Farnebo LO, Auer G, Larsson C, Bäckdahl M (1996): Genetic aberrations in adrenocortical tumors detected using comparative genomic hybridization correlate with tumor size and malignancy. Cancer Res $\underline{56}, 4219-$ 4223

Klingbeil P, Marhaba R, Jung T, Kirmse R, Ludwig T, Zöller M (2009): CD44 variant isoforms promote metastasis formation by a tumor cell-matrix cross-talk that supports adhesion and apoptosis resistance. Mol Cancer Res 그, 168-179

Knudson AG (1971): Mutation and cancer: statistical study of retinoblastoma. Proc Natl Acad Sci U S A $\underline{68}, 820-823$ 
Landegent JE, Jansen in de Wal N, Dirks RW, Baao F, van der Ploeg M (1987): Use of whole cosmid cloned genomic sequences for chromosomal localization by non-radioactive in situ hybridization. Hum Genet $\underline{77}, 366-370$

Lefter LP, Sunamura M, Furukawa T, Takeda K, Kotobuki N, Oshimura M, Matsuno S, Horii A (2003): Inserting chromosome 18 into pancreatic cancer cells switches them to a dormant metastatic phenotype. Clin Cancer Res $\underline{9}, 5044-5052$

Lefter LP, Sunamura M, Furukawa T, Yastsuoka T, Abe H, Inoue H, Abe T, Egawa S, Miura K, Morita R, Horii A, Matsuno S (2004): Functional analysis of chromosome 18 in pancreatic cancer: strong evidence for new tumour suppressor genes. Asian J Surg 27, 85-92

Leung SY, Ho C, Tu IP, Li R, So S, Chu KM, Yuen ST, Chen X (2006): Comprehensive analysis of 19q12 amplicon in human gastric cancers. Mod Pathol $\underline{19}$, 854-863

Levin NA, Brzoska PM, Warnock ML, Gray JW, Christman MF (1995): Identification of novel regions of altered DNA copy number in small cell lung tumors. Genes Chromosomes Cancer $\underline{13}, 175-185$

Lewin B: Genes IX, 9. Auflage; Jones and Bartlett Publishers, Sudbury (Massachusetts) 2008.

Lichter P, Cremer T, Borden J, Manuelidis L, Ward DC (1988): Delineation of individual human chromosomes in metaphase and interphase cells by in situ suppression hybridization using recombinant DNA libraries. Hum Genet $\underline{80}$, 224-234

Lindström I, Nordling S, Nissén AM, Tammilehto L, Mattson K, Knuutila S (2002): DNA copy number changes in lung adenocarcinoma in younger patients. Mod Pathol $\underline{15}, 372-$ 378

Liu J, Mohammed J, Carter J, Ranka S, Kahveci T, Baudis M (2006): Distance-based clustering of CGH data. Bioinformatics 22, 1971-1978

Liu XP, Li DY, Liu XL, Xu JD, Furuya T, Kawauchi S, Oga A, Sasaki K (2009): Comparison of chromosomal aberrations between primary tumors and their synchronous lymph-node metastases in intestinal-type gastric carcinoma. Pathol Res Pract 205, 105-111

Lu T, Hano H (2007): Identification of minimal regions of deletion at 8p23.1-22 associated with metastasis of hepatocellular carcinoma. Liver Int 27, 782-790

Lui WO, Tanenbaum DM, Larsson C (2001): High level amplification of 1p32-33 and 2p22-24 in small cell lung carcinomas. Int J Oncol 19, 451-457

Luk C, Tsao MS, Bayani J, Shepherd F, Squire JA (2001): Molecular cytogenetic analysis of non-small cell lung carcinoma by spectral karyotyping and comparative genomic hybridization. Cancer Genet Cytogenet $\underline{125}, 87-99$ 
Lundsteen C, Maahr J, Christensen B, Bryndorf T, Bentz M, Lichter P, Gerdes $\mathrm{T}$ (1995): Image analysis in comparative genomic hybridization. Cytometry $\underline{19}, 42-50$

Ma J, Gao M, Lu Y, Feng X, Zhang J, Lin D, Xiao T, Hu Z, Yuan J, Su K (2006): Gain of 1q25-32, 12q23-24.3, and 17q12-22 facilitates tumorigenesis and progression of human squamous cell lung cancer. J Pathol 210, 205-213

Macartney-Coxson DP, Hood KA, Shi HJ, Ward T, Wiles A, O'Connor R, Hall DA, Lea RA, Royds JA, Stubbs RS (2008): Metastatic susceptibility locus, an 8p hot-spot for tumour progression disrupted in col orectal liver metastases: 13 candidate genes examined at the DNA, mRNA and protein level. BMC Cancer $\underline{8}, 187$

Mahner M, Kary M (1997): What exactly are genomes, genotypes and phenotypes? And what about phenomes? J Theor Biol 186, 55-63

Marmur J, Lane D (1960): Strand Separation and specific Recombination in deoxyribonucleic Acids: Biological Studies. Proc Natl Acad Sci U S A 뜨, 453-461

McConaughy BL, Laird CD, McCarthy BJ (1969): Nucleic acid reassociation in formamide. Biochemistry $\underline{8}, 3289-3295$

McNeil N, Ried T (2000): Novel molecular cytogenetic techniques for identifying complex chromosomal rearrangements: technology and applications in molecular medicine. Expert Rev Mol Med (Online-Journal), 1-14; doi: 10.1017/S1462399400001940

MEDLINE - Medical Literature Analysis and Retrieval System Online (o. Verf.). United States National Library of Medicine. Bethesda, 2009. Verfügbar über das Internetportal PubMed: http://www.ncbi.nlm.nih.gov/pubmed/. Zugriff am 16.07.2008.

Meselson M, Stahl FW (1958): The Replication of DNA in Escherichia Coli. Proc Natl Acad Sci U S A $\underline{44}, 671-682$

Minn AJ, Massagué J: Invasion and Metastasis; in: DeVita, Hellman, and Rosenberg's Cancer: Principles \& Practive of Oncology, Band 1. 8. Auflage; hrsg. von DeVita VT, Lawrence TS, Rosenberg SA, Weinberg RA, DePinho RA; Lippincott Williams \& Wilkins, Philadelphia 2008, 117-134

Mitelman F, Johansson B, Mandahl N, Mertens F (1997): Clinical significance of cytogenetic findings in solid tumors. Cancer Genet Cytogenet $\underline{95}, 1-8$

Mitelman F, Johansson B, Mertens F. Mitelman Database of Chromosome Aberrations in Cancer. 2009. Verfügbar unter:http://cgap.nci.nih.gov/Chromosomes/Mitelman. Zugriff am 16.07.2008.

Moore DH, Pallavicini M, Cher ML, Gray JW (1997): A t-statistic for objective interpretation of comparative genomic hybridization (CGH) profiles. Cytometry $\underline{28}, 183-190$ 
Morishita H, Yagi T (2007): Protocadherin family: diversity, structure, and function. Curr Opin Cell Biol $\underline{19}, 584-592$

Mutation (o. Verf.); in: Talking Glossary of Genetic Terms. Website des National Human Genome Research Institute. Bethesda, 2009. Verfügbar unter: http:// www.gedazugehörigenome.gov/glossaryurl.cfm?key=mutation sowie die Abbildung unter http://www.genome.gov/Pages/Hyperion/DIR/VIP/Glossary/Illustration/ mutation.cfm?key=mutation. Zugriff am 29.09.2009.

Nick Translation Mix für in situ Sonden (o.Verf.); Produktbeschreibung. 3. Auflage; Roche, Mannheim 1999

Nowell PC (1962): The minute chromosome (Phl) in chronic granulocytic leukemia. Blut $\underline{8}, 65-66$

Nussbaum ES, Djalilian HR, Cho KH, Hall WA (1996): Brain metastases. Histology, multiplicity, surgery, and survival. Cancer $\underline{78}$, 1781-1788

O-charoenrat P, Rusch V, Talbot SG, Sarkaria I, Viale A, Socci N, Ngai I, Rao P, Singh B (2004): Casein kinase II alpha subunit and C1-inhibitor are independent predictors of outcome in patients with squamous cell carcinoma of the lung. Clin Cancer Res $\underline{10}, 5792-5803$

Okamoto A, Hussain SP, Hagiwara K, Spillare EA, Rusin MR, Demetrick DJ, Serrano M, Hannon GJ, Shiseki M, Zariwala M (1995): Mutations in the p16INK4/MTS1/CDKN2, p15INK4B/MTS2, and p18 genes in primary and metastatic lung cancer. Cancer Res 55, 1448-1451

Onken MD, Worley LA, Harbour JW (2008): A metastasis modifier locus on human chromosome $8 \mathrm{p}$ in uveal melanoma identified by integrative genomic analysis. Clin Cancer Res 14, 3737-3745

Padalecki SS, Weldon KS, Reveles XT, Buller CL, Grubbs B, Cui Y, Yin JJ, Hall DC, Hummer BT, Weissman BE (2003): Chromosome 18 suppresses prostate cancer metastases. Urol Oncol 21, 366-373

Pardue ML, Gall JG (1969): Molecular hybridization of radioactive DNA to the DNA of cytological preparations. Proc Natl Acad Sci U S A $\underline{64}, 600-604$

Park SY, Kim YH, In KH, Chun YH, Park SH (2004): Chromosomal aberrations in Korean nonsmall cell lung carcinomas: degenerate oligonucleotide primed polymerase chain reaction comparative genomic hybridization studies. Cancer Genet Cytogenet $\underline{152}, 153-157$

Parkin M, Samet J, Tyczynski JE, Shields P, Boffetta P, Caporaso N: Lung cancer epidemiology and etiology; in: World Health Organization Classification of Tumors: 
Pathology and genetics of tumours of the lung, pleura, thymus and heart; hrsg. von Travis WD, Brambilla E, Müller-Hermelink K, Harris CC; IARC Press, Lyon 2004, 12-15

Paterson AH, Agarwal M, Lees A, Hanson J, Szafran O (1982): Brain metastases in breast cancer patients receiving adjuvant chemotherapy. Cancer $\underline{49}, 651-654$

Pathak S, Multani AS: Aneuploidy, stem cells and cancer; in: Cancer: Cell Structures, Carcinogens and Genomic Instability; hrsg. von Bignold LP; Birkhäuser, Basel 2006, 49-64

Pearson PL: Trisomy; in: Encyclopedia of Genetics, Band 4; hrsg. von Brenner S, Miller JH; Academic Press, London 2002, 2056-2057

Pei J, Balsara BR, Li W, Litwin S, Gabrielson E, Feder M, Jen J, Testa JR (2001): Genomic imbalances in human lung adenocarcinomas and squamous cell carcinomas. Genes Chromosomes Cancer 31, 282-287

Percy AK, Elveback LR, Okazaki H, Kurland LT (1972): Neoplasms of the central nervous system. Epidemiologic considerations. Neurology 22, 40-48

Petersen I: Genetik von Karzinomen des Respirationstraktes: Korrelation GenotypPhänotyp. Med. Habil.-Schr. Berlin 1998

Petersen I (1999): Genetik von Karzinomen des Respirationstraktes: Korrelation von Genotyp und Phänotyp. Verh Dtsch Ges Pathol 푸, 195-204

Petersen I, Bujard M, Petersen S, Wolf G, Goeze A, Schwendel A, Langreck H, Gellert K, Reichel M, Just K (1997a): Patterns of chromosomal imbalances in adenocarcinoma and squamous cell carcinoma of the lung. Cancer Res $\underline{57}, 2331-2335$

Petersen I, Langreck H, Wolf G, Schwendel A, Psille R, Vogt P, Reichel MB, Ried T, Dietel M (1997 b): Small-cell lung cancer is characterized by a high incidence of deletions on chromosomes 3p, 4q, 5q, 10q, 13q and 17p. Br J Cancer 푸 79-86

Petersen I, Hidalgo A, Petersen S, Schlüns K, Schewe C, Pacyna-Gengelbach M, Goeze A, Krebber B, Knösel T, Kaufmann O (2000): Chromosomal imbalances in brain metastases of solid tumors. Brain Pathol 10, 395-401

Petersen S, Aninat-Meyer M, Schlüns K, Gellert K, Dietel M, Petersen I (2000): Chromosomal alterations in the clonal evolution to the metastatic stage of squamous cell carcinomas of the lung. Br J Cancer $\underline{82}, 65-73$

Pinkel D, Landegent J, Collins C, Fuscoe J, Segraves R, Lucas J, Gray J (1988): Fluorescence in situ hybridization with human chromosome-specific libraries: detection of trisomy 21 and translocations of chromosome 4. Proc Natl Acad Sci U S A $\underline{85}, 9138-9142$ 
Piper J, Rutovitz D, Sudar D, Kallioniemi A, Kallioniemi OP, Waldman FM, Gray JW, Pinkel D (1995): Computer image analysis of comparative genomic hybridization. Cytometry $\underline{19}, 10-23$

Poetsch M, Schuart BJ, Schwesinger G, Kleist B, Protzel C (2007): Screening of microsatellite markers in penile cancer reveals differences between metastatic and nonmetastatic carcinomas. Mod Pathol 20, 1069-1077

QIAamp DNA Mini and Blood Mini Handbook (o.Verf.). 2. Auflage; Qiagen, Hilden 2007

Ried T, Petersen I, Holtgreve-Grez H, Speicher MR, Schröck E, du Manoir S, Cremer $\mathrm{T}$ (1994): Mapping of multiple DNA gains and losses in primary small cell lung carcinomas by comparative genomic hybridization. Cancer Res $\underline{54}$, 1801-1806

Rigby PW, Dieckmann M, Rhodes C, Berg P (1977): Labeling deoxyribonucleic acid to high specific activity in vitro by nick translation with DNA polymerase I. J Mol Biol $\underline{113}, 237-251$

Rydzanicz M, Giefing M, Ziolkowski A, Kasprzyk M, Gabriel A, Dyszkiewicz W, Szyfter K (2008): Nonrandom DNA copy number changes related to lymph node metastases in squamous cell carcinoma of the lung. Neoplasma $\underline{55}, 493-500$

Sambrook J, Russell DW: Molecular Cloning: A Laboratory Manual. 3. Auflage; Cold Spring Harbor Laboratory Press, Cold Spring Harbor 2001.

Sarli L, Bottarelli L, Bader G, Iusco D, Pizzi S, Costi R, D'Adda T, Bertolani M, Roncoroni L, Bordi C (2004): Association between recurrence of sporadic colorectal cancer, high level of microsatellite instability, and loss of heterozygosity at chromosome 18q. Dis Colon Rectum 느, 1467-1482

Savage JR (1976): Classification and relationships of induced chromosomal structual changes. J Med Genet 13, 103-122

Savelyeva L, Schwab M (2001): Amplification of oncogenes revisited: from expression profiling to clinical application. Cancer Lett 167, 115-123

Schildkraut C (1965): Dependence of the melting temperature of DNA on salt concentration. Biopolymers $\underline{3}, 195-208$

Schmid CW, Jelinek WR (1982): The Alu family of dispersed repetitive sequences. Science 216, 1065-1070

Schmidt H. Was ist Genauigkeit? Zum Einfluß systematischer Abweichungen auf Meß- und Ausgleichungsergebnisse. Website des Geodätischen Instituts der RWTH Aachen. 1997. Verfügbar unter: http://www.gia.rwth-aachen.de/Forschung/ AngwStatistik/genauigkeit/. Zugriff am 11.06.2009. 
Schoumans J, Nielsen K, Jeppesen I, Anderlid MB, Blennow E, Brøndum-Nielsen K, Nordenskjöld M (2004): A comparison of different metaphase CGH methods for the detection of cryptic chromosome aberrations of defined size. Eur J Hum Genet 12, 447454

Schouten LJ, Rutten J, Huveneers HAM, Albert Twijnstra A (2002): Incidence of brain metastases in a cohort of patients with carcinoma of the breast, colon, kidney, and lung and melanoma. Cancer 94, 2698-2705

Schwendel A, Langreck H, Reichel M, Schröck E, Ried T, Dietel M, Petersen I (1997): Primary small-cell lung carcinomas and their metastases are characterized by a recurrent pattern of genetic alterations. Int J Cancer $\underline{74}, 86-93$

Seute T, Leffers P, ten Velde GP, Twijnstra A (2008): Detection of brain metastases from small cell lung cancer: consequences of changing imaging techniques (CT versus MRI). Cancer $\underline{112}, 1827-1834$

Shaffer LG, Slovak ML, Campbell LJ: ISCN 2009: An International System for Human Cytogenetic Nomenclature (2009) - Recommendations of the International Standing Committee on Human Cytogenetic Nomenclature. S. Karger, Basel 2009.

Shen H, Zhu Y, Wu YJ, Qiu HR, Shu YQ (2008): Genomic alterations in lung adenocarcinomas detected by multicolor fluorescence in situ hybridization and comparative genomic hybridization. Cancer Genet Cytogenet 181, 100-107

Shiseki M, Kohno T, Nishikawa R, Sameshima Y, Mizoguchi H, Yokota J (1994): Frequent allelic losses on chromosomes 2q, 18q, and 22q in advanced non-small cell lung carcinoma. Cancer Res 54, 5643-5648

Shiseki M, Kohno T, Adachi J, Okazaki T, Otsuka T, Mizoguchi H, Noguchi M, Hirohashi S, Yokota J (1996): Comparative allelotype of early and advanced stage non-small cell lung carcinomas. Genes Chromosomes Cancer 17, 71-77

Singer MF (1982): Highly repeated sequences in mammalian genomes. Int Rev Cytol $\underline{76}, 67-112$

SKY/M-FISH \& CGH Datenbank (o. Verf.). National Cancer Institute (NCI) und National Center for Biotechnology Information (NCBI). Bethesda, 2001. Verfügbar unter: http: //www.ncbi.nlm.nih.gov/sky/skyweb.cgi. Zugriff am 16.07.2008.

Speicher MR, du Manoir S, Schröck E, Holtgreve-Grez H, Schoell B, Lengauer C, Cremer T, Ried T (1993): Molecular cytogenetic analysis of formalin-fixed, paraffin-embedded solid tumors by comparative genomic hybridization after universal DNA-amplification. Hum Mol Genet $\underline{2}, 1907-1914$ 
Stehelin D, Varmus HE, Bishop JM, Vogt PK (1976): DNA related to the transforming gene(s) of avian sarcoma viruses is present in normal avian DNA. Nature $\underline{260}, 170-173$

Surzycki S: Human molecular biology laboratory manual. Blackwell, Oxford 2003.

Sy SMH, Wong N, Lee TW, Tse G, Mok TSK, Fan B, Pang E, Johnson PJ, Yim A (2004): Distinct patterns of genetic alterations in adenocarcinoma and squamous cell carcinoma of the lung. Eur J Cancer 40, 1082-1094

Tai ALS, Yan WS, Fang Y, Xie D, Sham JST, Guan XY (2004): Recurrent chromosomal imbalances in nonsmall cell lung carcinoma: the association between 1q amplification and tumor recurrence. Cancer $\underline{100}, 1918-1927$

Takahashi K, Kohno T, Matsumoto S, Nakanishi Y, Arai Y, Yamamoto S, Fujiwara T, Tanaka N, Yokota J (2007): Clonal and parallel evolution of primary lung cancers and their metastases revealed by molecular dissection of cancer cells. Clin Cancer Res $\underline{13}, 111-120$

Tanaka T, Watanabe T, Kazama Y, Tanaka J, Kanazawa T, Kazama S, Nagawa $\mathrm{H}$ (2008): Loss of Smad4 protein expression and $18 \mathrm{qLOH}$ as molecular markers indicating lymph node metastasis in colorectal cancer - a study matched for tumor depth and pathology. J Surg Oncol 97, 69-73

Tönnies H, Stumm M, Wegner RD, Chudoba I, Kalscheuer V, Neitzel H (2001): Comparative genomic hybridization based strategy for the analysis of different chromosome imbalances detected in conventional cytogenetic diagnostics. Cytogenet Cell Genet $\underline{93}, 188-194$

Travis WD, Brambilla E, Müller-Hermelink K, Harris CC (Hrsg.): World Health Organization Classification of Tumors: Pathology and genetics of tumours of the lung, pleura, thymus and heart. IARC Press, Lyon 2004

Tyzzer EE (1916): Tumor immunity. J Cancer Res $\underline{1}, 125-155$

van de Pol M, ten Velde GP, Wilmink JT, Volovics A, Twijnstra A (1997): Efficacy and safety of prophylactic cranial irradiation in patients with small cell lung cancer. J Neurooncol 35, 153-160

van Oosterhout AG, van de Pol M, ten Velde GP, Twijnstra A (1996): Neurologic disorders in 203 consecutive patients with small cell lung cancer. Results of a longitudinal study. Cancer $\underline{77}$, 1434-1441

Virchow R: Die Krankhaften Geschwülste. Dreissig Vorlesungen, gehalten während des Wintersemesters 1862-1863 an der Universität zu Berlin, Band 1. August Hirschwald, Berlin 1863 
Walch AK, Zitzelsberger HF, Aubele MM, Mattis AE, Bauchinger M, Candidus S, Präuer HW, Werner M, Höfler H (1998): Typical and atypical carcinoid tumors of the lung are characterized by $11 \mathrm{q}$ deletions as detected by comparative genomic hybridization. Am J Pathol 153, 1089-1098

Walker AE, Robins M, Weinfeld FD (1985): Epidemiology of brain tumors: the national survey of intracranial neoplasms. Neurology $\underline{35}, 219-226$

Wang XC, Tian LL, Tian J, Wu HL, Meng AM (2009): Overexpression of Cks1 is associated with poor survival by inhibiting apoptosis in breast cancer. J Cancer Res Clin Oncol, Online-Veröffentlichung vor Druck; doi: 10.1007/s00432-009-0582-8

Watson JD, Crick FH (1953): Molecular Structure of Nucleic Acids. A Structure for Deoxyribose Nucleic Acid. Nature 171, 737-738

Weaver BAA, Cleveland DW (2006): Does aneuploidy cause cancer? Curr Opin Cell Biol $\underline{18}, 658-667$

Weiss MM, Hermsen MA, Meijer GA, van Grieken NC, Baak JP, Kuipers EJ, Diest PJ (1999): Comparative genomic hybridisation. Mol Pathol 느, 243-251

Weller M, Schackert G (Hrsg.): Solide Hirnmetastasen; in: Leitlinien der Deutschen Gesellschaft für Neurologie. 2008. Website der Deutschen Gesellschaft für Neurologie. Verfügbar unter: http://www.dgn.org/leitlinien-der-dgn-2008-70.html. Zugriff am 29.06.2009.

Wetmur JG (1975): Accerleration of DNA Renaturation Rates. Biopolymers 14, 2517-2524

Wetmur JG, Davidson N (1968): Kinetics of renaturation of DNA. J Mol Biol 31, 349-370

Wilfinger WW, Mackey K, Chomczynski P (1997): Effect of pH and ionic strength on the spectrophotometric assessment of nucleic acid purity. Biotechniques 22, 474-6, 478-81

Wittekind CH, Meyer HJ, Bootz F (Hrsg.): UICC International Union Against Cancer: TNM-Klassifikation maligner Tumoren, 6. Auflage; Springer, Berlin 2005

Wong MP, Fung LF, Wang E, Chow WS, Chiu SW, Lam WK, Ho KK, Ma ESK, Wan TSK, Chung LP (2003): Chromosomal aberrations of primary lung adenocarcinomas in nonsmokers. Cancer 97, 1263-1270

Wrage M, Ruosaari S, Eijk PP, Kaifi JT, Hollmén J, Yekebas EF, Izbicki JR, Brakenhoff RH, Streichert T, Riethdorf S (2009): Genomic profiles associated with early micrometastasis in lung cancer: relevance of 4q deletion. Clin Cancer Res 15, 1566-1574

Yakut T, Schulten HJ, Demir A, Frank D, Danner B, Egeli U, Gebitekin C, Kahler E, Gunawan B, Ürer N (2006): Assessment of molecular events in squamous and nonsquamous cell lung carcinoma. Lung Cancer 포, 293-301 
Yan W, Song L, Liang Q, Fang Y (2005 a): Progression analysis of lung squamous cell carcinomas by comparative genomic hybridization. Tumour Biol 므, 158-164

Yan W, Song L, Wei W, Li A, Liu J, Fang Y (2005 b): Chromosomal abnormalities associated with neck nodal metastasis in nasopharyngeal carcinoma. Tumour Biol $\underline{26}, 306-312$

Yuan BZ, Jefferson AM, Baldwin KT, Thorgeirsson SS, Popescu NC, Reynolds SH (2004): DLC-1 operates as a tumor suppressor gene in human non-small cell lung carcinomas. Oncogene 23, 1405-1411 


\section{Abbildungsverzeichnis}

1.1 Strukturelle Chromosomenaberrationen . . . . . . . . . . . . . . . 9

1.2 Normaler und aneuploider Karyotyp . . . . . . . . . . . . . . . . . . . 10

1.3 Strukturelle Grundlage der Amplifikation . . . . . . . . . . . . . . . . . . 10

1.4 Karyotyp eines Metaphasenpräparats nach CGH . . . . . . . . . . . . . 12

1.5 Prinzip der vergleichenden genomischen Hybridisierung $(\mathrm{CGH})$. . . . . . 13

2.1 Schema der CGH-Auswertung . . . . . . . . . . . . . . . . . . 35

2.2 ISCN Nomenklatur . . . . . . . . . . . . . . . . . . . . . . . . 37

3.1 CGH-Summenidiogramm der Hirnmetastasen vom kleinzelligen Karzinom 46

3.2 CGH-Summenidiogramm der Hirnmetastasen vom Plattenepithelkarzinom 48

3.3 CGH-Summenidiogramm der Hirnmetastasen vom Adenokarzinom . . . . 50

3.4 CGH-Summenidiogramm der Hirnmetastasen vom adenosquamösen Karzinom 52

3.5 CGH-Summenidiogramm der Hirnmetastasen vom großzelligen Karzinom 54

3.6 CGH-Summenidiogramm der Primärtumoren des kleinzelligen Karzinoms 58

3.7 CGH-Summenidiogramm der Primärtumoren des Plattenepithelkarzinoms 61

3.8 CGH-Summenidiogramm der Primärtumoren des Adenokarzinoms . . . . 64

3.9 Differenzhistogramm von Primärtumoren und Hirnmetastasen des kleinzelligen Karzinoms . . . . . . . . . . . . . . . . . . . . . 68

3.10 Differenzhistogramm von Primärtumoren und Hirnmetastasen des Plattenepithelkarzinoms . . . . . . . . . . . . . . . . 71

3.11 Differenzhistogramm von Primärtumoren und Hirnmetastasen des Adenokarzinoms . . . . . . . . . . . . . . . . . 74

3.12 Clusteranalyse von Primärtumoren und Hirnmetastasen des Plattenepithelkarzinoms . . . . . . . . . . . . . . . . 75

3.13 Eigene Standardreferenzintervalle . . . . . . . . . . . . . . . . . 76

4.1 Veranschaulichung von Präzision und Richtigkeit . . . . . . . . . . . . . 80

4.2 Korrektur einer systematischen Messabweichung . . . . . . . . . . . . . 82

4.3 Messabweichung der CGH in der Negativkontrolle . . . . . . . . . . . . . 83

4.4 Standardreferenzintervalle nach Kirchhoff et al. (1998) . . . . . . . . . . . 86

4.5 Eigene Standardreferenzintervalle . . . . . . . . . . . . . . . . . . . 87

4.6 Kritische Beurteilung Chromosom 4 (SCLC) . . . . . . . . . . . . . . . 89

4.7 Kritische Beurteilung Chromosom 19 (SCLC) . . . . . . . . . . . . . . . 90

4.8 Kritische Beurteilung Chromosom 1 (SQC) . . . . . . . . . . . . . . . 92 
4.9 Kritische Beurteilung Chromosom 2 (SQC) . . . . . . . . . . . . . . . 93

4.10 Kritische Beurteilung Chromosom 5 (SQC) . . . . . . . . . . . . . . . 94

4.11 Kritische Beurteilung Chromosom 6 (SQC) . . . . . . . . . . . . . . 94

4.12 Kritische Beurteilung Chromosom 7 (SQC) . . . . . . . . . . . . . . . . . 95

4.13 Kritische Beurteilung Chromosom 8 (SQC) . . . . . . . . . . . . . . 96

4.14 Kritische Beurteilung Chromosom 9 (SQC) . . . . . . . . . . . . . . 96

4.15 Kritische Beurteilung Chromosom 10 (SQC) . . . . . . . . . . . . . . . . 97

4.16 Kritische Beurteilung Chromosom 13 (SQC) . . . . . . . . . . . . . . . 97

4.17 Kritische Beurteilung Chromosom 18 (SQC) . . . . . . . . . . . . . . . 98

4.18 Kritische Beurteilung Chromosom 11 (ADC) . . . . . . . . . . . . . 100

4.19 Tendenzielle Veränderungen (ADC) … . . . . . . . . . . . . . 100

4.20 Tendenzielle Veränderungen (ADSQ, LCC) . . . . . . . . . . . . . . 101

4.21 Beispielhistogramm: Chromosom 14 bei chronisch lymphatischer Leukämie 106 


\section{Tabellenverzeichnis}

1.1 WHO-Klassifikation der Lungentumoren . . . . . . . . . . . . . . . . . 4

3.1 Häufige chromosomale Veränderungen der 22 Hirnmetastasen vom kleinzelligen Karzinom . . . . . . . . . . . . . . . . . . . 47

3.2 Häufige Veränderungen der 32 Hirnmetastasen vom Plattenepithelkarzinom 49

3.3 Häufige Veränderungen der 16 Hirnmetastasen vom Adenokarzinom . . . 51

3.4 Häufige Veränderungen der 11 Hirnmetastasen vom adenosquamösen Karzinom 53

3.5 Häufige Veränderungen der 7 Hirnmetastasen vom großzelligen Karzinom 55

3.6 In die Metaanalyse eingeschlossene Publikationen . . . . . . . . . . . . 56

3.7 Häufige Veränderungen von 71 Primärtumoren des kleinzelligen Karzinoms 59

3.8 Häufige Veränderungen von 121 Primärtumoren des Plattenepithelkarzinoms 62

3.9 Häufige Veränderungen von 95 Primärtumoren des Adenokarzinoms. . . . 65

3.10 Vergleich häufiger Veränderungen von Primärtumoren und Hirnmetastasen des kleinzelligen Karzinoms . . . . . . . . . . . . . . . . . . . 67

3.11 Signifikante Unterschiede zwischen Primärtumoren und Hirnmetastasen beim kleinzelligen Karzinom . . . . . . . . . . . . . . . . . . . . 69

3.12 Vergleich häufiger Veränderungen von Primärtumoren und Hirnmetastasen des Plattenepithelkarzinoms . . . . . . . . . . . . . . . . . 70

3.13 Signifikante Unterschiede zwischen Primärtumoren und Hirnmetastasen beim Plattenepithelkarzinom . . . . . . . . . . . . . . . 72

3.14 Vergleich häufiger Veränderungen von Primärtumoren und Hirnmetastasen des Adenokarzinoms . . . . . . . . . . . . . . . . 73

3.15 Signifikante Unterschiede zwischen Primärtumoren und Hirnmetastasen beim Adenokarzinom . . . . . . . . . . . . . . . . . . . . 74

A.1 Pathologische, allgemeine und klinische Daten der untersuchten Patienten 134

A.2 CGH-Befunde aller untersuchten Hirnmetastasen . . . . . . . . . . . . . 138

A.3 CGH-Befunde kleinzelliger Primärtumoren aus der Literaturrecherche . . 141

A.4 CGH-Befunde von Primärtumoren des Plattenepithelkarzinoms aus der Literaturrecherche . . . . . . . . . . . . . . . . . . . 146

A.5 CGH-Befunde von Primärtumoren des Adenokarzinoms aus der Literaturrecherche . . . . . . . . . . . . . . . . . . 152

A.6 Statistische Auswertung des kleinzelligen Kollektivs . . . . . . . . . . . . 156

A.7 Statistische Auswertung des Plattenepithelkarzinom-Kollektivs . . . . . 156

A.8 Statistische Auswertung des Adenokarzinom-Kollektivs . . . . . . . . . . 158 


\title{
9 Abkürzungsverzeichnis
}

\author{
ADC $\ldots . . . \ldots$ Adenocarcinoma \\ ADSQ .......... Adenosquamous Carcinoma \\ amp ........... amplified \\ Aqua bidest. .... Aqua bidestillata \\ bp ........... Basenpaare \\ CGH....... Comparative Genomic Hybridization \\ DAPI $\ldots \ldots \ldots$ 4',6-Diamidin-2-phenylindol \\ dATP ......... Desoxyadenosintriphosphat \\ dCTP ......... Desoxycytidintriphosphat \\ dGTP ........ Desoxyguanosintriphosphat \\ $\operatorname{dim} \ldots \ldots \ldots$ diminished \\ DIN .......... Deutsches Institut für Normung \\ DNA $\ldots . . \ldots$.... Deoxyribonucleic Acid \\ dNTP ......... Desoxyribonukleosidtriphosphat \\ dTTP ........ Desoxythymidintriphosphat \\ dUTP ........ Desoxyuridintriphosphat \\ EDTA ......... Ethylendiamintetraessigsäure \\ enh ............ enhanced \\ FDR $\ldots . . . \ldots$ False Discovery Rate \\ FISH...$\ldots \ldots$. Fluorescence in situ Hybridization \\ FITC .......... Fluoresceinisothiocyanat
}


ISCN ......... International System for Human Cytogenetic Nomenclature

ISO $\ldots \ldots \ldots \ldots$ International Organization for Standardization

kbp $\ldots . . . \ldots . .$. Kilobasenpaare

LCC $\ldots . . . \ldots$ Large Cell Carcinoma

Mbp ......... Megabasenpaare

MEDLINE .... Medical Literature Analysis and Retrieval System Online

MeSH $\ldots . . . . .$. Medical Subject Heading

NCBI ........ National Center for Biotechnology Information

NCI ......... National Cancer Institute

NLM $\ldots . . . \ldots$ United States National Library of Medicine

NSCLC ....... Non Small Cell Lung Cancer

PSA $\ldots \ldots \ldots$. Prostataspezifisches Antigen

rev ish ....... Reverse in situ Hybridization

SCLC ......... Small Cell Lung Cancer

SQC $\ldots . . . \ldots$.... Squamous Cell Carcinoma

SSC .......... Saline Sodium Citrate

TBE $\ldots \ldots \ldots$ Tris/Borat/EDTA

Tris $\ldots \ldots \ldots$ Tris(hydroxymethyl)-aminomethan

TRITC ........ Tetramethylrhodamin-5-(6)-isothiocyanat

WHO ........ World Health Organization 


\section{A Anhang}

\section{A.1 Pathologische, allgemeine und klinische Daten}

Tabelle A.1: Pathologische, allgemeine und klinische Daten der untersuchten Patienten

\begin{tabular}{llcccl} 
Fall & Histologie $^{a}$ & Geschlecht & Alter $^{b}$ & Intervall $^{c}$ & Vorbehandlung $^{d}$ \\
SCLC-01 & SCLC & $\mathrm{m}$ & 60 & $\mathrm{k} . A$. & $\mathrm{k} . \mathrm{A}$. \\
SCLC-02 & SCLC & $\mathrm{m}$ & 62 & 0 & - \\
SCLC-03 & SCLC & $\mathrm{f}$ & 51 & 0 & - \\
SCLC-04 & SCLC & $\mathrm{m}$ & 51 & 0 & - \\
SCLC-05 & SCLC & $\mathrm{m}$ & 59 & 0 & - \\
SCLC-06 & SCLC & $\mathrm{m}$ & 59 & 16 & OP, CTH \\
SCLC-07 & SCLC & $\mathrm{f}$ & 51 & 0 & - \\
SCLC-08 & SCLC & $\mathrm{m}$ & 71 & 0 & - \\
SCLC-09 & SCLC & $\mathrm{m}$ & 59 & 0 & CTH \\
SCLC-10 & SCLC & $\mathrm{f}$ & 48 & 6 & CTH, RT \\
SCLC-11 & SCLC & $\mathrm{f}$ & 40 & 0 & - \\
SCLC-12 & SCLC & $\mathrm{m}$ & 61 & 15 & CTH, RT, PCI \\
SCLC-13 & SCLC & $\mathrm{f}$ & 52 & k.A. & k.A. \\
SCLC-14 & SCLC & $\mathrm{m}$ & 58 & 0 & - \\
SCLC-15 & SCLC & $\mathrm{m}$ & 61 & 0 & - \\
SCLC-16 & SCLC & $\mathrm{m}$ & 67 & 1 & - \\
SCLC-17 & SCLC & $\mathrm{f}$ & 53 & k.A. & k.A. \\
SCLC-18 & SCLC & $\mathrm{f}$ & 60 & 0 & CTH \\
SCLC-19 & SCLC & $\mathrm{m}$ & 65 & $\mathrm{k} . A$. & $\mathrm{k} . A$. \\
SCLC-20 & SCLC & $\mathrm{m}$ & 57 & k.A. & k.A. \\
SCLC-21 & SCLC & $\mathrm{m}$ & 49 & 11 & CTH, RT \\
\hline
\end{tabular}

a SCLC: kleinzellig; SQC: Plattenepithelkarzinom; ADC: Adenokarzinom; ADSQ: adenosquamös; LCC: großzellig.

${ }^{b}$ Gemeint ist das Alter bei Entfernung der Hirnmetastase.

${ }^{c}$ Erstdiagnose des Tumorleidens bis Diagnose der Hirnmetastase in Monaten.

${ }^{d} \mathrm{CTH}$ : Chemotherapie; OP: Operation; PCI: prophylaktische Hirnbestrahlung; RT: Strahlentherapie.

Fortsetzung... 
Tabelle A.1: Pathologische, allgemeine und klinische Daten der untersuchten Patienten ...Fortsetzung

\begin{tabular}{|c|c|c|c|c|c|}
\hline Fall & Histologie $^{a}$ & Geschlecht & Alter $^{b}$ & Intervall ${ }^{c}$ & Vorbehandlung $^{d}$ \\
\hline SCLC-22 & SCLC & $\mathrm{m}$ & 76 & k.A. & k.A. \\
\hline SQC-01 & $\mathrm{SQC}$ & $\mathrm{m}$ & 66 & k.A. & k.A. \\
\hline SQC-02 & SQC & $\mathrm{m}$ & 55 & 9 & $\mathrm{CTH}, \mathrm{RT}$ \\
\hline SQC-03 & SQC & $\mathrm{f}$ & 68 & 0 & - \\
\hline SQC-04 & $\mathrm{SQC}$ & $\mathrm{m}$ & 76 & 5 & $\mathrm{OP}$ \\
\hline SQC-05 & SQC & $\mathrm{m}$ & 52 & 0 & - \\
\hline SQC-06 & $\mathrm{SQC}$ & $\mathrm{m}$ & 65 & 4 & $\mathrm{RT}$ \\
\hline SQC-07 & SQC & $\mathrm{m}$ & 55 & 21 & $\mathrm{OP}$ \\
\hline SQC-08 & SQC & $\mathrm{m}$ & 65 & 6 & $\mathrm{OP}$ \\
\hline SQC-09 & SQC & $\mathrm{m}$ & 55 & 3 & $\mathrm{CTH}$ \\
\hline SQC-10 & SQC & $\mathrm{m}$ & 65 & 5 & $\mathrm{OP}$ \\
\hline SQC-11 & $\mathrm{SQC}$ & $\mathrm{m}$ & 58 & 4 & $\mathrm{CTH}$ \\
\hline SQC-12 & SQC & $\mathrm{f}$ & 63 & 6 & $\mathrm{OP}$ \\
\hline SQC-13 & SQC & $\mathrm{f}$ & 48 & 0 & - \\
\hline SQC-14 & SQC & $\mathrm{m}$ & 72 & 5 & $\mathrm{CTH}, \mathrm{RT}$ \\
\hline SQC-15 & SQC & $\mathrm{f}$ & 43 & 0 & - \\
\hline SQC-16 & SQC & $\mathrm{f}$ & 55 & 0 & - \\
\hline SQC-17 & SQC & $\mathrm{m}$ & 67 & 0 & - \\
\hline SQC-18 & $\mathrm{SQC}$ & $\mathrm{m}$ & 57 & k.A. & k.A. \\
\hline SQC-19 & SQC & $\mathrm{m}$ & 51 & 14 & $\mathrm{OP}$ \\
\hline SQC-20 & SQC & $\mathrm{m}$ & 63 & k.A. & k.A. \\
\hline SQC-21 & SQC & $\mathrm{m}$ & 62 & 8 & $\mathrm{RT}$ \\
\hline SQC-22 & SQC & $\mathrm{m}$ & 57 & 10 & $\mathrm{RT}$ \\
\hline SQC-23 & SQC & $\mathrm{m}$ & 50 & 0 & - \\
\hline SQC-24 & SQC & $\mathrm{m}$ & 62 & 17 & $\mathrm{OP}$ \\
\hline SQC-25 & SQC & $\mathrm{m}$ & 59 & 11 & $\mathrm{OP}$ \\
\hline SQC-26 & SQC & $\mathrm{m}$ & 72 & 2 & $\mathrm{OP}$ \\
\hline SQC-27 & SQC & $\mathrm{m}$ & 59 & 0 & - \\
\hline SQC-28 & SQC & $\mathrm{m}$ & 66 & 0 & - \\
\hline SQC-29 & SQC & $\mathrm{m}$ & 58 & k.A. & k.A. \\
\hline
\end{tabular}

${ }^{a}$ SCLC: kleinzellig; SQC: Plattenepithelkarzinom; ADC: Adenokarzinom; ADSQ: adenosquamös; LCC: großzellig.

${ }^{b}$ Gemeint ist das Alter bei Entfernung der Hirnmetastase.

${ }^{c}$ Erstdiagnose des Tumorleidens bis Diagnose der Hirnmetastase in Monaten.

${ }^{d} \mathrm{CTH}$ : Chemotherapie; OP: Operation; PCI: prophylaktische Hirnbestrahlung; RT: Strahlentherapie. 
Tabelle A.1: Pathologische, allgemeine und klinische Daten der untersuchten Patienten ...Fortsetzung

\begin{tabular}{|c|c|c|c|c|c|}
\hline Fall & Histologie $^{a}$ & Geschlecht & Alter $^{b}$ & Intervall ${ }^{c}$ & Vorbehandlung $^{d}$ \\
\hline SQC-30 & $\mathrm{SQC}$ & $\mathrm{m}$ & 73 & k.A. & k.A. \\
\hline SQC-31 & $\mathrm{SQC}$ & $\mathrm{m}$ & 71 & 0 & - \\
\hline SQC-32 & SQC & $\mathrm{m}$ & 68 & 0 & - \\
\hline ADC-01 & $\mathrm{ADC}$ & $\mathrm{f}$ & 49 & 0 & - \\
\hline ADC-02 & $\mathrm{ADC}$ & $\mathrm{m}$ & 52 & 0 & - \\
\hline ADC-03 & $\mathrm{ADC}$ & $\mathrm{m}$ & 56 & 0 & - \\
\hline ADC-04 & $\mathrm{ADC}$ & $\mathrm{m}$ & 65 & 0 & - \\
\hline ADC-05 & $\mathrm{ADC}$ & $\mathrm{m}$ & 68 & 7 & $\mathrm{OP}$ \\
\hline ADC-06 & $\mathrm{ADC}$ & $\mathrm{m}$ & 51 & k.A. & k.A. \\
\hline $\mathrm{ADC}-07$ & $\mathrm{ADC}$ & $\mathrm{f}$ & 57 & 23 & $\mathrm{OP}$ \\
\hline ADC-08 & $\mathrm{ADC}$ & $\mathrm{m}$ & 78 & 0 & - \\
\hline ADC-09 & $\mathrm{ADC}$ & $\mathrm{m}$ & 57 & 0 & - \\
\hline ADC-10 & $\mathrm{ADC}$ & $\mathrm{m}$ & 70 & 0 & - \\
\hline ADC-11 & $\mathrm{ADC}$ & $\mathrm{f}$ & 23 & k.A. & k.A. \\
\hline $\mathrm{ADC}-12$ & $\mathrm{ADC}$ & $\mathrm{m}$ & 55 & k.A. & k.A. \\
\hline ADC-13 & $\mathrm{ADC}$ & $\mathrm{m}$ & 54 & k.A. & k.A. \\
\hline ADC-14 & $\mathrm{ADC}$ & $\mathrm{m}$ & 58 & 4 & $\mathrm{CTH}$ \\
\hline ADC-15 & $\mathrm{ADC}$ & $\mathrm{m}$ & 63 & 0 & - \\
\hline ADC-16 & $\mathrm{ADC}$ & $\mathrm{f}$ & 57 & k.A. & k.A. \\
\hline ADSQ-01 & ADSQ & $\mathrm{f}$ & 42 & 6 & $\mathrm{RT}$ \\
\hline ADSQ-02 & ADSQ & $\mathrm{m}$ & 63 & 1 & - \\
\hline ADSQ-03 & ADSQ & $\mathrm{m}$ & 68 & 0 & - \\
\hline ADSQ-04 & ADSQ & $\mathrm{m}$ & 50 & 0 & - \\
\hline ADSQ-05 & ADSQ & $\mathrm{m}$ & 57 & k.A. & k.A. \\
\hline ADSQ-06 & ADSQ & $\mathrm{m}$ & 54 & 0 & $\mathrm{OP}$ \\
\hline ADSQ-07 & ADSQ & $\mathrm{m}$ & 62 & 0 & - \\
\hline ADSQ-08 & ADSQ & $\mathrm{m}$ & 52 & 12 & $\mathrm{CTH}, \mathrm{RT}$ \\
\hline ADSQ-09 & ADSQ & $\mathrm{f}$ & 66 & 0 & - \\
\hline ADSQ-10 & ADSQ & $\mathrm{m}$ & 70 & 0 & - \\
\hline ADSQ-11 & ADSQ & $\mathrm{m}$ & 70 & k.A. & k.A. \\
\hline
\end{tabular}

${ }^{a}$ SCLC: kleinzellig; SQC: Plattenepithelkarzinom; ADC: Adenokarzinom; ADSQ: adenosquamös; LCC: großzellig.

${ }^{b}$ Gemeint ist das Alter bei Entfernung der Hirnmetastase.

${ }^{c}$ Erstdiagnose des Tumorleidens bis Diagnose der Hirnmetastase in Monaten.

${ }^{d}$ CTH: Chemotherapie; OP: Operation; PCI: prophylaktische Hirnbestrahlung; RT: Strahlentherapie. 
Tabelle A.1: Pathologische, allgemeine und klinische Daten der untersuchten Patienten ...Fortsetzung

\begin{tabular}{llcccl} 
Fall & Histologie $^{a}$ & Geschlecht & Alter $^{b}$ & Intervall $^{c}$ & Vorbehandlung $^{d}$ \\
LCC-01 & LCC & $\mathrm{m}$ & 59 & 0 & - \\
LCC-02 & LCC & $\mathrm{m}$ & 65 & 1 & - \\
LCC-03 & LCC & $\mathrm{m}$ & 44 & 0 & - \\
LCC-04 & LCC & $\mathrm{m}$ & 70 & 0 & - \\
LCC-05 & LCC & $\mathrm{m}$ & 73 & 0 & - \\
LCC-06 & LCC & $\mathrm{m}$ & 64 & $\mathrm{k} . \mathrm{A}$. & $\mathrm{k} . \mathrm{A}$. \\
LCC-07 & LCC & $\mathrm{m}$ & 62 & 3 & CTH, RT \\
\hline
\end{tabular}

a SCLC: kleinzellig; SQC: Plattenepithelkarzinom; ADC: Adenokarzinom;

ADSQ: adenosquamös; LCC: großzellig.

${ }^{b}$ Gemeint ist das Alter bei Entfernung der Hirnmetastase.

${ }^{c}$ Erstdiagnose des Tumorleidens bis Diagnose der Hirnmetastase in Monaten.

${ }^{d}$ CTH: Chemotherapie; OP: Operation; PCI: prophylaktische Hirnbestrahlung; RT: Strahlentherapie. 


\section{A.2 CGH-Befunde}

\section{A.2.1 Befunde der Hirnmetastasen}

Tabelle A.2: CGH-Befunde aller untersuchten Hirnmetastasen

\begin{tabular}{|c|c|c|}
\hline Fall & Schwellen $^{a}$ & CGH-Befund \\
\hline SCLC-01 & 0,$8 ; 1,2$ & $\begin{array}{l}\text { enh(1p21p31, 2p21pter, 5p, 7p, 6q11q22, 8q11q23, 12p11q12, 12p12pter, 16p, 17, 20q) dim(1q24qter, 2p12qter, 3p, } \\
\text { 4p14pter, 5q12qter, 7q11qter, 8p, 10, 13q31qter) amp (1q11q22, 5p14pter, 6p21p22, 8q21q23, 14q12q21, 17q11q21) }\end{array}$ \\
\hline $\begin{array}{l}\text { SCLC-02 } \\
\text { SCLC-03 }\end{array}$ & $\begin{array}{l}0,85 ; 1,15 \\
0.8 ; 1,2\end{array}$ & 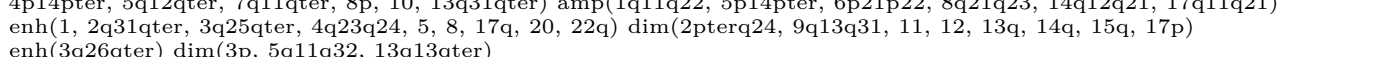 \\
\hline SCLC-04 & 0,$85 ; 1,15$ & $\begin{array}{l}\operatorname{enh}(7,8,12 \mathrm{p}, 15 \mathrm{q} 25 \mathrm{qter}, 17 \mathrm{q} 22 \mathrm{qter}, 18 \mathrm{p}) \operatorname{dim}(3 \mathrm{p}, 11 \mathrm{p}) \operatorname{amp}(10 \mathrm{p}, 12 \mathrm{p} 11,17 \mathrm{q} 22 \mathrm{qter}, 18 \mathrm{q} 11 \mathrm{q} 12) \\
\operatorname{enc}\end{array}$ \\
\hline SCLC-05 & 0,$8 ; 1,2$ & enh(5p14pter, $9 \mathrm{p}, 16 \mathrm{p}, 18) \operatorname{dim}(10 \mathrm{p} 11 \mathrm{p} 12,15 \mathrm{q} 11 \mathrm{q} 21)$ \\
\hline $\begin{array}{l}\text { SCLC-06 } \\
\text { SCLC-07 }\end{array}$ & $\begin{array}{l}0,8 ; 1,2 \\
0,85 ; 1,15\end{array}$ & 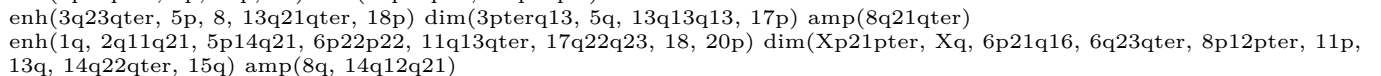 \\
\hline SCLC-08 & 0,$8 ; 1,2$ & $\operatorname{enh}(5 \mathrm{p}) \operatorname{dim}(3 \mathrm{p}, 4,5 \mathrm{q}, 10,13 \mathrm{q}, 15 \mathrm{q}, 17 \mathrm{p}) \operatorname{amp}(1 \mathrm{q})$ \\
\hline SCLC-09 & 0,$8 ; 1,2$ & $\begin{array}{l}\text { enh(1q,3q, 8p11qter, 17q21qter, 18) dim(8p21pter, 10, 11q23qter, 12q14qter, 13q11q21, 17p) amp }(6 \mathrm{p} 21 \mathrm{pter}, 8 \mathrm{q} 23 \mathrm{q} 24, \\
18 \mathrm{pterq} 11)\end{array}$ \\
\hline SCLC-10 & 0,$8 ; 1,2$ & $\operatorname{enh}(3 \mathrm{q}, 7 \mathrm{q}, 8 \mathrm{q}, 18) \operatorname{dim}\left(\mathrm{X}_{\mathrm{p}}, 2 \mathrm{pterq} 12,3 \mathrm{p}, 4 \mathrm{q} 13 \mathrm{q} 23,5 \mathrm{q}, 8 \mathrm{p}, 10,11 \mathrm{q} 23 \mathrm{qter}, 13 \mathrm{q}, 15 \mathrm{q}, 16 \mathrm{q}, 17 \mathrm{p}, 22 \mathrm{q}\right)$ amp $(5 \mathrm{p}, 8 \mathrm{q} 23 \mathrm{qter})$ \\
\hline SCLC-11 & 0,$8 ; 1,2$ & 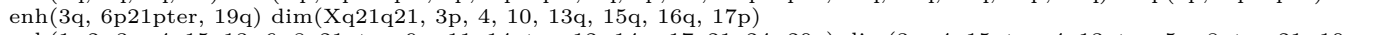 \\
\hline SCLC-12 & 0,$8 ; 1,2$ & $\begin{array}{l}\operatorname{enh}(1,2,3 \mathrm{q}, 4 \mathrm{p} 15 \mathrm{q} 13,6,8 \mathrm{q} 21 \mathrm{q} t e r, 9 \mathrm{q}, 11 \mathrm{p} 14 \mathrm{qter}, 12,14 \mathrm{q}, 17 \mathrm{q} 21 \mathrm{q} 24,20 \mathrm{q}) \operatorname{dim}(3 \mathrm{p}, 4 \mathrm{p} 15 \mathrm{pter}, 4 \mathrm{q} 13 \mathrm{qter}, 5 \mathrm{q}, 8 \mathrm{pterq} 21,10, \\
15 \mathrm{q}, 16,17 \mathrm{p}, 18) \text { amp }(5 \mathrm{p})\end{array}$ \\
\hline SCLC-13 & 0,$85 ; 1,15$ & $\begin{array}{l}\operatorname{enh}(2 \mathrm{pterq} 33,5 \mathrm{p}, 6 \mathrm{p} 21 \mathrm{q} 24,8 \mathrm{q} 21 \mathrm{q} 22,13 \mathrm{q} 21 \mathrm{qter}, 17 \mathrm{q}, 19 \mathrm{q} 12 \mathrm{q} 12) \operatorname{dim}(\mathrm{Xq}, 2 \mathrm{q} 35 \mathrm{qter}, 3 \mathrm{p}, 5 \mathrm{q}, 10 \mathrm{q} 22 \mathrm{qter}, 11 \mathrm{q} 21 \mathrm{qter}) \\
\operatorname{amp}(6 \mathrm{q} 21 \mathrm{q} 23)\end{array}$ \\
\hline SCLC-14 & 0,$82 ; 1,18$ & $\operatorname{enh}(3 \mathrm{q}, 8 \mathrm{q} 23 \mathrm{q} 24) \operatorname{dim}(1 \mathrm{p} 34 \mathrm{pter}, 3 \mathrm{p}, 4,5 \mathrm{q}, 8 \mathrm{p}, 13 \mathrm{q} 11 \mathrm{q} 14,15 \mathrm{q} 11 \mathrm{q} 15,17 \mathrm{p}, 22 \mathrm{q})$ \\
\hline SCLC-15 & 0,$85 ; 1,15$ & enh 3 q $26 \mathrm{qter}, 6 \mathrm{p} 21 \mathrm{pter}) \operatorname{dim}(1 \mathrm{p} 11 \mathrm{p} 22,3 \mathrm{p}, 5 \mathrm{q}, 6 \mathrm{q} 16 \mathrm{q} 22,8 \mathrm{p} 21 \mathrm{pter}, 9 \mathrm{p} 13 \mathrm{pter}, 13 \mathrm{q} 11 \mathrm{q} 14,14 \mathrm{q}, 15 \mathrm{q}, 20,22 \mathrm{q}, 17 \mathrm{p}) \operatorname{amp}(5 \mathrm{p}, 18)$ \\
\hline $\begin{array}{l}\text { SCLC-16 } \\
\text { SCLC-17 }\end{array}$ & $\begin{array}{l}0,85 ; 1,15 \\
0,8 ; 1,2\end{array}$ & $\begin{array}{l}\text { enh(1p31pter, 1q, 3q, 14q) } \\
\text { enh(1p32pter, 5p15p15, 6p, 6q22qter, 7p13pter, 7q32qter, 9p, 14q, 17q) dim(3p, 4, 5q, 7q11q22, 10, 13q, 15q14q22, 17p) }\end{array}$ \\
\hline SCLC-18 & 0,$8 ; 1,2$ & $\begin{array}{l}\operatorname{mpp}(3 q, 14 q 24 q \text { ter }) \\
\text { enh } 3 q 13 q 22,3 q 26 q t e r, 5 p, 14 q 21 q t e r, 18) \operatorname{dim}(3 p, 4,5 q 11 q 21,10,13 q 11 q 21,15 q, 17 p, 22 q)\end{array}$ \\
\hline SCLC-19 & 0,$85 ; 1,15$ & 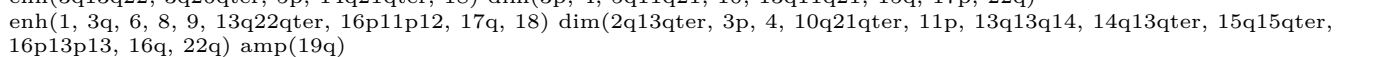 \\
\hline SCLC-20 & 0,$8 ; 1,2$ & $\operatorname{enh}(1,5 \mathrm{p}, 12 \mathrm{q} 22 \mathrm{qter}, 18 \mathrm{q}) \operatorname{dim}(3 \mathrm{p}, 4,5 \mathrm{q} 11 \mathrm{q} 23,5 \mathrm{q} 32 \mathrm{qter}, 6 \mathrm{q} 16 \mathrm{q} 23,13 \mathrm{q} 11 \mathrm{q} 21) \operatorname{amp}(1 \mathrm{p} 31 \mathrm{p} 33,1 \mathrm{q}, 3 \mathrm{q})$ \\
\hline SCLC-21 & 0,$8 ; 1,2$ & enh(3q26qter, 8q22qter, 10q11q21, 11p15p15, 20q11q11) dim(3p12pter, 10p12pter, 10q22qter, 16q) \\
\hline SCLC-22 & 0,$8 ; 1,2$ & $\operatorname{enh}(2 \mathrm{p}, 3 \mathrm{q}, 5 \mathrm{p}, 6 \mathrm{q} 23 \mathrm{qter}, 10 \mathrm{p}, 15 \mathrm{q} 21 \mathrm{q} 25,18) \operatorname{dim}(3 \mathrm{p}, 4 \mathrm{p}, 4 \mathrm{q} 26 \mathrm{qter}, 5 \mathrm{q} 12 \mathrm{q} 23,5 \mathrm{q} 32 \mathrm{qter}, 7 \mathrm{q} 33 \mathrm{qter}, 9 \mathrm{p} 13 \mathrm{pter}, 11 \mathrm{q} 22 \mathrm{qter}, 13 \mathrm{q})$ \\
\hline SQC-01 & 0,$8 ; 1,2$ & $\begin{array}{l}\text { enh(1q11q24, 3p24pter, 3q, 5p15pter, 5q33qter, 6p12p21, 6p23pter, 7, 8q23qter, 10p, 17, Xq26qter) dim(4q23q32, 5q12q23, } \\
\text { 6q11q21, 8p12pter, 11q22qter, 13q14q31, 15q24qter, 18q, 21q11q21) amp(12p12pter, 17q23qter) }\end{array}$ \\
\hline $\mathrm{SQC}-02$ & 0,$8 ; 1,2$ & $\begin{array}{l}\text { enh (1q, } 2 \mathrm{p} 1 \mathrm{p} 23,7 \mathrm{q} 2 \mathrm{q} 21,8 \mathrm{q} 2 \mathrm{q} 23,9 \mathrm{p} 1 \mathrm{ppter}, 13 \mathrm{q}, 16 \mathrm{p}, 17 \mathrm{q}) \operatorname{dim}(1 \mathrm{p}, 3 \mathrm{p} 13 \mathrm{pter}, 4,7 \mathrm{q} 34 \mathrm{qter}, 8 \mathrm{p} 12 \mathrm{p} 22,9 \mathrm{q}, 14 \mathrm{q}, 15 \mathrm{q} 21 \mathrm{qter} \\
20 \mathrm{p}) \operatorname{amp}(3 \mathrm{q} 22 \mathrm{q} \text { ter, } 5 \mathrm{p}, 13 \mathrm{q} 22 \mathrm{qter}, 19 \mathrm{q} 12 \mathrm{q} 122)\end{array}$ \\
\hline $\mathrm{SQC}-03$ & 0,$85 ; 1,15$ & enh(1q41qter, 2q31q32, 3q, 4q12q13, 12p12p12, 17q22qter) dim(Xp, 1p13p22, 1p $36 \mathrm{pter}, 2 \mathrm{p} 23 \mathrm{pter}, 2 \mathrm{q} 35 \mathrm{qter}, 3 \mathrm{p}, 4 \mathrm{p}$ \\
\hline $\mathrm{SQC}-04$ & 0,$8 ; 1,2$ & enh(3q13qter, $5 p) \operatorname{dim}(9 \mathrm{p} 13 \mathrm{pter})$ \\
\hline SQC-1 & 0,$8 ; 1,2$ & $\begin{array}{l}\text { enh(3q22qter, 5p, 6p21pter) dim(3p, 5q12qter, 8p21pter, 9p13pter, 13q21qter, 14q13q24, 10q, 16p12pter, 17p, 20p) }\end{array}$ \\
\hline SQC-06 & 0,$85 ; 1,15$ & $\begin{array}{l}\text { amp(19q11q13) } \\
\text { enh(Xp21per, 1q, 3q, 5p, 7p21pter, 8p11qter, 13q32qter) dim(3p12p21, 6q25qter, 7p11p21, 8p12pter, 9, 14q21q24, }\end{array}$ \\
\hline SQC-07 & 0,$85 ; 1,15$ & $\begin{array}{l}15 \mathrm{q} 11 \mathrm{q} 22) \\
\text { enh(1q2) } \\
4 \mathrm{q} 2525 \mathrm{q} 2 \mathrm{q} 11 \mathrm{q} 31,3 \mathrm{q}, 7 \mathrm{p} 21 \mathrm{pter}, 7 \mathrm{q} 11 \mathrm{q} 21,8 \mathrm{p} 11 \mathrm{p} 12,12 \mathrm{p}, 14 \mathrm{q} 11 \mathrm{q} 12,14 \mathrm{q} 24 \mathrm{qter}, 19 \mathrm{q}, 20 \mathrm{q} 11) \operatorname{dim}(1 \mathrm{p} 13 \mathrm{p} 22,2 \mathrm{q} 33 \mathrm{q} 35,3 \mathrm{p},\end{array}$ \\
\hline SQC-08 & 0,$85 ; 1,15$ & $\begin{array}{l}\text { 4q26qter, 5q, 6q13q16, 7q31, 8q13q21, 9p, 9q21, 10q21q22, 11p13p14, 11q14qter, 13q13qter, 18q12qter, 21q11) } \\
\text { enh 3q. 5p, 6p, 6q21qter, 7pterq11, 8q, 11q. 12p, 12q21qter, 15q) dim(3p, 4, 5q, 8p12pter, 9, 10, 12q11q13, 13q, 21q) }\end{array}$ \\
\hline
\end{tabular}


Tabelle A.2: CGH-Befunde aller untersuchten Hirnmetastasen

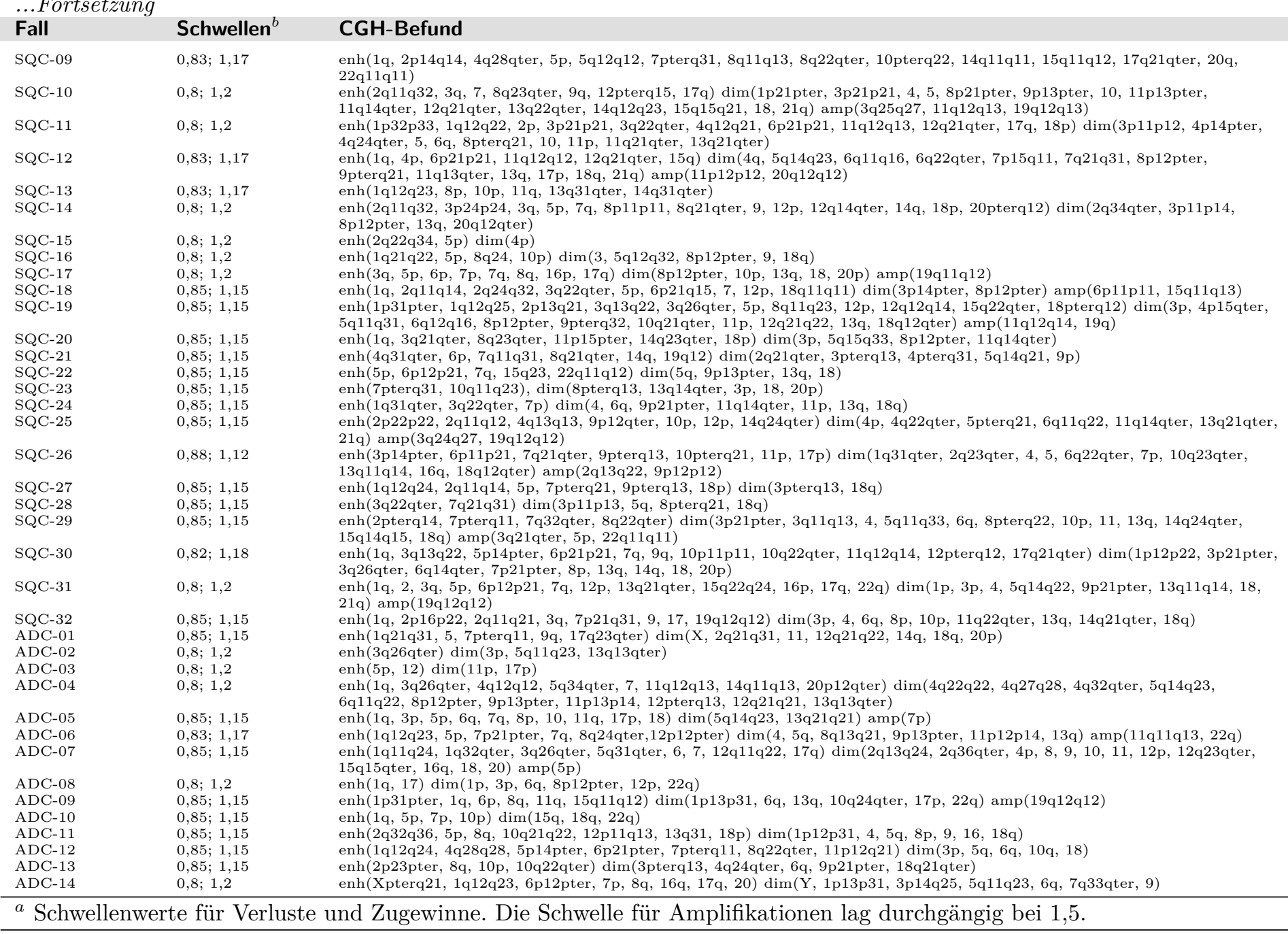


Tabelle A.2: CGH-Befunde aller untersuchten Hirnmetastasen

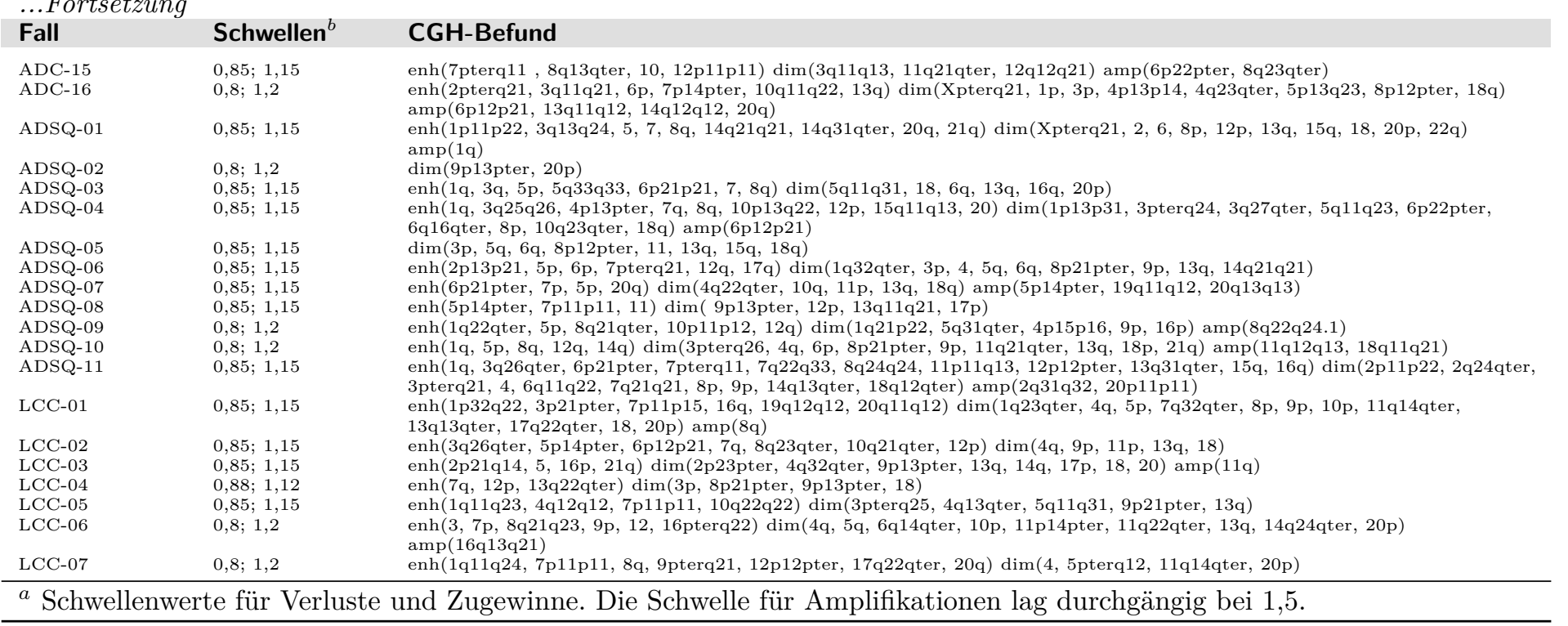




\section{A.2.2 Befunde der Primärtumoren}

Tabelle A.3: CGH-Befunde kleinzelliger Primärtumoren aus der Literaturrecherche

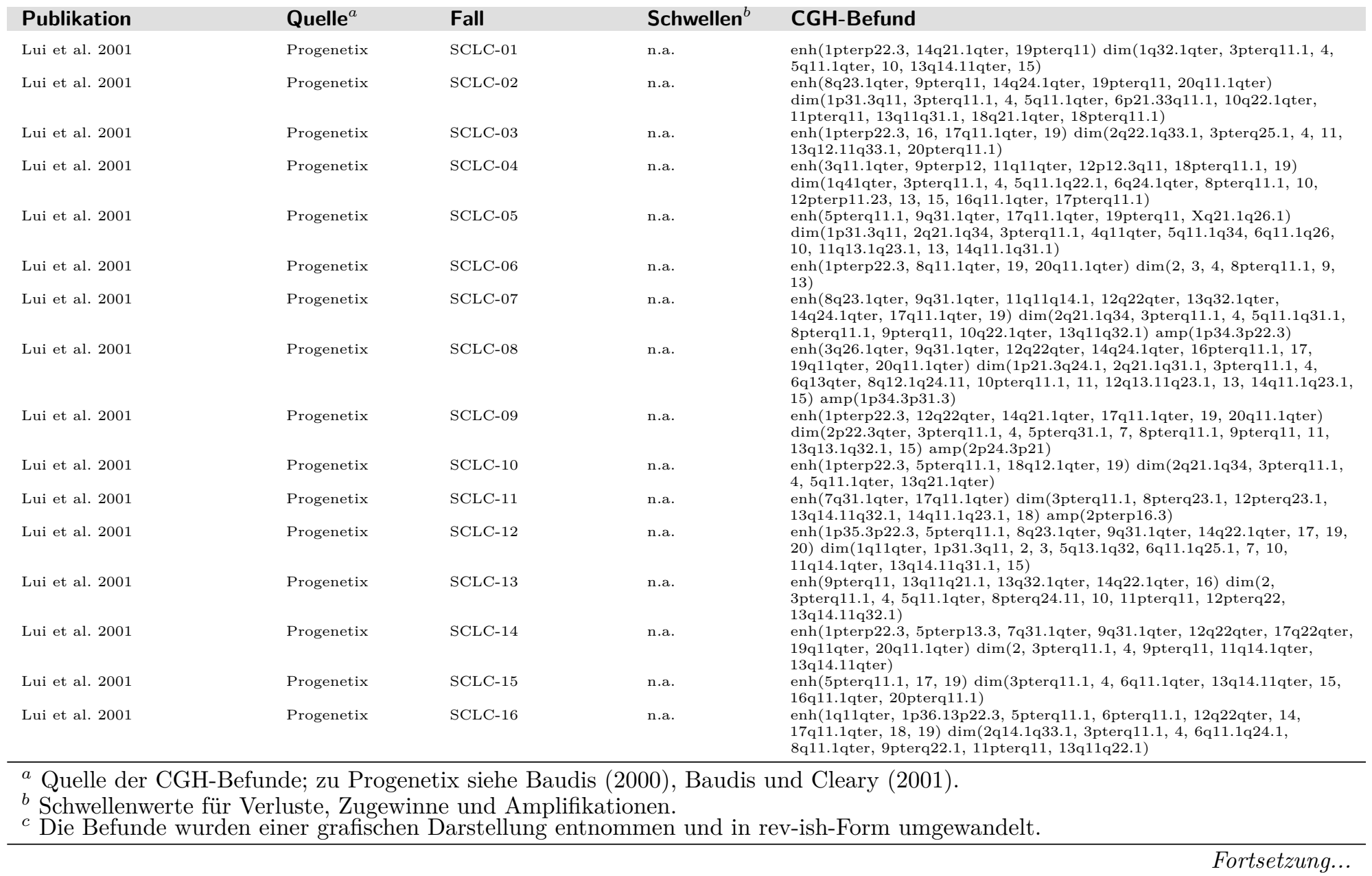


Tabelle A.3: CGH-Befunde kleinzelliger Primärtumoren aus der Literaturrecherche

\begin{tabular}{|c|c|c|c|c|}
\hline Publikation & Quelle $^{a}$ & Fall & Schwellen ${ }^{b}$ & CGH-Befund \\
\hline Lui et al. 2001 & Progenetix & SCLC-17 & n.a. & $\begin{array}{l}\text { enh(1pterp22.3, 5pterp13.3, 7q31.1qter, 8q23.1qter, 9q31.1qter, } \\
1 \text { 2q22qter, 17q22qter, 19q1qter, 20q11.14ter dim(2q21.1q33.1, } \\
\text { 3pterq11.1, 4, 5q14.1q31.1, 9q11qter, 9pterq11, 13q14.11qter, } \\
\text { 16q12.1q22.1) }\end{array}$ \\
\hline Lui et al. 2001 & Progenetix & SCLC-18 & n.a. & $\begin{array}{l}\text { enh(1pterp22.3, 17q22qter, 19, 20q11.1qter, Xq21.1q25) dim(2q21.1q33.1, } \\
3,4,8 \mathrm{q} 13.1 \mathrm{q} 24.21,9 \mathrm{pterq} 11,10,11 \mathrm{pterq} 11,13 \mathrm{q} 14.11 \mathrm{qter}, 18 \mathrm{q} 11.1 \mathrm{q} \text { ter })\end{array}$ \\
\hline Lui et al. 2001 & Progenetix & SCLC-19 & n.a. & $\begin{array}{l}\text { enh(1pterp22.3, 5pterq11.1, 8q11.1qter, 9q31.1qter, 16pterq11.1, 19) } \\
\operatorname{dim}(2 \mathrm{q} 21.1 \mathrm{q} 32.1,2 \text { pterq11.1, 3pterq11.1, 4, 9pterq11,10,11,13) }\end{array}$ \\
\hline Lui et al. 2001 & Progenetix & SCLC-20 & n.a. & $\begin{array}{l}\text { enh(13q21.1qter, 19, Xpterq11.1) dim(2q11.1qter, 3pterq11.1, } 4 \\
5 \mathrm{q} 13.1 \mathrm{q} 31.1,9,13 \mathrm{q} 11 \mathrm{q} 22.1)\end{array}$ \\
\hline Lui et al. 2001 & Progenetix & SCLC-21 & n.a. & $\begin{array}{l}\operatorname{enh}(19) \operatorname{dim}(2 \mathrm{q} 21.1 \mathrm{q} 35,3 \mathrm{pterq} 11.1,4,5 \mathrm{q} 11.1 \mathrm{q} 31.1,8 \mathrm{pterq} 11.1,9, \\
10 \mathrm{q} 23.1 \mathrm{qter}, 13,14,15 \mathrm{q} 11.1 \mathrm{q} 22.1,18) \operatorname{amp}(1 \mathrm{p} 33 \mathrm{p} 21.3)\end{array}$ \\
\hline Lui et al. 2001 & Progenetix & SCLC-22 & n.a. & $\begin{array}{l}\text { enh(1p34.3p22.3, 11q11q14.1, 19pterq11) dim (2q21.1qter, 2p15q11.1, } \\
\text { 3pterg11.1. 4pterg11. 9.11q14.1qter, 13q11q22.1. 20pterg11.1) }\end{array}$ \\
\hline Lui et al. 2001 & Progenetix & SCLC-23 & n.a. & $\begin{array}{l}\text { enh(5pterp13.3, 8q23.1qter, 13q31.1qter, 14, 19) dim(2q23.1qter, } \\
\text { 3pterq11.1,4, 6q11.1qter, 8pterp12,9, 10,11,13q11q32.1, 15, } \\
\text { 20pterg11.1) }\end{array}$ \\
\hline Petersen I et al. 1997b & Publikation $^{c}$ & 1 & 0,$75 ; 1,25 ; 1,5$ & $\begin{array}{l}\text { enh(5p, 8q21.1qter, 18) } \operatorname{dim}(2 \mathrm{p}, 3 \mathrm{p}, 4 \mathrm{q} 13 \mathrm{qter}, 5 \mathrm{q} 31 \mathrm{qter}, 10,12 \mathrm{q} 24.1 \mathrm{qter} \\
13 \mathrm{gcenq} 14,16 \mathrm{p}, 17,19,20 \mathrm{p})\end{array}$ \\
\hline Petersen I et al. 1997b & Publikation $^{c}$ & 2 & 0,$75 ; 1,25 ; 1,5$ & $\begin{array}{l}\text { enh(3q, 4q, 8q22qter, 12, 14q, 17q, 19, 20, 22q) } \operatorname{dim}(3 \mathrm{p}, 4 \mathrm{qcenq} 25,5, \mathrm{X} \\
1 \mathrm{q} 14 \mathrm{q} 22,11 \mathrm{p} 12 \mathrm{p} 14,15 \mathrm{q}, 17 \mathrm{p})\end{array}$ \\
\hline Petersen I et al. 1997b & Publikation $^{c}$ & 3 & 0,$75 ; 1,25 ; 1,5$ & $\begin{array}{l}\text { enh (3q, 9q32qter, 19) dimm(1q24q31, 2q36qter, 3pcenp 14, 4q31.1qter, } \\
5 \mathrm{q} 15 \mathrm{qter}, 8 \mathrm{p} 21 \mathrm{pter}, 10 \mathrm{q} 21 \mathrm{qter}, 11 \mathrm{p} 12 \mathrm{p} 15.3,13 \mathrm{q} 12 \mathrm{q} 14,16 \mathrm{q}, 20 \mathrm{qcenq} 12) \\
\text { amp }(2 \mathrm{q} 32 \mathrm{q} 35,8 \mathrm{pcenp} 12,19 \mathrm{q} 13.1 \mathrm{q} 13.3)\end{array}$ \\
\hline Petersen I et al. 1997b & Publikation $^{c}$ & 4 & 0,$75 ; 1,25 ; 1,5$ & $\begin{array}{l}\operatorname{enh}(1 \mathrm{q} 21 \mathrm{qter}, 4 \mathrm{p} 15.3 \mathrm{pter}, 5 \mathrm{p}, 18,19,20,12 \mathrm{q} 22) \operatorname{dim}(3 \mathrm{p}, 4 \mathrm{q}, 5 \mathrm{q}, \\
10 \mathrm{qcenq} 21,10 \mathrm{p} 12 \text { pter, } 11 \text { pcenp } 13,11 \mathrm{q} 14 \mathrm{q} 22,12 \mathrm{q} 21 \mathrm{q} 22,13 \mathrm{q} c e n \mathrm{q} 21.2,16 \mathrm{q}, \\
17 \mathrm{p})\end{array}$ \\
\hline Petersen I et al. 1997b & Publikation $^{c}$ & 5 & 0,$75 ; 1,25 ; 1,5$ & $\begin{array}{l}\text { enh(1q21qter, 3q, 14q, 15q26, 17q21qter, 19,20q) } \operatorname{dim}(2,3 \mathrm{q}, 5 \mathrm{q}, 6,7 \\
10 \mathrm{q} 21.2 \mathrm{qter}, 11,12,13 \mathrm{q}, 15 \mathrm{q} 22,16,17 \mathrm{q} 12 \mathrm{pter}, 18,22 \mathrm{q}) \operatorname{amp}(5 \mathrm{p} 11, \\
8 \mathrm{q} 23 \mathrm{q} 24.1,19 \mathrm{p} 13.1 \mathrm{p} 13.2,21 \mathrm{q} 21 \mathrm{q} 22.1)\end{array}$ \\
\hline Petersen I et al. 1997b & Publikation $^{c}$ & 6 & 0,$75 ; 1,25 ; 1,5$ & $\begin{array}{l}\text { enh } 3 \mathrm{q}, 6 \mathrm{p}, 7 \mathrm{qcenq} 11.22,9 \mathrm{q} 34,10 \mathrm{q} 22 \mathrm{pter}, 11 \mathrm{qcenq} 13.4,16 \mathrm{p}, 17 \mathrm{q}, 19,20 \mathrm{q}, \\
22 \mathrm{q} \text { ) dim(3p, 4q31.1qter, 5q, Xq21, 9p23p24,10q23qter, 17p }, 20 \mathrm{p}) \\
\operatorname{amp}(17 \mathrm{q} 12 \mathrm{q} 21,17 \mathrm{q} 25,19 \mathrm{q} 13.1 \mathrm{q} 13.3)\end{array}$ \\
\hline Petersen I et al. 1997b & Publikation $^{c}$ & 7 & 0,$75 ; 1,25 ; 1,5$ & 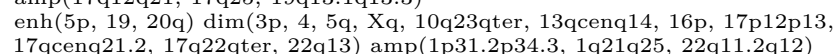 \\
\hline Petersen I et al. 1997b & Publikation $^{c}$ & 8 & 0,$75 ; 1,25 ; 1,5$ & $\operatorname{enh}(3 \mathrm{q}, 7 \mathrm{q}$ cenq11.22) $\operatorname{dim}(3 \mathrm{p}, 4 \mathrm{p}, 12 \mathrm{q} 21,13 \mathrm{q} \operatorname{cenq} 14,17 \mathrm{p})$ \\
\hline Petersen I et al. 1997b & Publikation $^{c}$ & 9 & 0,$75 ; 1,25 ; 1,5$ & $\begin{array}{l}\text { enh(1q21q23, 3q, Xq24pter, 7qcenq22, 7q32qter, 11q13,19,20q) dim } \\
\text { (1pcenp1, 2q12q23, 3p, 4p151p15.3, 4q1328, 4q32,6quenq22, 7p, } \\
13 q 21 \mathrm{q} 33,9 \mathrm{q} 13 \mathrm{q} 21,14 \mathrm{q} 21 \mathrm{qter}, 10 \mathrm{q}, 18 \mathrm{q}, 11 \mathrm{p} 14 \mathrm{pter}, 21 \mathrm{qcenq} 21,12 \mathrm{q} 21) \\
\text { amp(1q41qter, 5pcenp13,11q24q25, 19q13.1) }\end{array}$ \\
\hline Petersen I et al. 1997b & Publikation $^{c}$ & 10 & 0,$75 ; 1,25 ; 1,5$ & $\begin{array}{l}\operatorname{enh}(7 \mathrm{q}, 1) \operatorname{dim}(2,3 \mathrm{p}, 4,5,9 \mathrm{q} 33 \mathrm{q} t e r, 10 \mathrm{q} 25 \mathrm{q} 26,11 \mathrm{q} 14 \mathrm{q} 22,13 \mathrm{q} 12.1 \mathrm{q} 31 \\
15 \mathrm{q}, 17 \mathrm{p} 11.2 \mathrm{p} 12,22 \mathrm{q})\end{array}$ \\
\hline Petersen I et al. 1997b & Publikation $^{c}$ & 11 & 0,$75 ; 1,25 ; 1,5$ & $\begin{array}{l}\operatorname{enh}(5 \mathrm{p}, \mathrm{Xq}, 16 \mathrm{p}) \operatorname{dim}(3 \mathrm{p}, 4 \mathrm{p} 15.3 \mathrm{pter}, 4 \mathrm{q} 22 \mathrm{qter}, 5 \mathrm{q}, 8 \mathrm{p}, 9 \mathrm{q} 21 \mathrm{q} 33 \\
10 \mathrm{q} 23 \mathrm{qter}, 13 \mathrm{qcenq} 21,16 \mathrm{q}, 17 \mathrm{p} 12 \mathrm{p} 13,21 \mathrm{q}) \text { amp (3q26.3qter, Xq23qter, } \\
19 \mathrm{q} 13.1)\end{array}$ \\
\hline Petersen I et al. 1997b & Publikation $^{c}$ & 12 & 0,$75 ; 1,25 ; 1,5$ & $\begin{array}{l}\text { enh (1q21qter, 12p, } 6,7 \mathrm{p}, 8 \mathrm{q} 22 \mathrm{qter}, 8 \mathrm{p} 11.2,11 \mathrm{qcenq} 13.4,12 \mathrm{p} 13,13 \mathrm{q} \\
17 \mathrm{qcenq} 21,18,20) \operatorname{dim}(3 \mathrm{p}, 4,5 \mathrm{q}, \mathrm{x}, 7 \mathrm{p}, 10,15 \mathrm{q} 15 \mathrm{qter}, 16 \mathrm{p}) \\
\operatorname{amp}(7 \mathrm{q} 11.21 \mathrm{q} 11.22,19 \mathrm{p} 13.1 \mathrm{p} 13.2)\end{array}$ \\
\hline
\end{tabular}


Tabelle A.3: CGH-Befunde kleinzelliger Primärtumoren aus der Literaturrecherche

\begin{tabular}{|c|c|c|c|c|}
\hline Publikation & Quelle $^{a}$ & Fall & Schwellen ${ }^{b}$ & CGH-Befund \\
\hline Petersen I et al. 1997b & Publikation $^{c}$ & 13 & 0,$75 ; 1,25 ; 1,5$ & $\begin{array}{l}\text { enh }(7 \mathrm{q} 21.1 \mathrm{pter}, 8,11 \mathrm{q} 23 \mathrm{qter}, 13,19,20,21 \mathrm{q} 21 \mathrm{q} 22,22 \mathrm{q} 12 \mathrm{q} 13) \operatorname{dim}(2,3, \\
5,6 \mathrm{q} 15 \mathrm{qter}, 6 \mathrm{p} 21.3 \mathrm{q} 13,14 \mathrm{q} 13 \mathrm{q} 21,14 \mathrm{q} 24 \mathrm{q} 31, \mathrm{x}, 10,16,15 \mathrm{q}, 17 \mathrm{p}, 12, \\
7 \mathrm{q} 21.2 \mathrm{q} 34) \text { amp }(19 \mathrm{q} 13.1)\end{array}$ \\
\hline Petersen I et al. 1997b & Publikation $^{c}$ & 14 & 0,$75 ; 1,25 ; 1,5$ & $\begin{array}{l}\text { 7q21.2q34) amp (19q13.1) } \\
\text { enh(3q, 5p, Xpcenp21, 9q12qter, 11pcenp14,12,13q, 14q, 15q, 17q, 18, } \\
20) \operatorname{dim}(3 \mathrm{p}, 4,5 \mathrm{q}, 8,9 \mathrm{p}, 10,17 \mathrm{p}) \text { amp }(2 \mathrm{p} 23 \mathrm{p} 24)\end{array}$ \\
\hline Petersen I et al. 1997b & Publikation $^{c}$ & 15 & 0,$75 ; 1,25 ; 1,5$ & 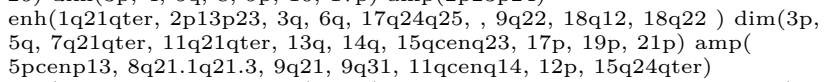 \\
\hline Petersen I et al. 1997b & Publikation $_{c}^{c}$ & 16 & 0,$75 ; 1,25 ; 1,5$ & enh $(3 \mathrm{q}, 4 \mathrm{p}, 14 \mathrm{p}, 17 \mathrm{q} 22 \mathrm{qter}) \operatorname{dim}(3 \mathrm{p}, 13 \mathrm{q}, 4 \mathrm{q} 21 \mathrm{qter}, 15 \mathrm{q}, 10,17 \mathrm{p} 12 \mathrm{p} 13)$ \\
\hline Petersen I et al. 1997b & Publikation $^{c}$ & 17 & 0,$75 ; 1,25 ; 1,5$ & 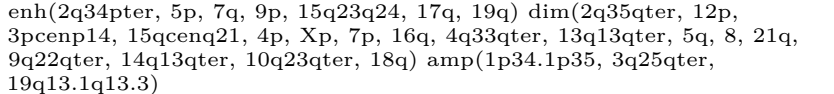 \\
\hline Petersen I et al. 1997b & Publikation $^{c}$ & 18 & 0,$75 ; 1,25 ; 1,5$ & $\begin{array}{l}\text { ent3q, 11q12q13, Xpcenp11.4, 8q, 14q31qter, 16p, 18, 19, 20) } \\
\text { dim(1pcenp31.2, 3p, 9q21q33, 4q13qter, 11p13p14, 11q14q22, 13q, 15q, } \\
16 \mathrm{q}, 5 \mathrm{q}, 10 \mathrm{q} 21 \mathrm{q} \text { ter, } 12 \mathrm{pcenp} 12,12 \mathrm{q} 13.3 \mathrm{q} 23,17 \mathrm{p}, 21 \mathrm{q} 21)\end{array}$ \\
\hline Petersen I et al. 1997b & Publikation $^{c}$ & 19 & 0,$75 ; 1,25 ; 1,5$ & $\begin{array}{l}\text { enh(5p, 6p, 9q33qter, 19, 20) dim }(2,3,4 \mathrm{q}, 4 \mathrm{pcenp} 15.3,6 \mathrm{q}, 11 \mathrm{p}, 22 \mathrm{q} \\
11 \mathrm{q} 22 \mathrm{qter}, 13 \mathrm{q}, 15 \mathrm{q}, 16 \mathrm{q}, 18 \mathrm{q} 12 \mathrm{qter}, 21 \mathrm{q} 21 \mathrm{q} 22) \text { amp }(1 \mathrm{p} 34.3 \mathrm{p} 36.2)\end{array}$ \\
\hline Petersen I et al. 1997b & Publikation $_{c}^{c}$ & 20 & 0,$75 ; 1,25 ; 1,5$ & $\operatorname{enh}(3 \mathrm{q}, 18) \operatorname{dim}(2 \mathrm{pcenp} 16,3 \mathrm{p}, 4 \mathrm{q} 13 \mathrm{qter}, 5 \mathrm{q}, 17,10,13 \mathrm{q}, 15 \mathrm{q}, 16 \mathrm{q}, 22 \mathrm{q})$ \\
\hline Petersen I & Publikation $^{c}$ & 21 & 0,$75 ; 1,25 ; 1,5$ & $\begin{array}{l}\text { enh(3q26.1qter, 9p, 12p12.3pter, 16p, 17q) dim (3p22pter, } 4 \mathrm{q} 21 \mathrm{quter}, 6,8 \mathrm{p}, \\
9 \mathrm{q} 21 \mathrm{q} 22.3,10,11 \mathrm{p} 11.2 \mathrm{p} 14,12 \mathrm{q} 21,16 \mathrm{q}, 13 \mathrm{q} \text { cenq21.2, } 17 \mathrm{pcenp} 12)\end{array}$ \\
\hline Petersen I et al. 1997b & Publikation $^{c}$ & 22 & 0,$75 ; 1,25 ; 1,5$ & $\begin{array}{l}\operatorname{enh}(1,3 \mathrm{q}, 14 \mathrm{q}, 17 \mathrm{q}, 19,20,22 \mathrm{q}) \operatorname{dim}(3 \mathrm{p}, 4,5 \mathrm{p}, 17 \mathrm{p}, 9 \mathrm{q} 13 \mathrm{q} 22,10,11 \mathrm{p} \\
13 \mathrm{q}, 15 \mathrm{q}) \operatorname{amp}(20 \mathrm{p} 11.2)\end{array}$ \\
\hline Ried et al. 1994 & Progenetix & NCBISKYCGH-2248 & 0,$75 ; 1,25 ; 2$ & $\begin{array}{l}\text { enh(1q32.1qter, 1pterq41, 6pterq13, 7p22.3q31.1, 8p23.3qter, } \\
11 \mathrm{p} 15.5 \mathrm{q} \text { ter, 13q33.1qter, 13q12.11q34, 18p11.32qter, 19p13.3q13.2, }\end{array}$ \\
\hline Ried et al. 1994 & Progenetix & NCBISKYCGH-2249 & 0,$75 ; 1,25 ; 2$ & 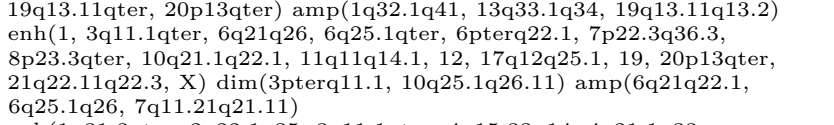 \\
\hline Ried et al. 1994 & Progenetix & NCBISKYCGH-2250 & 0,$75 ; 1,25 ; 2$ & 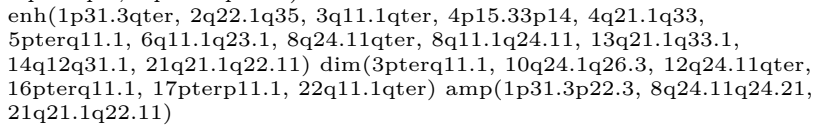 \\
\hline Ried et al. 1994 & Progenetix & NCBISKYCGH-2251 & 0,$75 ; 1,25 ; 2$ & $\begin{array}{l}\text { enh(1pterq11, 2q14.1q22.1, 5pterp15.1, 8q11.21qter, 18p11.32qter, } \\
\text { 22q11.1qter, Xpterq11.1) dim(2pterq11.1,3pterq11.1, 5q32qter, } \\
10 \text { pterq26.3, 20p13p11.1) amp (5p15.33p15.2, 8q24.11q24.21) }\end{array}$ \\
\hline Ried et al. 1994 & Progenetix & NCBISKYCGH-2252 & 0,$75 ; 1,25 ; 2$ & $\begin{array}{l}\text { enh(1q12qter, 2pterq11.1, 3q11.1qter, 5p14.3p13.3, 5pterp13.3, } \\
\text { 7q11.1qter, 14q12q21.1, 14q13.1q22.1, 19q12q13.41, 21q22.11q22.3, } \\
\text { Xpterq26.1) amp(5p14.3p13.3, 14q13.1q21.1, 19q13.11q13.2) }\end{array}$ \\
\hline Ried et al. 1994 & Progenetix & NCBISKYCGH- 2253 & 0,$75 ; 1,25 ; 2$ & 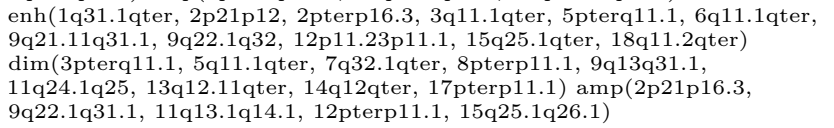 \\
\hline
\end{tabular}

${ }^{a}$ Quelle der CGH-Befunde; zu Progenetix siehe Baudis (2000), Baudis und Cleary (2001).

${ }^{b}$ Schwellenwerte für Verluste, Zugewinne und Amplifikationen.

${ }^{c}$ Die Befunde wurden einer grafischen Darstellung entnommen und in rev-ish-Form umgewandelt. 
Tabelle A.3: CGH-Befunde kleinzelliger Primärtumoren aus der Literaturrecherche

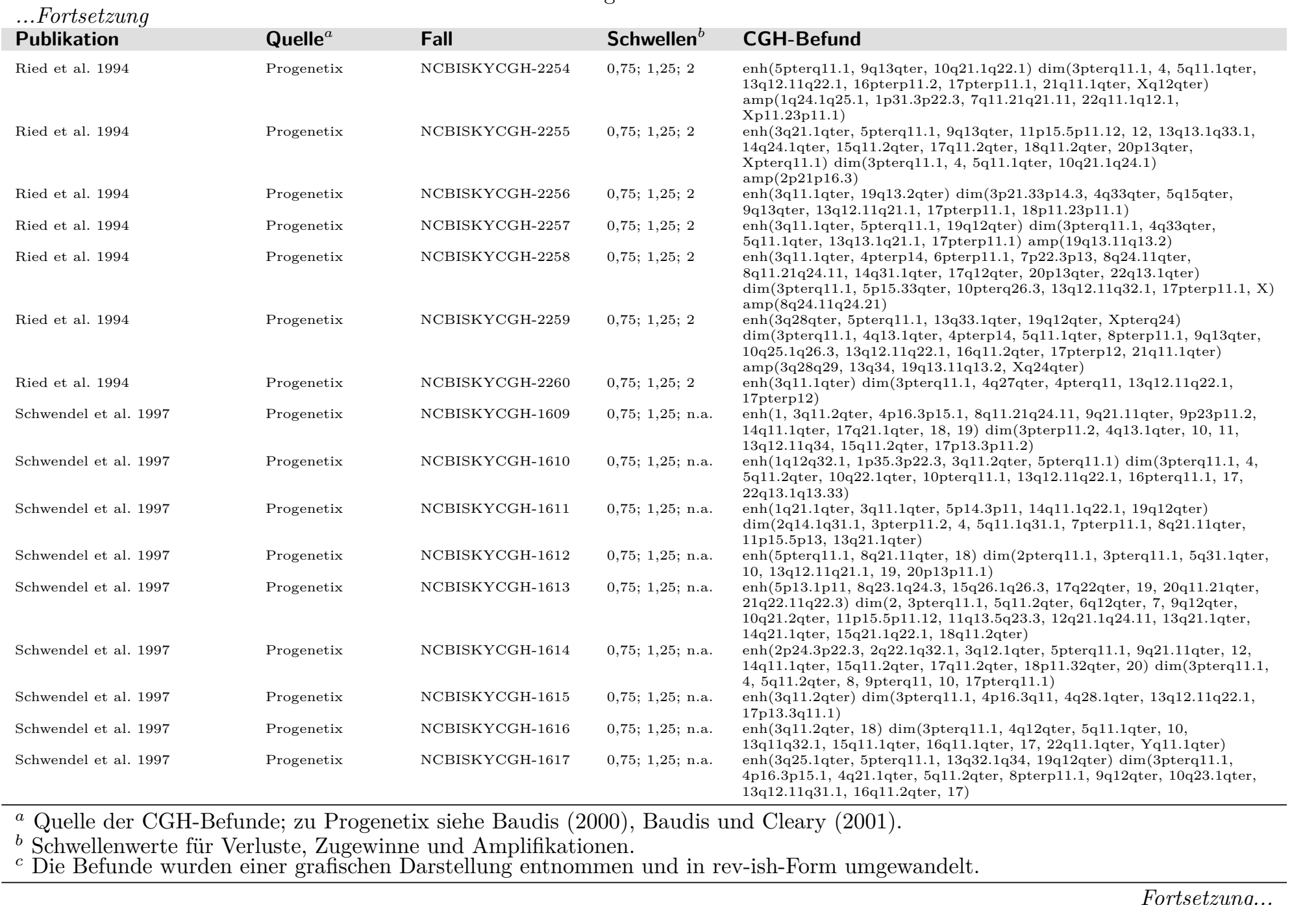


Tabelle A.3: CGH-Befunde kleinzelliger Primärtumoren aus der Literaturrecherche

...Fortsetzung

Publikation

Quelle $^{a}$

Fall

Schwellen

CGH-Befund

Schwendel et al. 1997

Progenetix

NCBISKYCGH-1618

0,$75 ; 1,25 ;$ n.a

Walch et al. 1998

Progenetix

NETL-01

statistisch

enh(3q11.2qter, 5pterq11.1, 17q11.2qter, 19pterq13.2) dim(3pterq11.1,

Walch et al. 1998

Progenetix

NETL-02

statistisch

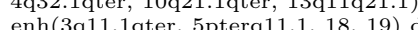

13. 1913.1qter, 5q14.1qter,

Progenetix NETL-03

tatistisch - tong

19, 19) $\operatorname{dim}(3 p$ terp11.2, 4q12qter, 5q15qter.

${ }^{a}$ Quelle der CGH-Befunde; zu Progenetix siehe Baudis (2000), Baudis und Cleary (2001).

${ }^{b}$ Schwellenwerte für Verluste, Zugewinne und Amplifikationen.

$c$ Die Befunde wurden einer grafischen Darstellung entnommen und in rev-ish-Form umgewandelt. 
Tabelle A.4: CGH-Befunde von Primärtumoren des Plattenepithelkarzinoms aus der Literaturrecherche

\begin{tabular}{|c|c|c|c|c|}
\hline Publikation & Quelle $^{a}$ & Fall & Schwellen ${ }^{b}$ & CGH-Befund \\
\hline Björkqvist et al. 1998a & Progenetix & 1 & 0,$85 ; 1,17 ; 1,5$ & $\operatorname{enh}(1 \mathrm{q} 11 \mathrm{qter}, 3 \mathrm{q} 24 \mathrm{qter}, 18 \mathrm{q} 11.1 \mathrm{q} 22.1, \mathrm{Xq} 21.1 \mathrm{q} 27.1)$ \\
\hline $\begin{array}{l}\text { Björkqvist et al. 1998a } \\
\text { Börkquist et al. } 1998 \mathrm{a}\end{array}$ & Progenetix & 2 & 0,$85 ; 1,17 ; 1,5$ & $\operatorname{enh}(3 q 24 q t e r, 6 p 21.33 q 11.1,7)$ \\
\hline Björkqvist et al. 1998a & Progenetix & 3 & 0,$85 ; 1,17 ; 1,5$ & 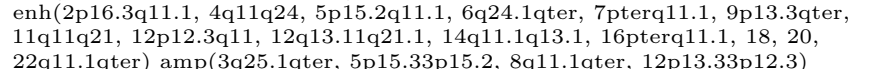 \\
\hline Björkqvist et al. 1998a & Progenetix & 4 & 0,$85 ; 1,17 ; 1,5$ & 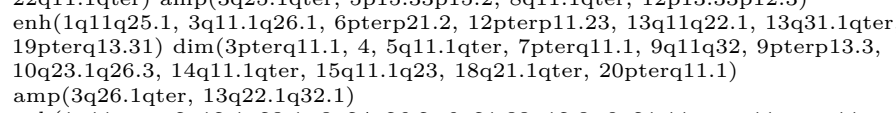 \\
\hline Björkqvist et al. 1998a & Progenetix & 5 & 0,$85 ; 1,17 ; 1,5$ & $\begin{array}{l}\text { enh(1q11qter, 2q12.1q23.1, 3q24q26.2, 6p21.33p12.3, 8q21.11qter, 11pterq11, } \\
\text { 14q24.1qter, 15q11.1q21.1, 17, 19p13.2q11) dim(3p14.3q11.1, 4q22.1qter, } \\
\text { 4pterq11, 5q12.1q22.1, 10q11.1qter, 16) amp(3q26.1qter, 6pterp21.33, } \\
\text { 19q11q13.41) }\end{array}$ \\
\hline Björkqvist et al. 1998a & Progenetix & 6 & 0,$85 ; 1,17 ; 1,5$ & $\begin{array}{l}\text { enh(1q24.1q43, 3q13.31q27.1, } 4 \mathrm{p} 15.33 \mathrm{q} 24,8 \mathrm{q} 11.1 \mathrm{q} 24.11,13 \mathrm{q} 21.1 \mathrm{q} 31.1 \\
13 \mathrm{q} 32.1 \mathrm{q} t \mathrm{ter}, 15 \mathrm{q} 11.1 \mathrm{q} 23) \text { dim(11p15.5p14.3, 17pterq11.1) amp (3q27.1qter, } \\
13 \mathrm{q} 22.1 \mathrm{q} 32.1)\end{array}$ \\
\hline Björkqvist et al. 1998a & Progenetix & 7 & 0,$85 ; 1,17 ; 1,5$ & enh(1q24.1qter, 2q24.1q33.1, 3q11.1qter, 5pterq11.1, 8q11.1qter, 10) \\
\hline Björkqvist et al. 1998a & Progenetix & 8 & 0,$85 ; 1,17 ; 1,5$ & $\begin{array}{l}\text { enh(7, 8pterq11.1, 11q11q14.1, 12, 15q11.1q23, 17q11.1qter, 18p11.32qter, } \\
\text { 19q11qter, 20) dim(21q11.1qter) amp(5pterq11.1, 8q11.1qter) }\end{array}$ \\
\hline Björkqvist et al. 1998a & Progenetix & 9 & 0,$85 ; 1,17 ; 1,5$ & enh(3q13.31qter, 6q11.1qter, 8q11.1qter, 18q11.1qter, 22q12.1qter) \\
\hline Björkqvist et al. 1998a & Progenetix & 10 & 0,$85 ; 1,17 ; 1,5$ & enh(3q21.1qter) \\
\hline Björkqvist et al. 1998a & Progenetix & 11 & 0,$85 ; 1,17 ; 1,5$ & $\begin{array}{l}\text { enh(2pterq23.1, 3q11.1qter, 7, 8, 9q31.1qter, 9p21.3q22.1, 12, 15q14qter, } \\
\text { 16pterq11.1, 17q11.1qter, 19, 20pterq11.1, 22q11.1qter) amp(9q22.1q31.1) }\end{array}$ \\
\hline Björkqvist et al. 1998a & Progenetix & 12 & 0,$85 ; 1,17 ; 1,5$ & $\operatorname{enh}(2 \mathrm{q} 31.1 \mathrm{q} 34,3 \mathrm{q} 11.1 \mathrm{qter}, 8 \mathrm{q} 23.1 \mathrm{qter}, 17 \mathrm{q} 11.1 \mathrm{qter}) \operatorname{dim}(13 \mathrm{q} 21.1 \mathrm{q} 33.1)$ \\
\hline Björkqvist et al. 1998a & Progenetix & 13 & 0,$85 ; 1,17 ; 1,5$ & $\begin{array}{l}\text { enh(3q11.1qter, 5pterq11.1, 7p21.3q11.1, 8q11.1qter, 15q21.1qter, 22q11.1qter) } \\
\operatorname{dim}(4)\end{array}$ \\
\hline Björkqvist et al. 1998a & Progenetix & 14 & 0,$85 ; 1,17 ; 1,5$ & $\begin{array}{l}\text { enh(2p24.3p21, 3q11.1qter, 5pterq11.1, 13q31.1qter, 18q11.1q22.1) } \\
\operatorname{dim}(19 \mathrm{pterq} 11)\end{array}$ \\
\hline Björkqvist et al. 1998a & Progenetix & 15 & 0,$85 ; 1,17 ; 1,5$ & $\begin{array}{l}\operatorname{enh}(2 \mathrm{q} 14.1 \mathrm{q} 32.1,2 \mathrm{p} 22.3 \mathrm{p} 12,3 \mathrm{q} 11.1 \mathrm{q} 21.1,4 \mathrm{p} 15.33 \mathrm{p} 13,5 \mathrm{pterq} 11.1,7 \mathrm{p} 21.3 \mathrm{qter} \\
\text { 9pterp21.3, 14q13.1q32.11, Xq11.1q22.1) dim(10pterq11.1, 17pterq11.1, } \\
\text { 19pterq11) amp(3q13.31qter, Xq22.1qter) }\end{array}$ \\
\hline Björkqvist et al. 1998a & Progenetix & 16 & 0,$85 ; 1,17 ; 1,5$ & 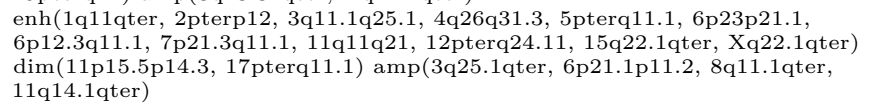 \\
\hline Chujo et al. 2002 & Progenetix & L-98 & 0,$75 ; 1,25 ; 1,5$ & $\begin{array}{l}\text { enh(4q11qter, 5pterq11.1, 12pterq11) dim(3pterq11.1, 5q11.1qter, 6q11.1qter, } \\
10 \mathrm{q} 11.1 \mathrm{qter}, 10 \mathrm{pterq} 11.1,11 \mathrm{q} 11 \mathrm{qter}, 12 \mathrm{q} 11 \mathrm{qter}, 15 \mathrm{q} 11.1 \mathrm{qter}, 16 \mathrm{q} 11.1 \mathrm{qter},\end{array}$ \\
\hline Chujo et al. 2002 & Progenetix & $\mathrm{L}-20$ & 0,$75 ; 1,25 ; 1,5$ & $\begin{array}{l}\text { 16pterq11.1, 17q11.1qter, 17pterq11.1) amp (3q25.2qter) } \\
\text { enh() dim(1q1quter, 3pterq11.1, 9q11qter, 11q11qter, 15q11.1qter, 16pterq11.1, } \\
\text { 20pterq11.1, Xpterq11.1) amp(3q21.1qter) }\end{array}$ \\
\hline $\begin{array}{l}\text { Chujo et al. } 2002 \\
\text { Chujo et al. } 2002\end{array}$ & $\begin{array}{l}\text { Progenetix } \\
\text { Progenetix }\end{array}$ & $\begin{array}{l}\text { L-6 } \\
\text { L-82 }\end{array}$ & $\begin{array}{l}0,75 ; 1,25 ; 1,5 \\
0.75 ; 1,25 ; 1,5\end{array}$ & $\begin{array}{l}\text { enh (3q11.1qter) dim(1pterq11, 10pterq11.1) } \\
\text { enh(3q11.qter, 20pterq11.1) }\end{array}$ \\
\hline Chujo et al. 2002 & Progenetix & $\mathrm{L}-38$ & 0,$75 ; 1,25 ; 1,5$ & $\begin{array}{l}\text { enh(3q11.1qter, 5pterq11.1, 7pterq11.1) dim(4pterq11, 8pterq11.1, 9q11qter) } \\
\text { amp(13q21.2q33.1) }\end{array}$ \\
\hline Chujo et al. 2002 & Progenetix & $\mathrm{L}-47$ & 0,$75 ; 1,25 ; 1,5$ & $\operatorname{enh}(2$ pterq11.1) dim(9pterq11) \\
\hline $\begin{array}{l}\text { Chujo et al. } 2002 \\
\text { Chujo et al. } 2002\end{array}$ & $\begin{array}{l}\text { Progenetix } \\
\text { Progenetix }\end{array}$ & $\begin{array}{l}\mathrm{L}-19 \\
\mathrm{~L}-32\end{array}$ & 0,$75 ; 1,25 ; 1,5$ & enh(15q11.1qter, 17pterq11.1) dim(3pterq11.1) \\
\hline Chujo et al. 2002 & Progenetix & & 0,$75 ; 1,25 ; 1,5$ & $\begin{array}{l}\text { enh(2q11.1qter, 2pterq11.1, 3q11.1qter, 4q11qter, Xq11.1qter) dim(5q11.1qter, } \\
\text { 8pterq11.1, 9q11qter, 16pterq11.1) }\end{array}$ \\
\hline
\end{tabular}

${ }^{a}$ Quelle der CGH-Befunde; zu Progenetix siehe Baudis (2000), Baudis und Cleary (2001).

${ }^{b}$ Schwellenwerte für Verluste, Zugewinne und Amplifikationen. 
Tabelle A.4: CGH-Befunde von Primärtumoren des Plattenepithelkarzinoms aus der Literaturrecherche

Fortsetzung

\begin{tabular}{|c|c|c|c|c|}
\hline Publikation & Quelle $^{a}$ & Fall & Schwellen ${ }^{b}$ & CGH-Befund \\
\hline Chujo et al. 2002 & Progenetix & L-46 & 0,$75 ; 1,25 ; 1,5$ & \multirow{25}{*}{ 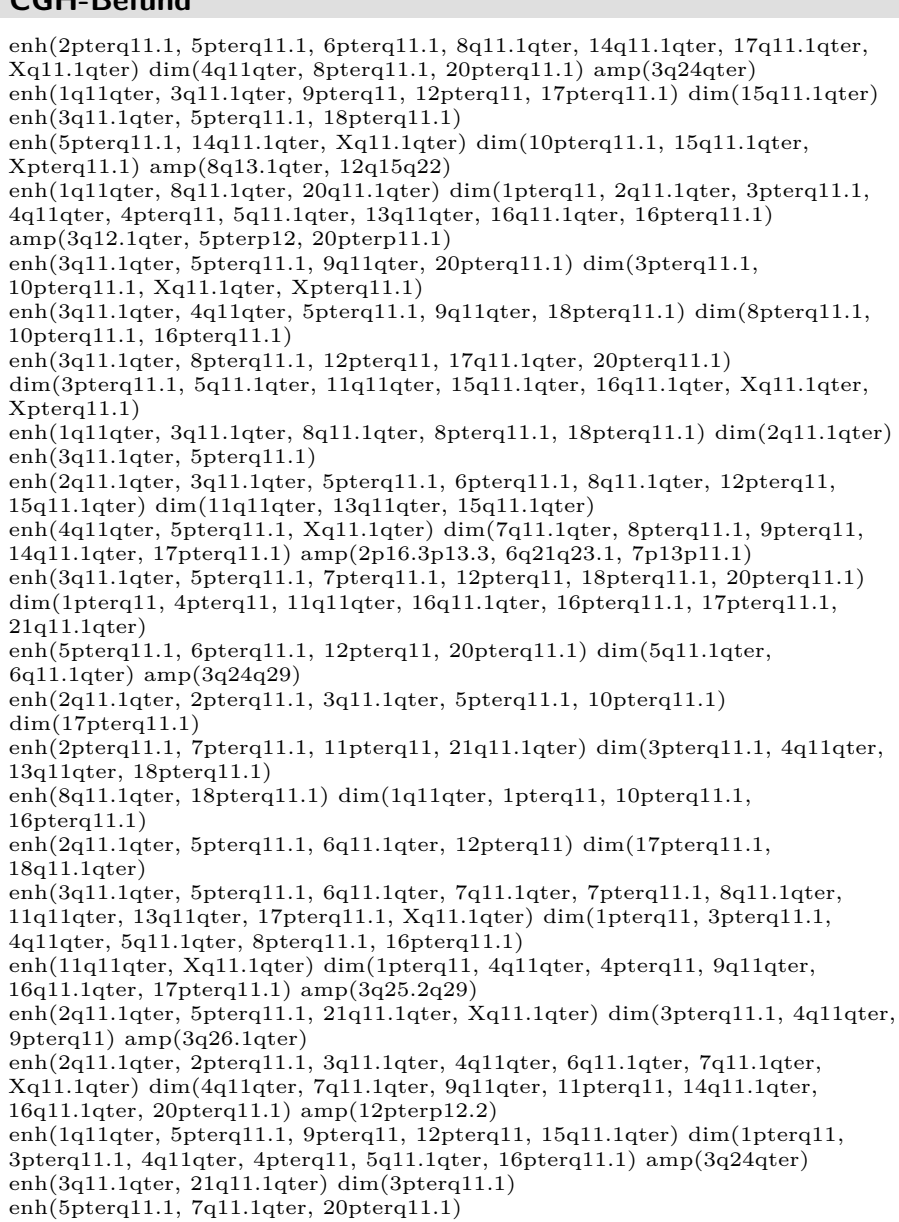 } \\
\hline Chujo et al. 2002 & Progenetix & L-72 & 0,$75 ; 1,25 ; 1,5$ & \\
\hline Chujo et al. 2002 & Progenetix & L-73 & 0,$75 ; 1,25 ; 1,5$ & \\
\hline Chujo et al. 2002 & Progenetix & $\mathrm{L}-58$ & 0,$75 ; 1,25 ; 1,5$ & \\
\hline Chujo et al. 2002 & Progenetix & $\mathrm{L}-41$ & 0,$75 ; 1,25 ; 1,5$ & \\
\hline Chujo et al. 2002 & Progenetix & L-11 & 0,$75 ; 1,25 ; 1,5$ & \\
\hline Chujo et al. 2002 & Progenetix & L-71 & 0,$75 ; 1,25 ; 1,5$ & \\
\hline Chujo et al. 2002 & Progenetix & L- 88 & 0,$75 ; 1,25 ; 1,5$ & \\
\hline Chujo et al. 2002 & Progenetix & L-64 & 0,$75 ; 1,25 ; 1,5$ & \\
\hline & Progenetix & L-31 & 0,$75 ; 1,25 ; 1,5$ & \\
\hline Chujo et al. 2002 & Progenetix & $\mathrm{L}-17$ & 0,$75 ; 1,25 ; 1,5$ & \\
\hline Chujo et al. 2002 & Progenetix & $\mathrm{L}-13$ & 0,$75 ; 1,25 ; 1,5$ & \\
\hline Chujo et al. 2002 & Progenetix & L-87 & 0,$75 ; 1,25 ; 1,5$ & \\
\hline Chujo et al. 2002 & Progenetix & $\mathrm{L}-42$ & 0,$75 ; 1,25 ; 1,5$ & \\
\hline Chujo et al. 2002 & Progenetix & $\mathrm{L}-45$ & 0,$75 ; 1,25 ; 1,5$ & \\
\hline Chujo et al. 2002 & Progenetix & L-14 & 0,$75 ; 1,25 ; 1,5$ & \\
\hline Chujo et al. 2002 & Progenetix & $\mathrm{L}-21$ & 0,$75 ; 1,25 ; 1,5$ & \\
\hline Chujo et al. 2002 & Progenetix & L-49 & 0,$75 ; 1,25 ; 1,5$ & \\
\hline Chujo et al. 2002 & Progenetix & L-55 & 0,$75 ; 1,25 ; 1,5$ & \\
\hline Chujo et al. 2002 & Progenetix & $\mathrm{L}-40$ & 0,$75 ; 1,25 ; 1,5$ & \\
\hline Chujo et al. 2002 & Progenetix & L-35 & 0,$75 ; 1,25 ; 1,5$ & \\
\hline Chujo et al. 2002 & Progenetix & L-50 & 0,$75 ; 1,25 ; 1,5$ & \\
\hline Chujo et al. 2002 & Progenetix & L-18 & 0,$75 ; 1,25 ; 1,5$ & \\
\hline Chujo et al. 2002 & Progenetix & $\mathrm{L}-16$ & 0,$75 ; 1,25 ; 1,5$ & \\
\hline Chujo et al. 2002 & Progenetix & L- 67 & 0,$75 ; 1,25 ; 1,5$ & \\
\hline
\end{tabular}

${ }^{a}$ Quelle der CGH-Befunde; zu Progenetix siehe Baudis (2000), Baudis und Cleary (2001).

${ }^{b}$ Schwellenwerte für Verluste, Zugewinne und Amplifikationen. 
Tabelle A.4: CGH-Befunde von Primärtumoren des Plattenepithelkarzinoms aus der Literaturrecherche

\section{Fortsetzung}

Chujo et al. 2002
Chujo et al. 2002

Chujo et al. 2002

Chujo et al. 2002

Chujo et al. 2002

Progenetix

Chujo et al. 2002

Chujo et al. 2002

Progenetix

Progenetix

Chujo et al. 2002

Luk et al. 2001
Luk et al. 2001

Progenetix

Progenetix
Progenetix

Progenetix
Progenetix

Publikation
Publikation

Publikation

Publikation

Publikation

Publikation

Publikation

Publikation

Publikation

Publikation
L-84

0,$75 ; 1,25 ; 1,5$

L-37

L-65

L-63

L100
L45

Schwellen ${ }^{b}$

0,$75 ; 1,25 ; 1,5$
0,$75 ; 1,25 ; 1,5$

0,$75 ; 1,25 ; 1,5$

0,$75 ; 1,25 ; 1,5$

0,$75 ; 1,25 ; 1,5$

0,$75 ; 1,25 ; 1,5$

0,$75 ; 1,25 ; 1,5$

0,$8 ; 1,2 ; 1,5$
0,$8 ; 1,2 ; 1,5$

$\begin{array}{ll}\text { L58 } & 0,8 ; 1,2 ; 1,5 \\ \text { L } 88 & 0,8 \cdot 1,2 ; 1,5\end{array}$

SCC1 0,$8 ; 1,2 ; 1,4$

0,$8 ; 1,2 ; 1,4$
0,$8 ; 1,2 ; 1,4$

SCC3 0,$8 ; 1,2 ; 1,4$

0,$8 ; 1,2 ; 1,4$

$\mathrm{SCC} 5$

0,$8 ; 1,2 ; 1,4$

$\mathrm{SCC} 6$
$\mathrm{SCC} 7$

0,$8 ; 1,2 ; 1,4$

$\mathrm{SCC} 8$

0,$8 ; 1,2 ; 1,4$

$\mathrm{SCC} 10 \quad 0,8 ; 1,2 ; 1,4$

SCC11

\section{CGH-Befund}

enh(5pterq11.1) $\operatorname{dim}(16 \mathrm{q} 11.1 \mathrm{qter})$ amp (3q22.1qter)

enh(5pterq11.1, 7q11.1qter, 8q11.1qter) dim(1pterq11, 4q11qter, 4pterq1

21q11.19ter) amp(3q25.2q28)

enh(3q11.1qter, 17q11.1qter, 17pterq11.1, 18q11.1qter, 18pterq11.1,
20q11.1qter, 20pterq11.1) dim(2q11.1qter, 3pterq11.1, 4q11qter, 5q11.1qter,

enh(1q11qter, 2q11.1qter, 3q11.1qter, 5pterq11.1, 7q11.1qter, 7pterq11.1,

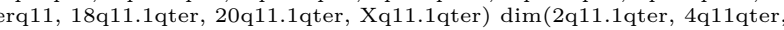

14q11.1qter, 15q11.1qter, 16q11.1qter, 16pterq11.1.17q11.1qter, 17pterq11.1 18q11.1qter, 20q11.1qter, 20pterq11.1, 21q11.1qter) amp(4q28.1q31.3,

enh(1q11qter, 5pterq11.1, 7q11.1qter, 8q11.1qter, 11pterq11, Xq11.1qter)

$\operatorname{dim}(2 \mathrm{q} 11.1 \mathrm{qter}, 4 \mathrm{q} 11 \mathrm{qter}, 4 \mathrm{pterq} 11,5 \mathrm{q} 11.1 \mathrm{qter}, 11$ pterq11, 16 pterq11.1,

17q11.1qter, 17pterq11.1, 18q11.1qter) amp(3q24q29, 18pterp11.1) enh(15q11.1qter) dim(10pterq11.1, 12q11qter, 12pterq11, 16pterq11.1,

enh(3q11.1qter, 5pterq11.1, 7q11.1qter, 9q11qter, 18pterq11.1, 20pterq11.1) dim(1pterq11, 2q11.1qter, 3q11.1qter, 4q11qter, 5q11.1qter, 8pterq11.1, 9q11qter, 10q11.1qter, 10pterq11.1, 12q11qter, 17pterq11.1, 18q11.1qter, 21q11.1qter) amp (8q23.1qter, 12pterq11)
enh(3q11.1qter, 5pterq11.1, 6pterq11.1, 8q11.1qter, 11q11qter, 20q11.1qter) dim(16pterq11.1)

enh(1q31.1q42.11, 2pterp22.3, 3q11.1q28, 8q21.3q24.3, 11q13.1q14.1, 12q22q24.33, 16pterp11.2, 17q11.1q23.1, 18q12.1q23) $\operatorname{dim}(2 \mathrm{q} 24.1 \mathrm{q} 32.1$ 3pterp14.3, 5q21.1q33.1,

enh(5p15.2q11.1, 13q31.1q33.1, 18q12.1q23) dim(Xp22.13q28)

$\operatorname{enh}(7 \mathrm{p}, 11 \mathrm{q}) \operatorname{dim}(18)$

enh ( 3q24-qter, 5pter-q11.2, 6q23-qter, 8q22.3-qter, 12pter-q15, 17q22-qter)

$\operatorname{dim}(3 \mathrm{p}, 5 \mathrm{q} 12-\mathrm{q} 31.3,6 \mathrm{pter}-\mathrm{p} 22.1,9,13) \mathrm{amp}(12 \mathrm{p})$

enh( $2 \mathrm{p} 23-\mathrm{p} 11,2,3 \mathrm{q}, 6 \mathrm{p}, \mathrm{er}-\mathrm{p} 211,11 \mathrm{p} 12-\mathrm{qter}, 18 \mathrm{p}$ - $\mathrm{q}$ 2q14.2-qter, 3p, 4q, 5q, 6p12-q21, 7p, 8p, 9q, 10p, 11pter-p13, 12p, 13q12-q21.3 16q12.1-qter, 19p, 22) amp(3q26.1-qter, 8q21.1-qter,13q22-qter) enh( 1q41-qter, 2p22-q11,2, 3q25.1-qter, 5pter-q11.2, 12pter-q13) dim(

enh( $3 \mathrm{q} 13.3$-qter, 5 pter-p13.1) dim( $5 \mathrm{q} 15$ - $\mathrm{pter}, 11)$

enh( 3q, 6q13-qter, 8q12-qter, 9p, 14) dim( 2pter-q24, 3p, 4, 5q13.1-qter, 7, $13 \mathrm{q} 12.1-\mathrm{q} 22,15,16,17,18 \mathrm{q}, 22)$ amp ( 5 pter-q12)

$\operatorname{enh}(12 \mathrm{p}) \operatorname{dim}(17 \mathrm{q}, 19)$
$\operatorname{enh}(1 \mathrm{q} 12-\mathrm{q} 25,2 \mathrm{p} 23-\mathrm{p} 16,4 \mathrm{p} 12-\mathrm{q} 23,5 \mathrm{p}, 11 \mathrm{pter}-\mathrm{p} 12,12 \mathrm{p}, 17 \mathrm{q}) \operatorname{dim}(2 \mathrm{q} 14.1-\mathrm{qter}$ 3p, 4pter-13, 4q24-qter, 5q11.2-q22, 8p, 9pter-q12, 10q, 13) amp(3q21-qter) 14q11.2-q21, 19p, 22q) dim( 2q33-qter, 4, 5q, 6p21.3-qter, 8p, 10, 11q14-qter, $13,15 \mathrm{q} 11.2-\mathrm{q} 23$ ) $16 \mathrm{pter}-\mathrm{p} 12,19 \mathrm{p}, 21)$
$\operatorname{enh}(2,5 \mathrm{p}, 7 \mathrm{q}) \operatorname{dim}(1 \mathrm{pter}-\mathrm{q} 12,4 \mathrm{q} 13.1-\mathrm{q} 28,16,17 \mathrm{p}, 18 \mathrm{q}, 20 \mathrm{p}, 21)$

$a$ Quelle der CGH-Befunde; zu Progenetix siehe Baudis (2000), Baudis und Cleary (2001).

${ }^{b}$ Schwellenwerte für Verluste, Zugewinne und Amplifikationen. 
Tabelle A.4: CGH-Befunde von Primärtumoren des Plattenepithelkarzinoms aus der Literaturrecherche

\section{...Fortsetzung}

\begin{tabular}{|c|c|c|c|}
\hline Publikation & Quelle $^{a}$ & Fall & Schwellen \\
\hline $\begin{array}{l}\text { Tai et al. } 2004 \\
\text { Tai et al. } 2004\end{array}$ & $\begin{array}{l}\text { Publikation } \\
\text { Publikation }\end{array}$ & $\begin{array}{l}\mathrm{SCC} 12 \\
\mathrm{SCC} 13\end{array}$ & $\begin{array}{l}0,8 ; 1,2 ; 1,4 \\
0,8 ; 1,2 ; 1,4\end{array}$ \\
\hline Tai et al. 2004 & Publikation & $\mathrm{SCC} 14$ & 0,$8 ; 1,2 ; 1,4$ \\
\hline Tai et al. 2004 & Publikation & $\mathrm{SCC} 15$ & 0,$8 ; 1,2 ; 1,4$ \\
\hline Tai et al. 2004 & Publikation & $\mathrm{SCC} 16$ & 0,$8 ; 1,2 ; 1,4$ \\
\hline $\begin{array}{l}\text { Tai et al. } 2004 \\
\text { Tai et al. } 2004\end{array}$ & Publikation & SCC17 & 0,$8 ; 1,2 ; 1,4$ \\
\hline Tai et al. 2004 & Publikation & SCC18 & 0,$8 ; 1,2 ; 1,4$ \\
\hline Tai et al. 2004 & Publikation & SCC19 & 0,$8 ; 1,2 ; 1$ \\
\hline Tai et al. 2004 & Publikation & $\mathrm{SCC} 20$ & 0,$8 ; 1,2 ; 1$ \\
\hline Tai et al. 2004 & Publikation & $\mathrm{SCC} 21$ & 0,$8 ; 1,2 ; 1,4$ \\
\hline Tai et al. 2004 & Publikation & $\mathrm{SCC} 22$ & 0,$8 ; 1,2 ; 1,4$ \\
\hline Tai et al. 2004 & Publikation & $\mathrm{SCC} 23$ & 0,$8 ; 1,2 ; 1,4$ \\
\hline Tai et al. 2004 & Publikation & $\mathrm{SCC} 24$ & 0,$8 ; 1,2 ; 1,4$ \\
\hline Tai et al. 2004 & Publikation & $\mathrm{SCC} 25$ & 0,$8 ; 1,2 ; 1,4$ \\
\hline Tai et al. 2004 & Publikation & SCC26 & 0,$8 ; 1,2 ; 1,4$ \\
\hline Tai et al. 2004 & Publikation & $\mathrm{SCC} 27$ & 0,$8 ; 1,2 ; 1$ \\
\hline Tai et al. 2004 & Publikation & $\mathrm{SCC} 28$ & 0,$8 ; 1,2 ;$ \\
\hline Tai et al. 2004 & Publikation & $\mathrm{SCC} 29$ & 0,$8 ; 1,2 ; 1,4$ \\
\hline $\begin{array}{l}\text { Tai et al. } 2004 \\
\text { Tai et al. } 2004\end{array}$ & $\begin{array}{l}\text { Publikation } \\
\text { Publikation }\end{array}$ & $\begin{array}{l}\text { SCC30 } \\
\text { SCC31 }\end{array}$ & $\begin{array}{l}0,8 ; 1,2 ; 1,4 \\
0,8 ; 1,2 ; 1,4\end{array}$ \\
\hline Tai et al. 2004 & Publikation & $\mathrm{SCC} 32$ & 0,$8 ; 1,2 ; 1,4$ \\
\hline Tai et al & Publikation & $\mathrm{SCC} 33$ & 0,$8 ; 1,2$ \\
\hline
\end{tabular}

\section{CGH-Befund}

$\operatorname{enh}(11 \mathrm{q} 13.1-\mathrm{q} 22.3) \operatorname{dim}(1 \mathrm{pter}-\mathrm{p} 33,3 \mathrm{p} 21-14.1)$

enh( 1q41-qter, $3 p$ d d

13q14.2-qter, 16p, 17p, 19pter-q12)

enh( 3q, 5p, 12pter-p13.1, 18p, 20, Xpter-p21.2) dim( 9pter-q13, 13, 18q,

19pter-q12)

enh( 5 q32-qter, 20pter-p12)

enh( 3q23-qter, 5pter-p14, 6q23.1-qter, 18p, Xpter-p21.3) dim( 1p, 3pter-q22, 11p11.2-qter, 13q13-q21.3, 16) amp ( 8q22.2-qter)

enh (10q21-q25)

$\operatorname{dim}(1 \mathrm{q} 41$-qter, 2pter-p22, 7q, 8q, 12pter-q12, 15q23-qter, 17q, 20p, Xpter-q21)

$14,16 \mathrm{p}) \operatorname{amp}(3 \mathrm{q} 23$-qter,

enh(1p32-p31.1, 1q21.1-qter, 2p, 2q35-qter, 3pter-21.2, 3q, 5p, 7q21.1-qter, 10p, 12pter-q13.2, 15q22.1-qter, 17pter-q12, 18p) dim( (1pter-p33, 2q32-q34,

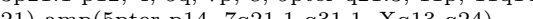
enh( 1q25-qter, 3q, 5p, 6q22-qter, 9p13-q12, 9q22.2-qter, 10q22.1-qter, 12p, 15 18p, Xq21.2-qter) $\operatorname{dim}(1 \mathrm{p}, 2 \mathrm{q} 32$-qter, 3p, 4, 5q, 6p, 7q31.1-qter, 8p22-p11.2, 14 17p) amp (3q21-qter, 5p14-p12)
enh( 1q, 2pter-p22, 3q13.3-qter, 8q22.1-qter) $\operatorname{dim}(3 \mathrm{p} 23$-p11.2, 4pter-q31.3,

enh( 1pter-p22, 1q41-qter, 3q, 5p, 6pter-p22,6q, 10p, 19q12-q13.2, 20q) dim( 2q24-qter, 3pter-p13, 4pter-q24, 4q31.2-qter, 5q, 7pter-q31, 8q11.2-q22, 9q, 16q 22q) $\operatorname{amp}(3 q 13.1-\mathrm{q} 23,18 \mathrm{q} 12$-qter

enh (3q26.1-qter)
enh( 1q32-qter, 2pter-p12, 3q, 9q12-q33, 11q13, 14q24-qter, 16pter-p13.1, 17q,

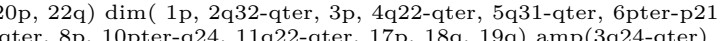

$\operatorname{enh}() \operatorname{dim}()$

enh( 5p, 8q23-qter, 15q11.2-q14) dim( 3pter-p21, 5q, 6p21.1-q15, 13q12-q31) $8 \mathrm{p}, 9,11 \mathrm{q} 14.1$-qter, 13q12,1-q22,

enh( 1q, 2p, 3q, 5p, 7pter-q21.1, 8q21.3-qter, 12p, 16p, 17p11.1-q22, 18 pter-q11.2, 19q13.1-qter, 20q) dim( 1 p31-p12, 2q21.1-qter, 3pter-p 22 4p13-qter, 5q, 6q14-qter, spter-q12, 10 pte-p

(16 4pter-q31.2, 5p13.2-qter, 6, 8p, 11q14.1-qter, 13, 14, 19p, 21, 22, Y)

enh( 1p32-p31, 2p, 2q22-q31, 3q, 5p, 6p, 8q22.1-qter, 10p11.2-q22.1, 13q22-qter 14q11.2-q12, 16q22-qter, 17, 18p11.3, 19q) dim(1p22.1-p13.3, 2q32-q35, 3p, 4q 15q15-qter, 16p13.1-q21, 18q, 19p, 22pter-q12) amp(1q, 3q24-qter, 5pter-p14,

$6 \mathrm{p} 21.3-\mathrm{p} 12,12 \mathrm{q} 12-\mathrm{q} 14)$

${ }^{a}$ Quelle der CGH-Befunde; zu Progenetix siehe Baudis (2000), Baudis und Cleary (2001)

${ }^{b}$ Schwellenwerte für Verluste, Zugewinne und Amplifikationen. 
Tabelle A.4: CGH-Befunde von Primärtumoren des Plattenepithelkarzinoms aus der Literaturrecherche

\begin{tabular}{|c|c|c|c|c|}
\hline Publikation & Quelle $^{a}$ & Fall & Schwellen ${ }^{b}$ & CGH-Befund \\
\hline Tai et al. 2004 & Publikation & $\mathrm{SCC} 34$ & 0,$8 ; 1,2 ; 1,4$ & $\begin{array}{l}\text { enh( 1p13.1-q22, 2p12-q31, 5p, 7, 8q, 9p13-q21.3, 11pter-p13, 15q11.2-q21.3, } \\
18 \text { pter-q11.2, 20q) dim( } 1 \text { pter-p13.3, 2q32-1-qter, 3p, } 4 \text {, 5q, 8p, 9q22.1-qter, } \\
\text { 11q21-qter, 13q12.1-q31, 18q12.1-qter, 20p, Xpter-q13) amp (3q22-qter, } \\
\text { 8q22.1-qter, Xq21.3-q25) }\end{array}$ \\
\hline Tai et al. 2004 & Publikation & $\mathrm{SCC} 35$ & 0,$8 ; 1,2 ; 1,4$ & 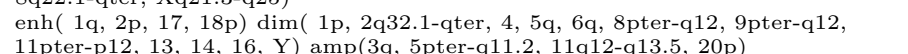 \\
\hline Tai et al. 2004 & Publikation & $\mathrm{SCC} 36$ & 0,$8 ; 1,2 ; 1,4$ & $\begin{array}{l}\text { enh ( } 1 \mathrm{q}, 2 \mathrm{p}, 3 \mathrm{q} 23 \text {-qter, } 5 \mathrm{p}, 7,8 \mathrm{q}, 9 \mathrm{p}, 12 \mathrm{q} 14 \text {-qter, } 17 \mathrm{q}) \operatorname{dim}(1 \mathrm{p}, 5 \mathrm{q}, 6,13,14 \text {, } \\
16,18 \mathrm{q} 12 \text { - }\end{array}$ \\
\hline Tai et al. 2004 & Publikation & $\mathrm{SCC} 37$ & 0,$8 ; 1,2 ; 1,4$ & $\begin{array}{l}\text { enh( 1q31-qter, 3pter-p22, 3q24-qter, 5pter-p14, 5q14-qter, 8q21.1-qter, 10q) } \\
\operatorname{dim}(6 \mathrm{q} .7 \mathrm{p}, 8 \mathrm{p}, 9 \text { pter-q22, 11p.13, 15, 17p. 18, 19p 20p, 22) amp(12) }\end{array}$ \\
\hline Tai et al. 2004 & Publikation & $\mathrm{SCC} 38$ & 0,$8 ; 1,2 ; 1,4$ & $\begin{array}{l}\text { enh (4q31.1-qter, 5pter-p14, 8p12-q24.1, 13q31-qter, 15q11.2-q14, 20pter-q12) } \\
\text { dim( } 1 \text { pter-p31, 3p, 4pter-p15.1, 5q, } 1 \text { p, 8pter-p21, 9pter-q21, 10q, 16p, } \\
17 \text { pter-q21,21q) amp (3q24-qter, 22q) }\end{array}$ \\
\hline Tai et al. 2004 & Publikation & $\mathrm{SCC} 39$ & 0,$8 ; 1,2 ; 1,4$ & $\begin{array}{l}\text { enh( } 1 \mathrm{q}, 3 \mathrm{q}, 7,16,18 \mathrm{q} 22 \text {-qter, 20) dim( } 3 \mathrm{p}, 4 \mathrm{q} 31.1 \text {-qter, } 5 \mathrm{q} 12 \text {-qter, } 6 \\
10 \mathrm{pter}-\mathrm{q} 23,13,14,15,17 \mathrm{p}) \text { amp }(3 \mathrm{q} 24 \text {-qter, } 5 \mathrm{p}, 9 \mathrm{q} 21 \text {-qter })\end{array}$ \\
\hline Yakut et al. 2006 & Progenetix & L1 & 0,$85 ; 1,15 ; 1,5$ & enh(11q21q23.1) \\
\hline Yakut et al. 2006 & Progenetix & $\mathrm{L} 2$ & 0,$85 ; 1,15 ; 1,5$ & $\begin{array}{l}\text { enh(1q31.1qter, 3q11.1qter, 5pterq11.1, 15q22.1qter, 19q11qter) dim(2q34qter, } \\
\text { 3pterq11.1, 4pterq11, 5q11.1qter, 9q31.1qter, 10pterq23.1, 11q13.1qter, } \\
\text { 13q11q32.1, 14q11.1q22.1, 17p12qter) }\end{array}$ \\
\hline Yakut et al. 2006 & Progenetix & L3 & 0,$85 ; 1,15 ; 1,5$ & enh(3q23qter) \\
\hline Yakut et al. 2006 & Progenetix & $\mathrm{L} 4$ & 0,$85 ; 1,15 ; 1,5$ & $\begin{array}{l}\operatorname{enh}(2 \mathrm{q} 23.1 \mathrm{q} 33.1,7 \mathrm{p} 11.2 \mathrm{q} 11.1,8 \mathrm{p} 11.23 \mathrm{qter}, 18,19 \mathrm{q} 13.11 \mathrm{q} 13.43) \operatorname{dim}(1 \mathrm{q} 11 \mathrm{qter} \\
3 \text { terp13, 8pterp12) amp(3q25.1qter) }\end{array}$ \\
\hline Yakut et al. 2006 & Progenetix & L5 & 0,$85 ; 1,15 ; 1,5$ & $\begin{array}{l}\text { enh(1q21.1q25.1, 18q11.1qter, 20pterq11.1, 22q11.1qter) dim(2q24.1qter, } \\
\text { 3pterq11.1, 4q28.1qter, } 5 \mathrm{q} 11.1 \mathrm{q} \text { ter, } 9 \text { pterp12, 1q222.1qter, 13q11qter, }\end{array}$ \\
\hline Yakut et al. 2006 & Progenetix & L6 & 0,$85 ; 1,15 ; 1,5$ & $\begin{array}{l}\text { enh(1q1114ter, 3q23qter, 5pterq11.1, 9q11qter, 13q31.1qter, 16q11.1qter, } \\
18 \text { pterq21.1) dim(3pterq11.1, 4q22.1qter, 5q11.1qter, 10, 11q23.1qter, } \\
18 \mathrm{q} 21.1 \mathrm{qter}, 20 \mathrm{q} 13.11 \mathrm{qter})\end{array}$ \\
\hline Yakut et al. 2006 & Progenetix & L7 & 0,$85 ; 1,15 ; 1,5$ & $\operatorname{enh}(3 \mathrm{q} 26.1 \mathrm{q} 28,20 \mathrm{p} 11.23 \mathrm{q} 11.1)$ \\
\hline Yakut et al. 2006 & Progenetix & L8 & 0,$85 ; 1,15 ; 1,5$ & $\operatorname{enh}() \operatorname{dim}() \operatorname{amp}(3 \mathrm{q} 26.1 \mathrm{q} 27.1,7 \mathrm{p} 11.2 \mathrm{q} 11.1,8 \mathrm{q} 24.11 \mathrm{q} 24.3)$ \\
\hline Yakut et al. 2006 & Progenetix & L9 & 0,$85 ; 1,15 ; 1,5$ & enh(3q24qter, 5pterq11.1, 8q22.1qter, 12pterp11.23) \\
\hline Yakut et al. 2006 & Progenetix & L10 & 0,$85 ; 1,15 ; 1,5$ & enh(18pterq12.1, 19q11q13.43) \\
\hline Yakut et al. 2006 & Progenetix & L11 & 0,$85 ; 1,15 ; 1,5$ & $\begin{array}{l}\text { enh(3q13.11ter, 7q11.1qter, 12pterq11) dim(3p11.2q11.1, 5q11.1qter, } \\
\text { 9pterp13.3, 13q11qter) amp(7p11.2q11.1) }\end{array}$ \\
\hline Yakut et al. 2006 & Progenetix & L12 & 0,$85 ; 1,15 ; 1,5$ & $\operatorname{enh}(3 \mathrm{q} 11.1 \mathrm{qter}) \operatorname{dim}(1 \mathrm{p} 35.3 \mathrm{p} 34.3,2 \mathrm{q} 34 \mathrm{q} 36.1,4 \mathrm{p} 15.33 \mathrm{p} 14,8 \mathrm{p} 22 \mathrm{p} 12,10)$ \\
\hline Yakut et al. 2006 & Progenetix & L13 & 0,$85 ; 1,15 ; 1,5$ & $\begin{array}{l}\text { enh(3q25.1qter, 8p11.23q11.1, 11q12.1q14.1, 14q21.1q31.1, 15q14q22.1) } \\
\operatorname{dim}(11 \mathrm{q} 23.1 \mathrm{q} t \mathrm{q})\end{array}$ \\
\hline Yakut et al. 2006 & Progenetix & L14 & 0,$85 ; 1,15 ; 1,5$ & enh(5pterq11.1) \\
\hline $\begin{array}{l}\text { Yakut et al. } 2006 \\
\text { Yakut et al. } 2006\end{array}$ & $\begin{array}{l}\text { Progenetix } \\
\text { Progenetix }\end{array}$ & $\begin{array}{l}\text { L15 } \\
\text { L16 }\end{array}$ & $\begin{array}{l}0,85 ; 1,15 ; 1,5 \\
0,85 ; 1,15 ; 1,5\end{array}$ & $\begin{array}{l}\text { enh(3q26.1qter, 9pterp13.3, 18pterq11.1) } \\
\text { enh(2p13.3p12, 3q21.1qter, 7pterp11.2, 11q21qter) dim(3pterp13, 4, 5q11.1qter, } \\
\text { 7q31.1qter, 8pterp12, 9p21.3p12,11pterp12, 13q11q14.11, 17, 21q11.1qter, }\end{array}$ \\
\hline Yakut et al. 2006 & Progenetix & L17 & $0.85: 1.15 ; 1.5$ & $\begin{array}{l}\text { 22q11.1qter) amp }(7 \mathrm{p} 11.2 \mathrm{q} 11.1,7 \mathrm{q} 21.11 \mathrm{q} 32.1) \\
\operatorname{enh}(3 \mathrm{q} 25.1 \mathrm{q} 27.1)\end{array}$ \\
\hline Yakut et al. 2006 & Progenetix & L18 & 0,$85 ; 1,15 ; 1,5$ & enh(3q13.11qter, 4q13.1q22.1,9p12q11, 22q11.1qter) \\
\hline Yakut et al. 2006 & Progenetix & L19 & 0,$85 ; 1,15 ; 1,5$ & $\begin{array}{l}\text { enh (2pterp13.3, 3q11.1qter, 5pterq11.1, 8q11.1q24.3, 11q23.1qter, } \\
12 \mathrm{q} 13.11 \mathrm{q} 21.1,12 \mathrm{pterq} 11,18 \mathrm{pterq} 11.1, \mathrm{Xq} 13.1 \mathrm{qter}) \operatorname{dim}(\mathrm{p} 21.3 \mathrm{q} 11,4 \mathrm{pterp} 14 \text {, } \\
6 \mathrm{q} 22.1 \mathrm{qter}, 8 \text { pterp11.23, } 9,10,12 \mathrm{q} 24.11 \mathrm{q} 24.33,15 \mathrm{q} 11.1 \mathrm{qter}, 16,17 \mathrm{pterq} 11.1 \\
18 \mathrm{q} 21.1 \mathrm{qter}, 19 \mathrm{pterg} 11)\end{array}$ \\
\hline Yakut et al. 2006 & Progenetix & L20 & 0,$85 ; 1,15 ; 1,5$ & $\operatorname{enh}(7 \mathrm{q} 21.11 \mathrm{q} 32.1,22 \mathrm{q} 11.1 \mathrm{q} 12.1)$ \\
\hline
\end{tabular}

Fortsetzung.. 
Tabelle A.4: CGH-Befunde von Primärtumoren des Plattenepithelkarzinoms aus der Literaturrecherche ...Fortsetzung

Publikation

Quelle $^{a}$

Fall

Schwellen

CGH-Befund

${ }^{a}$ Quelle der CGH-Befunde; zu Progenetix siehe Baudis (2000), Baudis und Cleary (2001).

${ }^{b}$ Schwellenwerte für Verluste, Zugewinne und Amplifikationen. 
Tabelle A.5: CGH-Befunde von Primärtumoren des Adenokarzinoms aus der Literaturrecherche

\begin{tabular}{|c|c|c|c|c|}
\hline Publikation & Quelle $^{a}$ & Fall & Schwellen $^{b}$ & CGH-Befund \\
\hline Björkqvist et al. 1998a & Progenetix & 17 & 0,$85 ; 1,17 ; 1,5$ & $\operatorname{enh}(1 \mathrm{q} 11 \mathrm{q} 32.1,4,5,6 \mathrm{pterq} 11.1) \operatorname{dim}(6 \mathrm{q} 11.1 \mathrm{q} 25.1,9) \operatorname{amp}(1 \mathrm{q} 31.1 \mathrm{qter})$ \\
\hline Björkqvist et al. 1998a & Progenetix & 18 & 0,$85 ; 1,17 ; 1,5$ & $\operatorname{enh}(7)$ \\
\hline Björkqvist et al. 1998a & Progenetix & 19 & 0,$85 ; 1,17 ; 1,5$ & $\operatorname{enh}(3 \mathrm{q} 22.1 \mathrm{qter}, 14 \mathrm{q} 13.1 \mathrm{q} 22.1)$ \\
\hline Björkqvist et al. 1998a & Progenetix & 20 & 0,$85 ; 1,17 ; 1,5$ & enh(5pterq11.1, 12q11q24.11, 16) \\
\hline $\begin{array}{l}\text { Björkqvist et al. 1998a } \\
\text { Biörkgist }\end{array}$ & Progenetix & 21 & 0,$85 ; 1,17 ; 1,5$ & $\operatorname{enh}(1 \mathrm{p} 31.3 \mathrm{p} 13.3$, 3q13.31qter, 7q11.1qter, 12, 14q11.1qter, Xq11.1qter) \\
\hline $\begin{array}{l}\text { Bjö̈kqvist et al. 1998a } \\
\text { Bïökqvist et al 1998a }\end{array}$ & Progenetix & 22 & 0,$85 ; 1,17 ; 1,5$ & enh(1q11qter) $\operatorname{dim}(6 \mathrm{q} 11.1 \mathrm{q} t e r, 9,19$ pterq11) \\
\hline $\begin{array}{l}\text { Björkqvist et al. 1998a } \\
\text { Bjökqvist et al. 1998a }\end{array}$ & $\begin{array}{l}\text { Progenetix } \\
\text { Progentix }\end{array}$ & 23 & 0,$85 ; 1,17 ; 1,5$ & enh(12p12.3q11) \\
\hline $\begin{array}{l}\text { Björkqvist et al. 1998a } \\
\text { Björkqvist et al. 1998a }\end{array}$ & $\begin{array}{l}\text { Progenetix } \\
\text { Progenetix }\end{array}$ & $\begin{array}{l}24 \\
25\end{array}$ & $\begin{array}{l}0,85 ; 1,17 ; 1,5 \\
0,85 ; 1,17 ; 1,5\end{array}$ & $\begin{array}{l}\text { enh(8q24.11qter, 8q21.11q24.11, 12p12.3q11, 19q11q13.2) amp(8q23.1q24.21) } \\
\text { enh(1q11q42.11, 5pterq11.1, 8q21.11qter, 12p12.3qter) }\end{array}$ \\
\hline Björkqvist et al. 1998a & Progenetix & 26 & 0,$85 ; 1,17 ; 1,5$ & $\begin{array}{l}\text { enh(1q11qter, 3q13.31qter, 6pterq11.1, 7pterp13, 8q24.11qter, 8q11.1q23.1, } \\
12 \mathrm{p} 13.33 \mathrm{p} 12.3,12 \mathrm{p} 11.23 \mathrm{q} 14.1) \text { amp }(8 \mathrm{q} 23.1 \mathrm{q} 24.21,12 \mathrm{p} 12.3 \mathrm{p} 11.23)\end{array}$ \\
\hline Björkqvist et al. 1998a & Progenetix & 27 & 0,$85 ; 1,17 ; 1,5$ & enh(1q11qter, 5p13.3q11.1, 17q11.1qter) amp(5pterp13.3) \\
\hline Björkqvist et al. 1998a & Progenetix & 28 & 0,$85 ; 1,17 ; 1,5$ & enh(1q11qter) \\
\hline Björkqvist et al. 1998a & Progenetix & 29 & 0,$85 ; 1,17 ; 1,5$ & $\begin{array}{l}\text { enh(1q11qter, 3q11.1qter, 4pterq33, 7q21.11qter, 7pterq11.1, 12p12.3q24.11, } \\
\text { 14q13.1q22.1, Xq23q27.1) dim(19) amp(5pterq11.1, Xq26.1qter) }\end{array}$ \\
\hline Björkqvist et al. 1998a & Progenetix & 30 & 0,$85 ; 1,17 ; 1,5$ & $\operatorname{enh}(1 \mathrm{q} 11 \mathrm{qtar}, 7 \mathrm{q} 22.1 \mathrm{q} 32.1,20 \mathrm{q} 12 \mathrm{qter})$ \\
\hline Björkqvist et al. 1998a & Progenetix & 31 & 0,$85 ; 1,17 ; 1,5$ & $\begin{array}{l}\text { enh(1, 2q13q33.1, 8, 10q21.1q24.1, 11q11qter, 12q14.1q24.11, 14q13.1q23.1, } \\
\text { 17q11.1qter, 18q11.1q23, 20q11.1q13.11) dim(3pterq11.1, 4q32.1qter, } \\
\text { 18pterq11.1) amp(5pterq11.1, 20q13.11qter) }\end{array}$ \\
\hline Björkqvist et al. 1998a & Progenetix & 32 & 0,$85 ; 1,17 ; 1,5$ & $\begin{array}{l}\text { 18pterq11.1) amp(5pterq11.1, 20q13.11qter) } \\
\text { enh(16pterq11.1, 17q11.1qter, 19q11qter) }\end{array}$ \\
\hline Björkqvist et al. 1998a & Progenetix & 33 & 0,$85 ; 1,17 ; 1,5$ & $\operatorname{enh}(7)$ \\
\hline Björkqvist et al. 1998b & Progenetix & 35 & 0,$85 ; 1,17 ; 1,5$ & $\begin{array}{l}\text { enh(1q11qter, 5, 6pterq11.1, 7pterq11.1, 8q23.1qter, 8q21.11q21.3, 12q14.1q22, } \\
12 \mathrm{q} 14.1 \mathrm{q} 22,14 \mathrm{q} 11.1 \mathrm{qter}, 17 \mathrm{q} 24.1 \mathrm{qter}, 21 \mathrm{q} 11.1 \mathrm{qter}, 21 \mathrm{q} 11.1 \mathrm{qter}) \\
\operatorname{amp}(2 \mathrm{p} 16.3 \mathrm{p} 12,8 \mathrm{q} 21.3 \mathrm{q} 24.11, \mathrm{X})\end{array}$ \\
\hline Björkqvist et al. 1998b & Progenetix & 36 & 0,$85 ; 1,17 ; 1,5$ & $\begin{array}{l}\text { enh(1,2q22.1q31.1, 3, 5q23.1q34, 6q21qter, 7q11.1qter, 14q11.1qter, Xq23qter) } \\
\operatorname{dim}(17 \mathrm{pterg} 11.1) \text { amp (5pter 31.1, 7pterg11.1,8q22.1qter) }\end{array}$ \\
\hline Björkqvist et al. 1998b & Progenetix & 37 & 0,$85 ; 1,17 ; 1,5$ & 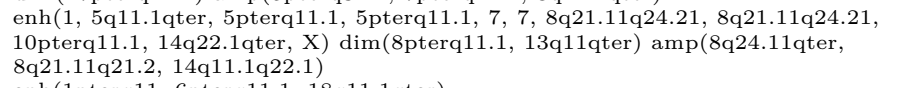 \\
\hline Björkqvist et al. 1998b & Progenetix & 38 & 0,$85 ; 1,17 ; 1,5$ & enh(1pterq11, 6pterq11.1, 18q11.1qter) \\
\hline Björkqvist et al. 1998b & Progenetix & 39 & 0,$85 ; 1,17 ; 1,5$ & $\operatorname{enh}() \operatorname{dim}()$ \\
\hline Björkqvist et al. $1998 \mathrm{~b}$ & Progenetix & 40 & 0,$85 ; 1,17 ; 1,5$ & $\begin{array}{l}\text { enh(1,2p15q23.1, 7pterq11.1, 8q21.3qter, 10q11.1q23.1, 11q11q14.1) } \\
\operatorname{dim}(8 \mathrm{pterq} 11.1) \text { amp (2q22.1q33.1, 5pterq11.1, 8q11.1q21.3, 11q14.1qter, } \\
\text { 12p12.3q11) }\end{array}$ \\
\hline Björkqvist et al. 1998b & Progenetix & 41 & 0,$85 ; 1,17 ; 1,5$ & enh(8q11.1qter, 10q11.1qter) \\
\hline Björkqvist et al. 1998b & Publikation & 42 & 0,$85 ; 1,17 ; 1,5$ & $\operatorname{enh}() \operatorname{dim}()^{2}$ \\
\hline Björkqvist et al. 1998b & Publikation & 43 & 0,$85 ; 1,17 ; 1,5$ & $\begin{array}{l}\text { enh(Xp21-qter, 1qcen-q32, 5p, 6q23-qter, 12q, 8q23-qter, 12pcen-p13) dim(3p, } \\
\text { 9p21-pter) }\end{array}$ \\
\hline Björkqvist et al. 1998b & Publikation & 44 & 0,$85 ; 1,17 ; 1,5$ & $\operatorname{enh}(1 \mathrm{q}, 2 \mathrm{p} 23-\mathrm{pter}, 6 \mathrm{p}) \operatorname{dim}(4 \mathrm{q} 24-\mathrm{qter})$ \\
\hline I et al. 2002 & Pro & 1 & 0,$85 ; 1,17 ; 1,5$ & $\operatorname{enh}(5 \mathrm{p} 15.33 \mathrm{p} 14.1,11 \mathrm{q} 13.1 \mathrm{q} 13.5,16 \mathrm{p} 13.3 \mathrm{p} 11.1,20 \mathrm{q} 11.1 \mathrm{q} 13.33,22 \mathrm{p} 13 \mathrm{q} 13.33)$ \\
\hline Lindström et al. 2002 & Progenetix ${ }^{c}$ & 2 & 0,$85 ; 1,17 ; 1,5$ & $\operatorname{enh}(1 \mathrm{q} 22 \mathrm{q} 44,16 \mathrm{p} 13.3 \mathrm{q} 24.3) \operatorname{dim}(9 \mathrm{p} 24.3 \mathrm{p} 21.1) \operatorname{amp}(16 \mathrm{p} 13.1)$ \\
\hline Lindström et al. 2002 & Progenetix $^{c}$ & 3 & 0,$85 ; 1,17 ; 1,5$ & $\begin{array}{l}\operatorname{enh}(1 \mathrm{q} 11 \mathrm{q} 44,5 \mathrm{p} 15.33 \mathrm{p} 11,7 \mathrm{p} 22.3 \mathrm{p} 15.1,7 \mathrm{q} 32.1 \mathrm{q} 36.3,11 \mathrm{q} 13.1 \mathrm{q} 25,14 \mathrm{q} 12 \mathrm{q} 32.33 \\
17 \mathrm{p} 13.3 \mathrm{p} 11.1,20 \mathrm{q} 11.1 \mathrm{q} 13.33,22 \mathrm{p} 13 \mathrm{q} 13.33) \operatorname{dim}(6 \mathrm{q} 11.1 \mathrm{q} 22.33,9 \mathrm{p} 24.3 \mathrm{p} 21.1) \\
\operatorname{amp}(5 \mathrm{p} 15.1 \mathrm{pter})\end{array}$ \\
\hline Lindström et al. 2002 & Progenetix $^{c}$ & 4 & 0,$85 ; 1,17 ; 1,5$ & $\begin{array}{l}\text { enh(1q12q44, 2p25.3p21, 5p15.33p13.1, 6p } 25.3 \mathrm{p} 12.1,7 \mathrm{q} 32.1 \mathrm{q} 36.3,11 \mathrm{q} 13.1 \mathrm{q} 14.3, \\
15 \mathrm{q} 21.1 \mathrm{q} 26.3,20 \mathrm{q} 11.21 \mathrm{q} 13.33,22 \mathrm{p} 13 \mathrm{q} 13.33) \operatorname{dim}(1 \mathrm{p} 31.3 \mathrm{p} 21.1,4 \mathrm{p} 15.1 \mathrm{q} 31.3 \\
\text { 5q15q23.3, 6q11.1q22.33, 13q14.11q31.3, Xp22.33q28) amp (20q13.1, } \\
\text { 22q11.1q13) }\end{array}$ \\
\hline
\end{tabular}

${ }^{a}$ Quelle der CGH-Befunde; zu Progenetix siehe Baudis (2000), Baudis und Cleary (2001).

${ }^{b}$ Schwellenwerte für Verluste, Zugewinne und Amplifikationen.

${ }^{c}$ Amplifikationen waren fehlerhaft erfasst und wurden gemäß der Publikation korrigiert. 
Tabelle A.5: CGH-Befunde von Primärtumoren des Adenokarzinoms aus der Literaturrecherche

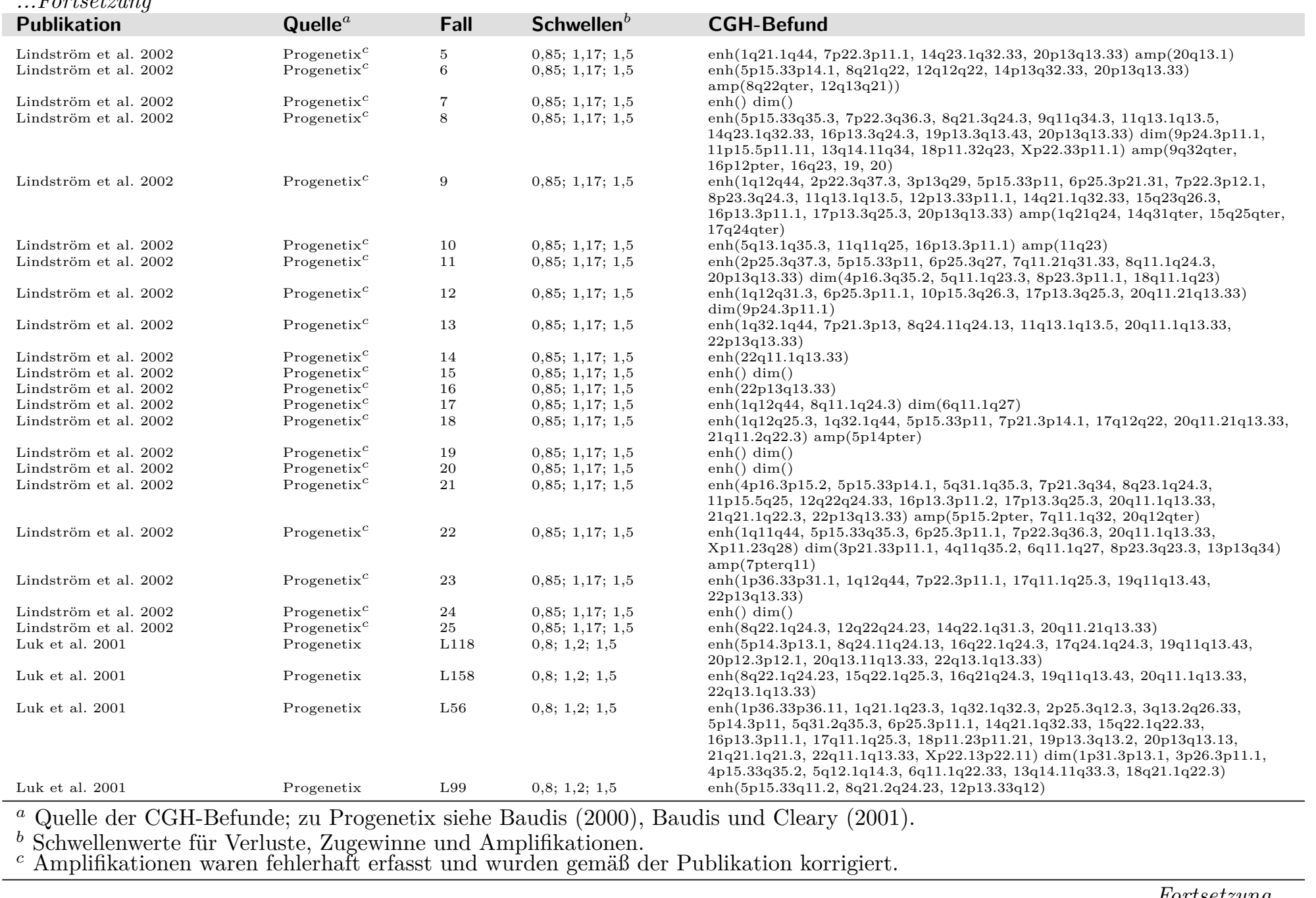


Tabelle A.5: CGH-Befunde von Primärtumoren des Adenokarzinoms aus der Literaturrecherche

\begin{tabular}{|c|c|c|c|c|}
\hline Publikation & Quelle $^{a}$ & Fall & Schwellen ${ }^{b}$ & CGH-Befund \\
\hline Tai et al. 2004 & Publikation & A1 & 0,$8 ; 1,2 ; 1,4$ & $\begin{array}{l}\text { enh }(2 \mathrm{p} 16.2-\mathrm{q} 14.1,3 \mathrm{q} 22-\mathrm{qter}, 5 \mathrm{p}, 6 \mathrm{q}, 9 \mathrm{q} 31 \text {-qter, 11q21-qter, 20) dim }(2 \mathrm{q} 33-\mathrm{qter} \\
3 \mathrm{p}, 4 \mathrm{p}, 4 \mathrm{q} 27-\mathrm{qter}, 5 \mathrm{q}, 6 \mathrm{pter}-\mathrm{p} 21.3,9 \mathrm{p} 13-\mathrm{q} 22,10 \mathrm{q} 22-\mathrm{q} 24,12 \mathrm{q} 22-\mathrm{qter}, 13 \mathrm{q} 12-\mathrm{q} 32\end{array}$ \\
\hline Tai et al. 2004 & Publikation & A2 & 0,$8 ; 1,2 ; 1,4$ & 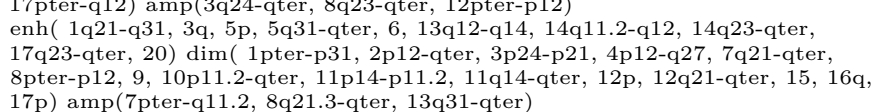 \\
\hline Tai et al. 2004 & Publikation & A3 & 0,$8 ; 1,2 ; 1,4$ & $\begin{array}{l}\operatorname{enh}(5 \text { pter-q11.2, 8q13-qter, 10p11.2-q11.2, 14q11.2-q13, 16pter-q13, 20) } \operatorname{dim}( \\
5 \mathrm{q} 14-\mathrm{q} 23,6 \mathrm{q} 22 \text {-qter, } 9 \mathrm{p} 12-\mathrm{q} 22,13)\end{array}$ \\
\hline Tai et al. 2004 & Publikation & A4 & 0,$8 ; 1,2 ; 1,4$ & enh( 5 pter-q12, 7pter-p15, 20q) dim( $9 \mathrm{p} 12-\mathrm{q} 21,12 \mathrm{p}, 13)$ \\
\hline Tai et al. 2004 & Publikation & A5 & 0,$8 ; 1,2 ; 1,4$ & $\begin{array}{l}\text { enh( 1pter-p21, 1q12-q42, 7p, 8p, 13q22-qter, 14q11.2-q13, 15q, 17q12-qter, } \\
\text { 18q, 20) dim( 4q, 5q11.2-q23, 6, 7q32-qter, 9pter-q21, 10pter-q11.2, 16pter-q21, } \\
21) \operatorname{map}(5 \mathrm{p}, 20 \mathrm{q})\end{array}$ \\
\hline Tai et al. 2004 & Publikation & A6 & 0,$8 ; 1,2 ; 1,4$ & $\begin{array}{l}\text { enh ( 1q12-q23, 8q24.1-qter, 16p, 17pter-q21) } \operatorname{dim}(3 \mathrm{p}, 4 \mathrm{q} 23 \text {-qter, 5q14-qter, 8p, } \\
18 \mathrm{q} 12 \text {-qter })\end{array}$ \\
\hline Tai et al. 2004 & Publikation & $\mathrm{A} 7$ & 0,$8 ; 1,2 ; 1,4$ & $\begin{array}{l}\text { enh( 2pter-p12, 5pter-q11.2, 7, 18q21-qter, 19, 20p, 21q22, 22) dim( (2q33-q36, } \\
\text { 3p23-p12, 4, 5q12-qter, 8p, 10, 11p13-qter, Xpter-q13) amp(3q24-qter) }\end{array}$ \\
\hline Tai et al. 2004 & Publikation & A8 & 0,$8 ; 1,2 ; 1,4$ & $\begin{array}{l}\text { enh }(2 \mathrm{pter}-\mathrm{p} 22,3 \mathrm{q}, 5 \mathrm{p}, 7 \mathrm{q} 21-\mathrm{qter}, 15 \mathrm{q} 23-\mathrm{qter}, 18 \mathrm{pter}-\mathrm{q} 11.2) \operatorname{dim}(1 \mathrm{pter}-\mathrm{p} 21,3 \mathrm{p} \\
4,5 \mathrm{q}, 9,13 \mathrm{q} 21-\mathrm{qter}, 18 \mathrm{q} 12-\mathrm{qter}) \text { amp }(1 \mathrm{q} 32-\mathrm{qter}, 10 \mathrm{p} 11.2-\mathrm{q} 11.2,18 \mathrm{p} 11.3)\end{array}$ \\
\hline Tai et al. 2004 & Publikation & A9 & 0,$8 ; 1,2 ; 1,4$ & $\begin{array}{l}\text { enh( } 5 \text { pter-q12, 7, 8q13-qter, } 15,17 \mathrm{q} 12 \text {-q21) } \operatorname{dim}(1 \mathrm{p}, 3 \mathrm{pter}-\mathrm{q} 21,4,5 \mathrm{q} 13 \text {-qter, } 6 \\
9,11 \mathrm{q} 14-\mathrm{q} \text { - } \\
\end{array}$ \\
\hline Tai et al. 2004 & Publikation & A10 & 0,$8 ; 1,2 ; 1,4$ & $\begin{array}{l}\operatorname{enh}(5 \mathrm{p}, 5 \mathrm{q} 31-\mathrm{qter}, 6 \mathrm{pter}-\mathrm{p} 21.3,8 \mathrm{q} 13-\mathrm{qter}, 12 \mathrm{q} 13-\mathrm{q} 21,15 \mathrm{q} 15-\mathrm{q} 23,19 \mathrm{q}, 20 \mathrm{q}) \\
\operatorname{dim}(1,3 \mathrm{p} 21-\mathrm{qter}, 4 \mathrm{p}, 5 \mathrm{q} 11.2-\mathrm{q} 15,6 \mathrm{q} 22-\mathrm{qter}, 8 \mathrm{p}, 9,10 \mathrm{q} 22-\mathrm{qter}, 13 \mathrm{q} 12-\mathrm{q} 14,19 \mathrm{p}, \\
21) \operatorname{amp}(6 \mathrm{q} 15-\mathrm{q} 21,8 \mathrm{q} 22 \text {-qter })\end{array}$ \\
\hline Tai et al. 2004 & Publikation & A11 & 0,$8 ; 1,2 ; 1,4$ & $\operatorname{enh}(5 \mathrm{p}, 8 \mathrm{q}) \operatorname{dim}(5 \mathrm{q} 14$-qter) amp $(5$ pter-p14) \\
\hline Tai et al. 2004 & Publikation & $\mathrm{A} 12$ & 0,$8 ; 1,2 ; 1,4$ & $\begin{array}{l}\text { enh( 1q21-qter, 2pter-p13, 2q13-qter, 3q21-qter, 5p, 6p22-p12, 7pter-q21, } \\
\text { 8q23-qter, 11p14-q13, 17q21-qter, 18p, 19q, 20q) dim( } 1 \mathrm{p}, 3 \text { pter-p13, 4, } \\
\text { 5q13-qter, 14q13-q24, 18q) }\end{array}$ \\
\hline Tai et al. 2004 & Publikation & A13 & 0,$8 ; 1,2 ; 1,4$ & $\begin{array}{l}\text { enh( 1q21-qter, 4pter-p15.1, 5, 10p, 10q23-qter, 15q24-qter, 17q) dim( } \\
\text { 6pter-q24, 8p, 13, 15q12-q23, 16pter-q22, 17p, 18q, 21) amp (8q22-qter) }\end{array}$ \\
\hline Tai et al. 2004 & Publikation & A14 & 0,$8 ; 1,2 ; 1,4$ & $\operatorname{enh}(7 \mathrm{p}, 14 \mathrm{q} 11.2-\mathrm{q} 12,21 \mathrm{q} 22,22 \mathrm{q} 13)$ \\
\hline Tai et al. 2004 & Publikation & A15 & 0,$8 ; 1,2 ; 1,4$ & $\begin{array}{l}\text { enh( 4pter-p15.3, 5p15.2-q12, 5q32-qter, 7p14-q11.2, 8q24.1-qter, 9q31-qter, } \\
16 \text { pter-p13.1, 20q12-qter) dim( 4q31.1-qter, 8pter-p22, 13q31-qter, 16q21-qter, } \\
17 \mathrm{q} 22 \text {-qter, } 18 \mathrm{p}, 20 \mathrm{p})\end{array}$ \\
\hline Tai et al. 2004 & Publikation & A16 & 0,$8 ; 1,2 ; 1,4$ & $\begin{array}{l}\text { enh( } 5 \mathrm{p}, 10 \mathrm{q} 24-\mathrm{qter}, 11 \mathrm{q}, 17 \mathrm{q}, 18 \mathrm{q}, 22 \mathrm{q} 13) \operatorname{dim}(1 \mathrm{p} 34.1-\mathrm{p} 13,3 \mathrm{pter}-\mathrm{q} 24, \\
4 \mathrm{p} 15.2 \text {-qter, } 5 \mathrm{q} 14-\mathrm{qter}, 6 \mathrm{p} 22-\mathrm{qter}, 8 \mathrm{p}, 9 \mathrm{q}, 13,14 \mathrm{q} 21 \text {-qter }) \text { amp(1q12-q22, 8q, } \\
15 \mathrm{q} 24 \text {-qter, 20q) }\end{array}$ \\
\hline Tai et al. 2004 & Publikation & $\mathrm{A} 17$ & 0,$8 ; 1,2 ; 1,4$ & $\begin{array}{l}\text { enh }(1 \mathrm{q}, 5 \mathrm{q} 23-\mathrm{qter}, 7 \mathrm{p}, 10 \mathrm{p} 12-\mathrm{q} 11.2,12 \mathrm{q} 13.3-\mathrm{q} 21,14 \mathrm{q} 12 \text {-q } 13,14 \mathrm{q} 31 \text {-qter, } \\
16 \mathrm{q} 22-\mathrm{qter}, 20 \mathrm{pter}-\mathrm{p} 12,21 \mathrm{q} 22) \operatorname{dim}(6 \mathrm{q} 13-\mathrm{q} 24,9,10 \mathrm{q} 21-\mathrm{q} 23,13,15)\end{array}$ \\
\hline Tai et al. 2004 & Publikation & A18 & 0,$8 ; 1,2 ; 1,4$ & $\begin{array}{l}\operatorname{enh}(1 \mathrm{q}, 3 \mathrm{q} 25 \text {-qter, 6q24-qter, 16p12-qter, 19q13.2-qter) } \operatorname{dim}(3 \mathrm{pter}-\mathrm{q} 24,9, \\
12 \mathrm{q} 22 \text {-qter, 18, 19pter-p13.2) }\end{array}$ \\
\hline Tai et al. 2004 & Publikation & A19 & 0,$8 ; 1,2 ; 1,4$ & $\begin{array}{l}\text { enh( 1q, 5p, 5q13-q14, 5q31-qter, 7p, 8q23-qter, 15q, 21q) dim( } 1 \mathrm{p} 22-\mathrm{p} 13 \\
3 \mathrm{pter-p} 24.3, \mathrm{q} 15-23,6 \mathrm{q} 14-\mathrm{q} 24,8 \mathrm{p}, 10 \mathrm{p}, 13 \mathrm{q} 13-\mathrm{qter}, 14 \mathrm{q} 12-\mathrm{q} 24,22 \mathrm{q}) \\
\text { amp(1q12-q23) }\end{array}$ \\
\hline Tai et al. 2004 & Publikation & $\mathrm{A} 20$ & 0,$8 ; 1,2 ; 1,4$ & 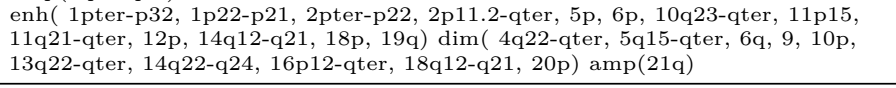 \\
\hline
\end{tabular}


Tabelle A.5: CGH-Befunde von Primärtumoren des Adenokarzinoms aus der Literaturrecherche

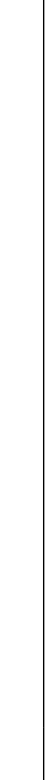

...Fortsetzung

\begin{tabular}{|c|c|c|c|c|}
\hline Publikation & Quelle $^{a}$ & Fall & Schwellen $^{b}$ & CGH-Befund \\
\hline Tai et al. 2004 & Publikation & A21 & 0,$8 ; 1,2 ; 1,4$ & $\begin{array}{l}\operatorname{enh}(7 \mathrm{q} 31-\mathrm{qter}, 8 \mathrm{q}, 11 \mathrm{pter}-\mathrm{p} 12,12 \mathrm{q} 21 \text {-qter, 14q11.2-q13, 14q24-qter, 20) } \operatorname{dim}( \\
3 \mathrm{p}, 4 \mathrm{q} 22-\mathrm{q} 32,5 \mathrm{q}, 9 \mathrm{q} 21-\mathrm{qter}, 16 \mathrm{p}, 18 \mathrm{q}, 19 \mathrm{p})\end{array}$ \\
\hline Tai et al. 2004 & Publikation & A22 & 0,$8 ; 1,2 ; 1,4$ & $\begin{array}{l}\operatorname{enh}(1 \mathrm{q} 12-\mathrm{q} 23,3 \mathrm{q} 25-\mathrm{qter}, 7 \mathrm{q} 32-\mathrm{qter}, 8 \mathrm{q}, 12 \mathrm{q} 15-\mathrm{qter}, 18 \mathrm{p} 11.2-\mathrm{q} 12,19 \mathrm{q}, 20 \mathrm{p} 11.2) \\
\operatorname{dim}(3 \mathrm{p}, 4 \mathrm{p} 15.3-\mathrm{p} 12,4 \mathrm{q} 21-\mathrm{q} 32,5 \mathrm{q} 31-\mathrm{qter}, 8 \mathrm{p}, 9,13 \mathrm{q} 12-\mathrm{q} 31,15,19 \mathrm{p}) \\
\operatorname{amp}(16 \mathrm{p} 11.2-\mathrm{q} 13)\end{array}$ \\
\hline Tai et al. 2004 & Publikation & A23 & 0,$8 ; 1,2 ; 1,4$ & $\begin{array}{l}\text { enh( 3q, 4q32-qter, 5q32-qter, 8q23-qter, 15q25-qter, 20p12-qter) } \operatorname{dim}( \\
1 \text { pter-p33, 2q33-qter, } 7 \mathrm{q} 32 \text {-qter, 19pter-q13.2) }\end{array}$ \\
\hline Tai et al. 2004 & Publikation & A24 & 0,$8 ; 1,2 ; 1,4$ & enh( 1q12-q25, 5pter-p14, 10q24-qter, 18p) dim( 10pter-p13) \\
\hline Tai et al. 2004 & $\begin{array}{l}\text { Publikation } \\
\text { Publikation }\end{array}$ & $\mathrm{A} 25$ & 0,$8 ; 1,2 ; 1,4$ & enh $(1 \mathrm{q}, 5 \mathrm{p}, 8 \mathrm{q} 23-\mathrm{qter}, 12 \mathrm{p} 12-\mathrm{q} 13,17 \mathrm{q}, 20 \mathrm{q}) \operatorname{dim}(4 \mathrm{q}, 5 \mathrm{q} 12-\mathrm{q} 22,6 \mathrm{q}, 8 \mathrm{p}, 9 \mathrm{q})$ \\
\hline $\begin{array}{l}\text { Tha et al. } 2004 \\
\text { Tai et al. } 2004\end{array}$ & $\begin{array}{l}\text { Publikation } \\
\text { Publikation }\end{array}$ & $\begin{array}{l}\text { A26 } \\
\text { A27 }\end{array}$ & $\begin{array}{l}0,8 ; 1,2 ; 1,4 \\
0,8 ; 1,2 ; 1,4\end{array}$ & $\begin{array}{l}\text { enh( } 17 \mathrm{p} 11.2 \text {-qter, 19q13.3-qter) } \operatorname{dim}(4 \mathrm{q} 26 \text {-qter, 9, 13q, 16p) } \\
\text { enh( 4q31.1-qter, 5pter-14, 11p15, 17pter-q12, 20q12-qter) dim(9q21-qter, }\end{array}$ \\
\hline Tai et al. 2004 & Publikation & A28 & 0,$8 ; 1,2 ; 1,4$ & $\begin{array}{l}\text { enh( 1tter-p33, 5p, 7p, 8q13-qter, 10p11.2-q21, 15q11.2-q14, 16pter-q12.2, 20p) } \\
\operatorname{dim}(1 \mathrm{p} 1-\mathrm{p} 21,3 \text { pter-p14, 8p21-p } 11.2,9,18,19 \mathrm{p})\end{array}$ \\
\hline Tai et al. 2004 & Progenetix & A29 & 0,$8 ; 1,2 ; 1,4$ & enh(17p11.2p11.1) dim(9pterq31.1) \\
\hline Tai et al. 2004 & Publikation & $\mathrm{A} 30$ & 0,$8 ; 1,2 ; 1,4$ & $\begin{array}{l}\text { enh ( } 5 \mathrm{p}, 7,10,11 \mathrm{q} 14-\mathrm{q} 22,12 \mathrm{p}, 13 \mathrm{q} 31-\mathrm{qter}, 17 \mathrm{q}, 20 \mathrm{q}) \operatorname{dim}(1 \mathrm{p}, 3 \mathrm{p}, 4 \mathrm{q} 22-\mathrm{qter} \\
6 \mathrm{p} 21.3 \mathrm{q}, \mathrm{qter}, 8 \mathrm{p}, 9 \mathrm{q}, 11 \mathrm{p}, 12 \mathrm{q} 13-\mathrm{q} 15,13 \mathrm{q} 12 \mathrm{q} 22,14 \mathrm{q} 13-\mathrm{qter}, 15,16,17 \mathrm{p}, 18 \mathrm{q} \\
19 \mathrm{p}) \text { amp } 8 \mathrm{q}, 12 \mathrm{p} 13.3,17 \mathrm{q} 11.2 \mathrm{q} 23)\end{array}$ \\
\hline Yakut et al. 2006 & Publikation & $\mathrm{L} 22$ & 0,$85 ; 1,15 ; 1,5$ & $\operatorname{enh}(5 \mathrm{p})$ \\
\hline Yakut et al. 2006 & Publikation & L23 & 0,$85 ; 1,15 ; 1,5$ & $\operatorname{enh}(2 \mathrm{p} 14 \mathrm{p} 22,4 \mathrm{q} 12 \mathrm{q} 13,14 \mathrm{q} 12 \mathrm{q} 13,18 \mathrm{q})$ \\
\hline Yakut et al. 2006 & Publikation & L24 & 0,$85 ; 1,15 ; 1,5$ & $\begin{array}{l}\operatorname{enh}() \operatorname{dim}(3 \mathrm{p} 14,5 \mathrm{q} 13 \mathrm{q} 23,18 \mathrm{q} 11) \operatorname{enh}(1 \mathrm{q} 21,5 \mathrm{p}, 6 \mathrm{q} 21,8 \mathrm{q} 11 \mathrm{q} 12,10 \mathrm{pterq} 11 \\
13 \mathrm{p} 13 \mathrm{qter}, 14 \mathrm{q} 12 \mathrm{q} 13,17 \mathrm{p} 11 \mathrm{q} 21,20 \mathrm{q})\end{array}$ \\
\hline Yakut et al. 2006 & Publikation & $\mathrm{L} 25$ & 0,$85 ; 1,15 ; 1,5$ & $\operatorname{enh}(19 \mathrm{q} 12)$ \\
\hline Yakut et al. 2006 & Publikation & L26 & 0,$85 ; 1,15 ; 1,5$ & $\operatorname{enh}(16 \mathrm{p}, 11 \mathrm{q} 13 \mathrm{qter})$ \\
\hline Yakut et al. 2006 & Publikation & L27 & 0,$85 ; 1,15 ; 1,5$ & enh(8p12pter, 11) \\
\hline Yakut et al. 2006 & Publikation & L28 & 0,$85 ; 1,15 ; 1,5$ & $\begin{array}{l}\text { enh() dim }(9 \mathrm{p}, 1 \mathrm{p}, 3 \mathrm{p} 13 \mathrm{pter}, 4 \mathrm{q} 33 \mathrm{qter}, 5 \mathrm{q}, 6 \mathrm{p}, 9 \mathrm{q}, 11 \mathrm{p} 13 \mathrm{pter}) \text { enh }(\text { Xp11, } \\
\text { 3q22qter, 4p14p15, 5p, 6q16q22, 10p13pter, 20q) }\end{array}$ \\
\hline Yakut et al. 2006 & $\begin{array}{l}\text { Publikation } \\
\text { Publikation }\end{array}$ & L29 & 0,$85 ; 1,15 ; 1,5$ & $\begin{array}{l}\operatorname{enh}(5 p) \\
\text { (n) }\end{array}$ \\
\hline & Publikation & & 0,$85 ; 1,15 ; 1,5$ & \\
\hline
\end{tabular}

${ }^{a}$ Quelle der CGH-Befunde; zu Progenetix siehe Baudis (2000), Baudis und Cleary (2001).

${ }^{b}$ Schwellenwerte für Verluste, Zugewinne und Amplifikationen.

${ }^{c}$ Amplifikationen waren fehlerhaft erfasst und wurden gemäß der Publikation korrigiert. 


\section{A.3 Statistische Auswertung}

Tabelle A.6: Statistisch signifikante Unterschiede zwischen 22 Hirnmetastasen und 71 Primärtumoren des kleinzelligen Karzinoms

\begin{tabular}{|c|c|c|c|c|c|c|}
\hline \multirow[t]{2}{*}{ Bande } & \multirow{2}{*}{$\frac{\text { Zugewinne }}{\text { Metastase }}$} & \multicolumn{3}{|c|}{ Verluste } & \multirow[t]{2}{*}{ p-Wert } & \multirow[t]{2}{*}{ adjustierter $\mathbf{p}$-Wert } \\
\hline & & Primärtumor & Metastase & Primärtumor & & \\
\hline $3 q 11$ & 10 & 29 & 1 & 62 & $<0,01$ & $<0,01$ \\
\hline $4 q 32$ & 0 & 2 & 9 & 53 & $<0,01$ & 0,03 \\
\hline $4 q 33$ & 0 & 2 & 9 & 53 & $<0,01$ & 0,03 \\
\hline $5 \mathrm{p} 11$ & 12 & 30 & 0 & 32 & $<0,01$ & $<0,01$ \\
\hline $5 q 11$ & 2 & 30 & 11 & 36 & $<0,01$ & $<0,01$ \\
\hline 13p11 & 0 & 4 & 0 & 27 & $<0,01$ & $<0,01$ \\
\hline $13 q 14^{a}$ & 0 & 8 & 14 & 58 & $<0,01$ & 0,01 \\
\hline $13 \mathrm{q} 21^{a}$ & 2 & 8 & 11 & 58 & $<0,01$ & $<0,01$ \\
\hline 17q11 & 5 & 22 & 0 & 26 & $<0,01$ & $<0,01$ \\
\hline 19p11 & 0 & 40 & 0 & 3 & $<0,01$ & $<0,01$ \\
\hline 19p12 & 0 & 37 & 0 & 3 & $<0,01$ & $<0,01$ \\
\hline 19p13 & 0 & 37 & 0 & 3 & $<0,01$ & $<0,01$ \\
\hline $19 q 11$ & 2 & 45 & 0 & 3 & $<0,01$ & $<0,01$ \\
\hline 19q12 & 3 & 46 & 0 & 2 & $<0,01$ & $<0,01$ \\
\hline $19 q 13$ & 2 & 43 & 0 & 2 & $<0,01$ & $<0,01$ \\
\hline
\end{tabular}

${ }^{a}$ Der signifikante Unterschied liegt bei den unveränderten Banden und wird nicht als Ergebnis verwendet.

Tabelle A.7: Statistisch signifikante Unterschiede zwischen 32 Hirnmetastasen und 121 Primärtumoren des Plattenepithelkarzinoms

\begin{tabular}{lcccccc} 
Bande & $\frac{\text { Zugewinne }}{\text { Metastase }}$ & Primärtumor & $\begin{array}{c}\text { Verluste } \\
\text { Metastase }\end{array}$ & Primärtumor & p-Wert & adjustierter p-Wert \\
& 14 & 22 & 0 & 13 & $<0,01$ & 0,02 \\
$1 \mathrm{q} 12$ & 16 & 22 & 0 & 4 & $<0,01$ & 0,01 \\
$1 \mathrm{q} 21$ & 16 & 22 & 0 & 3 & $<0,01$ & 0,01 \\
$1 \mathrm{q} 22$ & 16 & 14 & 0 & 8 & $<0,01$ & 0,03 \\
$2 \mathrm{q} 12$ & 11 & 15 & 0 & 9 & 0,01 & 0,04 \\
\hline 2q13 & 11 & 15 &
\end{tabular}

${ }^{a}$ Der signifikante Unterschied liegt bei den unveränderten Banden und wird nicht als Ergebnis verwendet. 
Tabelle A.7: Statistisch signifikante Unterschiede zwischen 32 Hirnmetastasen und 121 Primärtumoren des Plattenepithelkarzinoms

...Fortsetzung

\begin{tabular}{|c|c|c|c|c|c|c|}
\hline \multirow[t]{2}{*}{ Bande } & \multirow{2}{*}{$\frac{\text { Zugewinne }}{\text { Metastase }}$} & \multicolumn{3}{|c|}{ Verluste } & \multirow[t]{2}{*}{ p-Wert } & \multirow[t]{2}{*}{ adjustierter $p$-Wert } \\
\hline & & Primärtumor & Metastase & Primärtumor & & \\
\hline $2 q 14$ & 11 & 15 & 0 & 11 & $<0,01$ & 0,03 \\
\hline 3p11 & 0 & 45 & 15 & 36 & $<0,01$ & $<0,01$ \\
\hline $3 \mathrm{p} 24^{a}$ & 3 & 2 & 16 & 38 & 0,01 & 0,04 \\
\hline $5 \mathrm{p} 12$ & 16 & 59 & 4 & 1 & $<0,01$ & 0,02 \\
\hline $5 \mathrm{p} 13$ & 16 & 64 & 4 & 1 & $<0,01$ & 0,03 \\
\hline $5 \mathrm{p} 14$ & 17 & 65 & 4 & 0 & $<0,01$ & $<0,01$ \\
\hline $5 \mathrm{p} 15$ & 18 & 65 & 4 & 0 & $<0,01$ & $<0,01$ \\
\hline $5 q 11$ & 0 & 56 & 10 & 36 & $<0,01$ & $<0,01$ \\
\hline $6 \mathrm{p} 12$ & 8 & 9 & 0 & 10 & 0,01 & 0,04 \\
\hline $6 \mathrm{p} 21$ & 12 & 11 & 0 & 11 & $<0,01$ & $<0,01$ \\
\hline $7 \mathrm{p} 21$ & 13 & 20 & 3 & 7 & 0,01 & 0,04 \\
\hline $7 \mathrm{q} 21^{a}$ & 17 & 23 & 1 & 4 & $<0,01$ & $<0,01$ \\
\hline $8 \mathrm{p} 12$ & 2 & 7 & 17 & 29 & $<0,01$ & 0,03 \\
\hline $8 \mathrm{p} 21$ & 1 & 5 & 19 & 29 & $<0,01$ & $<0,01$ \\
\hline $8 \mathrm{p} 22$ & 1 & 4 & 19 & 29 & $<0,01$ & $<0,01$ \\
\hline $8 \mathrm{p} 23$ & 1 & 4 & 18 & 29 & $<0,01$ & 0,01 \\
\hline $9 \mathrm{p} 13^{a}$ & 5 & 11 & 12 & 19 & 0,01 & 0,04 \\
\hline $9 \mathrm{p} 21$ & 5 & 11 & 13 & 18 & $<0,01$ & 0,01 \\
\hline 9p22 & 5 & 8 & 13 & 18 & $<0,01$ & $<0,01$ \\
\hline 9p23 & 5 & 7 & 13 & 17 & $<0,01$ & $<0,01$ \\
\hline 9p24 & 5 & 7 & 13 & 17 & $<0,01$ & $<0,01$ \\
\hline 10p13 & 6 & 4 & 6 & 18 & $<0,01$ & 0,03 \\
\hline 10p14 & 6 & 4 & 6 & 18 & $<0,01$ & 0,03 \\
\hline 10p15 & 6 & 4 & 6 & 18 & $<0,01$ & 0,03 \\
\hline $13 q 21$ & 2 & 6 & 17 & 29 & $<0,01$ & 0,03 \\
\hline $13 \mathrm{q} 22$ & 2 & 10 & 18 & 28 & $<0,01$ & 0,01 \\
\hline $13 \mathrm{q} 31$ & 3 & 10 & 18 & 26 & $<0,01$ & $<0,01$ \\
\hline $13 \mathrm{q} 32$ & 4 & 10 & 17 & 23 & $<0,01$ & $<0,01$ \\
\hline $13 \mathrm{q} 33$ & 4 & 10 & 17 & 20 & $<0,01$ & $<0,01$ \\
\hline $13 \mathrm{q} 34$ & 4 & 8 & 17 & 19 & $<0,01$ & $<0,01$ \\
\hline $16 \mathrm{p} 11$ & 3 & 7 & 0 & 34 & $<0,01$ & 0,02 \\
\hline $16 q 11$ & 0 & 6 & 1 & 34 & $<0,01$ & 0,02 \\
\hline
\end{tabular}

${ }^{a}$ Der signifikante Unterschied liegt bei den unveränderten Banden und wird nicht als Ergebnis verwendet. 
Tabelle A.7: Statistisch signifikante Unterschiede zwischen 32 Hirnmetastasen und 121 Primärtumoren des Plattenepithelkarzinoms

...Fortsetzung

\begin{tabular}{|c|c|c|c|c|c|c|}
\hline \multirow[t]{2}{*}{ Bande } & \multirow{2}{*}{$\frac{\text { Zugewinne }}{\text { Metastase }}$} & \multicolumn{3}{|c|}{ Verluste } & \multirow[t]{2}{*}{ p-Wert } & \multirow[t]{2}{*}{ adjustierter $\mathbf{p}$-Wert } \\
\hline & & Primärtumor & Metastase & Primärtumor & & \\
\hline $18 q 11$ & 2 & 33 & 15 & 15 & $<0,01$ & $<0,01$ \\
\hline $18 q 12$ & 1 & 18 & 18 & 17 & $<0,01$ & $<0,01$ \\
\hline $18 q 21$ & 0 & 16 & 18 & 17 & $<0,01$ & $<0,01$ \\
\hline $18 q 22$ & 0 & 13 & 18 & 17 & $<0,01$ & $<0,01$ \\
\hline $18 q 23$ & 0 & 11 & 18 & 17 & $<0,01$ & $<0,01$ \\
\hline $19 q 12$ & 10 & 12 & 0 & 7 & $<0,01$ & 0,03 \\
\hline
\end{tabular}

${ }^{a}$ Der signifikante Unterschied liegt bei den unveränderten Banden und wird nicht als Ergebnis verwendet.

Tabelle A.8: Statistisch signifikante Unterschiede zwischen 16 Hirnmetastasen und 95 Primärtumoren des Adenokarzinoms

\begin{tabular}{lcccccc} 
Bande & $\frac{\text { Zugewinne }}{\text { Metastase }}$ & Primärtumor & $\begin{array}{c}\text { Verluste } \\
\text { Metastase }\end{array}$ & Primärtumor & p-Wert & adjustierter p-Wert \\
& 1 & 43 & 6 & 10 & $<0,01$ & 0,01 \\
$5 \mathrm{q} 11$ & 1 & 4 & 5 & 5 & $<0,01$ & 0,02 \\
$11 \mathrm{p} 13$ & 0 & 6 & 5 & 5 & $<0,01$ & 0,02 \\
$11 \mathrm{p} 14$ & 0 & 6 & 7 & 11 & 0,01 & 0,03 \\
$18 \mathrm{q} 23$ & 1 & 10 & 3 & 1 & $<0,01$ & 0,01 \\
\hline $2 \mathrm{q} 11$ & 1 & &
\end{tabular}




\section{Danksagung}

Hiermit danke ich Herrn Prof. Dr. L. Füzesi für die Überlassung des Themas, die fachliche Betreuung und für seinen steten Einsatz, diese Arbeit gelingen zu lassen. Besonderen Dank möchte ich auch für seine Förderung kritischen und eigenständigen wissenschaftlichen Denkens aussprechen; einen besseren Einstieg in die Welt der Forschung könnte ich mir nicht vorstellen.

Herrn PD Dr. B. Gunawan und Herrn Dr. H.-J. Schulten danke ich sehr für ihre Unterstützung bei der Gewinnung und Berichtigung der Ergebnisse.

Ganz besonders möchte ich Frau C. Enders, Frau I. Dückmann, Frau N. Kunkel und Frau J. Wolf-Salgo für ihren Beitrag zum experimentellen Teil danken. Ohne ihre Hilfe und das große fachliche Können wäre das Zustandekommen dieser Dissertation nicht möglich gewesen. Frau K. Hannemann gilt ebenfalls ein großer Dank. Zudem möchte ich für die freundliche Stimmung in der Abteilung danken.

Herrn Dr. K. Jung aus der Abteilung für medizinische Statistik der Georg-AugustUniversität Göttingen danke ich sehr für die statistische Auswertung.

Auch den in den Jahren 1995 bis 2004 an der Universitätsklinik Göttingen und dem Evangelischen Krankenhaus Oldenburg tätigen Neurochirurgen, insbesondere Frau PD Dr. A. Gutenberg, gilt ein Dank: Durch ihr operatives Geschick wurde die Grundlage für diese Dissertation gelegt.

Schlussendlich möchte ich meinen Freunden und Mitdoktoranden J.S. Gerdes und M. D. Nischwitz danken: Die gegenseitige Unterstützung und Inspiration war von einem unschätzbaren Wert. 